University of New Hampshire

University of New Hampshire Scholars' Repository

Winter 2006

\title{
Examination of Eco-Behavioral Assessments Designed for Understanding Complex Behaviors and Environments.
}

\author{
Kristie L. Pretti-Frontczak \\ Kent State University - Kent Campus \\ Sarah M. Stitzlein \\ University of New Hampshire \\ Laura Vilardo \\ Kent State University - Kent Campus \\ Melody Tankersley \\ Kent State University - Kent Campus
}

Follow this and additional works at: https://scholars.unh.edu/educ_facpub

Part of the Education Commons

\section{Recommended Citation \\ Pretti-Frontczak, Kristie L., McGough, Sarah M., Vilardo, Laura and Tankersley, Melody. Examination of Eco-Behavioral Assessments Designed for Understanding Complex Behaviors and Environments. Journal of Early and Intensive Behavior Intervention 3, no. 1 (2006): 81-102.}

This Article is brought to you for free and open access by the Education at University of New Hampshire Scholars' Repository. It has been accepted for inclusion in Education Scholarship by an authorized administrator of University of New Hampshire Scholars' Repository. For more information, please contact Scholarly.Communication@unh.edu. 


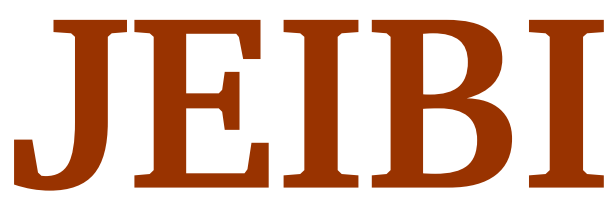

Volume No. 3 Journal of Early and Intensive Behavior Intervention Issue No. 1

Where Education and Behavioral Science Meet

\section{Table of Contents}

Page 1. Teaching Perspective-Taking Skills to Typically Developing Children through Derived Relational Responding - Amie I. Heagle and Ruth Anne Rehfeldt

Page 35. Conditioned Observation of Books and Accelerated Acquisition of Textual Responding by Preschool Children - Hsin-hui Tsai and R. Douglas Greer

Page 62. The Effects of a Stimulus -Stimulus Pairing Procedure on the Acquisition of Conditioned Reinforcement on Observing and Manipulating Stimuli by Young Children with Autism - Jennifer M. Longano and R. Douglas Greer

Page 81. Examination of Eco-Behavioral Assessments Designed for Understanding Complex Behaviors and Environments - Kristie L. Pretti-Frontczak Sarah M. McGough Laura Vilardo and Melody Tankersley

Page 103. The Effects of Daily Intensive Tact Instruction on Preschool Students' Emission of Pure Tacts and Mands in Non-Instructional Setting - Nirvana Pistoljevic and R. Douglas Greer

Page 121. The Effects of Intensive Tact Instruction on Audience-Accurate Tacts and Conversational Units -Geneva Schauffler and R. Douglas Greer

Page 135. Effects of Speaker Immersion on the Spontaneous Speaker Behavior of Preschool Children with Communication Delays - Denise E. Ross, Robin Nuzzolo, Lauren Stolfi, and Sarah Natarelli

Page 151. Teaching the Function of Writing to Middle School Students with Academic Delays Tracy Reilly-Lawson and R. Douglas Greer

Page 171. Promoting Positive Learning Outcomes for Young Children in Inclusive Classrooms: A Preliminary Study of Children's Progress Toward Pre-Writing Standards - Jennifer GrishamBrown, Robyn Ridgley, Kristie Pretti-Frontczak, and Cissie Lit 


\section{PUBLISHER'S STATEMENT \\ Volume 3, No. 1 \\ Published: February 18, 2006}

The Journal of Early and Intensive Behavior Intervention (JEIBI) is published quarterly by Joseph Cautilli. JEIBI is an online, electronic publication of general circulation to the scientific community.

The materials, articles, and information provided on this website have been prepared by the staff of the JEIBI for informational purposes only. The information contained in this web site is not intended to create any kind of patient-therapist relationship or representation whatsoever.

For a free subscription to JEIBI, go to the subscriptions page on the website and follow the directions found there. You will receive notice of publication of each new issue via e-mail that will contain a hyperlink to the latest edition. You may also subscribe to JEIBI by visiting our online guest book.

JEIBI is copyright $\odot 2004-2005$ by Joseph $D$. Cautilli, publisher. The journal may be downloaded freely, however, all other rights are reserved. This journal may not be reproduced, modified, or distributed without the express prior written permission of the copyright holder. For permission, contact Joseph Cautill. All information contained within is provided as is. The Journal of Early and Intensive Behavior Intervention, its publishers, authors, and agents, cannot be held responsible for the way this information is used or applied. The Journal of Early and Intensive Behavior Intervention is not responsible for typographical errors.

The Publisher may be reached at: Joseph Cautilli: jcautilli@ cctckids.com

\section{A MESSAGE FROM THE PUBLISHER}

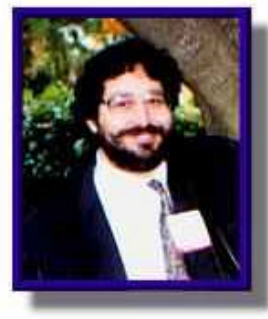

Dear Readers:

As we move into the New Year, I want to take this opportunity to thank each and every one of our readers, authors, and staff for their continued support.

All of us at JEIBI look forward to making JEIBI even bigger and better throughout this new season of JEIBI journals.

Yours truly,

J oe Cautilli

Joe Cautilli, Publisher

BAO Journals 


\section{JEIBI}

Journal of Early and Intensive Behavior Intervention

Where Education and Behavioral Science Meet

\section{Editorial Board}

\section{Below is a list of the JEIBI Editorial Board and Support Staff}

\section{Lead Editor:}

Joseph Cautilli, Ph.D., B.C.B.A.

Associate Editors:

Douglas Greer, Ph.D.

Jan Handleman, Ph.D.

David M. Richman, Ph.D.

\section{Editorial Review Board}

Sheila Alber Morgan, Ph.D.

John Banard

Thomas Barnes, Ph.D.

Yvonne Barnes-Holmes, Ph.D.

John C.Borrero, Ph.D.

Mappy Chavez-Brown, Ph.D.

Jo Ann Pereira Delgado, Ph.D.

Jacob Gewirtz, Ph.D.

Margaret Hancock, M.Ed.

Amoy Kito Hugh, M.Ed., M.Phil.

Bonny LeGrice, Ph.D.

Anjelika Kosanic

Eric Messick, MA

Robert Montgomery, Ph.D.

Matthew Normand, Ph.D.

Martha Pelaez, Ph.D.

Lillian V. Pelios, Ph.D.

Kimberly Ray, Ph.D., BCBA

Denise Ross, Ph.D.

Tracy A. Ruff, M.Ed., BCBA

Paul Strand, Ph.D.

Tim Vollmer, Ph.D.

Michael Weinberg, Ph.D.

Richard Weissman, Ph.D.

Thomas Zane, Ph.D., BCBA

LITERARY AGENT/WEB ADMINISTRATOR

G. Petersen, Paralegal 


\section{JEIBI}

Journal of Early and Intensive Behavior Intervention

Where Education and Behavioral Science Meet

\section{Mission Statement}

The mission of The Journal of Early and Intensive Behavioral Intervention (JEIBI) is to provide up to the moment information on critical issues and research in early intervention and intensive behavioral interventions. The journal perceives itself as being a primary source of information for those who work within the field of early childhood interventions and intensive interventions from a behavioral perspective. Topics will include issues, literature review, and research on successful interventions for children with various mental health, medical (pain, obesity, etc) or developmental disorders. In addition, articles and research conducted on organizational behavior management to facilitate program design and development of early intervention centers will also be accepted.

The Journal of Early and Intensive Behavioral Intervention (JEIBI) envisions a world in which early intervention is no longer needed, but until that time, JEIBI plans to bring to practitioners the latest in empirically valid interventions.

\section{Advertising in the Journal of Early and Intensive Behavior Intervention}

Advertising is available in JEIBI. All advertising must be paid for in advance. Make your check payable to Joseph Cautilli. The ad copy should be in our hands at least 3 weeks prior to publication. Copy should be in MS Word or Word Perfect, RTF format and advertiser should include graphics or logos with ad copy.

The prices for advertising in one issue are as follows:

1/4 Page: $\$ 50.00$ 1/2 Page: $\$ 100.00$ vertical or horizontal Full Page: $\$ 200.00$

If you wish to run the same ad in both issues for the year, you are eligible for the following discount:

1/4 Pg.: \$40 - per issue

1/2 Pg.: \$75 - per issue -vertical or horizontal

Full Page: \$150.00-per issue.

For more information, or place an ad, contact Halina Dziewolska by phone at (215) 462-6737 or e-mail at: halinadz@hotmail.com 


\title{
JEIBI
}

\section{Journal of Early and Intensive Behavior Intervention}

\author{
Where Education and Behavioral Science Meet
}

\section{Submissions}

Authors who wish to be considered for publication in JEIBI must submit a signed assignment of rights form with their article. The form is available on the JEIBI website.

The Journal of Early and Intensive Behavioral Intervention (JEIBI) is wholly owned by Joseph Cautilli and Craig Thomas. JEIBI contributions are by invitation of the lead editor or the associate editors only. All submissions are peer-reviewed. After acceptance, all articles are copyedited.

Peer Review: All submitted manuscripts are reviewed initially by a JEIBI editor. Manuscripts with insufficient priority for publication are rejected promptly. Other manuscripts are sent to expert consultants for peer review. Information from submitted manuscripts may be systematically collected and analyzed as part of research to improve the quality of the editorial or peer review process. Identifying information will remain confidential.

Manuscripts: Rejected manuscripts will be returned to authors when specifically requested in the cover letter. Print copies of original illustrations, photographs, and slides will be returned with the manuscript. In all cases, manuscripts must be submitted electronically and saved in "rich text format" (.rtf) only to Joseph Cautilli, Ph.D., M.Ed., BCBA.

A Word about Abstracts

In order to ensure that JEIBI will be accepted in the major psych databases, there are certain guidelines that must be followed for abstracts relating to our article and the Journal. The following guidelines are straight from the PsycINFO website: http://www.apa.org/psycinfo/about/covinfo.html

General Guidelines for Writing Effective Abstracts

For use in EBSCO and other databases, an abstract should not exceed 960 characters and spaces (approximately 120 words).

Characters may be conserved by:

- using digits for numbers (except at the beginning of sentences)

- using well-known abbreviations

- using the active voice

Begin with the most important information, but don't waste space by repeating the title. Include in the abstract only the four or five most important concepts, findings, or implications.

Embed as many key words and phrases in the abstract as possible; this will enhance the user's ability to find the citation for your article in a computer search.

Include in the abstract only information that appears in the body of the paper.

Style:

Remember that not all people who read your abstract will have a high level of psychological knowledge. Define all acronyms and abbreviations, except those for measurements. 
- Spell out names of tests

- Use generic names for drugs (when possible)

- Define unique terms

Use the present tense to describe results with continuing applicability or conclusions drawn and the past tense to describe variables manipulated or tests applied. As mu ch as possible, use the third person, rather than the first person.

Abstracts for Empirical Studies:

Abstracts of an empirical study are generally about 100--120 words. Include the following information:

- problem under investigation (in one sentence)

- pertinent characteristics of subjects (number, type, age, sex, and genus and species)

- experimental method, including apparatus, data-gathering procedures, complete test

- names, and complete generic names and the dosage and routes of administration of any drugs (particularly if the drugs are novel or important to the study)

- findings, including statistical significance levels

- conclusions and implications or applications

Abstracts for Review/Theoretical Articles

Abstracts for review or theoretical articles are generally about 75--100 words. Include the following information:

- the topic in one sentence

- purpose, thesis, or organizing construct and the scope (comprehensive or selective) of the article

- sources used (e.g., personal observation, published literature)

- conclusions

Editing: Accepted manuscripts are copyedited according to APA format and returned to the author for approval. Authors are responsible for all statements made in their work, including changes made by the copy editor and authorized by the corresponding author. Please adhere to APA format and use "Times New Roman" font in 11 pt. throughout. In references, however, please italicize the places where APA format would have you underline.

Additional requirements:

To be published in any of the BAO journals, we have additional requirements that authors must adhere to. Our requirements supercede any requirements that conflict with APA requirements.

* All articles must be created as one continuous document - no documents that are created in sections or sub documents.

* Graphics, figures, tables, etc., must be in jpg or bmp format. Graphics, figures, tables, etc., may be embedded in the text body of the article by the author. No Excel graphs will be accepted. If graphical materials are submitted as separate Word documents, they should be in portrait format and should be full page, or one half page or less only. Graphical materials larger than one page cause serious layout problems. If graphical materials are not inserted into the text portion of the article by the author, indicators must be placed in the text body so we know where the graphical materials belong.

* All articles should be single spaced, with one inch margins all around.

* All abstracts must contain keywords. Full author contact information must be included in the article.

* No author generated headers, footers, or pagination.

\section{Thank you!}

The Journal of Early and Intensive Behavioral Intervention Editorial Board 


\section{Overview and Contents of Volume 3.1}

This issue of JEIBI contains several articles that introduce new tactics or extend the scholarship base for well-tested procedures. Heagle and Rehfeldt apply procedures from relational frame theory for teaching perspective taking. This is an important application of Relational Frame Theory. Two papers extend the utility of conditioned reinforcement procedures. Conditioned reinforcement applications have been neglected in the applied literature and these two papers suggest the powerful potential of conditioned reinforcement for educationally significant goals. Tsai and Greer describe procedures for conditioning preference for choosing and reinforcement for observing books in free time by preschoolers that results in accelerated learning of textual responses.

Longano and Greer describe a different version of the conditioning procedures that result in the reduction or elimination of stereotypy in one child and increased responding and accuracy to seatwork by first graders with autism diagnoses. Pretti-Frontczak, McGough, Vilardo, and Tankersley provide and extensive treatment of types and uses of eco-behavioral assessments for understanding complex behaviors and environments. Their work provides an overview the important contributions of eco-behavioral assessment and support the need for more wide spread usage of this major contribution to behavior analysis.

Gresham-Brown, Ridgley, Pretti-Frontczak, and Litt introduce a tactic for teaching pre-writing standards. The growing need for ways to teach educational standards to preschool children makes their contributions particularly timely. I believe that the corpus of research, in and extension of, Skinner's verbal behavior theory has revolutionized the capacity for behavior analysis to bridge the educational gap for children from impoverished communities and the gap between children with native disabilities and those without disabilities. Four papers describe procedures for applying verbal behavior analysis to important educational objectives.

Pistoljevic and Greer describe the effects of intensive tact instruction on the emission of spontaneous or pure tacts by pre-school children with autism or language delays, while Schauffler and Greer describe the effects of another version of the intensive tact instructional protocol on the acquisition of audience appropriate conversational units in middle school students with "behavioral disorders" who are from an economically disenfranchised community.

Ross, Nuzzolo, Stolfi and Natarelli describe the effects of the speaker immersion tactic on the emission of spontaneous speaking on children with autism or communication delays. Finally, Reilly-Lawson and Greer describe the effects of the writer immersion tactic on the structural components and functional effects of writing in middle school students also from an economically disenfranchised community. These latter procedures draw on our capacity to use establishing operations in ways that allow the numbers of learning opportunities to be greatly expanded. One need not wait for naturally occurring conditions; rather, practitioners can create those natural conditions.

Each of the papers provides promising practices for practitioners and new directions for research. The use of, and further research on, the findings offered in these papers should expand the pedagogical armada of teaching as applied behavior analysis. Some of the papers introduce intensive and effective intervention protocols for young children. Other papers introduce intensive interventions for middle school children from economically disenfranchised communities. The papers introduce promising new or previously tested approaches that draw on and extend the basic science associated with Relational Frame Theory, verbal behavior analysis, and conditioned reinforcement via stimulus-stimulus pairings. The dependent variables consist of educationally significant educational goals. The procedures provide workable solutions to important learning problems that can be applied by behavior analysts who are working with children who can benefit from the procedures - now! We encourage practitioners to use and test these procedures and are confident that that they can benefit many children. 


\title{
Teaching Perspective-Taking Skills to Typically Developing Children Through Derived Relational Responding
}

\author{
Amie I. Heagle and Ruth Anne Rehfeldt
}

\begin{abstract}
Perspective-taking is an ability that requires a child to emit a selection response of informational states in himself or herself and in others. This study used an extended version of the Barnes-Holmes protocol developed in a series of studies by McHugh, Barnes-Holmes, and Barnes-Holmes (2004) to teach typically developing children between the ages of 6-11 perspective-taking skills. The present demonstrational study used a multiple probe design to evaluate the participants' abilities to demonstrate a number of simple and complex relations, and examined both relation type and relational complexity. We also tested for generalization of perspective taking to new stimuli and real-world conversational topics. Results demonstrate that the capacity to alter perspectives can be established by means of a history of reinforced relational responding.
\end{abstract}

Keywords: Perspective-taking, Relational Frame Theory, Theory of Mind, stimulus generalization, response generalization.

Perspective-taking is a phenomenon described in the developmental literature that requires a child to display knowledge of informational states in himself or herself and in others (Barnes-Holmes, Hayes, Dymond, \& O'Hara, 2001). A simple example of a child taking another's perspective occurs when, for instance, a child discriminates that when sitting in a different chair from which he is sitting in now, an object will look different from that different viewpoint. Perspective-taking skills are said by developmental psychologists to benefit children in their complex reasoning abilities. In addition, having the ability to take another person's perspective is an important social skill that children need in order to make and sustain friendships.

There have been a multitude of studies conducted concerning perspective-taking skills in children. The majority of these studies have focused on the age at which children develop these skills. For example, Newcombe and Huttenlocher (1992) discussed the developmental psychologist Piaget's view on perspective taking. Piaget did not believe that these skills are developed in children before the age of 9-10 because of children's tendency to be egocentric, meaning that children have problems realizing that other people see things in different ways than themselves. Specifically, Piaget believed that children couldn't develop perspective-taking skills because they code spatial location differently from adults. For example, Piaget thought that children use a topographical system of spatial representation. Children code relationships through touching or proximity, whereas adults use metric coding of distance, such as coding the position of objects as being in the vicinity of landmarks. Huttenlocher and Presson (1979), however, argued that this lack of perspective-taking in children is not due to the children's difficulty with coding spatial locations, but rather conflict between actual and imagined frames of reference. Instead of relying on these frames of reference as in Piaget's studies, these authors asked preschoolers what object occupied a specified location with respect to a hypothetical observer, and this led to improved performance. The Newcombe and Huttenlocher (1992) study extended the results of the Huttenlocher and Presson study. The results clearly showed that the preschool children in their study could indicate locations relative to another person. Surprisingly, although young children still made egocentric errors, it is still quite notable that 3-year old performance was considerably above chance.

Other studies conducted on perspective taking focused on the different aspects of this skill. Dixon and Moore (1990) for example, examined the difference between the two situations in which perspective taking can be seen. The authors labeled these two situations as Information effect-when the subject and the other person have contrasting information, and the Weighting effect—when the subject and the other person have the same information but use that information differently when deciding their 
own separate judgments. Therefore, the aim of this study was to observe the development of these two types of perspective-taking skills. The results of this study showed that the development of these skills progresses with age, but that there are also individual variations. In both preschool, second, and fifth grade, participants completed the task at different levels of capability.

Two important studies in this area that focused on the different aspects of perspective-taking skills are studies conducted by Jacobsen and Waters (1985) and Rosser and Lane (1993). These studies examined the visual and spatial perspective-taking skills of young children. In the Jacobsen and Waters study, 40 children, composed of 6, 8, and 10-year olds were presented with a stimulus display and were told that the display could look different to a puppet (Big Bird) depending on where the puppet was placed. The child's task was explained as building an equivalent display "to show me what Big Bird is seeing from here," while the experimenter pointed to one of the four positions around the display which Big Bird could occupy. For all three problems, a perspective construction was modeled at 90 degrees to the left of the subject, 90 degrees to the right, and 180 degrees opposite the subject. Results show that the 4-year old children failed to perform the perspective-taking problems successfully even though they were able to correctly replicate the stimulus displays when taking the perspective of another person's view was not necessary. Ten-year olds were successful on all positions of perspective-taking predictions, while the 6-8 year olds had mixed success.

Rosser and Lane (1993) also focused on the spatial and dimensional perspective-taking skills of second and fourth grade children (ages 6,8, and 10). In this study, a cylinder object in nine positions on a square $3 \times 3$ grid was presented to children from the 90,180 and $270^{\circ}$ positions. The results showed that when the object was placed differently from the child's view in the left-right and near-far dimensions, the participants produced more errors in taking that perspective. When the object was transformed in only one dimension, there were fewer errors produced, however, error rates decreased with age, and egocentric responding was high for both ages. In summary, the above studies follow the developmental theory approach to perspective taking and provide evidence that perspective-taking abilities vary with age.

The major cited theory in the area of perspective-taking is the developmental perspective, or the Theory of Mind approach, while an alternate behavioral approach that is somewhat new to this area of concern is the Relational Frame Theory approach. These two theories' views differ concerning exactly how these perspective-taking skills are established and what is the most effective and efficient way to develop interventions to teach these capabilities to children who are missing them.

Developmental psychologists have focused on perspective taking for several years, especially in the area of perspective-taking problems found in children diagnosed with autism spectrum disorders. "Developing perspective-taking skills in children with these deficits is necessary because of the dire importance of being able to infer other people's mental states (thoughts, beliefs, desires, etc.), and the ability to use this information to interpret what they say, make sense of their behavior and predict what they will do next" (Howlin, Baron-Cohen, \& Hadwin, 1999, pg. 2). In the life of a child with autism, these skills become a concern when the child is faced with the task of communicating and sustaining relationships with his/her peers. The majority of research has focused on the concepts of the "Theory of Mind" (TOM) approach (Howlin et al., 1999). This theory focuses on five levels of understanding of informational states involved in teaching children diagnosed with autism perspective-taking skills. These levels of perspective taking and the methods, by which they might be established, are as follows. Level 1 is simple visual perspective taking. This is the understanding that different people can see different things. At this level the child can judge what the experimenter can see or not see. To train this level, a child is presented with a two-sided card with a ball on one side and an airplane on the other, for example. The child is then asked, "What can I see and what can you see?" If the child responds incorrectly, corrective feedback is provided until correct responding is established (Howlin et al., 1999, BarnesHolmes, Barnes-Holmes, \& Cullinan, 2001). Level 2 is complex visual perspective taking. This involves 
discriminating between not only what people see and how it appears to them. This level requires the child to judge both what another person can see and how it appears to that person. This level is trained as follows. A child is presented with a card on which a character (e.g., a horse) is depicted the right way up on one side and upside down on the other. The child is asked, "When you or I look at this picture, is the horse the right-way-up or upside-down?" Correct responding again is established through corrective feedback (Howlin et al., 1999, Barnes-Holmes et al., 2001). Level 3 involves the principle that seeing leads to knowing. This is the ability to understand that people only know things that they have experienced (directly or indirectly). This level is established as follows: a child is asked to close his/her eyes, and the experimenter hides an object in a box. The child is asked, "Do you know what is in the box? Why don't you?" The child is then shown inside the box, and asked again, "Do you know what is inside the box?" and she is then asked, "How do you know?" The correct answers in this scenario are basically "I know because I have seen, and I do not know because I have not seen." A similar scenario is then enacted for the child from the perspective of a doll, for example, and the same questions are asked regarding the doll's perspective (Howlin et al., Barnes-Holmes et al.). Level 4 involves the principle that you can predict actions on the basis of knowledge. Level 4 tests the child's understanding of true belief. Here, children are required to predict a person's actions on the basis of where that person believes an object to be. A training task would utilize four toys: two identical trucks, one train, and one bus. One truck is placed next to the train and the other truck next to the bus. A child is then supplied with the following true belief story. "This morning, you saw the truck next to the train but you did not see the truck next to the bus." The child is then asked, "Where do you think the truck is? Why do you think it is near the train? Where will you go to get the truck? Why will you go to the train?" The same story is then enacted with a doll and the same questions are asked concerning the doll's perspective. The correct responses from these questions involve the knowledge that one will only know what one has seen (Howlin et al., 1999, Barnes-Holmes, et al., 2001). Level 5 includes the theory that you can predict actions on the basis of false belief, the standard approach to theory of mind reasoning. Here children are required to predict a person's actions on the basis of where that person falsely believes an object to be. This level might be established as follows. A child is shown a purse and asked, "What do you think is inside the purse?" The child is unaware that the purse does not contain money, but instead contains a hairbrush. The child is then shown inside the purse, and asked, "Before we opened the purse, what did you think was inside? And what is really inside?" A similar scenario is then acted out from the perspective of another (e.g., a doll), and the same questions are asked regarding this different perspective. Therefore, according to the Theory of Mind approach, taking the perspective of another may be trained across progressively more complex levels of informational states that evolve from simple visual perspective-taking to acting on the basis of false belief (Howlin et al., 1999, Barnes-Holmes et al., 2001).

A variety of studies have been conducted using this Theory of Mind approach. The majority of these studies focus on the last two levels of understanding that children develop concerning perspectivetaking ability determined by this theory - true and false belief. A primary study in this area, conducted by Wellman and Bartsch (1988) examined children's early understanding of belief in an attempt to provide an account of when and if children as young as the age of 3-4 years develop true and false belief tasks.

The study's results revealed that children as young as 3 conceive of people as thinking and not thinking, knowing and not knowing, desiring and not-desiring. The authors hypothesize that:

"Children fail false-belief tasks because from the perspective of the 3-year old, falsebelief tasks present a conflict between desire reasoning (Sam wants the object and it is at Location 2: Sam will look at Location 2) and belief reasoning (Sam believes the object is at Location 1: Sam will look at Location 1). In such situations, 3-year olds predict on the basis of desire. They do so not because they have no conception of belief but because for them belief and desire are in conflict and they weight desire over belief in arriving at a prediction" (Wellman \& Bartsch, 1988, pg. 273). 
This prediction suggests that young children have yet to understand difficulties concerning beliefdesire reasoning rather than that they are unsuccessful in participating in such mentalistic reasoning at all.

Bennett and Galpert (1992) took the Wellman and Bartsch study to the next level by investigating complex belief-desire reasoning skills in young children. These authors examined whether children would recognize that someone might resist acting upon a desire, even if they desired to do it. This complex version of belief-desire reasoning holds that "when an actor desires a particular end and believes that a particular action will achieve that end, and when it is believed that there are no co-occurring outcomes of that action whose avoidance is desired more highly than is the originally conceived end, then the actor will undertake the action which will satisfy the original desire" (Bennett \& Galpert, 1992, pg. 202).

This study was conducted with participants who were ages 4, 5, and 7-years-old. They were presented with similar stories as described above with the actor in the story either having a true or false belief concerning undesirable outcomes associated with the pursuit of a desired end. Children of all age groups scored fairly well on the complex belief-desire reasoning tasks; however, there was a great improvement with the 7-years-old participants compared to the 4-years-old age group when dealing with tasks concerning false beliefs. These results are predictable, since the ability to predict action on the basis of false belief is just appearing at this young age (Perner, Leekam, \& Wimmer, 1987) and these complex belief-desire reasoning skills may not yet be fully emerged in the 4-year-old's repertoire.

There is some controversy about what exact age children begin to show evidence that they understand false belief tasks. Wimmer and Perner (1983) argue that children as young as 3-years-old cannot correctly assign a false belief to a deceived actor. There is also controversy about why in fact children of this age cannot attribute false belief. Zaitchik (1990) examined three major hypotheses that guess as to why young children do not understand false belief tasks. The first hypothesis explains that children cannot understand false belief because children of this age attribute seeing to knowing. For example, if the child knows that the actor saw that the doll was in the dollhouse, the child will believe that the actor, when asked where the doll is, will say that he/she knows where the doll is because he/she saw it in the dollhouse. Hypothesis 2 supports that notion that children have difficulties with false belief because the belief was once true and changing the truth is hard for children of this young age to understand. Finally, hypothesis 3 states that it does not matter whether the actor's false belief was founded visually or verbally through testimony, but what is most important is that the child will believe that if he/she saw the objects true location, there is no way that anyone could think the object would be anywhere else. Through puppet skits, this experiment tested these hypotheses by contrasting the standard false belief task with two testimony conditions; the 'seen' condition, in which the participant saw the object's actual location, and the 'unseen' condition, in which the participant was verbally told the object's real location. In both conditions the false belief was predetermined as false from the start (the deceiver made known that he was going to tell a lie). Results from this study revealed that the 3 -year-olds in the 'unseen' condition effectively recognized a false belief, while 3-year-olds in the two other conditions did not. These results support the third hypothesis because only the subjects in the 'unseen' testimony condition did not actually see the object's true location (Zaitchik, 1990). This provides evidence that young children are unable to recognize a belief that is inconsistent with his or her direct observation. The child holds the belief that the object is in its true location; therefore he or she cannot understand that anyone could believe that the object is anywhere else. However, because children in the 'unseen' condition did successfully attribute a false belief, as long as they were only told and not shown the accurate location of the object, this study offers evidence that, under some conditions, even 3-year-olds can understand false belief and its effects on human action (Zaitchik, 1990). Hence, the above studies report that even children as young as preschool age have the ability to take the perspective of another. 
However, the field of behavior analysis has taken an alternative approach to understanding and teaching perspective-taking skills. Unlike the Theory of Mind proponents who view these simple and complex perspective-taking skills as specific stages of development that emerge through the course of childhood, behavior analysis labels perspective-taking as a form of generalized operant responding as supported by a behavioral account of human language and cognition knows as Relational Frame Theory (RFT; Hayes, Barnes-Holmes, \& Roche, 2001).

Skinner offered a behavioral definition of "self-awareness as discrimination of one's own behavior" (Barnes-Holmes, Hayes, \& Dymond, 2001, pg. 120). However, Relational Frame Theory provides a view of self-awareness as "not simply behaving with regard to his [a child's] own behavior, but [the child] is also behaving verbally with regard to his [non verbal] behavior" (Hayes and Wilson, 1993, pg. 297). This provides a clear functional distinction between verbal and nonverbal selfdiscrimination. However, a more complete RFT analysis of self requires the addition of the theory of perspective taking in the verbal construction of self.

RFT provides three perspective-taking frames. These frames are termed "deictic" relations, have no physical properties, and can only be abstracted through relational frames (Barnes-Holmes et al., 2001). The three frames of importance are the frames of "I and You," "Here and There," and "Now and Then." Examples of such frames are, "What are you doing now?" "What did I do then?" "What are you doing here?" and "What will I do there?" These questions require the speaker to change perspective between different references of person (i.e., I versus you), place (i.e., here versus there) and time (i.e., now versus then). When one of these deictic questions is asked, the relational frames of I versus You, Here versus There, and Now versus Then are the only constants, while the physical environment will always be different (Barnes-Holmes, Barnes-Holmes, \& Cullinan, 2001). In order for an individual to abstract his or her perspective on the world, as well as others' perspectives, a strong relational repertoire and a history of multiple exemplar training is required. In other words, over the course of development children are reinforced by caregivers for appropriately responding to questions such as those mentioned above. After being reinforced multiple times for responding to these "I-You" questions, the child's responding may generalize to simple "Here-There" and "Then-Now" questions, as well as to more complex combinations of each.

Barnes-Holmes, Hayes, and Dymond (2001) note that daily interactions present frequent occasions for a child to change perspective, as in responding to the questions, "what would you do if you were me," "what am I doing now," and "what will you do once you are there?" A child who does not change perspective between I-and-you, here-and-there, and now-and-then will be faced with social difficulties. The capacity to vary perspectives does more than allow a child to participate successfully in conversation; it also contributes to several additional complex skills. Perspective taking is involved in planning one's course of action, in showing empathy towards others, and in one's conceptualization of self (Barnes-Holmes et al., 2001).

Although Relational Frame Theory and it's Theory of Mind proponents differ on their views of perspective-taking, both theories are concerned with developing effective and efficient methods for teaching perspective-taking in individuals in which these skills are lacking. However, while the TOM training programs are concerned with establishing these skills by teaching children to understand complex informational states: RFT attempts to teach perspective-taking skills by targeting the relational frames directly (Barnes-Holmes, McHugh, \& Barnes-Holmes, 2004; McHugh, Barnes-Holmes, Barnes-Holmes, 2004). To date, little research has been conducted in this area.

LeBlanc et al. (2003) provided a behavior analytic approach to teaching perspective-taking skills to 3 children with autism, ages 7-13 years. Three common measures of perspective-taking skills and stimulus variations of each were taught, including the Sally-Anne task, the "Smarties" task conducted 
with M\&M's as a substitute candy, and the Hide and Seek task. The Sally-Anne task acted as the pre-and post test, while the M\&M and Hide and Seek task were trained via video modeling and reinforcement. During video modeling, each participant watched an adult on the video correctly completing each task. The video tape was then stopped and the participant was asked to answer perspective-taking questions. Correct answers to these questions resulted in praise and preferred edibles or stickers. An incorrect response resulted in a replay of the video and prompts to pay attention to the model completing the task correctly. Results revealed that video modeling and reinforcement was an effective teaching method for the perspective-taking tasks. However, only two of the three children passed an untrained task, demonstrating a failure of these newly taught skills to generalize to novel tasks. The author's comment that the intervention used in this study could be an effective strategy for teaching perspective-taking skills if researchers continue to develop methods for enhancing or programming generalization of these skills.

Another preliminary study that was derived from a behavioral account of perspective taking described the use of the Barnes-Holmes protocol. This study analyzed perspective-taking abilities in terms of the three deictic relational frames mentioned previously. McHugh et al. (2004) used this BarnesHolmes protocol in their study to evaluate the perspective-taking skills of 64 typically developing participants, ranging in age from early childhood to adulthood. This assessment evaluated the participants' ability to show a number of simple and complex relations, examining both relation type (Iyou, here-there, and now-then) and relational complexity (i.e., simple, reversed, and double reversed). For example, a simple I-you relation was composed as follows: "I have a red brick and you have a green brick. Which brick do I have? Which brick do you have? While an example of a reversed here-there relation was composed as, "I am sitting here on the blue chair and you are sitting there on the black chair. If here was there and there was here, where would you be sitting? Where would I be sitting?" Finally, a double reversed here-there/now-then relation was composed as, "Yesterday I was sitting there on the blue chair, today I am sitting here on the black chair. If here was there and there was here and if now was then and then was now. Where would I be sitting then? Where would I be sitting now?"

The procedure was administered in conversational format with the experimenter. The experimenter asked the questions listed above, and the participant was to answer in the absence of any feedback. The results revealed that there was a significant difference between age groups. In general, errors decreased as a function of age. Adults produced the lowest number of errors, while the early childhood (ages 3-5) group produced the highest number of errors. The middle (ages 6-8) and late (ages 9-11) childhood groups showed no significant difference in their number of errors produced.

This finding was important because the Theory of Mind literature argues that children's performance should improve on simple Theory of Mind tasks by the age of 5. The results of this study further support this claim because the performances of children in their middle childhood more closely resembled those in the adolescent and adult participants than did the performances of the children in the early childhood group, implying that RFT is consistent with the traditional and Theory of Mind research, showing that "relational perspective-taking is an important feature of normal cognitive development" (McHugh et al., 2004, pg. 143). More importantly, this study demonstrated that behavior analysis can identify responses that involve perspective-taking and that these responses may be defined as relational operants. In addition, Relational Frame Theory can assist in the analysis of these events, and this analysis can inform our science of what maintains a repertoire of perspective-taking. These conclusions have implications in terms of application in that by utilizing a behavioral approach to perspective-taking, effective interventions can be designed to establish these repertoires in both typically developing and developmentally disabled children in which these skills may not yet exist (McHugh et al., 2004).

Rehfeldt, Dillen, Ziomek, and Kowalchuk (submitted) were the first to use the behavioral account of perspective-taking to conduct an empirical investigation on relational learning deficits in perspectivetaking with the autistic population. This study utilized a version of the Barnes-Holmes automated 
protocol, and investigated in two experiments whether children with autism spectrum disorder demonstrated relational learning deficits in a perspective-taking task as compared to their age-matched typically-developing peers. They also investigated whether accuracy in perspective-taking correlated with scores on standardized instruments commonly used in the assessment of autism spectrum disorder, and whether relational responding in perspective-taking improved following a history of reinforcement for such responding. The results of Experiment 1 demonstrated statistically significant differences in errors as a function of relational complexity. The results also showed that participants with autism spectrum disorder made more errors than typically developing children on two of the three types of relations examined. Results of Experiment 2 illustrated that a history of reinforced relational responding improved performance on the perspective-taking task.

The present study set out to build on the findings of the McHugh et al. (2004) study and apply the Barnes-Holmes protocol in a computerized format with typically developing children. This study utilized the computer program developed by Rehfeldt et al. (submitted). Through the utilization of the computerized version, fewer experimenter cues were necessary, and a higher standard of procedural reliability was obtained (i.e., the investigators provided procedural reliability). The aim of the present study was to use an extended version of the Barnes-Holmes protocol (Barnes-Holmes, Barnes-Holmes, \& McHugh, 2004; Barnes-Holmes, McHugh, \& Barnes-Holmes, 2004) to teach typic ally developing children between the ages of 6-11 perspective-taking skills through training the simple, reversed and double-reversed, I-you, here-there, and now-then relations as described in the original protocol. Furthermore, this is the only study to date that has assessed these learned perspective-taking skills and tested for generalization of perspective-taking to a real-world conversation. To test for this generalization, the experimenter assessed both pre- and post training to decipher if these novel skills transferred into day-to-day conversations with the experimenter. During the generalization assessment, the experimenter asked the child the same form of questions as previously discussed; however, the questions now involved more day-to-day topic s that the child would encounter in a real-world setting conversational context. Moreover, we also tested for stimulus generalization. To test for this specific generalization, each participant was given pre-and post assessments of the exact questions composed of the three types of relations and complexities, however, this time with novel stimuli. We hypothesized that after training the simple, reversed and double reversed relations, participants' post assessment scores would be significantly higher than the pretest scores for each relation. We also hypothesized that the perspective-taking skills learned throughout the training portion of the study would in fact generalize to more real-world topics of the same format, and would also generalize to more questions of the same format with different stimuli. Such findings would show that the relations were truly derived and regardless of the stimuli involved, children may display relational skills in perspective taking with unique stimuli, in different situational contexts.

\section{Participants}

\section{METHOD}

Three typically developing children with no known disabilities participated in this study. All three participants were recruited via personal contacts. Parents and children were financially compensated for their time and travel. JH was a male of eleven years and 4 months (late childhood) at the time of his participation. DH was a male of 8 years and 1 month (middle childhood) at the time of his participation. WH was a female of 6 years and 9 months (middle childhood) at the time of her participation. Before each participant's first session, the participant's reading ability was screened by having each participant read a sample simple relation question out loud in the presence of the experimenter. This sample relation question was not presented in the actual experiment. All of the children in this study were reported by their parents to read at grade level and displayed no reading comprehension problems. Throughout the remainder of the study, each participant was periodically asked to read randomly selected trials out loud as he/she completed various portions of the experiment. This 
precaution was taken to ensure that the child was not misreading questions that could affect his or her ability to answer the perspective-taking questions to the best of his or her ability.

\section{Setting and Apparatus}

Experimental sessions were conducted in a quiet, secluded room in the Rehabilitation Institute at Southern Illinois University. The perspective-taking tasks were presented on a laptop PC, and were created in Microsoft ${ }^{\circledR}$ PowerPoint ${ }^{\circledR}$ with program macros controlled by Microsoft Visual Basic Editor ${ }^{\circledR}$ and were programmed by both authors. The perspective-taking and stimulus generalization programs were automated, while the response generalization questions were presented by the experimenter to each participant through a conversational context. A script for these response generalization questions was created and procedural reliability was also recorded during this portion of the experiment to avoid any procedural errors on the part of the experimenter. Participants were allowed brief breaks from the tasks at any time, during which they engaged in a fun activity with the experimenter (e.g., playing a computer game, playing with modeling clay). Participants were also compensated for their participation after each session with small tangible items (i.e., candy, small toys, etc.). Finally, parents and children were financially compensated for their time and travel. If the participant attended all scheduled sessions for the entire week, the participant was awarded $\$ 10$ for that week. Each participant in the current study attended every scheduled session and was compensated accordingly.

\section{Procedure}

All participants were exposed to the same procedure which consisted of a modified automated version of the Barnes-Holmes protocol (Barnes-Holmes, Barnes-Holmes, \& McHugh, 2004; BarnesHolmes, McHugh, \& Barnes-Holmes, 2004), as reported by McHugh et al. (2004). The protocol used in this study was the same protocol used in the Rehfeldt et al. study (submitted) and consisted of 57 total trials. Each trial consisted of two questions (e.g., "where am I sitting?" "Where are you sitting?"). The participant had to answer both questions correctly in order for the trial to be scored as correct. If the participant answered one of the two questions wrong, or answered both questions incorrectly, the trial was scored as incorrect. If the participant asked the experimenter a question during a task, the experimenter reminded the participant to answer the question as best as he/she could and that the experimenter was not allowed to help the participant. There was no time limit on each trial for a response to occur. Three types of relations varying in complexity were presented in the protocol including simple relations, reversed relations, and double reversed relations. Within each of these three types of relations were trials that assessed responding to three different perspective-taking frames (I-You, Here-There, and Now-Then). The simple relation protocol consisted of eight trials that included 2 I-You, 2 Here-There, and 4 NowThen trial types. The reversed relation protocol consisted of thirty-six trials, including 8 I-You, 12 HereThere, and 16 Now-Then relations. The double reversed relation protocol consisted of thirteen trials, including 4, I-You/Here-There and 9, Here-There/Now-then trial types. The number of trials for each relation and each trial type followed closely the procedure used by McHugh et al. (2004) and were identical to those used by Rehfeldt et al.

Table 1 shows the questions that were presented for each of the three relations and for each of the trial types within each relation tested. In order for the participant to receive a correct score on test trials for the simple relations, the participant had to choose the answer that was identical to the arrangements specified in the question. Correct answers to test trials for the reversed relations required the participant to reverse the I-You, Now-Then, or Here-There arrangements specified in the question. In order for the participant to receive a correct score on test trials for the double reversed relations, the participant had to simultaneously reverse the I-You and Here-There or Here-There and Now-then arrangements specified in the question. The stimulus generalization program was identical to the perspective-taking program (57 total trials) except the relation questions included different stimuli (e.g., instead of "I have a red brick and you have a green brick", the stimuli was now changed to "I have a yellow pencil and you have an orange pencil", etc.). Examples of stimulus generalization questions are shown in Table 2. The response 
generalization questions consisted of 8 questions of each relation (simple, reversed, and double reversed) and also tested for all three perspective-taking frames (I-You, Now-Then, Here-There), however the questions were presented in a conversational format and consisted of real world topics, for example, "I am eating here at McDonald's and you are eating there at Wendy's. If I were you and you were me, where would I be eating? Where would you be eating?" Examples of response generalization questions and corresponding correct answers are shown in Table 3.

\section{Table 1}

The Perspective-Taking Protocol. (The correct response for each question is shown in parentheses. The reader is also referred to McHugh et al., 2004.)

\section{SIMPLE RELATIONS:}

Simple I-YOU:

I have a red brick can you have a green brick.

Which brick do I have? (Red)

Which brick do YOU have? (Green)

I have a green brick and you have a red brick.

Which brick do YOU have? (Red)

Which brick do I have? (Green)

\section{Simple HERE-THERE:}

I am sitting here on the blue chair and you are sitting there on the black chair.

Where am I sitting? (Blue)

Where are YOU sitting? (Black)

I am sitting here on the black chair and you are sitting here on the blue chair.

Where are YOU sitting? (Blue)

Where am I sitting? (Black)

\section{Simple NOW-THEN:}

Yesterday I was watching television, today I am reading.

What am I doing now? (Reading)

What was I doing then? (Television)

Yesterday I was reading, today I am watching television.

What was I doing then? (Reading)

What am I doing now? (Television)

Yesterday you were reading, today you are watching television.

What are YOU doing now? (Television)

What were YOU doing then? (Reading)

Yesterday you were watching television, today you are reading.

What were YOU doing then? (Television)

What are YOU doing now? (Reading)

\section{REVERSED RELATIONS}

Reversed I-YOU:

I have a red brick and you have a green brick. If I was you and you were me.

Which brick would I have? (Green) 
Which brick would YOU have? (Red)

I have a green brick and you have a red brick. If I was you and you were me

Which brick would YOU have? (Green)

Which brick would I have? (Red)

I have a red brick and you have a green brick. If I was you and you were me.

Which brick would YOU have? (Red)

Which brick would I have? (Green)

I have a green brick and you have a red brick. If I was you and you were me.

Which brick would I have? (Red)

Which brick would YOU have? (Green)

I am sitting here on the black chair and you are sitting there on the blue chair. If I was you and you were me.

Where would YOU be sitting? (Black)

Where would I be sitting? (Blue)

I am sitting here on the black chair and you are sitting there on the blue chair. If I was you and you were me.

Where would I be sitting? (Blue)

Where would YOU be sitting? (Black)

I am sitting here on the blue chair and you are sitting there on the black chair. If I was you and you were me.

Where would I be sitting? (Black)

Where would YOU be sitting? (Blue)

I am sitting here on the blue chair and you are sitting there on the black chair. If I was you and you were me.

Where would YOU be sitting? (Blue)

Where would I be sitting? (Black)

Reversed HERE-THERE:

I am sitting here on the blue chair and you are sitting there on the black chair. If here was there and there was here.

Where would YOU be sitting? (Blue)

Where would I be sitting? (Black)

I am sitting here on the black chair and you are sitting there on the blue chair. If here was there and there was here.

Where would I be sitting? (Blue)

Where would YOU be sitting? (Black)

I am sitting here on the blue chair and you are sitting there on the black chair. If here was there and there was here.

Where would I be sitting? (Black)

Where would YOU be sitting? (Blue) 
I am sitting here on the black chair and you are sitting there on the blue chair. If here was there and there was here.

Where would YOU be sitting? (Black)

Where would I be sitting? (Blue)

Yesterday I was sitting there on the blue chair, today I am sitting here on the black chair. If here was there and there was here.

Where would I be sitting now? (Blue)

Where was I sitting then? (Black)

Yesterday I was sitting there on the black chair, today I am sitting here on the blue chair. If here was there and there was here.

Where was I sitting then? (Blue)

Where would I be sitting now? (Black)

Yesterday I was sitting there on the blue chair, today I am sitting here on the black chair. If here was there and there was here.

Where was I sitting then? (Black)

Where would I be sitting now? (Blue)

Yesterday I was sitting there on the black chair, today I am sitting here on the blue chair. If here was there and there was here.

Where would I be sitting now? (Black)

Where was I sitting then? (Blue)

Yesterday you were sitting there on the blue chair, today you are sitting here on the black chair. If here was there and there was here.

Where would you be sitting now? (Blue)

Where were you sitting then? (Black)

Yesterday you were sitting there on the blue chair, today you are sitting here on the black chair. If here was there and there was here.

Where were you sitting then? (Black)

Where would you be sitting now? (Blue)

Yesterday you were sitting there on the black chair, today you are sitting here on the blue chair. If here was there and there was here.

Where would you be sitting now? (Black)

Where were you sitting hen? (Blue)

Yesterday you were sitting here on the black chair, today you are sitting there on the blue chair. If here was there and there was here.

Where were you sitting then? (Blue)

Where would you be sitting now? (Black)

\section{Reversed NOW-THEN:}

Yesterday I was watching television, today I am reading. If now was then and then was now.

What was I doing then? (Reading)

What would I be doing now? (Television)

Yesterday I was reading, today I am watching television. If now was then and then was now. 
What would I be doing now? (Reading)

What was I doing then? (Television)

Yesterday I was watching television, today I am reading. If now was then and then was now.

What was I doing now? (Television)

What would I be doing then? (Reading)

Yesterday I was reading, today I am watching television. If now was then and then was now.

What was I doing then? (Television)

What would I be doing now? (Reading)

Yesterday you were watching television, today you are reading. If now was then and then was now.

What were you doing then? (Reading)

What would you be doing now? (Television)

Yesterday you were reading, today you are watching television. If now was then and then was now.

What were you doing then? (Television)

What would you be doing now? (Reading)

Yesterday you were watching television, today you are reading. If now was then and then was now.

What would you be doing now? (Television)

What were you doing then? (Reading)

Yesterday you were reading, today you are watching television. If now was then and then was now.

What would you be doing now? (Reading)

What were you doing then? (Television)

Yesterday I was sitting there on the blue chair, today I am sitting here on the black chair. If now was then and then was now.

Where would I be sitting now? (Blue)

Where was I sitting then? (Black)

Yesterday I was sitting there on the blue chair, today I am sitting here on the black chair. If now was then and then was now.

Where was I sitting then? (Black)

Where would I be sitting now? (Blue)

Yesterday I was sitting there on the black chair, today I am sitting here on the blue chair. If now was then and then was now.

Where would I be sitting now? (Black)

Where was I sitting then? (Blue)

Yesterday I was sitting there on the black chair, today I am sitting here on the blue chair. If now was then and then was now.

Where was I sitting then? (Blue)

Where would I be sitting now? (Black)

Yesterday you were sitting there on the blue chair, today you are sitting here on the black chair. If now was then and then was now.

Where were you sitting then? (Black)

Where would you be sitting now? (Blue) 
Yesterday you were sitting there on the blue chair, today you are sitting here on the black chair. If now was then and then was now.

Where would you be sitting now? (Blue)

Where were you sitting hen? (Black)

Yesterday you were sitting there on the black chair, today you are sitting here on the blue chair. If now was then and then was now.

Where were you sitting then? (Blue)

Where would you be sitting now? (Black)

Yesterday you were sitting there on the black chair, today you are sitting here on the blue chair. If now was then and then was now.

Where would you be sitting now? (Black)

Where were you sitting then? (Blue)

\section{DOUBLE REVERSED RELATIONS:}

I-YOU/HERE-THERE:

I am sitting here on the blue chair and you are sitting there on the black chair. If I was you and you were me and if here was there and there was here.

Where would I be sitting? (Blue)

Where would YOU be sitting? (Black)

I am sitting here on the black chair and you are sitting there on the blue chair. If I was you and you were me and if here was there and there was here.

Where would I be sitting? (Black)

Where would YOU be sitting? (Blue)

I am sitting here on the blue chair and you are sitting there on the black chair. If I was you and you were me and if here was there and there was here.

Where YOU be sitting? (Black)

Where would I be sitting? (Blue)

I am sitting here on the black chair and you are sitting there on the blue chair. If I was you and you were me and if here was there and there was here.

Where would YOU be sitting? (Blue)

Where would I be sitting? (Black)

\section{HERE-THERE/NOW-THEN:}

Yesterday I was sitting there on the blue chair, today I am sitting here on the black chair. If here was there and there was here and If now was then and then was now.

Where would I be sitting then? (Blue)

Where would I be sitting now? (Black)

Yesterday I was sitting there on the blue chair, today I am sitting here on the black chair. If here was there and there was here and If now was then and then was now.

Where would I be sitting now? (Black)

Where would I be sitting then? (Blue) 
Yesterday I was sitting there on the black chair, today I am sitting here on the blue chair. If here was there and there was here and If now was then and then was now.

Where would I be sitting then? (Black)

Where would I be sitting now? (Blue)

Yesterday I was sitting there on the black chair, today I am sitting here on the blue chair. If here was there and there was here and If now was then and then was now.

Where would I be sitting now? (Blue)

Where would I be sitting then? (Black)

Yesterday you were sitting there on the blue chair, today you are sitting here on the black chair. If here was there and there was here and If now was then and then was now.

Where would you be sitting then? (Blue)

Where would you be sitting now? (Black)

Yesterday you were sitting here on the blue chair, today you are sitting here on the black chair. If here was there and there was here and If now was then and then was now.

Where would you be sitting now? (Black)

Where would you be sitting then? (Blue)

Yesterday you were sitting there on the black chair, today you are sitting here on the blue chair. If here was there and there was here and If now was then and then was now.

Where would you be sitting then? (Black)

Where would you be sitting now? (Blue)

Yesterday you were sitting there on the black chair, today you are sitting here on the blue chair. If here was there and there was here and If now was then and then was now.

Where would you be sitting now? (Blue)

Where would you be sitting then? (Black)

\section{Table 2}

Stimulus Generalization Perspective Taking protocol.

\section{SIMPLE RELATIONS:}

Simple I-YOU:

I have an orange pencil and you have a yellow pencil.

Which pencil do I have? (Orange)

Which pencil do YOU have? (Yellow)

I have a yellow pencil and you have an orange pencil.

Which pencil do YOU have? (Orange)

Which pencil do I have? (Yellow)

\section{Simple HERE-THERE:}

I am sitting here on the pink couch and you are sitting there on the purple couch.

Where am I sitting? (Pink)

Where are YOU sitting? (Purple)

I am sitting here on the purple couch and you are sitting here on the pink couch.

Where are YOU sitting? (Pink)

Where am I sitting? (Purple) 


\section{Simple NOW-THEN:}

Yesterday I was playing video games, today I am listening to music.

What am I doing now? (Listening to music)

What was I doing then? (Video games)

Yesterday I was listening to music, today I am playing video games.

What was I doing then? (Listening to music)

What am I doing now? (Video games)

Yesterday you were listening to music, today you are playing video games.

What are YOU doing now? (Video games)

What were YOU doing then? (Listening to music)

Yesterday you were playing video games, today you are listening to music.

What were YOU doing then? (Video games)

What are YOU doing now? (Listening to music)

\section{REVERSED RELATIONS:}

\section{Reversed I-YOU:}

I have an orange pencil and you have a yellow pencil. If I was you and you were me.

Which pencil would I have? (Yellow)

Which pencil would YOU have? (Orange)

I have a yellow pencil and you have an orange pencil. If I was you and you were me

Which pencil would YOU have? (Yellow)

Which pencil would I have? (Orange)

I have an orange pencil and you have a yellow pencil. If I was you and you were me.

Which pencil would YOU have? (Orange)

Which pencil would I have? (Yellow)

I have a yellow pencil and you have an orange pencil. If I was you and you were me

Which pencil would I have? (Orange)

Which pencil would YOU have? (Yellow)

I am sitting here on the purple couch and you are sitting there on the pink couch. If I was you and you were me.

Where would YOU be sitting? (Purple)

Where would I be sitting? (Pink)

I am sitting here on the purple couch and you are sitting there on the pink couch. If I was you and you were me.

Where would I be sitting? (Pink)

Where would YOU be sitting? (Purple)

I am sitting here on the pink couch and you are sitting there on the purple couch. If I was you and you were me.

Where would I be sitting? (Purple)

Where would YOU be sitting? (Pink) 
I am sitting here on the pink couch and you are sitting there on the purple couch. If I was you and you were me.

Where would YOU be sitting? (Pink)

Where would I be sitting? (Purple)

\section{Reversed HERE-THERE:}

I am sitting here on the pink couch and you are sitting there on the purple couch. If here was there and there was here.

Where would YOU be sitting? (Pink)

Where would I be sitting? (Purple)

I am sitting here on the purple couch and you are sitting there on the pink couch. If here was there and there was here.

Where would I be sitting? (Pink)

Where would YOU be sitting? (Purple)

I am sitting here on the pink couch and you are sitting there on the purple couch. If here was there and there was here.

Where would I be sitting? (Purple)

Where would YOU be sitting? (Pink)

I am sitting here on the purple couch and you are sitting there on the pink couch. If here was there and there was here.

Where would YOU be sitting? (Purple)

Where would I be sitting? (Pink)

Yesterday I was sitting there on the pink couch, today I am sitting here on the purple couch. If here was there and there was here.

Where would I be sitting now? (Pink)

Where was I sitting then? (Purple)

Yesterday I was sitting there on the purple couch, today I am sitting here on the pink couch. If here was there and there was here.

Where was I sitting then? (Pink)

Where would I be sitting now? (Purple)

Yesterday I was sitting there on the pink couch, today I am sitting here on the purple couch. If here was there and there was here.

Where was I sitting then? (Purple)

Where would I be sitting now? (Pink)

Yesterday I was sitting there on the purple couch, today I am sitting here on the pink couch. If here was there and there was here.

Where would I be sitting now? (Purple)

Where was I sitting then? (Pink)

Yesterday you were sitting there on the pink couch, today you are sitting here on the purple couch. If here was there and there was here.

Where would you be sitting now? (Pink)

Where were you sitting then? (Purple) 
Yesterday you were sitting there on the pink couch, today you are sitting here on the purple couch. If here was there and there was here.

Where were you sitting then? (Purple)

Where would you be sitting now? (Pink)

Yesterday you were sitting there on the purple couch, today you are sitting here on the pink couch. If here was there and there was here.

Where would you be sitting now? (Purple)

Where were you sitting hen? (Pink)

Yesterday you were sitting here on the purple couch, today you are sitting there on the pink couch. If here was there and there was here.

Where were you sitting then? (Pink)

Where would you be sitting now? (Purple)

\section{Reversed NOW-THEN:}

Yesterday I was playing video games, today I am listening to music. If now was then and then was now. What was I doing then? (Listening to music)

What would I be doing now? (Video games)

Yesterday I was listening to music, today I am playing video games. If now was then and then was now. What would I be doing now? (Listening to music)

What was I doing then? (Video games)

Yesterday I was playing video games, today I am listening to music. If now was then and then was now. What was I doing now? (Video games)

What would I be doing then? (Listening to music)

Yesterday I was listening to music, today I am playing video games. If now was then and then was now. What was I doing then? (Video games)

What would I be doing now? (Listening to music)

Yesterday you were playing video games, today you are listening to music. If now was then and then was now.

What were you doing then? (Listening to music)

What would you be doing now? (Video games)

Yesterday you were listening to music, today you are playing video games. If now was then and then was now.

What were you doing then? (Video games)

What would you be doing now? (Listening to music)

Yesterday you were playing video games, today you are listening to music. If now was then and then was now.

What would you be doing now? (Video games)

What were you doing then? (Listening to music)

Yesterday you were listening to music, today you are playing video games. If now was then and then was now.

What would you be doing now? (Listening to music)

What were you doing then? (Video games) 
Yesterday I was sitting there on the pink couch, today I am sitting here on the purple couch. If now was then and then was now.

Where would I be sitting now? (Pink)

Where was I sitting then? (Purple)

Yesterday I was sitting there on the pink couch, today I am sitting here on the purple couch. If now was then and then was now.

Where was I sitting then? (Purple)

Where would I be sitting now? (Pink)

Yesterday I was sitting there on the purple couch, today I am sitting here on the pink couch. If now was then and then was now.

Where would I be sitting now? (Purple)

Where was I sitting then? (Pink)

Yesterday I was sitting there on the purple couch, today I am sitting here on the pink couch. If now was then and then was now.

Where was I sitting then? (Pink)

Where would I be sitting now? (Purple)

Yesterday you were sitting there on the pink couch, today you are sitting here on the purple couch. If now was then and then was now.

Where were you sitting then? (Purple)

Where would you be sitting now? (Pink)

Yesterday you were sitting there on the pink couch, today you are sitting here on the purple couch. If now was then and then was now.

Where would you be sitting now? (Pink)

Where were you sitting hen? (Purple)

Yesterday you were sitting there on the purple couch, today you are sitting here on the pink couch. If now was then and then was now.

Where were you sitting then? (Pink)

Where would you be sitting now? (Purple)

Yesterday you were sitting there on the purple couch, today you are sitting here on the pink couch. If now was then and then was now.

Where would you be sitting now? (Purple)

Where were you sitting then? (Pink)

\section{DOUBLE REVERSED RELATIONS:}

\section{I-YOU/HERE-THERE:}

I am sitting here on the pink couch and you are sitting there on the purple couch. If I was you and you were me and if here was there and there was here.

Where would I be sitting? (Pink)

Where would YOU be sitting? (Purple)

I am sitting here on the purple couch and you are sitting there on the pink couch. If I was you and you were me and if here was there and there was here.

Where would I be sitting? (Purple)

Where would YOU be sitting? (Pink) 
I am sitting here on the pink couch and you are sitting there on the purple couch. If I was you and you were me and if here was there and there was here.

Where YOU be sitting? (Purple)

Where would I be sitting? (Pink)

I am sitting here on the purple couch and you are sitting there on the pink couch. If I was you and you were me and if here was there and there was here.

Where would YOU be sitting? (Pink)

Where would I be sitting? (Purple)

\section{HERE-THERE/NOW-THEN:}

Yesterday I was sitting there on the pink couch, today I am sitting here on the purple couch. If here was there and there was here and If now was then and then was now.

Where would I be sitting then? (Pink)

Where would I be sitting now? (Purple)

Yesterday I was sitting there on the pink couch, today I am sitting here on the purple couch. If here was there and there was here and If now was then and then was now.

Where would I be sitting now? (Purple)

Where would I be sitting then? (Pink)

Yesterday I was sitting there on the purple couch, today I am sitting here on the pink couch. If here was there and there was here and If now was then and then was now.

Where would I be sitting then? (Purple)

Where would I be sitting now? (Pink)

Yesterday I was sitting there on the purple couch, today I am sitting here on the pink couch. If here was there and there was here and If now was then and then was now.

Where would I be sitting now? (Pink)

Where would I be sitting then? (Purple)

Yesterday you were sitting there on the pink couch, today you are sitting here on the purple couch. If here was there and there was here and If now was then and then was now.

Where would you be sitting then? (Pink)

Where would you be sitting now? (Purple)

Yesterday you were sitting here on the pink couch, today you are sitting here on the purple couch. If here was there and there was here and If now was then and then was now.

Where would you be sitting now? (Purple)

Where would you be sitting then? (Pink)

Yesterday you were sitting there on the purple couch, today you are sitting here on the pink couch. If here was there and there was here and If now was then and then was now.

Where would you be sitting then? (Purple)

Where would you be sitting now? (Pink)

Yesterday you were sitting there on the purple couch, today you are sitting here on the pink couch. If here was there and there was here and If now was then and then was now.

Where would you be sitting now? (Pink) 
Where would you be sitting then? (Purple)

Table 3

Response Generalization Questions.

\section{SIMPLE RELATIONS:}

I have the hamburger and you have the grilled cheese

Which sandwich do I have? (Hamburger)

Which sandwich do you have? (Grilled cheese)

You have the hamburger and I have the grilled cheese.

Which sandwich do you have? (Hamburger)

Which sandwich do I have? (Grilled cheese)

If I'm standing in the classroom, and you're standing on the playground.

Where are you standing? (Playground)

Where am I standing? (Classroom)

If you're standing in the classroom, and I'm standing on the playground.

Where am I standing? (Playground)

Where are you standing? (Classroom)

Yesterday I was playing X-Box, today I am watching "The Incredibles."

What was I doing then? (X-Box)

What am I doing now? ("The Incredibles")

Today you are watching "The Incredibles," yesterday you were playing X-Box.

What are you doing now? ("The Incredibles")

What were you doing then? (X-Box)

Yesterday you were reading comic books, today you are talking on the phone.

What are you doing now? (Phone)

What were you doing then? (Comic books)

Today I am talking on the phone, yesterday I was reading comic books.

What was I doing then? (Comic books)

What am I doing now? (Phone)

\section{REVERSED RELATIONS:}

I am holding the puppy and you are holding the kitten, if I was you and you were me.

Which animal am I holding? (Kitten)

Which animal are you holding? (Puppy)

You are holding the puppy and I am holding the kitten, if I was you and you were me.

Which animal are you holding? (Kitten)

Which animal am I holding? (Puppy)

Yesterday I was swimming there in the pool, today I am swimming here in the lake, if here was there and there was here.

Where was I swimming then? (Lake) 
Where am I swimming now? (Pool)

Today you are swimming here in the lake, yesterday you were swimming there in the pool, if here was there and there was here.

Where are you swimming now? (Pool)

Where were you swimming then? (Lake)

Yesterday I was doing my homework; today I am taking a nap. If now was then and then was now.

What would I be doing now? (Homework)

What was I doing then? (Nap)

Today you are doing your homework; yesterday you were taking a nap. If now was then and then was now.

What were you doing then? (Homework)

What would you be doing now? (Nap)

Yesterday you were playing soccer, today you are playing basketball. If now was then and then was now. What were you doing then? (Basketball)

What would you be doing now? (Soccer)

Today I am playing soccer, yesterday I was playing basketball. If now was then and then was now.

What would I be doing now? (Basketball)

What was I doing then? (Soccer)

\section{DOUBLE REVERSED RELATIONS:}

I am sleeping here in the bedroom and you are sleeping there in the living room. If I was you and you were me and if here was there and there was here.

Where would I be sleeping? (Bedroom)

Where would you be sleeping? (Living room)

You are sleeping here in the living room, and I am sleeping there in the bedroom.

If I was you and you were me and if here was there and there was here.

Where would you be sleeping? (Living room)

Where would I be sleeping? (Bedroom)

I am eating here at McDonalds and you are eating there at Wendy's. If I was you and you were me and if here was there and there was here.

Where would you be eating? (Wendy's)

Where would I be eating? (McDonalds)

You are eating here at Wendy's and I am eating there at McDonalds. If I was you and you were me and if here was there and there was here.

Where would I be eating? (McDonalds)

Where would you be eating? (Wendy's)

Yesterday I was shopping there at the mall; today I am shopping here at the grocery store. If here was there and there was here and if now was then and then was now.

Where would I be shopping then? (Mall)

Where would I be shopping now? (Grocery store)

Today you are shopping here at the mall; yesterday you were shopping there at the grocery store. If here was there and there was here and if now was then and then was now. 
Where would you be shopping now? (Mall)

Where would you be shopping then? (Grocery store)

Yesterday you were running there in the park; today you are running here in gym class. If here was there and there was here and if now was then and then was now.

Where would you be running now? (Gym class)

Where would you be running then? (Park)

Today I am running here in the park; yesterday I was running there in gym class. If here was there and there was here and if now was then and then was now.

Where would I be running then? (Gym class)

Where would I be running now? (Park)

Figure 1 shows on-screen representations of a simple I-You trial, a reversed Now-Then trial, and a double reversed Here-There/Now-Then trial. Participants were required to click the computer mouse on one of the two command buttons presented for each question in order to designate their answer. Once the participant responded to one of the two command boxes presented for the second question, they were advanced to the next trial. The left-right position of the correct and incorrect command boxes was randomly established across all trials.

Participants were first given three pretests for the simple relation. These pretests consisted of the simple relation pretest, the stimulus generalization pretest and the response generalization pretest. If the participant did not receive an $88 \%$ ( $7 / 8$ correct) on all three pretests, training of the simple relations was introduced. If the participant did not meet criterion on the simple relations training, the participant repeated training until a criterion of at least $88 \%$ was reached. Once a mastery criterion of $88 \%$ was reached on the simple relations training, the three post-tests (simple relation, stimulus generalization and response generalization) were given. If the participant met the criterion for inferring the emergence of the simple relations on the simple relations post-test and showed generalization (criterion of $88 \%$ ) on the two generalization post tests, pre-testing of the reversed relations was introduced. If the participant did not meet criterion for inferring the emergence of the simple relations or showing generalization on the two generalization post tests, training of the simple relations was repeated until a criterion of $88 \%$ mastery criterion was reached, and the simple relations post tests were repeated once the relations and generalization were again shown to be mastered. This process was then repeated for the reversed and double reversed relations. A mastery criterion of at least $88 \%$ correct on the simple relations pre-and post tests (7/8 test trials correct for the simple relations), and $90 \%$ correct on the reversed and double reversed pre-and post tests (33/36 correct for the reversed relations, and 12/13 correct for the double reversed relations) was taken as indicative of the emergence of the particular relations.

FIGURE 1, NEXT PAGE 


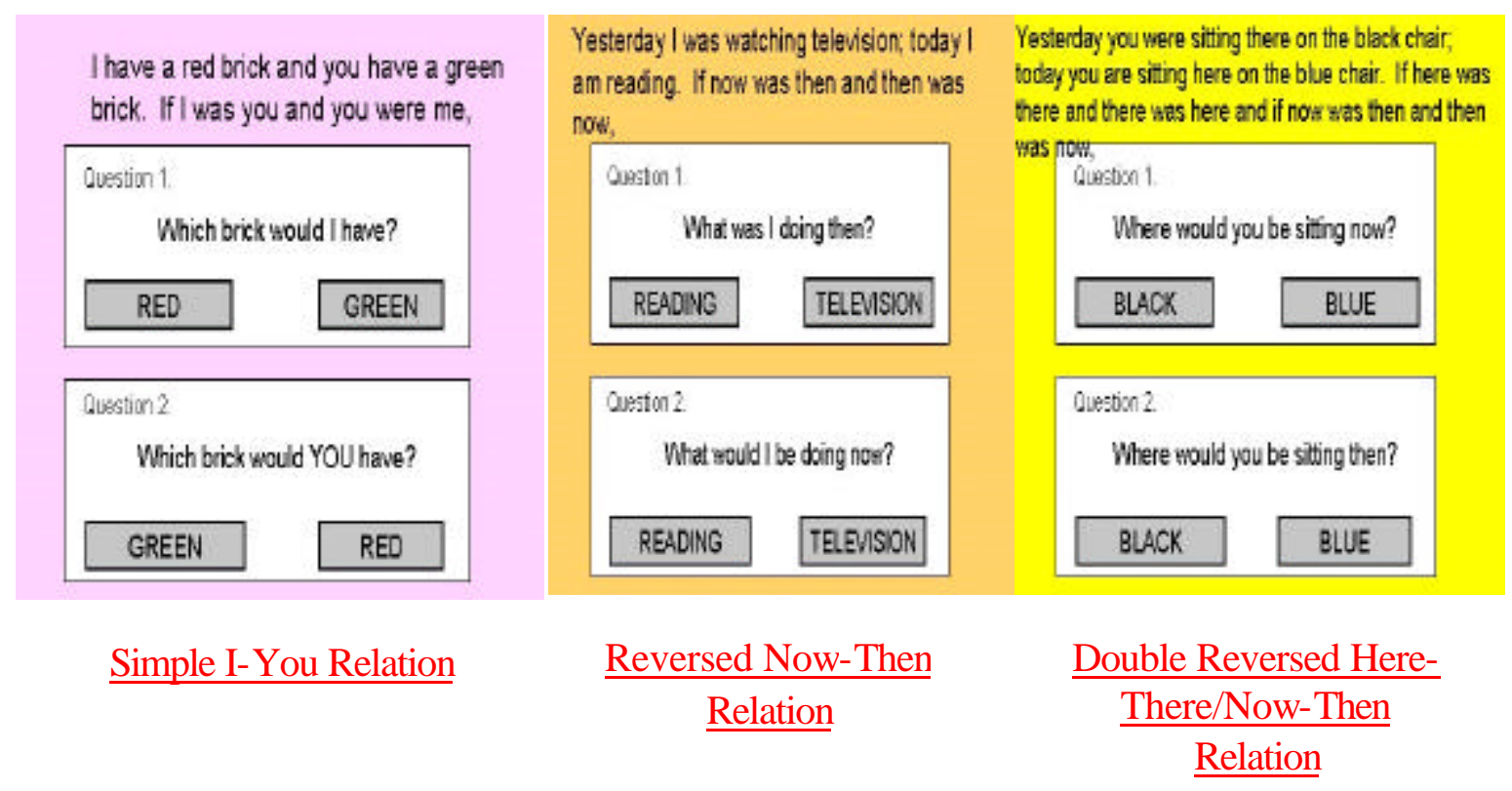

Figure 1. On-screen representation of simple, reversed, and double-reversed relations trials.

No feedback was presented during pre-and post tests. During the response generalization preand post tests the experimenter gave noncontingent praise (reinforced attending and responses unrelated to the accuracy of responses to the probes) throughout the protocol (e.g., "Keep up the good work," and "You're doing a great job"). During training for both the perspective-taking and stimulus generalization protocols, a variety of 3 second animation clips were presented as reinforcers following correct trials during training, whereas incorrect trials produced a slide which read, "Try again," and the respective trial was then repeated until the participant answered correctly.

\section{Design}

The present experiment utilized a multiple probe design across participants (Horner \& Baer, 1978). Three designs were used to train and test each relation (simple, reversed, and double reversed). For the simple relations, all three participants were given all three pre-test probes on the same day. DH was the only participant who needed training. He was then administered the three pre-test probes, in which he reached criterion and completed training on the simple relations. For the reversed relations, once again all three participants were given the pre-test probes on the same day. JH was the first participant to begin training, while the other two participants remained in the baseline period. When visual inspection of the data revealed an ascending trend, DH then began training on the reversed relations while WH remained in baseline. Finally, when visual inspection of DH's training data revealed an ascending trend, WH began training on the reversed relations. Once JH mastered criterion on the reversed relation training, he was administered the reversed relation, stimulus generalization and response generalization post tests. Since he did not reach criterion on all three post-tests, JH then began training a second time for the reversed relations. During this time, DH mastered criterion on the reversed relation training and was administered the three post tests. He did not master the criterion on all three post-tests and began training for a second time on the reversed relations. During this time, WH mastered criterion on the reversed relations training and was administered the three post tests. WH mastered criterion on all three post-tests and this concluded her training for the reversed relations. This process was repeated for 
both JH and DH until they met criterion on all three post-test probes. For the double reversed relations, all three participants were given the three pre-test probes on the same day. JH met criterion on the pretests probes and therefore did not require training. DH was the first to receive training for the double reversed relations. When visual inspection of the data revealed an ascending trend, WH began training on the double reversed relations. The same process described above was repeated for both DH and WH until they met criterion on the double reversed relation, stimulus generalization and response generalization post test probes. Figure 3 and 4 shows that WH was the last participant to be trained in both the reversed and double reversed relations, leaving her in baseline for 7 and 3 sessions respectively after her pre-test probes. Because at least three sessions were administered with each participant each day, three times a week, it was not necessary to administer training probes in baseline for either relation to $\mathrm{WH}$ because she was introduced to training in both relations the very next day.

\section{Interobserver Agreement}

Because the perspective-taking protocols were administered via an automated computerized format, and data collection was computer controlled, no interobserver agreement was collected on the simple, reversed, and double reversed pre-test, training, and post tests, or the stimulus generalization preand post tests. However, IOA was taken independently and simultaneously by a second observer for $100 \%$ of the response generalization pre- and post test probes that were administered by the experimenter. Interobserver agreement was assessed using the total number of agreements divided by the number of agreements plus the number of disagreements, multiplied by $100 \%$ formula. IOA was $100 \%$ across all response generalization pre-and post- tests.

\section{Procedural Reliability}

A second observer scored procedural reliability while the experimenter presented the response generalization pre-and post test-probes to ensure that the experimenter was following all aspects of the experimental protocol. A checklist of correct experimenter behaviors was developed and is shown in Table 4. The second observer recorded these behaviors as either occurring or not occurring. Procedural reliability was assessed using the number of experimenter behaviors recorded as occurring divided by the total number of experimenter behaviors listed on the checklist multiplied by $100 \%$ formula. Procedural reliability was $100 \%$ across all response generalization probes.

\section{Table 4}

Procedural Reliability Data Sheet

Phase

Date

Experimenter

Observer

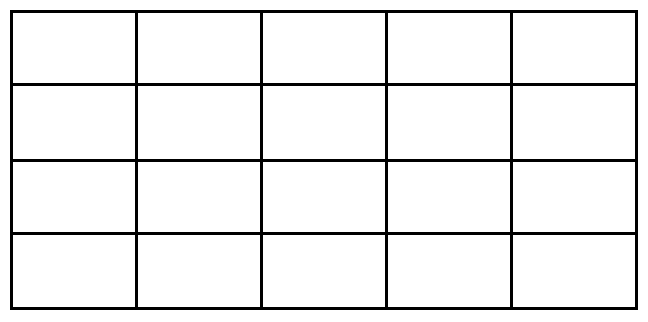

1. Did the experimenter follow the script as stated on the response generalization sheet when stating the response generalization instructions to the participant?

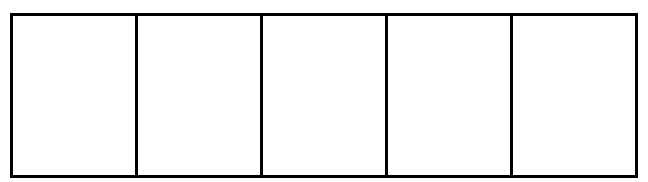


2. Is the experimenter's intermittent reinforcement truly noncontingent (i.e., the reinforcement is randomly emitted throughout the session and not contingent on any correct or incorrect response) on the participant's performance?

3. Is the experimenter refraining from giving the participant any verbal cues (i.e., "good job" or "that is incorrect") in response to the participant's correct or incorrect responses?

4. Is the experimenter refraining from giving the participant any nonverbal cues (i.e., approving or disapproving looks, looking away, etc.) in response to the participant's correct or incorrect responses?

5. Did the experimenter state the questions verbatim as written on the response generalization question sheet?

6. Were the response generalization questions randomized on the response generalization question sheet?

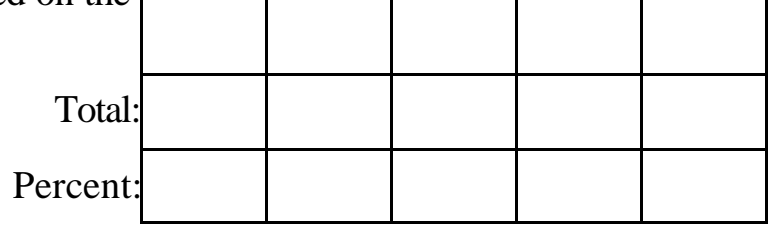

\section{Simple Relations}

Results

Figure 2 portrays all three participants' performances on the pre-tests, training trials, and posttests for the simple relations. The pre-and post-tests consisted of the simple relations pre-and post tests, as well as the stimulus and response generalization pre-and post tests. If the participant received a score of $88 \%$ or better on all three of the simple relations pre-test probes, training on the simple relations was not administered. Mastery criterion for the simple relations training was $88 \%$. Once the participant met criterion on the simple relations training, the three pre-test probes were introduced. If the participant met the criterion for inferring the emergence of the simple relations on the simple relations post test and showed generalization (criterion of $88 \%$ ) on the two generalization post-tests, emergence of the simple relations was indicated. Although DH initially did not meet criterion performance on the stimulus generalization pre-test for the simple relations (scoring 100\% on the simple relations pre-test, and $75 \%$ and $100 \%$ on the stimulus and response generalization pre-tests respectively), he required only one training block to master the simple relations, after which he responded with $100 \%$ accuracy on the simple relations and stimulus generalization post test and $88 \%$ on the response generalization post test.

$\mathrm{JH}$ met criterion on the simple relations, stimulus and response generalization pre-tests with a score of $100 \%, 88 \%$, and $100 \%$ respectively. Therefore no training on the simple relations was necessary.

WH also met criterion on all three pre-tests, scoring $88 \%, 100 \%$, and $88 \%$ on the simple relations pre-test, $100 \%$ on the stimulus generalization pre-test and $88 \%$ on the response generalization pre-test. Therefore, no training was necessary for WH as well. 


\section{Simple Relations}
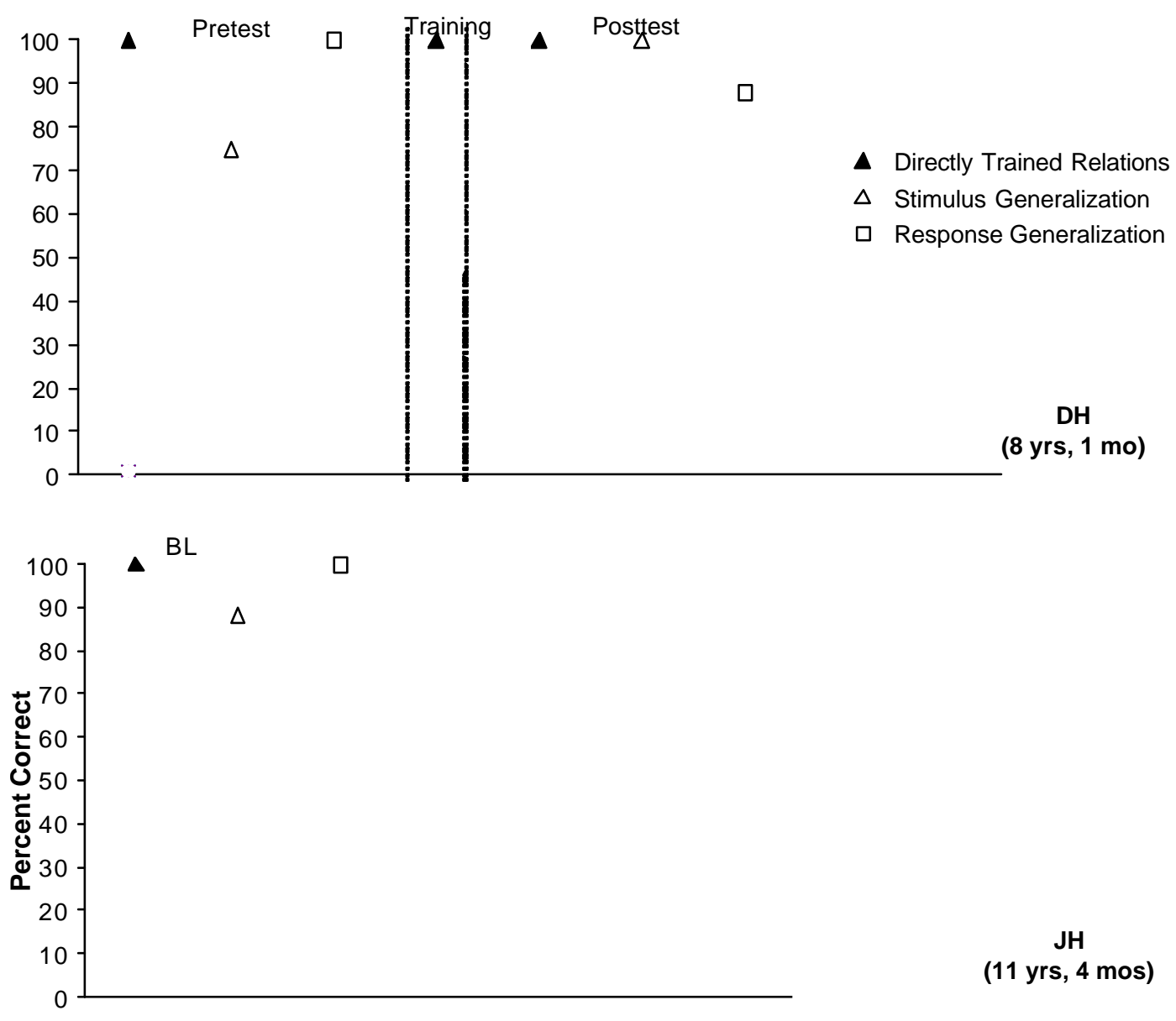

$\mathrm{JH}$

(11 yrs, 4 mos)

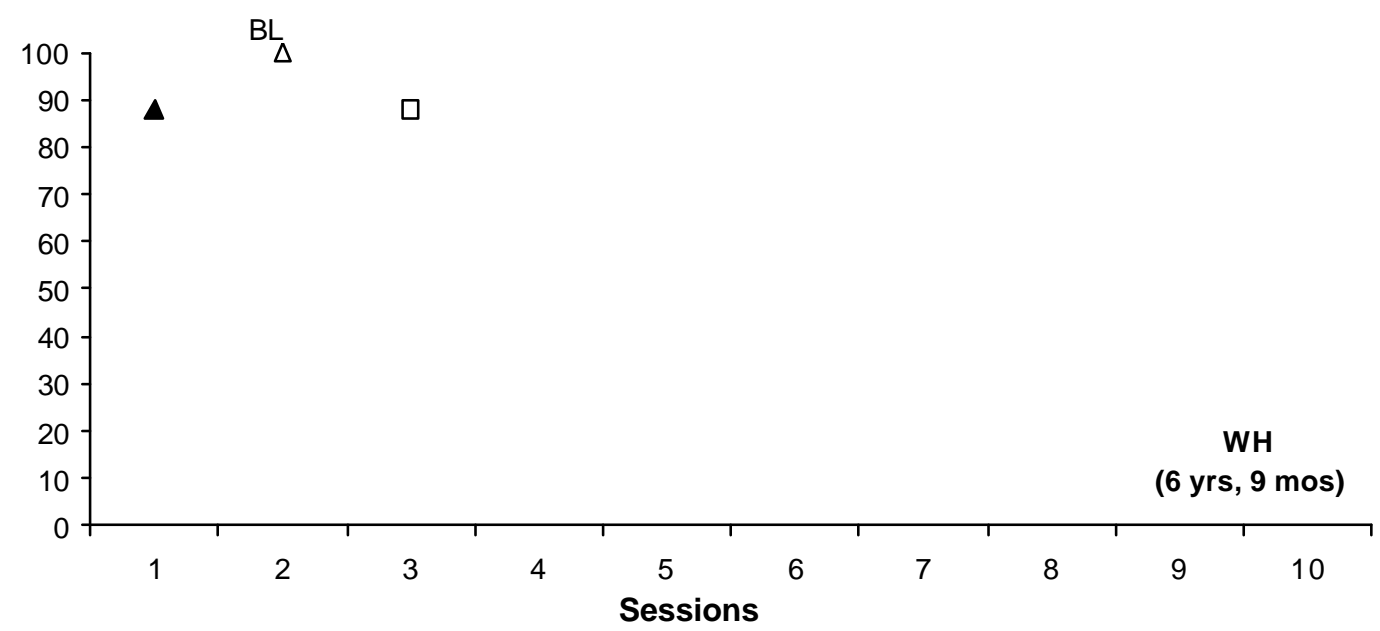

Figure 2. Participants' Performances on the Simple Relations.

Reversed Relations 
Shown in Figure 3 are all three participants' performances on the pre-tests, training trials, and post tests for the reversed relations. The pre-and post tests consisted of the reversed relations pre-and post tests, as well as the stimulus and response generalization pre-and post tests. If the participant received a score of $90 \%$ or better on all three of the reversed relations pre-test probes, training on the reversed relations was not administered. Mastery criterion for the reversed relations training was $90 \%$. Once the participant met criterion on the reversed relations training, the three pre-test probes were administered. If the participant met the criterion for inferring the emergence of the reversed relations on the reversed relations post test and showed generalization (criterion of 90\%) on the two generalization post tests, emergence of the reversed relations was indicated. The figure shows that $\mathrm{JH}$ performed with $86 \%, 94 \%$, and $63 \%$ accuracy on the reversed relation pre-test, stimulus generalization and response generalization pre-tests respectively, and then mastered the relations in three training blocks. He did not meet criterion performance on the first set of post-test probes (scoring 97\%, 100\%, and 75\% respectively). After two more training blocks, JH again demonstrated mastery of the reversed relations, after which he did not meet criterion performance on the second set of post test probes (scoring 97\%, 97\%, and 50\% respectively). JH was then administered training on the reversed relations for the third time and again demonstrated criterion performance after only one training block. He once again did not meet criterion performance on the third set of post-test probes (scoring $81 \%, 97 \%$, and $75 \%$ respectively). $\mathrm{JH}$ then demonstrated mastery of the reversed relations in only one more training block and finally met criterion performance on the fourth set of post test probes (scoring 97\%, 94\%, and $88 \%$ on the reversed relations, stimulus generalization and response generalization post tests respectively).

DH performed with $62 \%, 39 \%$, and $38 \%$ accuracy on the reversed relations pre-test, stimulus generalization and response generalization pre-tests respectively, and then mastered the relations in four training blocks. He did not meet criterion performance on the first set of post tests (scoring 100\%, 86\%, and $88 \%$ respectively), but required only one more training session to do so, after which he demonstrated criterion performance on the three post tests for the reversed relations (scoring 94\%, 100\%, and 88\% respectively).

WH received a score of $28 \%$ on the reversed relations pre-test, $32 \%$ on the stimulus generalization pre-test, and $50 \%$ on the response generalization pre-test. In spite of her low pre-test scores, WH required only one training session to master training, performing with $92 \%$ accuracy. She also met criterion performance on the first set of post tests for the reversed relations (scoring 94\%, 97\%, and $88 \%$ respectively). 


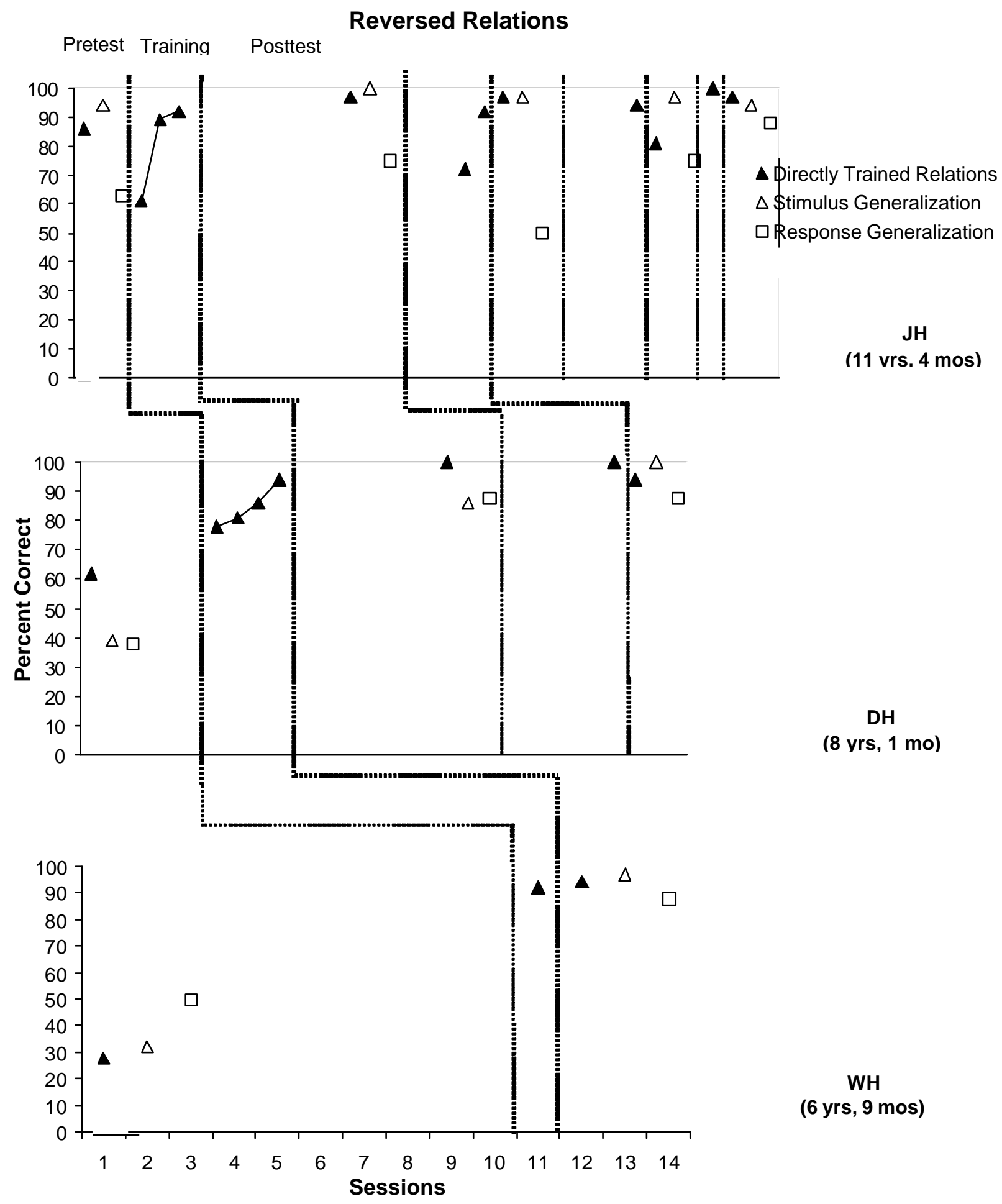

Figure 3. Participants' Performances on the Reversed Relations.

\section{Double Reversed Relations}

Shown in Figure 4 are all three participants' performances on the pre-tests, training trials, and post tests for the double reversed relations. The pre-and post tests consisted of the double reversed 
relations pre-and post tests, as well as the stimulus and response generalization pre-and post tests. If the participant received a score of $90 \%$ or better on all three of the double reversed relations pre-test probes, training on the double reversed relations was not administered. Mastery criterion for the double reversed relations training was $90 \%$. Once the participant met criterion on the double reversed relations, the three post test probes were introduced. If the participant met the criterion for inferring the emergence of the double reversed relations on the double reversed relations post test and showed generalization (criterion of $90 \%$ ) on the two generalization post tests, emergence of the double reversed relations was indicated. The figure shows that JH performed with $100 \%$ accuracy on all three pre-tests. Therefore training was not necessary for this participant.

DH performed with $100 \%, 85 \%$, and $75 \%$ on the double reversed relations pre-test, stimulus generalization and response generalization pre-tests respectively, and then mastered the relations in only one training block. He did not meet criterion performance on the first set of post tests (scoring 92\%, $100 \%$, and 50\% respectively), but required only one more training session to do so, after which he demonstrated criterion performance on the post tests for the double reversed relations (scoring 100\%, $100 \%$, and $88 \%$ respectively).

WH scored $8 \%$ on the double reversed relations pre-test, $0 \%$ on the stimulus generalization pretest, and $34 \%$ on the response generalization pre-test, after which she required two training blocks to master the double reversed relations. Although she did not meet criterion on the first set of post tests (scoring 100\%, 85\%, and 75\% respectively), she required only one more training session to do so. She then demonstrated criterion performance on all three post tests for the double reversed relations (scoring $92 \%, 100 \%$, and $88 \%$ respectively). 


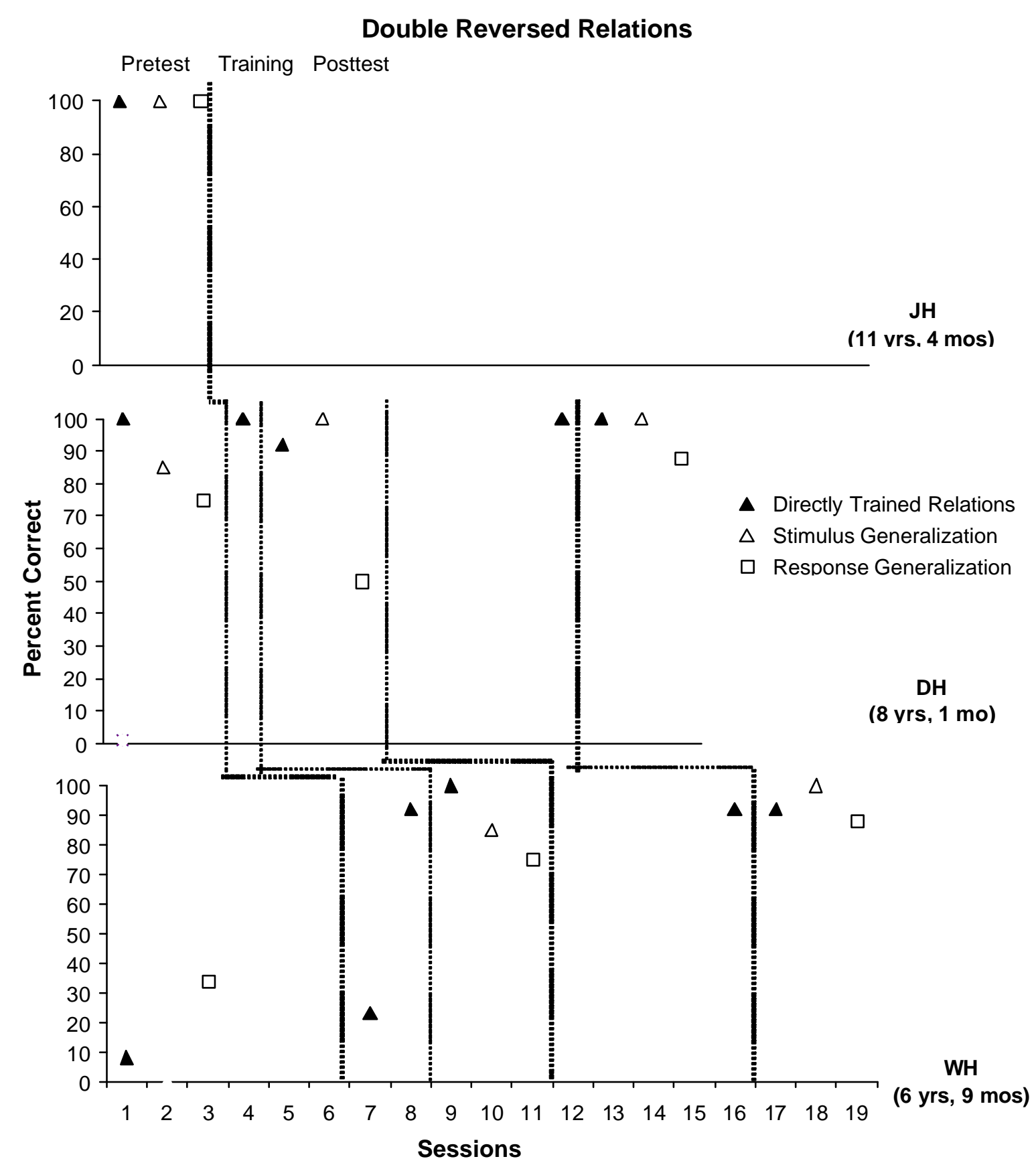

Figure 4. Participants' Performances on the Double Reversed Relations

Discussion

The results of the present experiment demonstrate that the capacity to alter the perspective between I-and-You, Here-and-There, and Now-and-Then can be established by means of a history of reinforced relational responding. All three participants displayed criterion performance on all three post tests for the reversed relations, conducted with no reinforcement, following contact with reinforcement contingencies during the training trials for correct changes in perspective. DH was the only participant 
who needed contact with reinforcement contingencies for the simple relations, and DH and WH only needed contact with reinforcement contingencies for the double reversed relations in order to display performance on the three post tests. Thus, the perspective-taking protocol used in the present experiment was effective in establishing I-You, Here-There, and Now-Then frames, which specified the relationship between stimuli in terms of the perspective of the speaker. This experiment was the first to test for response generalization in a realworld social situation that required the speaker to change his or her perspective with regards to different references of person. The present experiment was also the first to test for generalization to novel stimuli, in which questions in the same format as the original perspectivetaking protocol were presented with different stimuli (e.g., I have an orange pencil and you have a yellow pencil. Which pencil do I have? Which pencil do you have?). Consequently, the stimulus and response generalization probes revealed that for $\mathrm{DH}$, the simple, reversed, and double reversed relations, for $\mathrm{WH}$ the reversed and double reversed relations, and for $\mathrm{JH}$, the reversed relations, were truly learned and regardless of the stimuli involved, the participants displayed perspective-taking skills with unique stimuli, in different situational contexts. Results are consistent with Relational Frame Theory in that perspectivetaking is a generalized, overarching response class, with derived relational responding playing an apparent role.

Most predictable was the finding that the simple relations were the easiest for all three participants to master. These results are similar to the results of the McHugh et al. (2004) where children of all age groups produced significantly fewest errors on test trials for the simple relations. What is surprising, however, is that, DH, who was six years, 9 months old, required one training block on the simple relations before mastering criterion on the three post test probes. DH's performance on the simple relations contradicts the results of McHugh et al. (2004), in which errors decreased with age. One possible explanation as to how this may have occurred, concerning the simple relation results, is that while DH scored a $100 \%$ on the simple relations pre-test, he scored only a $75 \%$ on the stimulus generalization pretest. These results reveal that while he showed emergence of the simple relations, the simple relations were not able to generalize to new stimuli without further training. As will be discussed later, the generalization probes proved to be most difficult for all three participants.

Another predictable finding that coincided with the results of McHugh et al. (2004), was the fact that the reversed relations required the most training trials. McHugh et al. noted that this was due to the fact that the reversed and double reversed relations required more complex forms of derivation versus the simple relations. What was unexpected is that $\mathrm{WH}$, who was only 6 years, 9 months old, mastered the reversed relations in only one training session, and $\mathrm{JH}$, who was 11 years, 4 months old, mastered the relations in four training sessions. These results do not coincide with the results of the McHugh et al. study. However, there are several possible explanations as to how this may have occurred. Because of the length of the reversed relation trials (36 trials), JH often became discouraged and requested several breaks during the reversed relation sessions. He also became very upset when he found he had not in fact met mastery criterion on the three post tests and would have to go through more training sessions. In addition, WH, while only a first grader, was an excellent reader and was reported by her mother to read at a third grade reading level. She was also highly motivated by the automated reinforcement during the training trials. Furthermore, as shown in Figure 4, JH consistently failed the response generalization post test, requiring further training in the reversed relations. Similar to DH's performance on the simple relation tasks, this demonstrated that while JH showed emergence of the reversed relations, he was not able to generalize these relations to new stimuli without further training.

Another unpredic ted finding of the present study is that the double reversed relations did not require as many training trails compared to the reversed relations for the oldest participants, $\mathrm{JH}$ and $\mathrm{DH}$ to master. These results are not what one would foresee cognitively or developmentally and are unexpected, as the derivation is more complex compared to the simple and reversed relations. These results are similar to those reported by Rehfeldt et al. (submitted), in which participants required fewer training on 
the double reversed relations compared to the reversed relations as well. These results may be due to the fact that the double reverse relations protocol consisted of 13 trials, compared to 36 trials in the reversed relations protocol. Participants therefore had fewer questions to answer and were less discouraged due to the shorter length of the sessions. Furthermore, the double reversed relations were the final relations tested and trained in our perspective-taking program. The participants therefore had more experience with the testing context. Lastly, as with the previous relations, the participants often failed to demonstrate mastery criterion on the response generalization post-test probes. Consequently, this required further training in the relation until all three post-test probes were mastered.

As described above, the stimulus and response generalization pre-and post tests were more difficult to show criterion performance than the relations pre-and post tests. Stimulus generalization was shown when the participant mastered criterion on the stimulus generalization questions which were identical to the perspective-taking questions except the relation questions included different stimuli. Response generalization was shown when the participant mastered criterion on the response generalization questions which were presented in a conversational format and consisted of real world topics. The response generalization tests were especially difficult for all three participants. This is due to two factors. First, the participants were introduced to a new testing context in which the response generalization questions were read out loud by the experimenter. Even though the experimenter could repeat the questions an unlimited number of times if necessary to ensure the child understood the questions, the realworld conversational format of the response generalization tasks proved most problematic for the participants. Second, with increased complexity of the relations (reversed and double reversed) the questions increased in length. This made it even harder for participants of this age (middle late childhood) to sustain attention during the entire time the experimenter read the question.

Nevertheless, the results of this study reveal that each participant took no longer than four training sessions to master the stimulus and response generalization post-tests. This demonstrates that after providing children of middle-to-late childhood with a history of reinforced relational responding, simple, reversed, and double reversed relations can in fact generalize to novel stimuli and real-world conversational contexts.

Unlike developmental studies, in which large numbers of participants of specific age groups are typically used, the conclusions drawn from this study cannot speak to particular age groups of children. The results of the present experiment do, nonetheless, have various implications. The perspective-taking protocol used in the present experiment was effective in establishing I-You, Here-There, and Now-Then frames, which specified the relationship between stimuli in terms of the perspective of the speaker. The results also demonstrate that derived relational responding plays an apparent role in perspective-taking. These findings show, in terms of application, that taking the Relational Frame Theory approach to these phenomena provides a means of training and establishing perspective-taking repertoires in typically developing individual children. Understanding the perspective of others is an important skill that benefits children in their complex reasoning abilities that are important in math problems, such as story problems. In addition, having the ability to take another person's perspective is a vital social skill that children need in order to make and sustain friendships. The results of this study also demonstrate that the perspectivetaking skills trained in the present experiment also transfer to novel stimuli and real world situations. This finding demonstrates that the skills established in the laboratory can in fact transfer to a more conversational context in which children will face when applying these learned skills in the classroom or other social situations with their peers.

Future studies should be conducted to test whether the perspective-taking protocol developed in this study could also be used to train individuals for whom these repertoires appear to be absent. This would have profound implications for children diagnosed with autism or other spectrum disorders in which perspective-taking skills are lacking. Since this study included children of the middle-to-late childhood age group, further experiments should test for the generalization of perspective-taking skills 
with children of the early childhood age group (ages 3-5). Further studies should also focus on training these skills outside of the experimental environment in a more social context to better ensure the generalization of perspective-taking skills in real world settings.

\section{References}

Barnes-Holmes, D., Hayes, S. C., Dymond, S., \& O’Hara, D. (2001). Multiple stimulus relations and the transformation of stimulus functions. In S. C. Hayes, D. Barnes-Holmes, \& B. T. Roche (Eds.), Relational frame theory: A post-Skinnerian account of human language and cognition. New York: Plenum.

Barnes-Holmes, Y., Barnes-Holmes, D., \& Cullinan, V. (2001). Self and self-directed rules. In S. C. Hayes, D. Barnes-Holmes, \& B. T. Roche (Eds.), Relational frame theory: A post-skinnerian account of human language and cognition. New York: Plenum.

Barnes-Holmes, Y., Barnes-Holmes, D. \& McHugh, L. (2004). Teaching Derived Relational Responding to Young Children - JEIBI 1 (1), 4-13

Barnes-Holmes, Y., McHugh, L. \& Barnes-Holmes, D. (2004). Perspective-Taking and Theory of Mind: A Relational Frame Account, The Behavior Analyst Today, 5 (1), Pg.15-24

Bennett, M., \& Galpert, L. (1992). Complex belief-desire reasoning in children. Social Development, 1, 201-210.

Dixon, J. A., \& Moore, C. F. (1990). The development of perspective-taking: Understanding differences in information and weighting. Child Development, 61, 1502-1513.

Hayes, S. C., Barnes-Holmes, D., \& Roche, B. T. (2001). Relational frame theory: A post-skinnerian account of human language and cognition. New York: Plenum.

Hayes, S. C., \& Wilson, K. G. (1993). Some applied implications of a contemporary behavior-analytic account of verbal events. The Behavior analyst, 16, 283-301.

Horner, R. D., \& Baer, D. M. (1978). Multiple-probe technique: A variation of the multiple baseline. Journal of Applied Behavior Analysis, 11, 189-196.

Howlin, P., Baron-Cohen, S., \& Hadwin, J. (1990). Teaching Children with Autism to Mind-Read. England: John Wiley \& Sons Ltd.

Huttenlocher, J., \& Presson, C. C. (1979). The coding and transformation of spatial information. Cognitive Psychology, 11, 375-374.

Jacobsen, T. L., \& Waters, H. S. (1985). Spatial perspective-taking: Coordination of left-right and near-far spatial dimensions. Journal of Experimental Child Psychology, 39, 72-84.

LeBlanc, L. A., Coates, A. M., Daneshvar, S., Charlop-Christy, M. H., Morris, C., \& Lancaster, B. M. (2003). Using video modeling and reinforcement to teach perspective-taking skills to children with autism. Journal of Applied Behavior Analysis, 36, 253-257.

McHugh, L., Barnes-Holmes, Y., \& Barnes-Holmes, D. (2004). Perspective-taking as relational responding: A developmental profile. The Psychological Record, 54, 115-144. 
Newcombe, N., \& Huttenlocher, J. (1992). Children's early ability to solve perspective-taking problems. Developmental Psychology, 28, 635-643.

Perner, J., Leekam, S. R., \& Wimmer, H. (1987). Three-year-olds' difficulty with false belief: The case for a conceptual deficit. British Journal of Psychology, 5, 125-137.

Rehfeldt, R. A., Dillen, J. E., Ziomek, M. M., \& Kowalchuck, R. Assessing Relational Learning Deficits in Perspective-Taking in Children with High-Functioning Autism Spectrum Disorder (submitted).

Rosser, R. A., \& Lane, S. (1993). Children's computation of viewpoint from locational descriptions: Initial steps in the coordination of perspectives. Child Study Journal, 23, 1-16.

Wimmer, H., \& Perner, J. (1983). Beliefs about beliefs: Representation and constraining function of wrong beliefs in young children's understanding of deception. Cognition, 13, 103-128.

Wellman, H. M., \& Bartsch, K. (1988). Young children's reasoning about beliefs. Cognition, 30, 239-277.

Zaitchik, D. (1990). Is only seeing really believing?: Sources of the true belief in the false belief task. Cognitive Development, 6, 91-103.

\section{Author's Notes}

This investigation was supported by a research grant from TAP (The Illinois Autism Project, funded by Illinois Department of Human Services), awarded to the second author. The project constituted the Masters project completed by the first author under the supervision of the second author in the Behavior Analysis and Therapy program at Southern Illinois University. The authors thank Joanna Kooistra and Maranda Trahan for their assistance with reliability data. We also thank Louise McHugh and Simon Dymond for helpful comments.

Author Contact Information:

Amie I. Heagle, Graduate Student

Behavior Analysis and Therapy Program

Southern Illinois University

16 Pleasant St.

Southborough, MA 01772

$\underline{\text { aheagle@siu.edu }}$

(618) 203-2438

Ruth Anne Rehfeldt, Ph.D., BCBA

Associate Professor

Rehabilitation Services Program/MC 4609

Rehabilitation Institute

Southern Illinois University

Carbondale, IL 62901-4609

rehfeldt@siu.edu

(618) 453-8276 


\title{
Conditioned Observation of Books and Accelerated Acquisition of Textual Responding by Preschool Children
}

\author{
Hshin-hui Tsai and R. Douglas Greer \\ Columbia University Teachers College and Graduate School of Arts and Sciences
}

\begin{abstract}
We report an experiment investigating the effects of conditioning books as reinforcers for observing responses on the learning of textual responses by pre-school children. The independent variable was the acquisition of conditioned reinforcement of observing responses and choice of book stimuli in free play settings where children could choose to play with toys or look at books. Prior to the conditioning procedures, the children played with toys and did not look at books in free time in 4 preconditioning 5minute free-play sessions. During the treatment we conducted simultaneous stimulus conditioning procedures until looking at books became the preferred free-play activity. The dependent variable consisted of the numbers of learn-units-to mastery of textual responses before and after conditioning books as reinforcers for observing responses. Three boys and one girl (ages 2 years and 9 months to 4 years) participated in the experiment in a pre and post learn-units-to-criterion and simultaneous matched-pairs design with a time-lagged component. Prior to reinforcement conditioning, we matched children in pairs based on learn units they required to master a sets of 5 counterbalanced word sets. One child in each of 2 pairs received book conditioning initially, and another child received an equal number of conditioning trials with toys, as a control conditions, and then book conditioning. The results showed that (1) all four children required fewer learn-units-to-criterion on textual responses after books were conditioned as reinforcers for choice and observing and those who received the book conditioning first performed best. (2) Three of the four children maintained preference for books at $33 \%, 83 \%$, and $100 \%$ of time in free play probes at 1 month. (3) There were no maintenance effects on accuracy of textual responding.

Keywords: conditioned reinforcement, observing responses, preference, textual responding
\end{abstract}

Most early literacy theories concur on the importance of developing "positive literacy experiences" for young children by providing them with access to books and encouragement from adults (Neuman, 1999). They also agree on the importance of developing independent "readinglike" activity (i.e., book observation) as being important to children's subsequent reading repertoire (Holdaway, 1979, 1990). At least one research study reported that having opportunities to choose preferred activities, or preference for instructional activities, enhanced performance on such activity (Cooper Wacker, Thursby, Plagmann, Harding, Millard, \& Derby, 1992).

While the importance of children "choosing to look at" and "enjoy books" as a "reading readiness" activity is almost universally held to be important, the lack of precision in definitions and measurements of choice, preference, and observation has led to few substantial findings in mainstream educational research on reading. It is not surprising then that the relation between interest in books and children's textual responding has not been examined experimentally using direct measures. Helpfully, Skinner (1957) characterized observation as an operant behavior selected out by the consequences of that which is observed, and Holland (1958) empirically demonstrated operant observing responses.

When books and related stimuli select children's attention and looking at books becomes a preferred activity during periods of free play, the book stimuli are conditioned reinforcers for observing and selecting books. Presumably, if looking at books is a preferred activity, children should learn to read more quickly. It appears that this theory has not been experimentally tested in the applied literature and there is little research in the basic science on the relation between 
conditioned reinforcement for stimuli and discrimination learning (See Dinsmoor, 1983 for the exception).

The control of stimuli like those stimuli associated with books as reinforcement for looking at books is identified in the science of behavior as conditioned reinforcement of stimuli for observing responses (Dinsmoor, 1983; Greer, 1980) and the processes for conditioning stimuli involve both traditional operant and stimulus-stimulus pairing operations (M. Sundberg, Michael, Partington, \& C Sundberg, 1996). In the behavioral pedagogical literature, the operations of reinforcement conditioning are the source for broadening a child's community of interests (Greer, 2002). This important area has received little attention in the basic or applied literature in the last two decades, but a significant number of studies are found in an earlier literature.

Laboratory instrumentation was developed in the sixties and seventies for measuring reinforcement as moment-to-moment control for listening or looking responses to auditory and visual stimuli (Morgan \& Lindsley, 1966; Rheingold, Stanley, \& Doyle, 1964). Various conjugate reinforcement apparati were used to test the reinforcement control of episodic stimuli. A conjugate apparatus is one that provides the necessary experimental control for measuring alternative stimuli such that location and other variables are controlled and allows the experimenter to assess responding as "free operant responding." Episodic stimuli such as music, speech, television, and motion pictures are stimuli in which the specific content varies from moment-to-moment-hence they are episodic (Cotter \& Spradlin, 1971; Cotter \& Toombs, 1966; Greer, Dorow, Wachhaus, \& White, 1973; Lovitt, 1965, 1968). These procedures and instrumentation provided precise measures of the reinforcement control of observing responses as the relative duration that stimuli selected out observing responses.

This line of research led to numerous laboratory studies that resulted in a conditioning procedure whereby students were taught to prefer and to spend more free time with previously non-preferred episodic stimuli by stimulus-stimulus pairing procedures (Greer, Dorow, \& Hanser, 1973; Greer, Dorow, \& Randall, 1974; Greer, et al., 1973; Greer, Dorow, \& Wolpert, 1980). More recently, this conditioning procedure and the use of substitute human observers has been used in applied research in which the use of conditioning toys or observing books functioned to replace stereotypy as a preferred activity (Greer, Becker, Saxe, \& Mirabella, 1985; NuzzoloGomez, Leonard, Ortiz, Rivera, \& Greer, 2002). In addition to replacing stereotypy with appropriate play, by conditioning play responses to toys or observing responses to books, the procedures from these studies also introduced applied techniques and measures for conditioning books as reinforcers and procedures for observing responses and increased preference for books.

In the music conditioning studies and other conjugate reinforcement studies described above, the observing responses consisted of an assessment of listening that required the participants to maintain switch closures under laboratory free-operant conditions that resulted in measures of duration of selection or observation at the level of seconds. In the book conditioning procedure used herein, the target stimulus control for visual observing was attention to bookrelated stimuli (e.g., pictures, text) as determined by human observers using continuous 5-sec. observation intervals that is an applied measurement procedure for estimating duration. No prior research has tested for functional relations between conditioned reinforcement for observing book stimuli on children's learning to read. Indeed, other than the one participant in the NuzzoloGomez et al. (2002) study no prior research has demonstrated the conditioning of book stimuli as conditioned reinforcement for observing responses.

In addition to using a measure of preference and reinforcement control of book stimuli for the implementation of the independent variable, we used measures of children's acquisition of 
one component of reading, textual responding, as the dependent variable. Textual responding consists of speaking the printed stimuli (Skinner, 1957) and it is sometimes referred to as "see word and say word." In order to examine the relation between preference for books and children's acquisition of textual responding, an appropriate measure of the acquisition of textual responding was required. The use of the numbers of "instructional trials" required to achieve a predetermined criterion of mastery is a mainstay measurement of learning rate. The procedures used in conducting instructional trials varied significantly prior to the identification of learn units. The identification of learn units in recent decades provided a standardized and empirically based set of operations for instructional trials. Learn units are instructional trials that have all of the components of instruction that have been identified as necessary, if not sufficient, for the learning of new operants. The literature suggested that the numbers of learn units that children required to master a particular response is a tested and reliable predictor of the acquisition of operants (Albers, \& Greer, 1991; Emurian, Hu, Wang, Durham, 2000; Greer, 1994; Greer, 2002; Greer \& McDonough, 1999). Accordingly, we chose learn-units to a criterion as a measure of acquisition of the mastery of textual operant responses as our measure of rate of learning - the fewer the numbers of learn units to mastery the faster the rate of learning.

In the recent decades, some applied researchers have used "choice " to assess whether stimuli selected by individuals would act to reinforce other behaviors than the actual selection responses that were assessed (Deleon, Iwata, Conners, \& Wallace, 1999; Piazza, Fisher, Hagopian, Bowman, \& Toole, 1996). It is important to note that in operant research it is the stimuli that select out choice, not the individual who is selecting an observational response. It is important also to distinguish between the objectives of the reinforcement assessment studies and the objectives of our research. In the "choice" or reinforcement assessment studies, touching or selecting a stimulus served as the basis for determining whether the item selected would in fact act to reinforce another response or responses. In the present study, as in the music and toy conditioning studies (e.g., Greer, et al, 1973; Greer et al, 1985), the objective was to test the effects of certain stimuli on observing responses, not to identify possible reinforcers for other behaviors. That is we assessed, and then conditioned the reinforcer for stimulus control of print stimuli over observing responses.

Consistent with both the laboratory and applied literature on conditioning stimuli as reinforcers for observing responses, our book conditioning procedure consisted of the following features (1) insuring the children were observing and selecting books during training, (2) presenting adult praise and treats while the children were looking at books or selecting books during training sessions (the pairing procedure), and (3) assessing book observation in free play settings that approximated free operant conditions as a measure of when the independent variable was in place (i.e., conditioned stimulus control for observing and choosing books). The dependent variable consisted of pre and post-conditioning assessments of the numbers of learn units children required to master textual responses to sets of words.

The objective of the experiment was to determine whether the conditioning of book stimuli as reinforcers for choosing and looking at books would function to accelerate the rate of learning textual responses to words (i.e., decrease the numbers of learn units required to mastery). Our preconditioning probes showed that none of the children preferred books in settings in which they could choose between books and toys prior to the conditioning of book stimuli as conditioned reinforcement for observing, and none of the children had textual responses to words prior to the experiment.

Method 


\section{Participants}

Four typically developing children, Child 5, Child 6, Child 7, and Child 8, participated in this experiment. Their ages ranged from 33 months to 48 months and the mean age was 41 months. Child 5's parents were originally from Mainland China, and Child 8's parents were from Hong Kong. Both families spoke their native languages (Mandarin-Chinese and CantoneseChinese) with their children at home, and the primary caregiver for both of them communicated in Mandarin-Chinese with them. Both Child 5 and Child 8 received daycare with the same caregiver in a private residential home. Therefore, their verbal repertoires in English were very limited. Child 5 was a 3-year-and-9-month old male. While he spoke mainly in MandarinChinese, he could tact several common items in English. He could mand without using autoclitics in English. He also responded intraverbally and with tacts in some social situations (e.g., greetings, names, and apologies). His textual repertoire included saying all of the uppercase and lowercase alphabet letters when presented with the letters. According to Child 5's caregiver, Child 5 was read a short story book in Mandarin by the caregiver approximately once a week.

Child 6 was a 3-year-and-3-month old female, and Child 7 was 4-year-old male at the time they participated in this study. Both of them were from English speaking families and therefore had listener and intraverbal verbal repertoires in English. Child 6's textual behaviors included 21 uppercase and 10 lowercase alphabet letters, and Child 7 recognized 16 uppercase and 7 lowercase alphabet letters. Their English speaking preschool teacher reported that the children were read stories in a group and received both intraverbal and textual instruction on alphabet letters during school hours using standard preschool procedures of an eclectic nature. During the school day provision was made for individual reading times in which each child in the class was asked to choose one book to look at independently without any adult directions.

Child 8 was 2 years and 9 months old. He was from a Cantonese-speaking family. His verbal repertoires in Cantonese included listener, speaker, and intraverbal responses. Since his caregiver spoke Mandarin, Child 8 also learned to follow 5 common one-step commands and responded to yes or no when asked questions in Mandarin, and his speaker repertoires in Mandarin-Chinese were emerging. However, Child 8 had no verbal repertoires in English except textually responding to 24 uppercase and 20 lowercase English alphabet letters.

All four children were from upper-middle class families in which both of their parents were full-time professionals. Child 5 and Child 8 had been sent to the same caregiver's house during the day for two years. Child 6 and Child 7 were placed in a day care center from their infancy. Their parents volunteered their children for the study because they valued research and encouraged their children to take this learning opportunity.

Pre-treatment instruction on textual responding to English sight words was conducted, and the children were then matched based on the numbers of learn units each required to master a set of 5 words (See Table 1). None of them had textual responding to sight words prior to the instruction. Child 5 and Child 6 were matched as a pair, and Child 7 and Child 8 were matched as a pair.

\section{Settings}

The experiment took place in two settings - a private residential home for Child 5 and 8 , and a private preschool for Child 6 and 7. Both settings were located in upper-class suburban areas. The study was conducted in a study room of the private house and in the conference room 
of the preschool. Only the experimenter and the child were present in the room throughout the entire experiment.

The experimenter video-recorded all sessions with a camcorder that burned the elapsed time on the tape, including all conditioning sessions, free play sessions, and sessions involving instruction in textual responses. The camcorder was placed next to the child in the room. During free play probe sessions, several toy items and books were placed on the floor. At the beginning of these sessions, each child was told that she or he could either look at books or play with toys. The child was then directed to go to the play area where books and toys were available. The location of toys and books were systematically rotated between sessions. For the conditioning sessions, only the target conditioning items were present (either books or toys) on the floor. The child sat on the floor next to the experimenter and was instructed to attend to books (i.e., the experimenter said, "Let's look at books"). During the sight-word instruction, the child sat at a table facing the experimenter who presented individual flashcards to the child. For these sessions the experimenter presented the index card with the target words according to the procedures described below.

\section{Response Definitions}

Dependent Variable Responses. The dependent variable of this study was the numbers of learn units required to achieve the preset criterion on textual responses to sets of five words both before and after the acquisition of conditioned reinforcement for observing books. Learn units are: (a) instructional presentations by a teacher, experimenter, automated operant chamber presentation, or teaching device in which the antecedent stimulus presentation is unambiguous and the participant is attending to the antecedent stimulus, (b) the participant has an opportunity to respond (in our case this was a 3-secs intraresponse period), (c) correct responses are followed by reinforcement operations that have been shown to function as reinforcement for several learning and performance tasks in the participants history, and (d) incorrect responses are followed by a correction operation. The correction operation must include all of the following. (e) The student is provided the answer and (f) is presented the stimulus again, (g) after which the student is to provide the correct answer. (h) Corrected responses are not reinforced. A textual response to a learn unit presentation consisted of a vocal correspondence to a printed word. For example, when the student saw a textual stimulus "cat" and emitted the corresponding vocal verbal response "cat." All textual responding was taught in the visual and vocal form of English to all children. Criterion for mastery of the textual responses was $90 \%$ or better for two successive sessions. The words for each of the sets are shown in Table 1. Word sets were counterbalanced across students to control for word difficulty. The dependent variable was the numbers of learn units required of each student to meet the mastery criterion before and after the conditioning procedure.

Table 1: Sight Word Sets

Set $1 \quad$ one, popcorn, hat, shoe, flower

Set 2 bow, three, seven, umbrella, truck

Set 3 eggs, pants, muffin, farmer, sweater 
Independent Variable Measures. The independent variable was the achievement of criterion for reinforcement conditioning or the acquisition of book stimuli as conditioned reinforcement for observing books during five-minute free play sessions. The five-minute free play sessions consisted of 60 continuous 5-secs. intervals. To meet criterion the child had to look at the books for $70 \%$ of the 5 -secs. intervals out of 60 possible intervals for two consecutive sessions (separated by at least one day). Observation of books was measured in numbers of whole intervals of book observation in free play settings in which various books and toys were concurrently available to the child and the measure of choice was meeting the observing response interval criterion in the free play setting. A whole interval of book observation consisted of the child emitting book observation without distraction for the entire interval. Thus, in this study, book observation was defined as contact with or manipulation of books, including touching books, looking at books, turning the pages, pointing to pictures/textual stimuli, tacting pictures, and having textual responses to the text in the books. Of course, in order to meet the observation criterion, the children had to choose books over toys for the greater portion of the sessions. All books used in the experiment consisted of children's books with English printed words and pictures.

Control Toy Measures. As a contact control condition, two children, one in each pair, received the same conditioning procedures with toys, as did his/her pair with the books. Thus the pairing conditions were yoked or matched to the responses of the member of the pair receiving the book conditioning. Since all of the children chose and played with toys prior to the intervention, the students who received the toy conditioning procedure received additional conditioning experiences with toys. This provided an experimenter-contact control for the students who were simultaneously receiving book conditioning.

\section{Data Collection}

All free play probe sessions were videotaped, and at least $95 \%$ of the total book/toy conditioning sessions and textual instructional sessions were also videotaped. The experimenter and an independent observer recorded data for intervals engaged in toy play/book observation from the videotapes. The data on the number of approvals and correct/incorrect responses during toy/book conditioning sessions and instructional sessions for textual responding were recorded simultaneously with the implementation of these procedures to insure fidelity of treatment and recorded by an independent observer from the videotapes. The independent observers were blind to the nature of the experiment.

Conditioning procedures. The data collected throughout the conditioning procedures included (1) the numbers of verbal approvals delivered during training trials, and (2) the number of correct/incorrect responses during conditioning testing trials that were part of the conditioning procedure. Both types of data were recorded with pencil-and-paper by the experimenter while implementing the conditioning procedures. In the beginning of each conditioning session, a timer was set to a predetermined time period depending on the conditioning phase (e.g., 5 second, 10 second). During the training trials, the experimenter put a check mark for one count of verbal approval delivered to the child on the data record form. Two or three verbal approvals were delivered during a training trial, given that the child was continuously engaged in the target behavior. If the child discontinued the target behavior during training trials, the experimenter 
stopped the timer and began the pairing trial again prompting the child to play or look at books respectively. Thus for a training pairing trial to be completed the student had to observe the book or play with the toys throughout the interval under the pairing conditions. Immediately following each complete training trial, the timer was set for a testing trial with the same time period as the training trial. During the testing trials, the experimenter observed the emission of the target behavior and recorded a plus (+) on the data sheet when the child was engaged in the target stimuli for the entire time interval and recorded a minus (-) when the child engaged in any other non-target behaviors during this time interval. A session consisted of 20 training and testing trials. The approval and periodic edibles were the conditioning stimuli and the book stimuli were the unconditioned stimuli for observing responses to book stimuli. The procedure is referred to as a stimulus-stimulus pairing procedure for conditioning operant reinforcers.

Free play choice probes. The time distribution on books and toys during free play choice probes was obtained from observations of videotape recordings of sessions. The data sheet was designed with 60 fill-in blanks of 5-second time intervals. According to the time burned on the upper right corner of the videotape, the experimenter observed the behavior emitted by the child for 5 seconds and paused the tape to record data. If the child was engaging in any book-related activities for the entire 5 seconds, a "b" was filled in the blank next to the time interval. If the child was playing with toys for the entire time, a " $t$ " was marked. If the child was engaging in any other behaviors (e.g., paying attention to any other non-target stimuli), doing nothing, switching books to toys, or any discontinuation of the target behavior at any time during the 5second interval, an " $x$ " was marked. Also the primary and independent data collectors marked " $x$ " in cases in which the child was searching for a book or a toy but was not engaging in any book observation or toy play behaviors for 5 seconds.

\section{Interobserver Agreement}

Interobserver agreement was obtained from observation of videotapes across all experimental conditions (see Table 4) by an independent observer who was blind to the treatment conditions. The agreements were assessed for $25 \%$ of the total experimental sessions from videotapes by a second independent observer. Five measures of interobserver agreement were assessed: (1) numbers of correct/incorrect responses during toy/book conditioning testing trials, (2) numbers of adult approvals during toy/book conditioning teaching trials, (3) numbers of intervals engaging in toy play or book observations during free play probes (baseline and post conditioning phases), (4) numbers of correct/incorrect responses on instruction of textual responding (baseline and post conditioning), and (5) numbers of correct/incorrect responses on maintenance of textual responses. Prior to assessing agreement, an independent observer who was naïve to the conditions of the experiment was taught to record data from the videotapes instruction in the definitions of behaviors and then conducted training observations independently until 100\% agreement was achieved with the data observer on the numbers of correct/incorrect responses during conditioning testing trials, instruction on textual responses, and maintenance probes, and at least $95 \%$ agreement with regards to the number of adult approvals delivered during conditioning teaching trials and intervals engaging in toy play or book observations during free play probes. Once this was done, the second observer observed the tapes independently.

The interobserver agreement for correct/incorrect responses during book/toy conditioning testing trials was assessed point-to-point, and the percentage was computed with the number of agreements divided by the total number of agreements and disagreements multiplied by $100 \%$. The mean agreement on correct/incorrect responses was $96.3 \%$ (range $90 \%$ to 100\%) for book conditioning and $100 \%$ for toy conditioning. 
Point to point agreement on the numbers of experimenter approvals delivered during conditioning teaching trials was calculated by dividing the smaller total by the larger total and multiplying by $100 \%$. The mean agreement on adult approvals was $97 \%$ (range $94 \%$ to $100 \%$ ) for book conditioning trials and $96 \%$ (range $91 \%$ to $100 \%$ ) for toy conditioning trials.

The agreement on intervals of engaging in toy play/book observation during free play times was assessed with a point-by-point interval-by-interval method. We computed percentage of agreement by dividing the number of agreement intervals by the total number of agreement plus disagreement intervals and multiplying by $100 \%$. The agreement for observation of books during free play ranged from $89 \%$ to $100 \%$, with a mean of $98 . \%$; the agreement for toy play during free play ranged from $80 \%$ to $100 \%$, with a mean of $93 . \%$. The lowest percentage agreement $(80 \%)$ occurred in one session in which the experimenter recorded 5 intervals while another independent observer recorded 4 intervals for toy play.

The agreement on correct/incorrect textual responses during instruction and maintenance probes was assessed also on a point-to-point basis for responses to learn units. The percentage of agreement was calculated with the numbers of agreements divided by the total of agreements and disagreements multiplied by $100 \%$. The agreement on instruction for textual responding ranged from $93 \%$ to $100 \%$ with a mean of $99 \%$; the mean agreement for maintenance probes was $100 \%$.

\section{Experimental Design}

We used a pre and post training learn-units-to-criterion design, with a simultaneous matched pairs treatment control condition, to test for a functional relation between the acquisition of conditioned reinforcement of observing books and choosing books on the children's learnunits-to mastery for textual responses to printed words (Kazdin, 1982; Johnston \& Pennypacker, 1993). The design used features of a delayed multiple probe design also, and that feature will be described later. The independent variable was the acquisition of conditioned reinforcement for observing books that was defined as the child choosing books over toys and then observing books for a minimum of $70 \%$ of two consecutive 5-minute free play sessions (42 of 60 continuous 5secs whole intervals) (Figure 3 and 4). The dependent variable was the numbers of learn units that the children required to master the textual responses to word sets, when mastery was set at 18 of 20 correct responses for two consecutive sessions, or 19 or 20 correct responses for one session (Figure 5 and 6). Students were matched into two pairs based on their learn units to criterion on the preconditioning baseline probes. One student in each matched pair was assigned the conditioning treatment for books and the other a toy conditioning procedure.

The treatment consisted of conditioned reinforcement training sessions (stimulusstimulus pairing train and test trials, Figures 1 and 2) with probes in free play sessions until the data in the free plays setting showed that the treatment was implemented (i.e., the child chose and observed books for minimum of $70 \%$ of the time for two consecutive free play probes, Figures 3 and 4). The simultaneous treatment control component consisted of the provision of toy play conditioning for one of each matched pair of children, while the other child in each pair received the book conditioning. This provided a contact control treatment condition for the first phase. Probes on learn units to mastery for all four children followed this phase. Next, the two children who had received the toy conditioning control condition initially, received the book conditioning procedure and they were again probed on learn units to mastery for textual responses. The implementation of the book conditioning procedure for the children who had received the contact control condition in the first phase provided a time-lagged control for maturation and instructional history consistent with delayed multiple probe logic. That is the toy conditioning phase for the contact control students constituted a baseline condition for the subsequent book 
conditioning intervention for those students. The word sets used in the instruction on textual responding were counterbalanced within each pair to control for word difficulty. Toy conditioning pairing trials for the contact control children in the first phase were yoked to the numbers of pairing trials required for student receiving book conditioning in each pair to acquire conditioned reinforcement for observing books; that is, the toy control child in each pair received the same number of pairings with toys as her or his book pair required to acquire conditioned observing for books. Finally, we conducted probes for maintenance of the conditioned reinforcement for observing books one month following each child's last mastery session for textual responses and we probed them for maintenance of accuracy for words mastered before and after the book conditioning treatment.

The sequence of conditions was as follows. (Step 1) Free play probes were done to determine initial preference and reinforcement stimulus control for books and toys for all four children. All children preferred toys and no intervals were devoted to observing books. (Step 2) We then tested the numbers of learn-units-to-criterion each child required for the mastery of textual responding to a set of words and the children were paired based on this measure. (Steps 3 and 4) Next, we introduced the book conditioning procedure for one child in each matched pair (Children 5 and 7) and the toy conditioning for the control child in each pair (Children 6 and 8). There were two steps in this process: (a) the children received the pairing training trials until they reached criterion for a specific interval of time and then (b) they were probed in free play to test if the training had been adequate. If the child did not meet the free-play criterion, the child was returned to the training procedure with an advancement in the length of the time intervals (i.e., 5 secs., 10 secs.) until the free play criterion was met for the book-conditioning child. The toy play child in each pair was returned to toy conditioning based on the responses of the book conditioning child with the numbers of pairing trials for the toy participants derived from, (i.e. yoked to) his/her matched pair's numbers of training pairings that he/she required to meet the reinforcement stimulus control training criterion (2 consecutive sessions at least $70 \%$ of the intervals). (Step 5) We then conducted post book conditioning instruction on textual responses for the first child and post toy conditioning textual instruction for the second child. (Step 6) Next, we conditioned books for Children 6 and 8 in the same manner as we did for Children 5 and 7 , while conducting 1-month maintenance measures for book reinforcement control during free-play with the students who had received the book conditioning procedures. (Steps 7 and 8) We then conducted post-book conditioning sight-word instruction for Children 6 and 8 and a one-month probe for maintenance of textual responses for Children 5 and 7. (Step 9) Next, we conducted a one-month maintenance of reinforcement control for observing books for Children 6 and 8. (10) Finally, we conducted one-month maintenance probes for textual responding for Children 6 and 8 (see Table 2 for the sequence of the experiment). The outline of the sequence is shown in Table 2 and the details of each step in the sequence are described following the table. 
Table 2: Sequence of Steps in the Experiment

\begin{tabular}{|c|c|c|}
\hline Sequence & Children & Procedure \\
\hline 1 & $\begin{array}{l}\text { Child 5, } 7 \\
\text { Child 6, } 8\end{array}$ & Free play baseline \\
\hline 2 & $\begin{array}{l}\text { Child 5,7 } \\
\text { Child 6, } 8\end{array}$ & $\begin{array}{l}\text { Four sessions of learn-units-to criterion probes for } \\
1 \text { set of words. Children matched on numbers of } \\
\text { learn units required to achieve mastery (Children } \\
5 \text { and } 7 \text { matched and Children } 6 \text { and } 8 \text { matched) }\end{array}$ \\
\hline 3 & $\begin{array}{l}\text { Child 5,7 } \\
\text { Child 6,8 }\end{array}$ & $\begin{array}{l}\text { Book conditioning } \\
\text { Contact control toy conditioning with pairings } \\
\text { yoked to the book children }\end{array}$ \\
\hline 4 & $\begin{array}{l}\text { Child 5, } 7 \\
\text { Child 6, } 8\end{array}$ & $\begin{array}{l}\text { Free play probes following book conditioning } \\
\text { with returns to training until the free play criterion } \\
\text { was met } \\
\text { Free play probes following toy conditioning, with } \\
\text { returns to training yoked to the book conditioning } \\
\text { pair }\end{array}$ \\
\hline 5 & $\begin{array}{l}\text { Child 5, } 7 \\
\text { Child 6, } 8\end{array}$ & $\begin{array}{l}\text { Instructions on textual responses for a set of } \\
\text { words different than those for the preconditioning } \\
\text { baseline }\end{array}$ \\
\hline 6 & $\begin{array}{l}\text { Child 5, } 7 \\
\text { Child 6, } 8\end{array}$ & $\begin{array}{l}\text { 1-month maintenance free play probe for } \\
\text { observing books and choice of books over toys } \\
\text { Book conditioning procedure implemented as } \\
\text { above }\end{array}$ \\
\hline 7 & $\begin{array}{l}\text { Child 5, } 7 \\
\text { Child 6, } 8\end{array}$ & $\begin{array}{l}\text { 1-month probe on maintenance of textual } \\
\text { responses } \\
\text { Free play probes following book conditioning }\end{array}$ \\
\hline 8 & $\begin{array}{l}\text { Child 5,7 } \\
\text { Child 6,8 }\end{array}$ & $\begin{array}{l}\text { Completion } \\
\text { Instructions on textual responses for a different set } \\
\text { of words }\end{array}$ \\
\hline 9 & $\begin{array}{l}\text { Child 5,7 } \\
\text { Child 6,8 }\end{array}$ & $\begin{array}{l}\text { Completion } \\
\text { 1-month maintenance free play probe }\end{array}$ \\
\hline 10 & $\begin{array}{l}\text { Child 5,7 } \\
\text { Child 6,8 }\end{array}$ & $\begin{array}{l}\text { Completion } \\
1 \text {-month probe on textual responses }\end{array}$ \\
\hline
\end{tabular}

Free play baselines

Free play baseline probe sessions consisted of four 5-minute free play sessions with toys and book items arranged on the floor of the experimental settings. Each child was directed to the pre-arranged play area and was told that he/she could choose any items that they would like to play with. The purpose of the free play baseline was to determine each child's pre-experimental choice of and observation of toys and books and the reliability of their choices. The location of books and toys was rotated between each session to avoid location effects.

Learn-units-to criterion probes 
Each child was taught different sets of sight words. Any two out of the four children who required similar numbers of learn units to master one set of sight words were matched as a pair. These sight word sets were arranged in a counterbalanced order within each pair to control for word difficulty. That is, if Set 1 and Set 2 were taught to Child 5 prior to and after book conditioning, respectively, Child 6 (the matched counterpart for Child 5) was taught Set 2 during baseline and Set 1 after book conditioning. Therefore, if a child achieved criterion on textual responding with fewer numbers of learn units after book conditioning, it was because of the effects of book conditioning, not because one set of sight words was easier than another. There were two book/toy pairs in the study (Children 5, 6, and Children 7, 8). Children 5 and 7 were exposed to book conditioning only, while Children 6 and 8 (the counterparts for the other two children) were exposed to matched toy conditioning and then to book conditioning. Pre and post learn units to criterion for textual responses served as the dependent measure for the effect of acquisition of conditioned reinforcement for observing book stimuli and choosing books.

\section{Book conditioning procedures for conditioning reinforcement for observing and choosing books}

Each session of book conditioning instruction had 20-trial pairs of training/testing trials. Each trial consisted of two components-one stimulus-stimulus pairing training trial (reinforcement paired with observing books, and one test trial in which no pairings occurred). The length of each training/testing trial varied as the training progressed. We began at 5 seconds and added 5 seconds to the training sessions, if the child did not meet the reinforcement criterion in free play probe sessions ( 42 of 60,5 -second intervals or $70 \%$ of the 5-minute free play probe sessions following mastery of each of the interval training sessions). Each training trial involved stimulus-stimulus reinforcement pairings during periods when the child was observing the books for the particular interval being trained. Either two or three verbal approvals were delivered during a training trial alternated for each trial, while the child emitted book observation during that interval. One count of adult approval was defined as a positive verbal comment on the child's looking at books (e.g., "Good, I like the way you're looking at the books", or "Nice job pointing to the pictures!") Edibles were periodically delivered in conjunction with and paired with verbal approvals. However, if the child emitted any behavior other than observation of books, the experimenter stopped the timer and began the pairing trial again after the child was attending to the book. A training trial was not completed until the child met the criterion set for the sessions as described above. Different books were used for each session as a general case conditioning procedure.

The second component of the conditioning instruction was a test trial that consisted of an opportunity to look at or not to look at books. A test trial followed each training trial. During the test trials, adult approvals or any form of reinforcement was withdrawn. The child's responses on conditioning were recorded during this period of time. A correct response was defined as the child observing, touching, looking, turning pages, playing, pointing to pictures/textual stimuli, tacting pictures, or emitting textual responses to the text for the entire time interval under training. An incorrect response occurred when the child emitted any behaviors other than observing books (e.g., stopped looking at books and talked about irrelevant issues to the experimenter or searched for another book to look at for more than 5 seconds). When an incorrect response was emitted, a testing trial was terminated without any reinforcement or correction and the next pairing training trial opportunity immediately began. Train-test trials continued until 20-training/testing trials were completed. These are described in more detail below.

The book conditioning began with a 5-second intraresponse period for each training trial and each testing trial. If the child did not meet the free play criterion (that constituted the 
measure of book stimuli as conditioned reinforcement for looking at books) following achievement of criterion in the training settings, the length of the training/testing trial conditions were increased in 5-second intervals (i.e., 5, 10, 15 seconds). This progression in interval durations continued until the free play criterion was met (70\% of the total possible intervals, see Figures 1 and 2). It is important to note that as the duration increased, the reinforcement remained the same (e.g., the number of pairings for 10 secs. were the same as for 5-secs. trials). The twenty train-test trial conditioning sessions for each child were conducted at least one-day apart. The criterion for each book conditioning phase was set for 19 correct responses or better out of a total of 20-testing trial opportunities for two consecutive conditioning sessions.

Once the child achieved criterion for the conditioning training sessions, two 5-minute free play choice probes (see description below) were conducted the following day. The conditioning session and the subsequent free play probe sessions for each child were separated by at least one day throughout the experiment. If a child observed books for 42 intervals or more ( $70 \%$ of the total time intervals) for two consecutive free play probe sessions, the terminal goal for book conditioning was achieved, and the post conditioning sight-word instruction for a new set of words began. If a child did not meet criterion on free play choice probes, the child was returned to the training condition and the time requirement for the training trials was extended another 5-seconds. The time requirement for independent book observation in the conditioning testing trials was extended in this manner until the child met the terminal goal for book conditioning. It is important to note that when the time requirements were increased the numbers of approval or treatment pairings remained the same. Thus, a child who was on the 15 -seconds objective still received either two or three pairings during each pairing trial.

\section{Toy Conditioning Procedure}

The toy conditioning procedure was identical to the book conditioning procedure except that the target stimuli were toys. Toy play was defined as any contact or manipulation with any toy item, including touching toys, playing with toys, and looking at and talking to toys. The procedure was a control condition for the independent variable to eliminate the possibility that simply pairing adult reinforcement with any activity might result in control over the child's independent choices for books or decreasing learn-units-to criterion for textually responding to words following the conditioning procedures. The toy conditioning time and the numbers of verbal approvals a child received were matched to his/her peer who was undergoing the book conditioning treatment. That is, Child $6 /$ Child 8 received the same number of toy conditioning training/testing trials and verbal approvals as Child 5/Child 7 who were receiving reinforcement pairing for observing books. This procedure allows for the testing of increased reinforcement control of the stimuli for observing.

\section{Free play choice probes-test of implementation of the independent variable}

Free play choice probes consisted of measurement of the numbers of 5-second intervals (whole intervals) spent with books and toys during the 5-minute free play sessions. The procedures were the same as those done in the free-play baseline. A 5-second whole interval with books consisted of the child meeting the observing criterion for the entire 5 seconds without distraction. A count of a 5-second interval of playing with toys consisted of the toy play for the entire 5 seconds without distraction. If the child observed books/played with toys for only a portion of the interval (i.e., talked to the experimenter), or was passive during any part of the 5second interval, such intervals were not recorded as toy or not book intervals. In these 5-minute sessions, various toy and book items were available to the child, and the child was encouraged to interact with any items independently. The positions of toys and books were rotated 
systematically and sometimes interspersed within the play area for each session to control for the effects of location. Each 5-minute session was divided into sixty 5-second intervals to record the child's time distribution on toy and book items. The free play choice probes following conditioning sessions were conducted to determine when the terminal goal of the conditioning instruction was reached. That goal was for the child to be controlled by the target stimulus (e.g., books) in the conditioning instruction (i.e., did the book select out the child's observing responses?). The criterion for book conditioning was for the child to distribute $70 \%$ or more of the total intervals ( 42 whole intervals or more out of 60 intervals) for two consecutive sessions free play sessions.

\section{One-month maintenance free play choice probes}

The probes for maintenance of choice and observation of, books refers to the child's time distribution on the books in a 5-minute free play probe session one month after the child achieved the terminal criterion on book conditioning instruction. A single session of free play choice probe was conducted for each child one month after the child achieved the criterion on book conditioning. The one-month maintenance free play probes were conducted in the same fashion as the free play choice probes following book/toy conditioning sessions.

\section{Instruction on Textual Responses-Dependent Variable}

The performance on textual responding was measured by the numbers of learn-units-to criterion each child required for textually responding accurately to the words presented on flash cards. There were a total of 4 sets of sight words in this study. Each set consisted of 5 sight words sele cted from two of the most frequently presented books used in the book conditioning instruction and free play time. See Table 1 for the contents of each set of sight words. A general case instructional tactic was applied to sight-word instruction in which each word was presented with several variations in different fonts, scripts, and colors. Each variation of a sight word was printed on a $3 \times 5$ index card.

The sight-word instruction was delivered in the form of learn units (Emurian, Hu, Wang, \& Durham, 2000; Greer, 1994; Greer \& McDonough, 1999). As identified in the research literature, a learn unit consists of at least one potential three-term contingency for the student (i.e., the word is not yet a discriminated operant) and at least 2 three-term contingencies for the teacher. The completion of a learn unit required the teacher to obtain the child's attention, present textual stimuli to the child, and provide the child with an opportunity to respond. The teacher then immediately delivered reinforcement operations or corrections based upon the child's response. When an error occurred, the teacher implemented the correction procedure which consisted of repeating the correct word, having the child look at the word and say the correct answer, followed by no teacher consequence (Emurian et al, 2000; Greer 1994; Greer \& McDonough, 1999). Each session of sight-word instruction included 20-learn units.

The instruction on sight words began with selection-based visual discriminations on printed words (i.e., point to responses to the teacher instruction, "point to __"). During each discrimination instructional learn unit, the teacher presented two individual printed words on index cards placed on the table in front of the child along with the verbal antecedent "Point to (the word)." One target word was presented with rotated non-target words. Several nontarget words were rotated. If the child responded correctly, the teacher delivered verbal praise, edibles, or both to the child immediately. If the child responded incorrectly, the teacher performed the correction procedure by vocally or physically guiding the child to point to the correct textual stimulus and having the child repeat the correct response after hearing the teacher 
say, "point to __ " again. Once the child achieved criterion accuracy on the selection discrimination, the instruction moved to textual responses to each individual word.

For the instruction on textual responding, the teacher presented no verbal antecedent but only one textual stimulus on an index card on the table for the child to emit textual behavior. Similarly, verbal praise, along with tangible reinforcers, was immediately delivered when the child emitted correct response. When an error response was made, the teacher vocally modeled the correct textual response in conjunction with the associated target textual stimulus, and the child vocally made a correction to complete that particular learn unit with no reinforcement from the teacher. Again, the sight words were individually introduced based on each child's progress. For example, if the child responded correctly for ten consecutive learn units within one session, a new word was added. The mastery criterion was 18 correct out of 20 for two consecutive sessions or 19 or better out of 20 for one session.

If the child responded with a textual response independently of the experimenter's prompt (i.e., before the experimenter said, "point to _"), the response was counted as correct, and the point-to component or selection component was not used. In this case, this selection learn unit was applied only in the first couple of learn units in the beginning discrimination session. For example, the first and second learn-unit presentations typically involved a target sight word along with a blank card, and the child was more likely to respond correctly. Also, the introduction of a new word in the discrimination task was sele cted in which the word's topography was largely different from the previously learned word(s). Since a correct response occurred when the child responded to an antecedent presentation independently, no prompt procedure was employed in this study. For example, when the child responded "I don't know" to a new textual stimulus presented for the first time, the teacher then vocally corrected the child to respond until the child corrected the response, but the response was still recorded as incorrect.

\section{Maintenance of textual responses}

Maintenance on textual responses consisted of the numbers of correct responses emitted out of a total of 20-non-consequated probe trials for a set of sight words the child had mastered one month earlier. Each set consisted of 5 sight words, and each word was presented in counterbalanced format for 4 trials during maintenance probe.

Results

Conditioning procedures and measures of the acquisition of conditioned reinforcement for observing

Figures 1 and 2 show the numbers of correct responses for testing trials under the conditioning procedure(s) for all four children. All four children displayed a high level of correct responses during conditioning procedures. Child 5 reached the ultimate goal of book conditioning in 7 book conditioning sessions, after the 15 -second intraresponse conditioning period was implemented. Child 6 also responded to the matched toy conditioning trials with a high level of correct responses. Following the matched toy conditioning, Child 6 took 6 sessions ( 2 sessions each for 5-second conditioning, 10-second conditioning, and 15-second conditioning) to achieve the criterion performance on book conditioning. Child 7 also reached the criterion on book conditioning after 15-second conditioning sessions, and it took him a total of 8 conditioning sessions. Child 8 maintained a high level of correct conditioning trials under matched toy conditioning sessions. Child 8's book conditioning was completed after the criterion of 20- 
second conditioning was performed. He required a total of 10 book-conditioning sessions to achieve the terminal criterion performance.

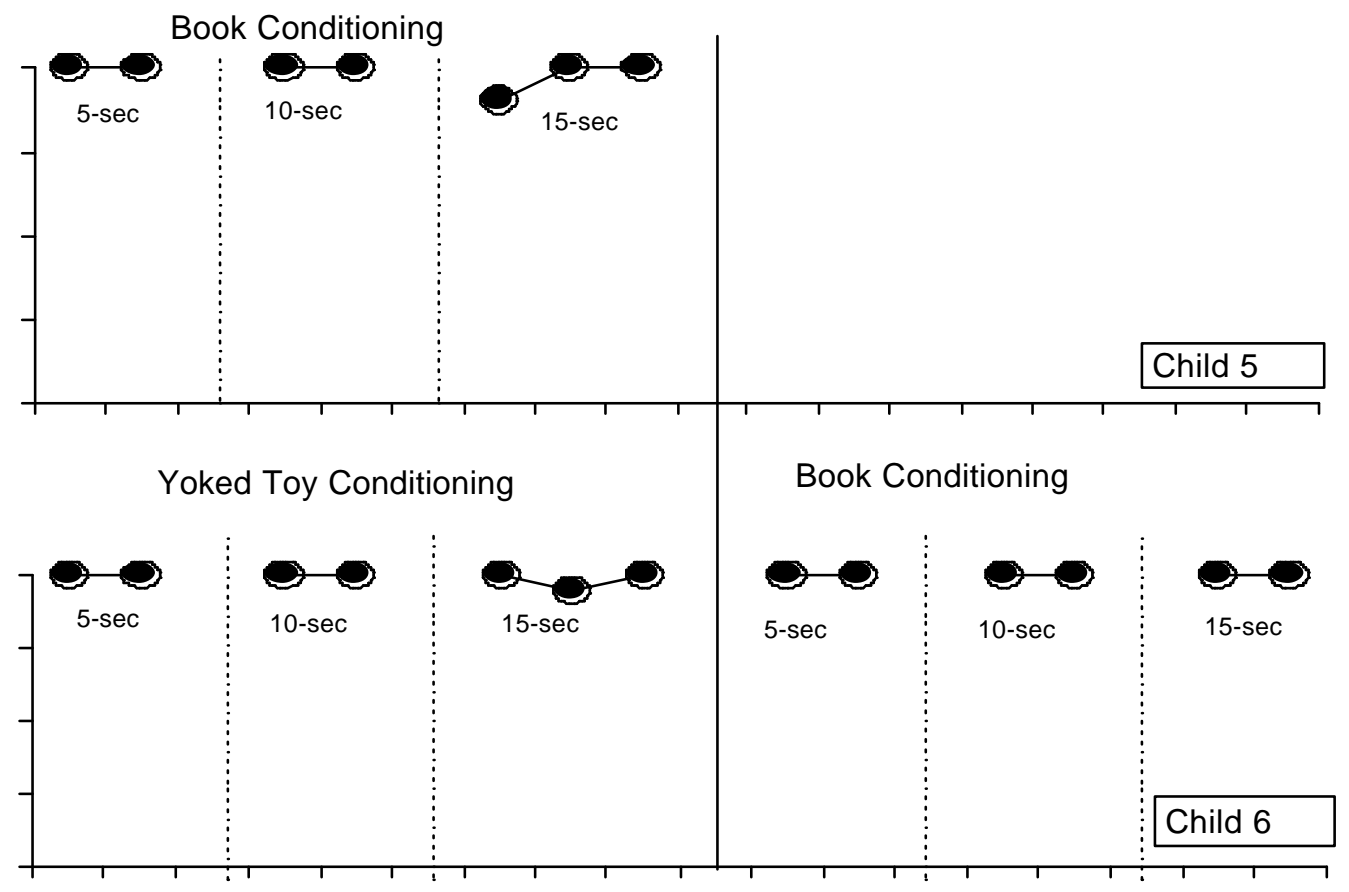

Figure 1. The numbers of correct responses for testing trials under the conditioning training test trial procedures for Child 5 and 6 


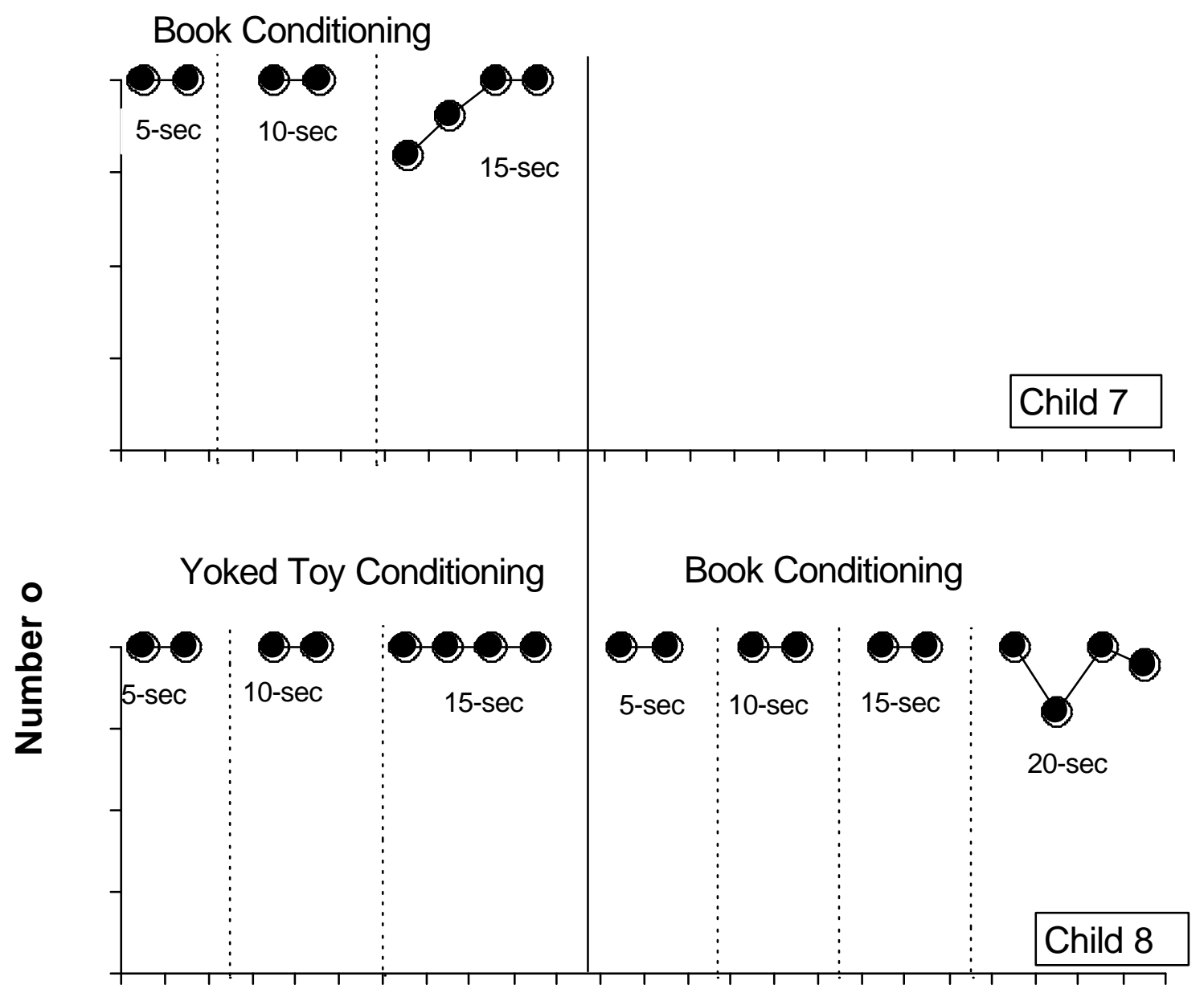

Figure 2. The numbers of correct responses for testing trials under the conditioning training test trial procedures for Child 7 and Child 8

Free play choice probes

Figure 3 and Figure 4 show the number of 5-second intervals in which the child was engaged in books and toys during 5-minute free play choice probe sessions (baseline, following each conditioning phase, and one-month probe). For Child 5, his baseline data showed that he spent the entire free playtime on playing with toys only. However, the free play probes after 5second and 10-second book conditioning sessions displayed a variable trend with a variable increased level of time intervals on books and the corresponding decreased level of time intervals on toys. During the free play probes following 15-second conditioning sessions, Child 5 observed books for 56 and 60 in the first and second sessions, respectively, and played with toys for 0 intervals during both sessions.

Child 6 also spent all 60 intervals on toys during baseline free play sessions. Her free play probes following toy-conditioning sessions displayed the same pattern as the baseline, with a high level of toy play behavior and a low level or no book observation behaviors. The data 
started to show crossovers during the free play probes following 5- and 10-second book conditioning sessions. She achieved the terminal goal for choice of books during free time after 15-second book conditioning sessions. In these two free play choice probes, she spent 55 and 56 time intervals with books and 0 intervals with toys.

Similarly, Child 7 played with toys for 60 intervals during all free play baseline sessions. The data showed an ascending trend with increased numbers of time intervals devoted to books across free play probes following three phases of book conditioning sessions. The time intervals on toys decreased to a medium level during free play sessions following 5- and 10-second book conditioning sessions and eventually decreased to zero occurrences in free play probes following 15-second book conditioning sessions.

Child 8 devoted all 60 intervals on toys and zero intervals to books throughout the baseline and the free play probes following matched toy conditioning phases. However, the overall trend for all free play probes following book conditioning sessions showed an ascending trend for the time intervals devoted to books and a corresponding descending trend for time intervals devoted to toys. The data on Child 8's free play probes after 20-second book conditioning sessions showed that he distributed 53 intervals on books and 0 intervals on toys for the first session and 43 intervals on books and 6 intervals on toys for the second session.

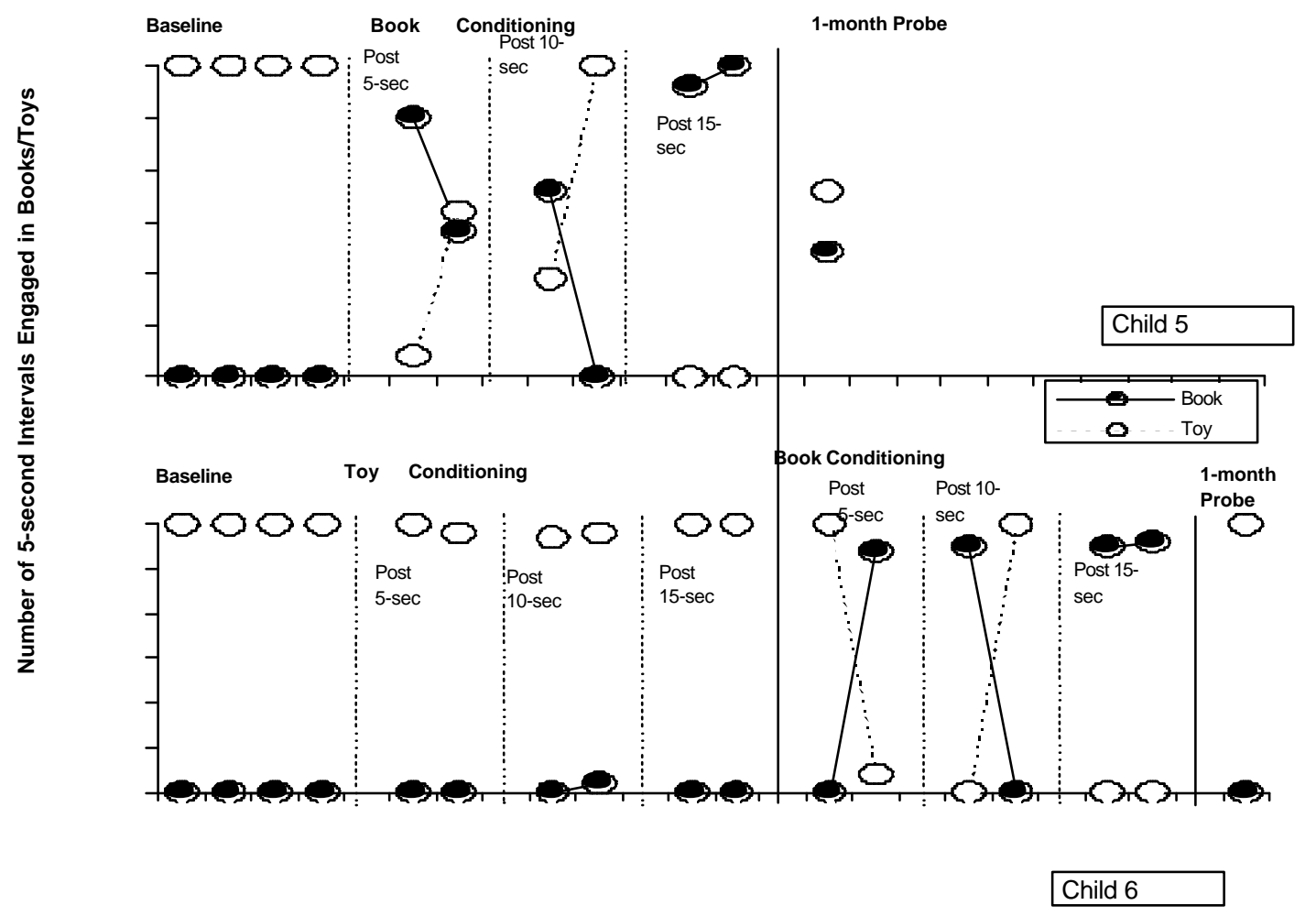

Figure 3. The numbers of whole intervals Children 5 and 6 engaged in observing books in free play probes 


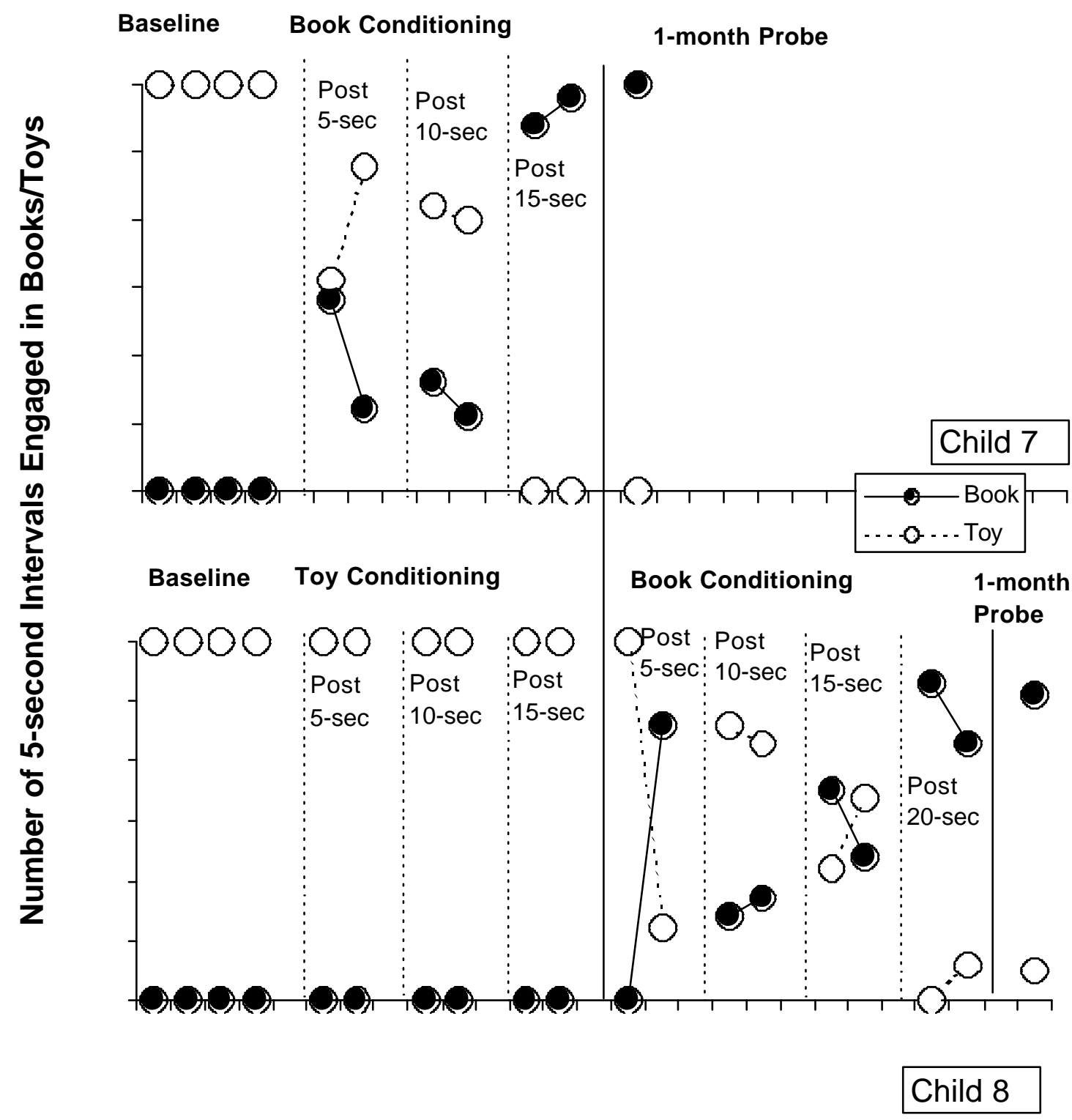

Figure 4. The numbers of whole intervals Children 7 and 8 engaged in observing books in free play probes

One-month free play choice probes-maintenance of choice and observation of books

As shown in Figure 3, Child 5's one-month free play probe showed that he looked at books for 24 intervals and played with toys for 36 intervals. His preference for books over toys was maintained at $33 \%$ of the intervals. For Child 6's one-month free play probe, she distributed all 60 intervals on toys and 0 intervals on books. She did not maintain conditioned preference toward books. Figure 4 also shows the one-month free play probe for Child 7 and Child 8 . Child 7 continued to devote a high number of time intervals devoted to books (60 intervals) and zero intervals on toys during one-month free play probe. Similarly, Child 8 spent 51, 5-second 
intervals on books ( $85 \%$ of the sessions intervals) and 5 intervals on toys. The data showed that 3 out of 4 children maintained the conditioned reinforcement stimulus control from $33 \%$ to $100 \%$ for books one month after they achieved the criterion for book conditioning.

\section{Learn-units-to criterion on textual responses}

Figure 5 and Figure 6 show the numbers of learn units required to achieve criterion on sight-word instruction before and after the book conditioning and the matched toy conditioning. Child 5 required 220 learn-units-to criterion on Set 1 (11 sessions) before book conditioning but required only 120 learn-units-to criterion on Set 2 (6 sessions) after the book conditioning procedure was completed. Following the book conditioning, Child 5 mastered the same number of sight words with 100 fewer learn units (5 sessions). Child 6 mastered Set 3 with 180 learn units ( 9 sessions) during baseline, Set 2 with 140 learn units ( 7 sessions) after toy conditioning, and Set 1 with 120 learn units (6 sessions) after book conditioning. For Child 6, the toy conditioning procedure decreased 40 learn units ( 2 sessions) to criterion, but the book conditioning procedure decreased 60 learn units ( 3 sessions) to criterion, compared to her learnunits-to criterion baseline. Since the 2 sets of sight words were arranged in a counterbalanced order between Child 5 and Child 6, the data for both children showed that the numbers of learnunits-to criterion were affected by the differences in treatment procedures (book versus toy conditioning) regardless of the difficulty level of the sight words taught.

Child 7's data on learn-units-to criterion showed a significant decrease in the total number of learn units after the introduction of the book conditioning procedure. It took him 400 learn units to master Set 4 ( 20 sessions) during baseline but 140 learn units for Set 2 ( 7 sessions) after books were conditioned as reinforcers. There was a decrease of 260 learn units (13 sessions). For Child 8, the learn-units-to criterion data showed that he needed 400 learn units to master Set 2 (20 sessions) during baseline, 560 learn units for Set 3 (28 sessions) after matched toy conditioning, and 360 learn units for Set 4 (18 sessions) after book conditioning. His learn units on post book conditioning sight-word instruction was 40 learn units fewer ( 2 sessions) than baseline and 200 learn units fewer (10 sessions) than post toy conditioning sight-word instruction. The between subject comparison also showed that the learn units required for Child 7 on post book conditioning sight-word instruction was significantly less than the learn units required for Child 8 on post toy conditioning sight-word instruction. The data for Child 7 and Child 8 also showed that the differences in the numbers of learn-units-to criterion were closely related to the experimental procedures and were not related to the difficulty of sight words because of the counterbalanced arrangement of the sight word sets.

The learn-units-to criterion data showed that the book conditioning procedure significantly decreased the numbers of learn units needed to master textual responding for all four children. Within each pair, the first child's learn units required for sight-word instruction after book conditioning was also significantly fewer than the second child's learn units required for the instruction after toy conditioning, given that the time and number of approvals during conditioning trials were matched. The data of the post toy conditioning instruction on textual responding also showed that the toy conditioning procedure slightly decreased the learn-units-to criterion for Child 6 but significantly increased the learn-units-to criterion for Child 8, indicating that the toy conditioning had an inconsistent effect on improving the children's learning on textual responding. 


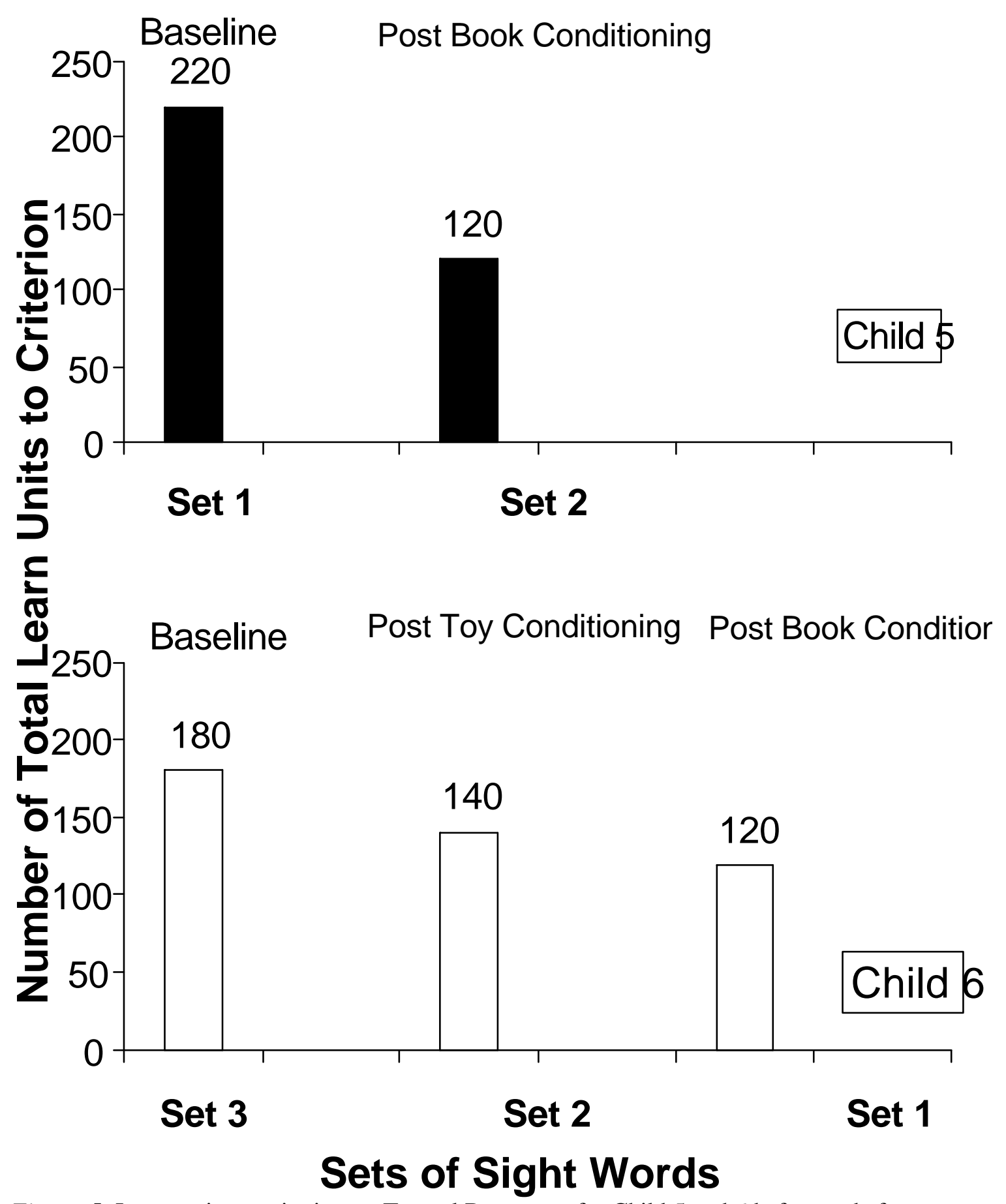

Figure 5: Learn-units-to criterion on Textual Responses for Child 5 and 6 before and after conditioning 


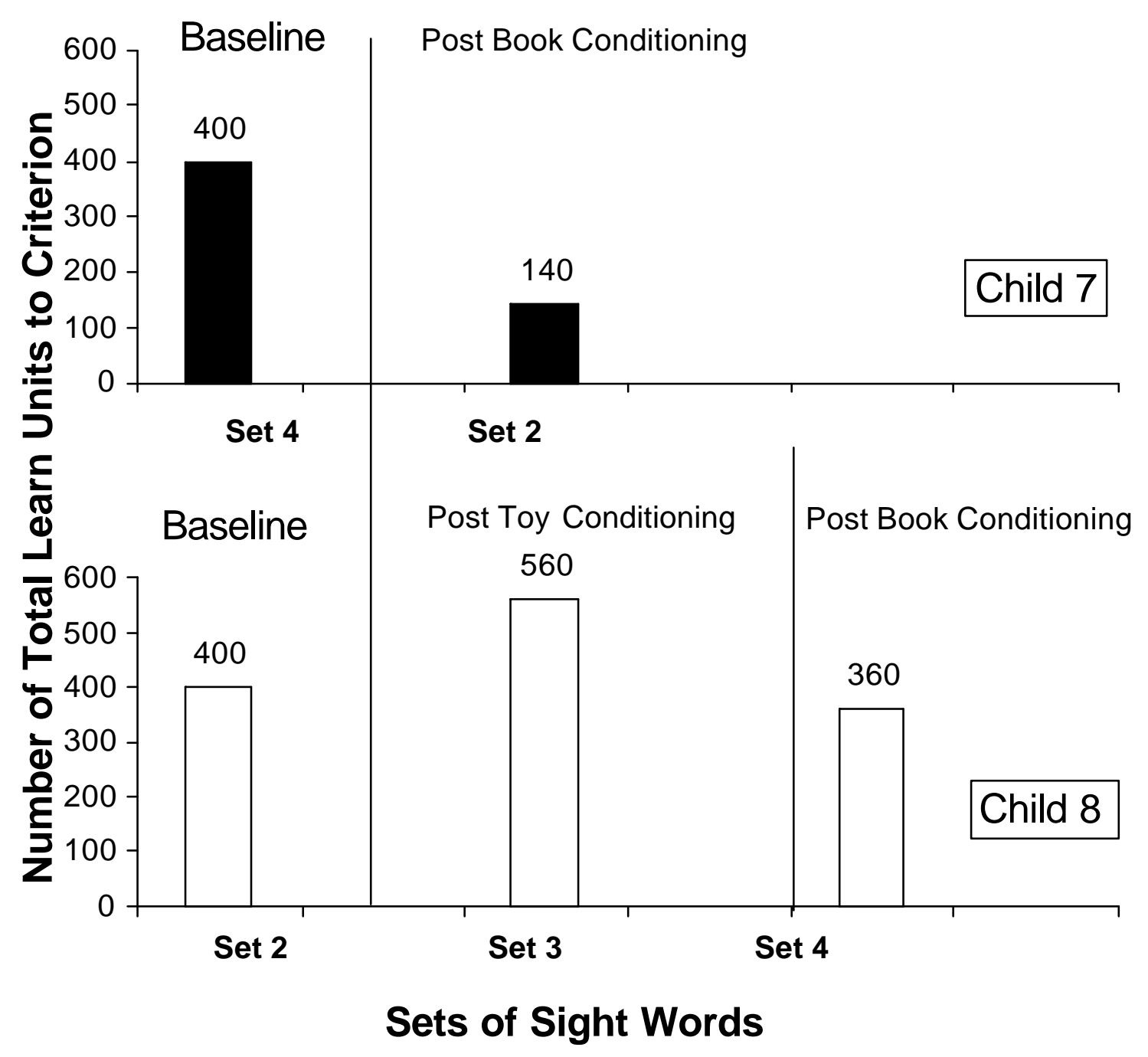

Figure 6: Learn-units-to criterion on Textual Responses for Child 7 and Child 8 before and after conditioning

\section{Maintenance of textual responses}

For the maintenance probes, Child 5 emitted 10 and 8 correct responses out of 20 opportunities for Set 1 and Set 2, respectively. Set 1 was taught in baseline and Set 2 was taught after book conditioning. For Child 5, words taught before and after book conditionings were maintained at a similar level. Child 6's maintenance data showed that she responded correctly for 9 out of 20 presentations on Set 3 (taught during baseline), 4 out of 20 on Set 2 (taught after toy conditioning), and 6 out of 20 for Set 1 (taught after book conditioning). Child 6's data showed that words taught during baseline and after book conditioning sessions were maintained better than words taught after toy conditioning. Words taught after book conditioning were not maintained better than words taught during baseline, showing that the book conditioning procedure did not make any difference on maintenance of textual responding.

Child 7 performed 9 correct responses out of 20 for Set 4 learned during baseline and 8 correct out of 20 for Set 2 learned after book conditioning. Both sets taught before and after book conditionings were maintained at approximately the same level. Child 8 emitted 4 correct 
responses out of 20 for all three sets of sight words taught during baseline, after toy conditioning, and after book conditioning, respectively. The data for the maintenance responses are not displayed because of the lack of maintenance.

\section{Discussion}

The results of the experiment showed that the book conditioning procedure served to decrease the numbers of learn units necessary to achieve criterion accuracy on textual responding across all four children. That is, the learning rate for textual responses was increased by the induction of new reinforcement for observing book stimuli. The results also extended the findings of a similar study of Greer, Dorow, and Wolpert (1980) in which conditioning auditory observing control of music stimuli was functionally related to the decreased learn units to mastering complex auditory discrimination tasks for first graders. Conditioning preference for books may serve to enhance children's learning on textual stimuli in the following ways. First, the stimulus control was shifted to books, and therefore, the children spent more time on independent book observation during free-play time. Second, the increased time spent on books over toys increased the probability of eye contact with print stimuli associated with pictures in books. Third, the frequent contacts with print stimuli along with the corresponding pictures in books enhanced the control of print stimuli because the children were attending to the relevant stimuli.

In learning experiments, baseline conditions need to include alternate control interventions rather than no intervention. The toy play control condition was done to isolate print stimuli from possible conditioning effects for observing the experimenter in the textual instruction. Indeed, in one case observing the experimenter may have been an artifact of the toy conditioning. That is, following the toy conditioning procedures, Child 6 decreased his numbers of learn units to criterion suggesting that observing of the experimenter's instructions may have been conditioned also. However, for Child 8 the numbers of learn units to mastery actually increased following the toy play control conditioning. It was clear that the toy conditioning procedure did not have a positive effect on reading for Child 8 . For Child 6 , although the toy conditioning decreased by 40 learn units over baseline (a decrease of 2 teaching sessions), the book conditioning intervention reduced learn-unit-to criterion by another 20 learn-units. It is possible that the toy conditioning functioned to condition Child 6 to attend to instructions from the experimenter during the toy conditioning process.

The two children who received the book conditioning sessions only were older than the children who received the matched toy conditioning control sessions as a result of our initial control condition for matching students on textual learning rate. The age difference was a possible explanation for the fact that the children who received book conditioning learned better than their peers who received matched toy conditioning. The older of the pair who received the toy conditioning prior to the book conditioning achieved criterion for his word set in 140 learn units. However for the conditioning procedure, the youngest child, Child 8 , required 7 sessions of pairing trials (140 pairing trials) to meet the free-play criterion, while child 7, the oldest child, required 8 sessions (160 pairing trials). The other two children required 5 and 6 sessions, respectively, to achieve the free-play criterion. The real differences in age occurred for textual responding in which the youngest child required 360 trials following book conditioning to master a word set, while the older children required 120, 120, and 140 learn units, respectively, to master their word sets after book conditioning. Thus, for one of the pair who received toy conditioning prior to the book conditioning condition, age, or more likely instructional histories, may have played a part. It is interesting to note that Child 8 had the lowest criterion level performance for the conditioning of books for observing. A more stringent criterion, say $90 \%$ of the intervals in 2 
consecutive sessions may have produced stronger results. Future research needs to control for age and instructional histories more rigorously by limiting the age range and probing possibly related verbal capabilities such as naming, joint stimulus control across print and naming, and joint picture-print-word sound stimulus control (Greer \& Keohane, 2005).

The data on the maintenance of textual responses showed little differences on textual responses learned before and after the acquisition of reinforcement value for books for all four children. This is not surprising since it is more likely that the pairings conditioned the stimuli for observing and this resulted in better observation to the stimuli and this, in turn, made learning textual responses occur more rapidly. However, the maintenance of textual responding requires other experiences such as the learning of many words with phonetic control and the development of comprehension before any benefits of conditioned observing are likely to accrue and these children had no such histories.

The children we studied included children from non-English speaking families. On the one hand this provided special control conditions for exposure to English. But, on the other hand this difference calls for further tests on English speaking children if we are to expand the generality of the procedures.

While the conditioning procedures were complicated they were thorough and can be done in everyday interventions by those who are trained in the use of the procedures. That is, these conditioning procedures have been used extensively in CABAS® schools for several years to provide reinforcers for behaviors that replace stereotypy (Nuzzolo-Gomez, 2002; Greer et al., 1985) and to condition book observing responses.

The design we used compared the effects of acquiring a new stimulus control over the learning of other stimulus control. Because it is a different type of design a few words of explanation are in order. In this and related studies on the effects of the acquisition of higher order operants or relational frames, the experimental design needs to address the effects of the teaching of new environmental stimulus control on either the emergence of responses not directly taught, learning rate, or acquisition of a different operant. In such studies it is first critical to demonstrate that a particular repertoire, capability, instructional history, or special stimulus control is not present. Next the missing stimulus control must be induced and the learning data on the process of acquiring the new missing stimulus control displayed. The relation of the dependent variable to the presence and absence of the newly created capability, repertoire, or higher order operant is determined by pre and post capability comparisons (Greer, Yuan, \& Gautreaux, 2005, Greer, Stolfi, Chavez-Brown, \& Rivera-Valdez, 2005; Singer-Dudek \& Greer, in press). Thus, in the present experiment, the independent variable was not the toy conditioning procedures; rather it was the presence of a newly conditioned reinforcer for observing. Moreover, nested within the experiment is an experiment showing that the children acquired conditioned reinforcement for observing books as a function of the conditioning procedure further replicating the Greer et al. (1985) and Nuzzolo et al. (2002) findings as well as the series of studies on conditioning auditory stimuli. The conditioning procedure data show the slope of acquisition of stimulus control, but the free-play probes showed when the independent variable was in place. Our study addressed the branch of our science devoted to the relation of newly developed stimulus control relations to the acquisition of other stimulus control. The questions and methods of experimentation differ from studies showing, for example the acquisition of the stimulus control for reading comprehension as new operants where the treatment might be a particular tactic of instruction such as tutoring (Greer \& Polirstok, 1982). In both of these cases, the learning of new operants and the learning of new capabilities, the effects are not reversible; however, what is learned and the source differs. In one case a new operant is learned by a 
teaching tactic, while in the other a new capability, or in our case a new conditioned reinforcer for a behavior, results in an effect on other learning (i.e., in our case the rate of learning of textual responses). Both of the latter are learning experiments and differ from those studies devoted to the controlling variables for existing behaviors or performance (Greer, 2005; Greer, SingerDudek, Gautreaux, in press).

The effects of the intervention were powerful given the relatively few pairing sessions involved. That is, there are probably many more instances in the lives of many children where parents incidentally pair social reinforcement with looking at books. Such pairings occur incidentally over months and years with young children. It is very likely that these incidental pairing sessions, that occur as a matter of course in homes in which books are highly valued, play a key role in children's subsequent literacy. The fact that the acquisition of reinforcement for observing accrued in our case as a result of a relatively short intervention, especially for those children with minimal English language exposure, is impressive and probably due to the intensive application of conditioning procedures from the basic science. The numbers of train and test sessions required for the children to acquire reinforcement for observing and preferring books ranged from 5 to 8 sessions. Like the Greer et al. (1980) study where 2 year olds learned to prefer Bartok string quartet recording excerpts over children's music excerpts, the children in our study learned to prefer books over toys in a relatively short time. If these results hold, conditioning children to acquire conditioned stimulus control for observing books may pay real dividends in their subsequent acquisition of reading skills.

Reading readiness has been an imprecise construct in the literature on reading. Like age in the developmental literature, reading readiness has been an empty variable. However, if "reading readiness" is operationally defined as conditioned reinforcement for observing books, parents and well-trained educators can use these procedures to significantly enhance their children's future literacy. Reading readiness need not be rele gated to non-empirically based assumptions about age; rather the readiness can be based on measures for each child. We would know that children are ready to read when books selected out observing responses in free play settings and the procedures we tested suggest how books can become conditioned reinforcers for observing. That is we know how to provide reading readiness. The results warrant future investigations to determine if these procedures constitute empirical measures of reading readiness. If five-year old children were taught to be relatively fluent readers who chose to look at books in free play settings by the time they entered school, the outcomes of schooling would be drastically improved.

\section{References}

Albers, A., \& Greer, R. D. (1991). Is the three-term contingency trial a predictor of effective instruction? Journal of Behavioral Education, 1, 337-354.

Cooper, L. J., Wacker, D. P., Thursby, D., Plagmann, L. A., Harding, J., Millard, T., \& Derby, M. (1992). Analysis of the effects of task preferences, task demands, and adult attention on child behavior in outpatient and classroom settings. Journal of Applied Behavior Analysis, 25, 823-940.

Cotter, V. W., \& Spradlin, J. E. (1971). A nonverbal technique for studying music preference. Journal of Experimental Child psychology, 11, 357-365.

Cotter, V. W. \& Toombs, S. A. (1966). A procedure for determining the music preferences of mental retardates. Journal of Music Therapy, 3, 57-64. 
De Leon, I. G., Iwata, B. A., Conners, J., \& Wallace, M. D. (1999). Examination of ambiguous preferences with duration-based measures. Journal of Applied Behavior Analysis, 32, 111-114.

Dinsmoor, J. A. (1983). Observing and conditioned reinforcement, Behavior and Brain Sciences, 6, 693-728.

Emurian, H. H., Hu, X., Wang, J., Durham, A. G. (2000). Learning Java: a programmed instruction approach using Applets. Computers in Human Behavior, 16, 395-422.

Greer, R. D. (1994). The measure of a teacher. In R. Gardner, III, D. M. Sainato, J. O. Cooper, W. L. Heward, J. Eschelman, \& T. A. Grossi (Eds.), Behavior analysis in education: Focus on measurably superior instruction (pp. 225-248). Pacific Grove, CA: Brooks/Cole.

Greer, R. D. (1980). Design for music learning. New York, NY: Teachers College Press.

Greer, R. D. (2002). Designing teaching strategies: An applied behavior analysis systems approach. New York: Academic Press.

Greer, R. D., Becker, B. J., Saxe, C. D., \& Mirabella, R. F. (1985). Conditioning histories and setting stimuli controlling engagement in stereotypy or toy play. Analysis and Intervention in Developmental Disabilities, 5, 269-284.

Greer, R. D., Dorow, L. G., \& Hanser, S. (1973). Music discrimination training and the music selection behavior of nursery and primary level children. Bulletin of the Council for Research in Music Education, 35, 30-43.

Greer, R. D., Dorow, L. G., \& Randall, A. (1974). Music listening preferences of elementary school children. Journal of Research in Music Education, 21, 345-354.

Greer, R. D., Dorow, L. G., Wachhaus, G., \& White, E. (1973). Adult approval and students' music selection behavior. Journal of Research in Music Education, 21, 293-299.

Greer, \& Polirstok, S. R. (1982). Collateral gains and short-term maintenance in reading and on task by inner-city adolescents as a function of their use of social reinforcement while tutoring. Journal of Applied Behavior Analysis, 15, 123-139.

Greer, R. D., Singer-Dudek, J, \& Gautreaux, G. (In Press). Observational learning. Journal of International Psychology.

Greer, R. D., Stolfi, L., Chavez-Brown, M., \& Rivera-Valdez, C. (2005). The emergence of the listener to speaker component of naming in children as a function of multiple exemplar instruction. The Analysis of Verbal Behavior, 21, 123-134.

Greer, R. D., Yuan, L. \& Gautreaux, G. (2005). Novel dictation and intraverbal responses as a function of a multiple exemplar history. The Analysis of Verbal Behavior, 21, 99-116.

Holland, J. G. (1958). Human vigilance. Science, 128, 61-67.

Holdaway, D. (1979). The foundation of literacy. Sidney: Ashton Scholastic. 
Holdaway, D. (1990). Independence in reading ( $3^{\text {rd }}$ ed.). Portsmouth, New Hampshire: Heinemann.

Johnston, J. M., \& Pennypacker, H. S. (1993). Strategies and tactics of behavioral research $\left(2^{\text {nd }}\right.$ ed.). Hillside, NJ: Lawrence Erlbaum Associates.

Kazdin, A. E. (1982). Single-case research designs: Methods for clinical and applied studies. New York: Oxford University Press.

Lovitt, T. C. (1968) Free operant assessment of musical preference. Journal of Experimental Psychology, 6, 361-367.

Lovitt, T. C. (1965). Narrative Rate preferences of Normal and Retarded Males as Assessed by Conjugate Reinforcement. Doctoral dissertation, University of Kansas.

Morgan, B. J. \& Lindsley, O. R. (1966). Operant preference for stereophonic over monophonic music. Journal of Music Therapy, 50, 493-496.

Neuman, S. B. (1999). Books make a difference: A study of access to literacy. Reading Research Quarterly, 34, 286-311.

Nuzzolo-Gomez, R., Leonard, M. A., Ortiz, E., Rivera, C. M., \& Greer, R. D. (2002). Teaching children with autism to prefer books or toys over stereotypy or passivity. Journal of Positive Behavior Interventions, 4, 80-87.

Oldfather, P. \& Dahl, K. (1994). Toward a social constructivist reconceptualization of intrinsic motivation for literacy learning. Journal of Reading Behavior, 26, 139-157.

Piazza, C. C., Fisher, W. W., Hagopian, L. P., Bowman, L. G., \& Toole, L. (1996). Using a choice assessment to predict reinforcer effectiveness. Journal of Applied Behavior Analysis, 29, 1-9.

Rheingold, H. L. Stanley, W., \& Doyle, G. B (1964). Visual and auditory reinforcement of a manipulatory response in the young child. Journal of Experimental Child Psychology, 1, 316-326.

Singer-Dudek, J., \& Greer, R. D, (in press). A Long-term Analysis of the Relationship between Fluency and the Training and Maintenance of Complex Math Skills. The Psychological Record.

Skinner, B. F. (1957). Verbal behavior. Cambridge, MA: B. F. Skinner Foundation.

Sundberg, M. L., Michael, J., Partington, J.W., \& Sundberg, C.A. (1996). The role of automatic reinforcement in early language acquisition. The Analysis of Verbal Behavior, 13, 21-37.

\section{Authors Note}

This experiment was conducted as part of the first author's $\mathrm{PhD}$ dissertation under the sponsorship of the second author. We are appreciative of the contributions of the children and the cooperation of their families during the conduct of this research. 
Author contact information:

Hshin-Hui Tsai

e-mail: gabtsai@hotmail.com

Or

R. Douglas Greer

e-mail: dgreer3872@aol.com

Box 76 Teachers College

Columbia University

New York, NY 10027

\section{Advertising in the Journal of Early and Intensive Behavior Intervention}

Advertising is available in JEIBI. All advertising must be paid for in advance. Make your check payable to Joseph Cautilli. The ad copy should be in our hands at least 3 weeks prior to publication. Copy should be in MS Word or Word Perfect, RTF format and advertiser should include graphics or logos with ad copy.

The prices for advertising in one issue are as follows:

1/4 Page: $\$ 50.00$ 1/2 Page: $\$ 100.00$ vertical or horizontal Full Page: $\$ 200.00$

If you wish to run the same ad in both issues for the year, you are eligible for the following discount:

1/4 Pg.: \$40 - per issue

1/2 Pg.: \$75 - per issue -vertical or horizontal

Full Page: \$150.00-per issue.

For more information, or place an ad, contact Halina Dziewolska by phone at (215) 462-6737 or e-mail at: halinadz@hotmail.com 


\title{
The Effects of a Stimulus-Stimulus Pairing Procedure on the Acquisition of Conditioned Reinforcement on Observing and Manipulating Stimuli by Young Children with Autism
}

\author{
Jennifer M. Longano and R. Douglas Greer \\ Columbia University Teachers College and Graduate School of Arts and Sciences
}

\begin{abstract}
In 2 multiple baseline experiments, we tested stimulus-stimulus pairing effects on acquisition of conditioned reinforcement for observing and manipulating stimuli and stereotypy/ passivity. In Experiment I we studied a 5 year-old male with autism and we collected data using continuous 5-sec whole interval recording in 5 min sessions in which the student emitted appropriate play, and partial intervals of stereotypy, or passivity. Experiment 2 tested the effects of same procedure on independent work by 2 male participants with autism. The dependent variables were: intervals in which students worked independently, percentage of correct responses, and worksheet completion. Results from both experiments showed significant increases in numbers of intervals students emitted the target behaviors and decreases in stereotypy and passivity.

Key words: stimulus-stimulus pairing procedure, conditioned reinforcement, observing responses, preference
\end{abstract}

Conditioned reinforcers are defined as initially neutral stimuli that have acquired reinforcing characteristics through the pairing of the neutral stimuli with a previously conditioned or unconditioned reinforcer (Cooper, Heron, Heward, 1988). For many students with disabilities, pairing procedures are necessary to condition stimuli that are important for development and academic progress. Dinsmoor (1985) found that greater observing or attending to specific stimuli (the reinforcement for observing are the stimuli) resulted in an increase in stimulus control for components of those stimuli.

Sundberg, Michael, Partington, \& Sundberg (1996) developed a stimulus-stimulus pairing procedure to condition vocal sounds as reinforcers for students who had a limited vocal verbal repertoire. Vocal repertoires were observed and analyzed during pre- and post-session observations across experimental conditions. One of the conditions was a stimulus-stimulus pairing condition, in which target sounds, words, or phrases was paired with a previously conditioned reinforcer. Results from the first experiment showed that all participants emitted the target sounds in the post-pairing condition. The results showed that children acquired new vocal responses without direct reinforcement, echoic training, or prompts. In the second experiment, the parameters of the pairing procedure were analyzed. Other studies ( Yoon \& Bennett, 2000; Miguel, Carr, \& Michael, 2002) have replicated the findings by Sundberg et al. showing the effectiveness of the stimulus-stimulus pairing procedure of the acquisition of vocal verbal behavior, also known as parroting. Yoon (1998) found that once parroting was acquired through the stimulus-stimulus pairing procedures, those acquired sounds can then be used to begin instruction for functional speaker behavior. After students acquired vocal sounds, as a result of the pairing procedure, mand instruction was implemented using those sounds using an echoic to mand procedure developed by Williams and Greer (1993).

Stimulus-stimulus pairing procedures have also been used to expand children's community of reinforcers by teaching them to prefer previously non-preferred stimuli (Greer, 
Becker, Saxe, \& Mirabella, 1985; Greer, Dorow, \& Hanser, 1973; Nuzzolo-Gomez, Leonard, Ortiz, Rivera, \& Greer, 2002). In the studies by Greer et al. and Nuzzolo-Gomez et al. a conditioning procedure was used to teach student to select books or toys as a preferred activity. This procedure also functioned to replace stereotypy with the reinforcement effects of observing books. As a result of the conditioning procedure, the students engaged in appropriate toy play or looking at books during their free time instead of emitting stereotypy. Furthermore, results showed that the conditioning procedure was an effective tactic to teach the student to play or look at books appropriately and independently.

More recently, Tsai \& Greer (see this issue of JEIBI) conducted a study to investigate the effects of the conditioning procedure on textual responding. Pre- and post-conditioning probes were conducted on the numbers of correct responses for textual responding to sight words. Also, a pre- and post-conditioning probe was conducted to determine if books functioned as a reinforcer for the participants in the study. Pairing training and test trial conditioning procedure was used to condition books as a reinforcer after the pre-conditioning probes. Following the completion of the conditioning procedure, probes were again conducted on the numbers of correct responses for textual responding. Findings showed a decrease in numbers of learn units required to master textual response, and maintenance of the reinforcement effects for observing books for three of the four children.

The purpose of studies reported herein was to test the applicability of the stimulusstimulus pairing procedure on independent play and independent responding to worksheets during seatwork. In the first study, the pairing procedure was implemented due to the low levels of appropriate play and high levels of stereotypy emitted by a student. The stimulus-stimulus reinforcement pairing procedure was implemented to condition toys as reinforcers for play, computers as reinforcers for manipulation, and books as reinforcers for observing and to test the effects of this conditioning on levels of stereotypy. In the second study, the conditioning procedure was implemented to condition worksheets as reinforcers for responding to the worksheets and the numbers of correct responses to worksheet skills before and after the stimulus-stimulus pairing procedure.

\section{Experiment 1}

Method

\section{Participants}

One student participated in the first experiment. Student A was a 5-year-old boy who was diagnosed with autism. The student was assessed using the PIRK (Greer \& McCorkle, 2003). Results for the assessment showed the student was functioning on a speaker and emergent reader/writer level of verbal behavior. Table 1 shows the participant's capabilities, programs of instruction, and behaviors in the student's repertoire.

Table 1: Characteristics of Student A

\begin{tabular}{|l|l|l|}
\hline Age/ Gender & $\begin{array}{l}\text { Standardized Assessment and } \\
\text { Diagnosis }\end{array}$ & Academic Behaviors \\
\hline$*$ Male & * Learning Accomplishment & *Generalize Matching and \\
*5 years old & Profile & Pointing repertoire \\
& - Matching: AE 36 mos. & $*$ Speaker repertoire includes \\
\hline
\end{tabular}




\begin{tabular}{|l|l|l|}
\hline & \multicolumn{1}{|c|}{ - Writing: AE 54 mos. } & $\begin{array}{l}\text { tacts and mands with } \\
\text { autoclitics, some sequelics, } \\
\text { and limited conversational } \\
\text { units. }\end{array}$ \\
& $\begin{array}{l}\text { *Overall cognitive functioning } \\
\text { falls within the low average to } \\
\text { below average range. } \\
\text { * Diagnosis of autism }\end{array}$ & $\begin{array}{l}\text { Emergent reader/writer } \\
\text { repertoires }\end{array}$ \\
& & \\
\hline
\end{tabular}

The student was selected for this study based on the high levels of stereotypy and low levels of appropriate play in free time when he was using the computer, playing with toys, and looking at books. The student frequently manded to use the computer, which indicated the computer functioned as a conditioned reinforcer for the student prior to the onset of the study. However, the student also had an instructional history in which stereotypy (hand-flapping) was a concomitant response with using the computer. The student frequently requested to earn to free time in the activity center. When in the activity center, the student emitted stereotypy or passivity instead of appropriately playing with toys and other materials in the activity center. Often, the student used toys as part of his stereotypy.

\section{Settings}

The study took place in a CABAS® classroom (Greer, 1996) located outside of a major metropolitan area. The classroom ratio consisted of five students, 2 teaching assistants and one teacher. For toy play and looking at books, baseline conditions consisted of the student sitting or standing in the activity center. When probes were conducted for toys, toys were placed on the carpet in the activity center. For baseline probes for looking at books, books were placed on the carpet of the activity center. The activity center contained a computer, stuffed animals, and shelves filled with toys and board games. The activity center was located in one of the corners of the classroom. During the intervention phase, the student sat at a rectangular table where instruction was presented. The experimenter sat next to the student during the implementation of the stimulus/stimulus pairing procedure. During baseline probes for playing on the computer, Student A sat at the computer while the experimenter sat at least 5 feet away. The materials used in this study consisted of the toys, board games, books, and the computer. The computer used in was located in one of the corners of the classroom near the teacher's desk. During the study, other students in the classroom were presented with instruction in 1:1 or small group settings. Other materials used included a timer, pen, graphs and data forms.

\section{Definitions of Behavior}

The dependent variables in this study included appropriate play on the computer and with toys, looking at books, stereotypy, and passivity. For Student A, the behaviors observed during pre and post-conditioning probes consisted of appropriately playing at the computer, stereotypy, and passivity. Appropriately playing with toys included the student holding a toy in his hand while making movements representing symbolic play (rolling a car on a floor), and/or talking to the toy or talking about the toy. Appropriately playing at the computer was defined as sitting on a chair by the computer, looking at the computer screen, typing on the key board or operating the mouse, or interacting with the computer game (reading along with the story, laughing, or describing the pictures on the screen). Looking at books was defined as pointing to pictures in the book, describing the pictures in the book, or simply looking at the book. Stereotypy was defined as "cycles of repetitive movements that have no apparent consequences for the individual who is emitting the response beyond the movement itself." (Greer et al.. 1985) In the case of the 
present study, the student's stereotypy consisted of hand flapping or flapping with objects in his hand.

\section{Data Collection}

During pre and post conditioning probes, data were recorded using whole interval recording. Each probe session was conducted for 5 minutes, and data were recorded for 60 continuous 5-sec intervals. If the student emitted the target behavior for the entire five-second interval, a plus (+) was recorded. Partial interval recording was used to mark instances of stereotypy and passivity. Therefore, an (S) was recorded if the student emitted stereotypy at any point in the five second interval. If the student emitted passivity at any point of the five second interval, a (P) was recorded.

There were 20 train-test trials in the stimulus-stimulus pairing procedure. Each training trial was a stimulus-stimulus pair followed by a test trial. To begin, the experimenters set a timer for the specified interval time. Then the experimenters conducted the stimulus-stimulus pairing trial. In the stimulus-stimulus component of the train and test trials the child was required to emit the target behaviors with no occurrences of stereotypy. If stereotypy occurred in this component, the train trial was begun again. In other words the child had to complete a stimulus-stimulus pairing trial with no stereotypy and he had to emit the target behavior for the entire pairing period. After the training trial was complete, the test trial began. Data were collected on the presence or absence of the target behavior for each test interval. A plus (+) was recorded if the student came into contact with the target item for the whole interval. A minus (--) was recorded if the student emitted stereotypy, passivity, or any other incompatible behavior at any moment of the test interval. One session of the stimulus/stimulus pairing procedure consisted of the completion of 20 train and test trials. Following each session, data were graphed as the number of intervals the student emitted the behavior out of 20 opportunities. Graphs were analyzed using the CABAS $®$ decision tree protocol (Greer, 2001). Criterion was set at 18/20 correct test trials or better for two consecutive sessions.

Design

A multiple baseline across behaviors was used to test the effects of the stimulus/stimulus pairing procedure. Pre-conditioning sessions were conducted. After stable levels of appropriate play for the first behavior, toy play, were observed, the stimulus/stimulus pairing procedure was implemented. Baseline sessions were continued for computer and books. Once effects of the stimulus/stimulus pairing procedure were observed for the first behavior, the procedure was implemented for the second behavior, appropriately playing on the computer. Baseline probes were continued for looking at books until stable responding was recorded and until effects of the stimulus/stimulus pairing procedure was observed for playing on the computer. Following the student achieving criterion, a post-stimulus/stimulus pairing probe was conducted. Post- probes were conducted until the student maximum effects were observed. Table 2 shows the sequence of phases in Experiment 1. 
Table 2: Design Sequence

\begin{tabular}{|c|c|}
\hline Phase & Description \\
\hline $\begin{array}{l}\text { 1. Baseline probe sessions } \\
* 5 \text { sessions for toy play } \\
* 6 \text { sessions for computer } \\
* 8 \text { session for looking at books }\end{array}$ & $\begin{array}{l}\text { *60 five second intervals }(5 \mathrm{~min}) \\
\text { *Whole interval recording for appropriate behavior } \\
\text { * Data were collected on appropriate behavior, } \\
\text { stereotypy, and passivity } \\
\text { * Consequences were not delivered }\end{array}$ \\
\hline $\begin{array}{l}\text { 2. Implementation of stimulus-stimulus pairing } \\
\text { procedure } \\
5 \text { sec intervals }\end{array}$ & $\begin{array}{l}\text { *Pair/test trial } \\
\text { * Pairing trial Reinforcement (praise) is } \\
\text { delivered } 2 \text { or } 3 \text { times during pairing session. } \\
* \text { Test trial Experimenter observed student for } \\
5 \text { sec. A (+) was recorded if student emitted } \\
\text { behavior for } 5 \mathrm{sec} \text {, and a (-) was recorded if } \\
\text { student did not. Consequences are not delivered } \\
\text { following the test trial } \\
* \text { Criteria: } 18 / 20 \text { test trials or better for two } \\
\text { consecutive sessions. Once students achieved } \\
\text { criteria the next phase was implemented. }\end{array}$ \\
\hline 3. One session probe & * Same as baseline probes \\
\hline $\begin{array}{l}\text { 4. Implementation of stimulus-stimulus pairing } \\
\text { procedure } \\
10 \mathrm{sec} \text { intervals }\end{array}$ & * Same as pair/test trial described above \\
\hline 5. One session probe & * Same as baseline probes \\
\hline $\begin{array}{l}\text { 6. Implementation of stimulus-stimulus pairing } \\
\text { procedure } \\
15 \mathrm{sec} \text { intervals }\end{array}$ & * Same as pair/test trial described above \\
\hline 7. One session probe & * Same as baseline probes \\
\hline
\end{tabular}

\section{Conditioning Procedure}

The independent variable was the stimulus/stimulus pairing procedure, which was derived from a previously tested protocol (Greer et al., 1985; Nuzzolo-Gomez et al., 2002; Tsai \& Greer, 2006). The stimulus/stimulus pairing procedure consisted of alternating between training trial and a test trial. A session was completed after 20 test trials were observed. To begin, both training and test trials were implemented for $5 \mathrm{sec}$. First, the experimenters conducted the training trial, in which the experimenters paired a conditioned reinforcer, most often in the form of vocal praise, with the student emitting the target behavior throughout the entire interval and no stereotypy. During the training or pairing trials, the experimenters delivered vocal praise 2 or 3 times in the specified interval. The experimenters alternated between 2 or 3 pairings of reinforcement so that reinforcement pairing was delivered on a variable schedule. A training trial was complete if and only if the student emitted the target behavior for the whole interval. If at any time during the training trial the student emitted any other behavior than the target behavior, the experimenters reset the timer and restarted the training trial. Once the student emitted the target behavior for the whole trial, the experimenters then observed the student during the test trial. The test trials consisted of the experimenter starting the timer for the specified time of the interval and observing the child. During the test trial, no pairings were presented. The presence or absence of the target behavior was observed during the test trials. Immediately following the test trial, the 
training trial was again implemented. No instruction in the form of learn units was presented during the conditioning procedure, and therefore no corrections were presented contingent upon incorrect responses and reinforcement was only delivered during the training trial.

Reinforcement was not delivered following the test trial. After the student met criterion, emitting the target behavior for 18/20 or more test trials for two consecutive sessions, a post-conditioning probe was conducted. If data collected during the probe session indicated that the target item did not function as a reinforcer, the conditioning procedure was again implemented. However, upon each implementation of the pairing procedure, the intervals were increased in $5 \mathrm{sec}$ increments but the same number of 2 or 3 pairings occurred in the training trial component of the train and test trials.

\section{Interobserver Agreement}

During probe sessions, interobserver agreement measurement was recorded by a second and independent observer taking data simultaneously with the experimenter. The percentage of interobserver agreement was calculated on an interval-by-interval basis by dividing the number of agreements by the total number of agreements and disagreements and multiplying this number by $100 \%$. During pre/post probes across behaviors, interobserver agreement was conducted for $12 \%$ of the sessions, in which $100 \%$ agreement was recorded.

\section{Results}

Figure 1 shows the numbers of intervals Student A emitted appropriate and independent play or looking at books, and the numbers of intervals in which the student emitted stereotypy or passivity across behaviors. For toy play, the mean numbers of intervals in which the student emitted appropriate toy play was 12.2 (range: 4 to 21), stereotypy was 37 (range: 31 to 45), and passivity 10.6 (range: 4-19). Following the completion of the $5 \mathrm{sec}$ training/test trial stimulusstimulus pairing, a post-probe was conducted. The student emitted appropriate toy play for 49 intervals, emitted stereotypy for 6 intervals, and passivity for 5 intervals. The stimulus-stimulus pairing procedure was again implemented. This time, $10 \mathrm{sec}$. training/test trials were used. A post-probed showed an increase in the numbers of intervals in which the student emitted appropriate toy play, 58 intervals, and a decrease in the numbers of intervals in which the student emitted stereotypy and passivity, 2 and 0 intervals respectively.

FIGURE 1, NEXT PAGE 


\section{FIGURE 1, NEXT PAGE}
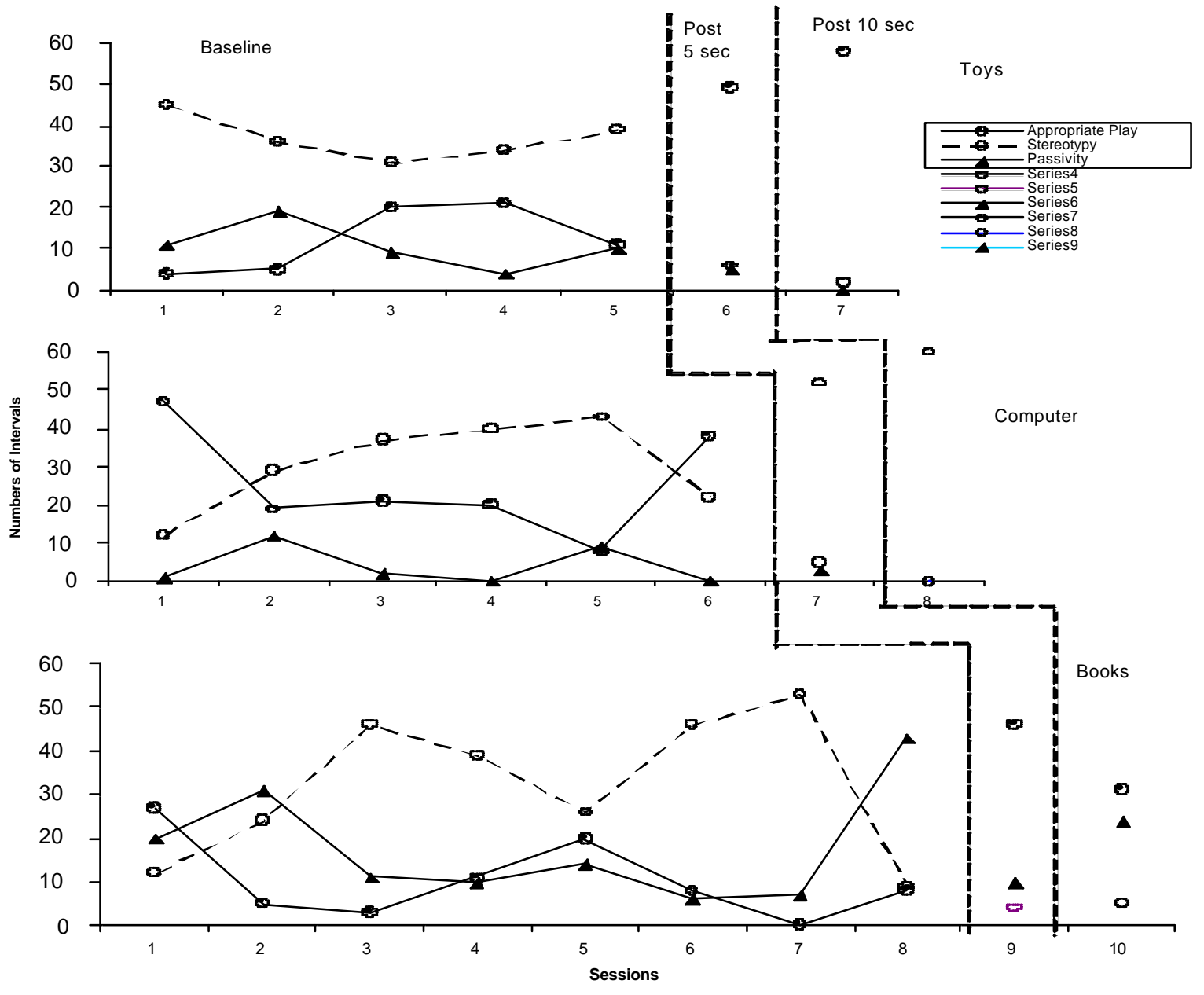

Figure 1. The graph shows a multiple baseline across behaviors design for Student A. Results from pre-pairing baseline probes are shown along with post-pairing probe sessions.

During baseline, the mean number of intervals in which appropriate computer play was recorded was 25 (range: 8-45), the mean number of intervals in which stereotypy was recorded was 30.5 (range: 12-43), and the mean number of intervals in which passivity was recorded was 4 (range: 0-12). Following baseline, the stimulus-stimulus pairing procedure was implemented for $5 \mathrm{sec}$ training/test trials. After the student met criterion, 18/20 tests trials or better for two consecutive sessions, a post-conditioning probe was conducted. During this probe, the student emitted appropriate computer play for 52 intervals, stereotypy for 5 intervals, and passivity for 3 intervals. The stimulus-stimulus pairing procedure was implemented for $10 \mathrm{sec}$. training/test trials. After the student achieved criterion for this phase, a post-conditioning probe was conducted. After the $10 \mathrm{sec}$. training/test trial phase, the student emitted 60 intervals of appropriate computer play during the post-stimulus-stimulus pairing probe and no instances of passivity or stereotypy.

For looking at books, data were recorded for 8 sessions under free play baseline conditions. The mean numbers of intervals the student emitted appropriate looking at books was 10.25 (range: 0 to 27), stereotypy was 31.75 (range: 9 to 53), and passivity for a mean of 17.88 
intervals (range: 6 to 43). Post 5 sec. training/test trial, the student emitted 46 intervals of looking at books, 4 intervals of stereotypy, and 10 intervals of passivity. Following the probe, the stimulus-stimulus pairing procedure was implemented for $10 \mathrm{sec}$ pairing/test trials. After the completion of this phase, a post-probe was conducted, in which the student emitted 31 intervals of looking at books, 5 intervals of stereotypy, and 24 intervals of passivity.

Data were also collected during the stimulus-stimulus pairing procedure, which is represented in Figure 2. Student A met criterion after seven sessions of the $5 \mathrm{sec}$. training/test trials. Test intervals of appropriate play ranged from 16-20 during this phase. Student A met criterion for $10 \mathrm{sec}$. training/test trials after three sessions. Test intervals of appropriate play ranged from 17-20.

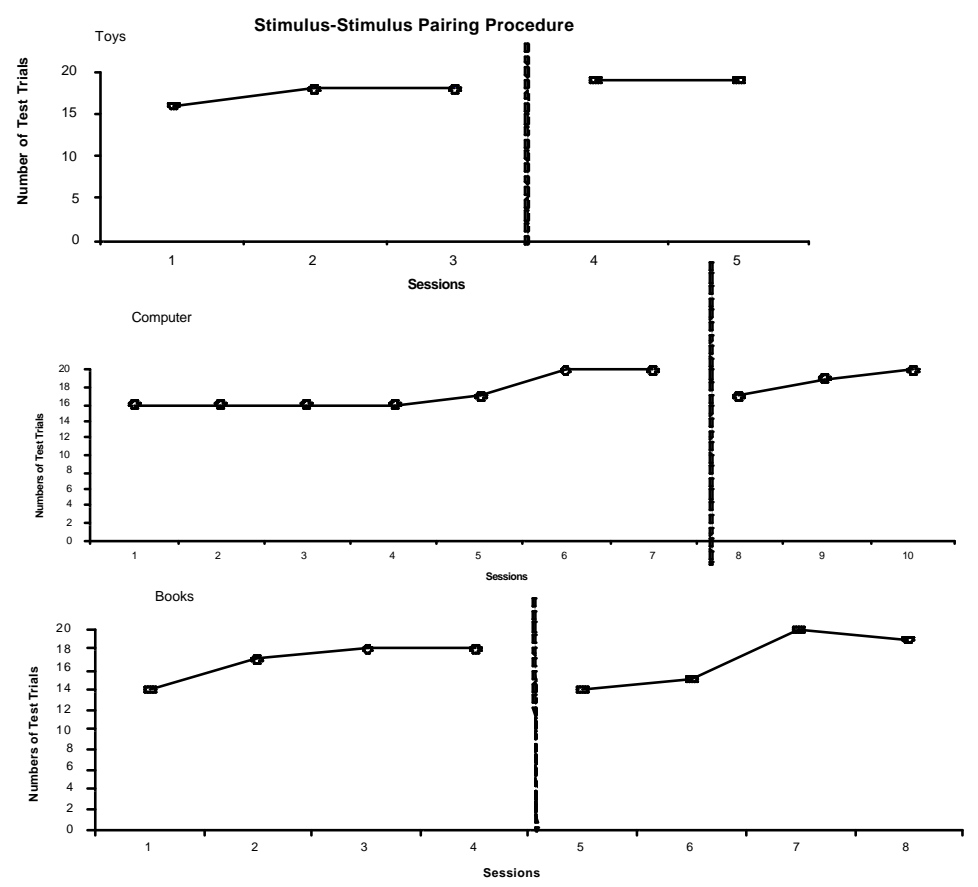

Figure 2. The figure shows the numbers of intervals out of a 20-test interval session in which Student A emitted appropriate behavior during the implementation of the stimulus-stimulus pairing procedure.

\section{Discussion}

An increase in appropriate and independent play was observed across three behaviors, playing with toys, playing on the computer, and looking at books. The stimulus-stimulus pairing procedure was effective in increasing appropriate play while decreasing stereotypy and passivity. For the third behavior, looking at books, in the second post probe, a decrease in the number of intervals in which the student appropriately looked at books decreased from the first post-probe, and an increase in passivity were observed. However, stereotypy occurred at low levels. These findings extended and replicated the findings from previous studies (Greer, Dorow, \& Hanser, 1973; Greer, Becker, Saxe, \& Mirabella, 1985; Nuzzolo-Gomez, Leonard, Ortiz, Rivera, \& Greer, 2002). In an expansion of the findings from the present study and the studies listed above, Tsai and Greer (in press.) found that conditioning book stimuli through a similar stimulus-stimulus pairing procedure lead to accelerated learning of textual responses. As are result, the following experimental question arose; would the conditioning of stimuli associated with independent 
seatwork, such as worksheets, increase the production of correct responses and increase the intervals in which the students independently emitted seatwork activities. Experiment 2 was designed to test the possibility.

\section{Experiment 2}

\section{Participants}

\section{Method}

Two students participated in the second study. Student B was a 7-year-old boy also diagnosed with autism. After being assessed using the PIRK (Greer \& McCorkle, 2003), the student was functioning on an emergent reader/writer level of verbal behavior. The student frequently emitted conversational units with peers and adults. General classroom instruction was most often delivered in a 1:1 setting and focused on increasing the student's reader, writer, and speaker, and social repertoires. The student was selected for this study because he had the prerequisite skills (following an activity schedule, staying in the activity center for 10 minutes, and emergent writer behaviors) for independent work. However, before worksheets were given to the student, baseline data indicated the student emitted low frequencies of working independently with worksheets and high frequencies of off-task behavior (passivity, talking to others, playing with materials, or stereotypy). Worksheets did not function as reinforcers during independent seatwork for Student B.

Student $\mathrm{C}$ was a 6-year-old boy diagnosed with autism. He functioned on an emergent reader/writer level of behavior, as indicated by the PIRK assessment (Greer \& McCorkle, 2003). The student frequently emitted conversational units with peer and adults. General classroom instruction was mostly delivered in a 1:1 setting or in a small group setting. The student did not work independently. The student was selected for this study because he had the prerequisite skills for working independently. However, when given worksheets or other activities the student emitted low levels of working independently and high levels of off-task behavior (passivity or stereotypy). Therefore, the stimulus-stimulus pairing procedure was implemented to test the effects on independent seatwork. Because worksheets did not function as a reinforcer for responding, the student chose not to complete the worksheets, but rather, emitted passivity or stereotypy. As a result, the student was a candidate for this study.

Table 3: Characteristics of Student B and C

\begin{tabular}{|c|c|c|}
\hline Student/Gender/Age & $\begin{array}{l}\text { Standardized Assessment \& } \\
\text { Diagnosis }\end{array}$ & Academic Behaviors \\
\hline $\begin{array}{l}* \text { Student B } \\
* \text { Male } \\
* 7 \text { years old }\end{array}$ & $\begin{array}{l}\text { * Wechsler Preschool \& } \\
\text { Primary Scales of Intelligence } \\
\text { III: Raw Score on full scale } \\
\text { was } 54 \\
\text { * Woodcock-Johnston III } \\
\text { ACH Tests: Grade Level } \\
\text { across academic areas- } \\
\text { Kindergarten level } \\
\text { * Student suffered oxygen } \\
\text { deprivation at birth and has } \\
\text { significant delays in all } \\
\text { academic readiness skills. }\end{array}$ & $\begin{array}{l}* \text { Generalize Matching and } \\
\text { Pointing repertoire } \\
* \text { Speaker repertoire includes } \\
\text { tacts and mands with } \\
\text { autoclitics, some sequelics, } \\
\text { and limited conversational } \\
\text { units. } \\
* \text { Emergent reader/writer } \\
\text { repertoires }\end{array}$ \\
\hline
\end{tabular}




\begin{tabular}{|c|c|c|}
\hline & * Diagnosis of autism & \\
\hline $\begin{array}{l}* \text { Student C } \\
* \text { Male } \\
* 6 \text { years old }\end{array}$ & $\begin{array}{l}\text { *Standardized assessments } \\
\text { were not updated at time of } \\
\text { study, and therefore did not } \\
\text { accurately represent the } \\
\text { student's ability levels. } \\
\text { *Diagnosis of autism }\end{array}$ & $\begin{array}{l}\text { * Speaker repertoire includes } \\
\text { tacts and mands with } \\
\text { autoclitics, some sequelics, } \\
\text { and limited conversational } \\
\text { units. } \\
\text { * Emergent reader/writer } \\
\text { repertoires } \\
\text { * Emergent self-editing } \\
\text { repertoire }\end{array}$ \\
\hline
\end{tabular}

\section{Setting}

For Student B and Student C, baseline was conducted at a table. The students were given a folder with several worksheets and the vocal instruction of "Please do your work". Again, the experimenters sat at least 5 feet away to collect data. During the treatment, the setting for each student remained the same except that the teacher sat either next to the student or across from the student. The materials used for this study included the computer and the variety of software that was programmed into the computer, worksheets (Spectrum Preschool Skills, Beginning Explode the Code, dot to dot, tracing, etc.), timer, writing tools, and data forms. During the study, other students in the classroom received instruction in a 1:1 setting or a small group setting.

\section{Definition of Behaviors}

For Student B and Student C, the dependent variables were working independently on worksheets, the number of correct responses to learn units (Greer \& McDonough, 1999), and completing an activity schedule. Independently working on worksheets was defined as the student using a writing tool to mark on the worksheet or emitting preparation responses to working on the worksheet, which included picking up the writing tool, getting a new worksheet out of his folder, or putting a completed worksheet into his folder. If the student emitted any other behaviors such as putting their writing tool down, talking about other activities or to other people while not completing their worksheets, or sitting and looking at other objects were recorded as the student not independently working. Correct responses to learn units consisted of the students' responses to specified written directions on worksheets (Greer \& McDonough, 1999). Each separate opportunity for the student to provide an answer was measured as one learn unit. The other dependent variable, completing the activity schedule, consisted of the reading the worksheet name to be completed and placing a check mark in the correct box following the completion of that worksheet. The student was required to emit the behaviors described above for each worksheet. For 10 worksheets there were 20 learn unit opportunities on the activity schedule.

\section{Stimulus-Stimulus Reinforcement Pairing Procedure}

The same procedure that was used in Experiment 1 was used in Experiment 2. However, the objective of implementing the procedure was to condition worksheets as a reinforcer for attending and responding. Worksheets were conditioned as reinforcers as a prerequisite skill to the implementation independent seatwork with worksheets and to increase the numbers of minutes the students engaged in independent work. 


\section{Data Collection}

For pre and post probes session for conditioning worksheets, data were recorded in the similar fashion as in Experiment I with several exceptions. First, each probe session was conducted for 15 minutes, and data were recorded after 1-minute intervals.(continuous 1-min. whole intervals) Therefore, data were recorded for 15 intervals. Whole interval was used to record the presence and absence of the target behavior, independently working on worksheets. If the student emitted the target behavior for the entire minute interval, a plus $(+)$ was recorded. If the student emitted incompatible or behaviors other than the target behavior at any point during the interval, a minus (--) was scored. Permanent products were also used to record data for the completion of the activity schedule, correct responses to learn units (Greer \& McDonough, 1999), and the total of completed worksheets during pre and post conditioning probes.

\section{Design}

In Experiment 2, the conditioning procedure was implemented to condition worksheets as a reinforcer to increase the numbers of minutes the students engaged in independent work. The procedure was implemented in the same sequence for each participant. The steps were as follows: First, pre-conditioning probes were conducted. Next, 20 five-second training/test trial sessions, the stimulus-stimulus pairing procedure, were implemented until student met the criterion. Next, post-conditioning probes were conducted. If the student did not achieve the set objective during the probes, 10-second training/test intervals were implemented to pair a reinforcing stimulus with the target item. Then, post-conditioning probes were conducted. The study continued follow this sequence, increasing the training/test trial by $5 \mathrm{sec}$ until the target stimuli, worksheets, functioned as a reinforcer for the student to perform responses to the worksheets. Table 4 shows the sequence of the design for Experiment 2.

Table 4: Design Sequence

\begin{tabular}{|c|c|}
\hline Phase & Description \\
\hline 1. Pre-pairing probe- one session & $\begin{array}{l}15 \text { one min intervals }(15 \mathrm{~min}) \\
* \text { Whole interval recording for independently } \\
\text { working on worksheets } \\
\text { * Data were also collected, using permanent } \\
\text { product, on the number of correct responses on } \\
\text { worksheets and number of worksheets } \\
\text { completed. } \\
* \text { Consequences were not delivered }\end{array}$ \\
\hline $\begin{array}{l}\text { 2. Implementation of stimulus-stimulus pairing } \\
\text { procedure } \\
5 \text { sec intervals }\end{array}$ & $\begin{array}{l}\text { *Pair/test trial } \\
\text { * Pairing trial Reinforcement (praise) is } \\
\text { delivered } 2 \text { or } 3 \text { times during pairing session. } \\
* \text { Test trial Experimenter observed student for } \\
5 \text { sec. A (+) was recorded if student emitted } \\
\text { behavior for } 5 \mathrm{sec} \text {, and a (-) was recorded if } \\
\text { student did not. Consequences are not delivered } \\
\text { following the test trial } \\
* \text { Criteria: } 18 / 20 \text { test trials or better for two } \\
\text { consecutive sessions. Once students achieved } \\
\text { criteria the next phase was implemented. }\end{array}$ \\
\hline 3. Post-pairing probe: one session & * Same as baseline \\
\hline
\end{tabular}




\begin{tabular}{|l|l|}
\hline & \\
\hline $\begin{array}{l}\text { 4. Implementation of stimulus-stimulus pairing } \\
\text { procedure } \\
10 \mathrm{sec} \text { intervals }\end{array}$ & $*$ Same as pair/test trial described above \\
\hline $\begin{array}{l}\text { 5. Post-pairing probe: one session } \\
\text { procedure } \\
15 \text { sec intervals }\end{array}$ & $*$ Same as baseline \\
\hline 7. Post-pairing probe: one session & $*$ Same as pair/test trial described above \\
\hline
\end{tabular}

\section{Interobserver Agreement}

Interobserver agreement was measured for $11 \%$ of the conditioning sessions for worksheets, which resulted in $100 \%$ agreement. During the pre/post probes, interobserver agreement was also conducted for $20 \%$ of the probe sessions that resulted in $100 \%$ agreement.

\section{Interscorer agreement}

During probe sessions for conditioning worksheets, data were recorded for several dependent variables using permanent product. Interscorer agreement was conducted by a second independent scorer for the numbers of correct response to learn units, the completion of the activity schedule, and the total number of completed worksheets. To measure agreement on the completion of the activity schedule, a second independent observer recorded data with the experimenters conducting the probe session. For correct responses to learn units on worksheets, the experimenters first scored the responses on a separate data form. Then, an independent second observer scored the responses on the actual worksheets. Scores were then compared. To determine inter-scorer agreement for total number of worksheets completed, the experimenter counted the number of completed worksheets and recorded the number on a separate data form. A second independent observer then counted the number of completed worksheets and recorded the number on a separate data form. Interscorer agreement was calculated by dividing the number of agreements by the total number of agreements and disagreements and multiplying this number by $100 \%$. Interscorer agreement was calculated for $20 \%$ of the sessions for completion of activity schedule, which resulted in $100 \%$ agreement. Interscorer agreement was conducted for $66 \%$ of the probe sessions for the number of correct response to learn units emitted on worksheets. For this, a mean inter-scorer agreement of $94 \%$ was calculated. For completion of worksheets, $100 \%$ inter-scorer agreement was recorded.

\section{FIGURE 3, NEXT PAGE}

Results 


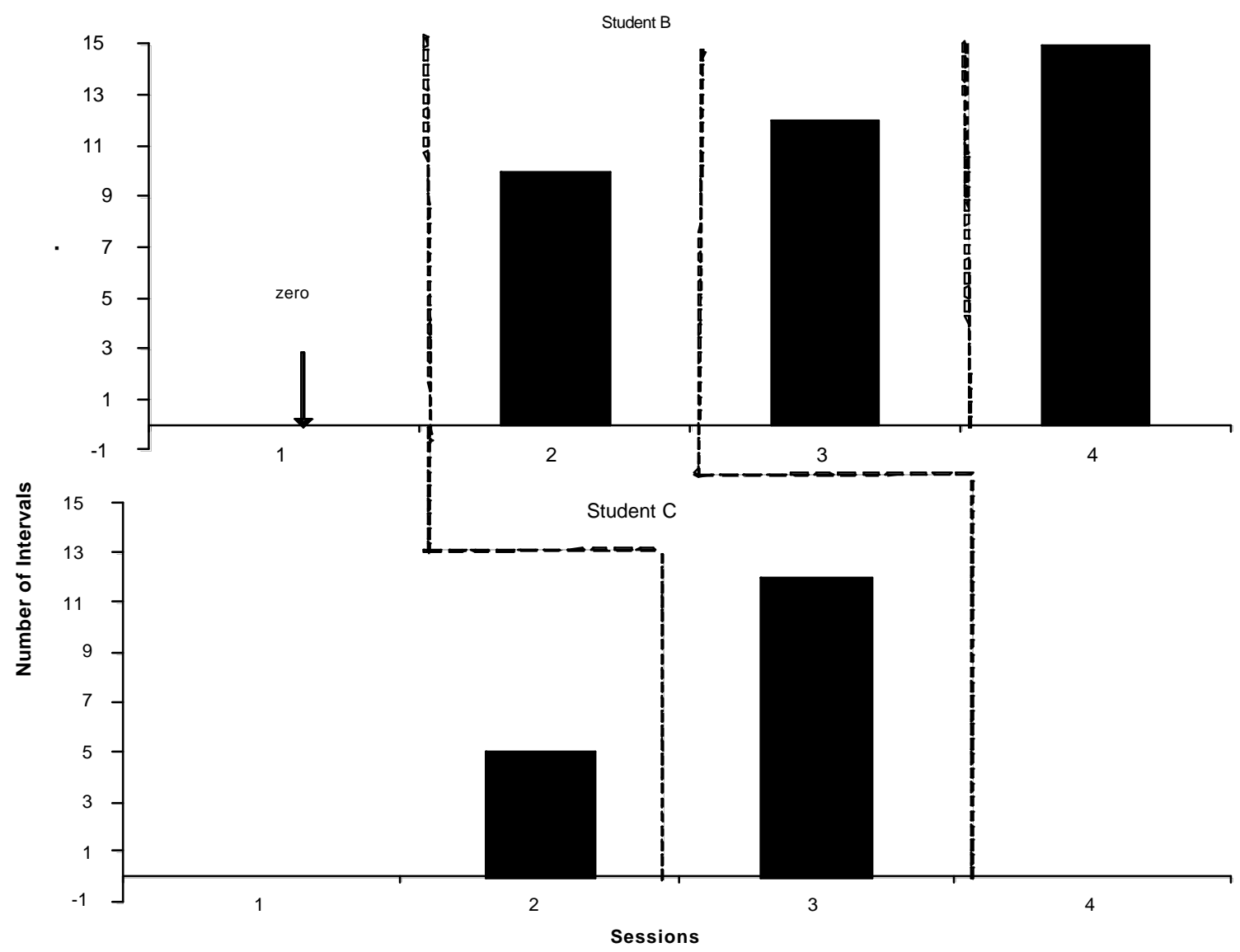

Figure 3. The figure shows the numbers of intervals, out of in which Students B and C appropriately and independently emitted seatwork activities in the form of worksheets during probe sessions. 


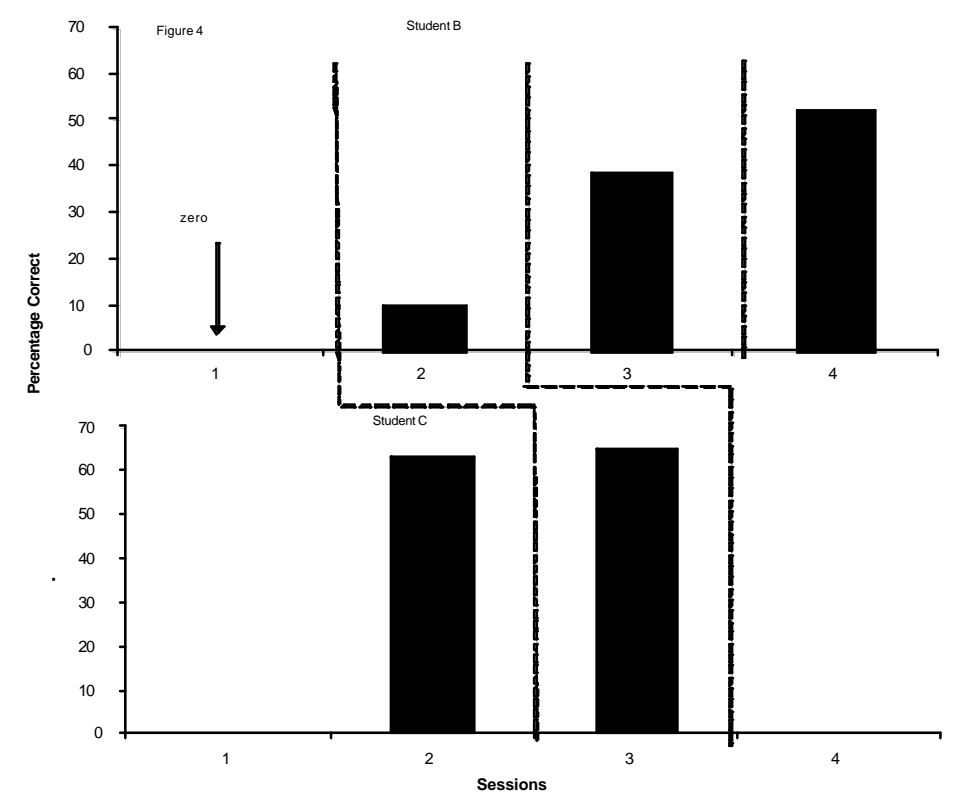

Figure 4. This graph shows the percentage of correct responses on worksheets emitted during each probe session for Students B and $\mathrm{C}$.

Table 5. Total Worksheets Completed

\begin{tabular}{|l|l|c|}
\hline Student & Probe Session & \# of Completed Worksheets \\
\hline Student B & Pre-pairing probe & 4 \\
\hline & $\begin{array}{l}\text { Post-pairing probe after } \\
\text { 5 sec pairing intervals }\end{array}$ & 6 \\
\hline & $\begin{array}{l}\text { Post-pairing probe after 10 sec } \\
\text { pairing intervals }\end{array}$ & 15 \\
\hline Student C & $\begin{array}{l}\text { Post-pairing probe after 15 sec } \\
\text { pairing intervals }\end{array}$ & 6 \\
\hline & $\begin{array}{l}\text { Pre-pairing probe } \\
\text { pairing intervals }\end{array}$ & 7 \\
\hline
\end{tabular}

During the pre-conditioning probe, Student B emitted 0 out of 15 intervals independently working on worksheets, and 0 out of 11 correct responses to learn units on worksheet ( $0 \%$ correct). The student did not complete any worksheets in the pre-baseline probe. A post-training probe was conducted after the student mastered the first phase of the stimulus-stimulus reinforcement 
pairing procedure, $5 \mathrm{sec}$. training/test intervals. During this probe, the student emitted 10 out of 15 intervals of independent work, 4 out of 40 correct responses to learn units (10\% correct), and the student completed 6 worksheets. The criterion required the student to independently work on worksheets for the entire $15 \mathrm{~min}$. without emitting any incompatible behaviors. Since the student did not achieve the criterion, a second phase of the stimulus-stimulus pairing procedure, $10 \mathrm{sec}$. training/test trials, was implemented. After the student met criterion on the second phase, a postprobe was conducted. Student B emitted 12 out of 15 intervals of independent work, 24 correct response out of 62 presented learn units (38.7\%), and the student completed 14 worksheets during the second post-conditioning probe. The third phase of the stimulus-stimulus pairing procedure was implemented. After the student met criterion for $15 \mathrm{sec}$. training/test, a third post-probe was conducted. In this probe, Student B worked independently on worksheets for 15 out of 15 intervals, emitted 67 correct responses to learn units out of 128 learn unit presentation (52.3\%), and completed 21 worksheets.

Similarly, results for Student C also showed a significant increase in independent work in the $15 \mathrm{~min}$. probe sessions post-stimulus-stimulus pairing. During pre-probes, Student $\mathrm{C}$ emitted 5 out 15 intervals of independent work, 33 correct responses to learn units out of 52 learn unit presentations (63.4\%), and completed 6 worksheets. Due to the data collected during the preprobe, a decision was made to implement the stimulus-stimulus reinforcement pairing procedure. After the student met the set criterion on the first phase, a post-probe was conducted, in which Student $\mathrm{C}$ emitted 12 out of the 15 intervals of independent work, 26 correct responses to learn units out of a possible $40(65 \%)$, and completed 7 worksheets.

Figure 5 shows the data collected during the stimulus-stimulus reinforcement pairing procedure for Student B and Figure 6 shows the data collected during the stimulus-stimulus pairing procedure for Student C. In the first phase, Student B met criterion after 5 sessions. Student B met criterion after 3 sessions in the second phase and third phase of conditioning. Student $\mathrm{C}$ met criterion after 7 sessions for the first phase, $5 \mathrm{sec}$. training/test trials.

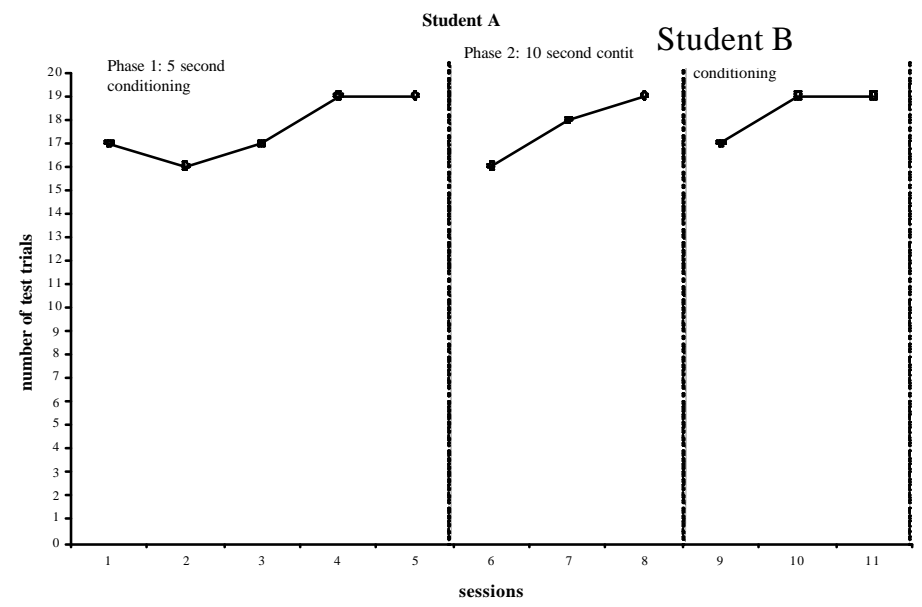

Figure 5. The figure shows the numbers of intervals out of a 20-test interval session in which Student B emitted appropriate behavior during the implementation of the stimulus-stimulus pairing procedure. 


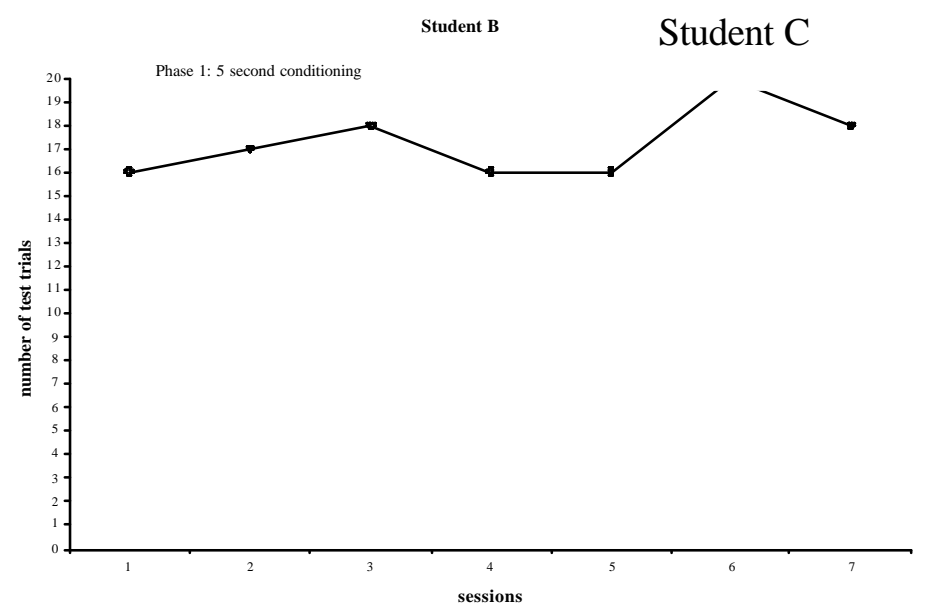

Figure 6. The figure shows the numbers of intervals out of a 20-test interval session in which Student $\mathrm{C}$ emitted appropriate behavior during the implementation of the stimulus-stimulus pairing procedure.

\section{Discussion}

Findings from Experiment 2 showed an increase in the number of intervals in which the student worked independently on worksheets, correct responses to seatwork activities, and an increase in the numbers of worksheets completed during probe session as a result of the stimulusstimulus pairing procedure. Similarly, Tsai and Greer (in press.) found an increase in accuracy of textual responses to textual stimuli after the stimuli acquired reinforcing properties. Results from Experiment II and Tsai and Greer suggested that the stimulus-stimulus pairing procedure was not only effective to decrease stereotypy, but was also effective to increase and accelerate learning.

\section{General Discussion}

Findings from this study suggested that the stimulus-stimulus pairing procedure was effective in increasing appropriate behaviors while decreasing stereotypy. Moreover, the findings from Experiment 2 showed the stimulus-stimulus pairing procedure to be effective to increase student learning and production. In Experiment 1, an increase was observed across appropriate behaviors following the completion of the pairing procedure, which also resulted in a decrease in stereotypy. Many students with autism emit stereotypical behaviors that may interfere with learning. Through the pairing procedure stimuli can be conditioned, teaching students to prefer previously neutral stimuli. As a result, students will select to emit useful behaviors to newly conditioned stimuli rather than stereotypy. Findings from Experiment 1 were consistent with previous research (Greer, Dorow, \& Hanser, 1973; Greer, Becker, Saxe, \& Mirabella, 1985; Nuzzolo-Gomez, Leonard, Ortiz, Rivera, \& Greer, 2002), in which a decrease in stereotypy was observed following the stimulus-stimulus pairing procedure. Furthermore, after the completion of the pairing procedure, students were more likely to emit more appropriate behaviors related to the stimuli that were conditioned.

Experiment 2 showed an increase in the numbers of intervals in which the students emitted independent seatwork and an increase in the production of correct responses to worksheets following the completion of the pairing procedure. Results from this study, along with the findings from Tsai and Greer were significant in that learning was accelerated as a result of the stimulus-stimulus pairing procedure. In the Tsai and Greer study, results showed 
accelerated learning of textual responses. In the present study, an increase in correct responses to worksheets resulted from the stimuli acquiring reinforcing qualities. Future studies should further explore the educational significance of this procedure and its effects across academic behaviors and learning.

Dinsmoor (1985) found that greater observing and attending to specific stimuli resulted in an increase in stimulus control for those stimuli. Results from both experiments presented herein show an increase in stimulus control following the pairing procedure. In Experiment 1, stimulus control was transferred to previously neutral stimuli, which resulted in students preferring to play with those stimuli. In Experiment 2, after stimulus control was transferred through observation, students not only selected to manipulate those stimuli, by increasing the numbers of intervals in which students emitted independent work, but they also increased their numbers of correct responses.

One limitation in Experiment 1 was baseline data on appropriate computer play were not at a stable state when the intervention was implemented. A decrease was observed for appropriate computer play during baseline with the exception of the final session of baseline. During this session, the student was laughing at the characters on the computer screen, and in previous sessions the student emitted stereotypy in the form of hand flapping. Laughing was recorded as an inappropriate behavior because it did fit the behavioral descriptions for stereotypy or passivity. The decision was made to intervene because the student was not manipulating the mouse or actively playing with the computer suggesting that the computer monitor screen was providing a source for stereotypy. After the pairing procedure, the student actively participated with the computer games and stories. However, data were not recorded on the actual participation responses. Future studies, which seek to investigate the effects of the pairing procedure on computer play, should also collect data on the behaviors related to playing and participating with computer software. Also, a decrease in appropriate play was observed in the second post-pairing probe session for looking at books. An increase in passivity was also observed, and instances of stereotypy remained at lower levels. Data suggested that the student did not prefer books at desired levels at the time of the probe. However, as a result of the pairing procedure, the student did not emit stereotypy.

One of the limitations of Experiment 2 was that only two students participated in the study. In future studies using multiple probe designs, at least three participants should be used. Another limitation of Experiment 2 was the limited post-stimulus-stimulus pairing probes conducted with Participant C. Due to the conclusion of the school year, implementation of the procedure was stopped. However, despite the limited sessions, increases were observed across all dependent variables and the findings are promising.

\section{References}

Dinsmoor, J. (1985). The role of observing and attention in establishing stimulus control. Journal of Experimental Analysis of Behavior, 43, 365-381.

Greer, R.D. (1996). Acting to save our schools (1984-1994). In Contemporary issues in behavior therapy: Improving the human condition. 137-157. New York: Plenum Press.

Greer, R.D. (2002). Designing teaching strategies: An applied behavior analysis systems approach. New York, NY: academic press. 
Greer, R.D. (2003). Reinforcement conditioning procedures for replacing stereotypy and enlarging students' reinforcement communities for books, toys, puzzles, games, television as conditioned reinforcers for observing and selection. Protocol for use in CABAS® schools.

Greer, R.D., Becker, J.B., Saxe, C.D., \& Mirabella, R.F. (1985). Conditioning histories and setting stimuli controlling engagement in stereotypy or toy play. Analysis and Intervention in Developmental Disabilities, 5, 269-284.

Greer, R. D., Dorow, L. G., Wachhaus, G., \& White, E. (1973). Adult approval and students' music selection behavior. Journal of Research in Music Education, $21,345-354$.

Greer, R.D., \& McCorkle, N.P. (2003). CABAS® International curriculum and inventory of repertoires for children from preschool to kindergarten. Yonkers, NY: CABAS® and the Fred S. Keller School.

Miguel, C. F., Carr, J. E., \& Michael, J. (2002). The effects of a stimulus-stimulus pairing procedure on the vocal behavior of children diagnosed with autism. The Analysis of Verbal Behavior, 18, 3-13.

Nuzzolo-Gomez, R., Leonard, M.A., Ortiz, E., Rivera, C.M., \& Greer, R.D. (2002). Teaching children with autism to prefer books or toys over stereotypy or passivity. Journal of Positive Behavior Interventions, 4, 80-87.

Sundberg, M. L., Michael, J., Partington, J. W., \& Sundberg, C.A. (1996). The role of automatic reinforcement in early language acquisition. The Analysis of Verbal Behavior, 13, 21-37.

Tsai, H., \& Greer, R. D. (2006). Conditioned observation of books and faster Acquisition of textual responding by preschool children. Journal of Early and Intensive Behavior Intervention, 3.1, 33-61.

Williams, G. \& Greer, R.D. (1993). A comparison of verbatbehavior and linguistic communication curricula for training developmentally delayed adolescents to acquire and maintain vocal speech. Behaviorology, 1, 31-46.

Yoon, S.Y. (1998). Effects of an adult's vocal sound paired with a reinforcing event on the subsequent acquisition of mand functions. . (Doctoral dissertation, 1998, Columbia University). Abstract from: UMI Proquest Digital Dissertations [on-line]. Dissertations Abstracts Item: AAT 9839031.

Yoon, S. \& Bennett, G. M. (2000). Effects of a stimulus-stimulus pairing procedure on conditioning vocal sounds as reinforcers. The Analysis of Verbal Behavior, 17, 75-88.

\section{Author's Notes}

We would like to acknowledge the data collection contributions made by Kristina Young and Shira Eisenberg. This research was done as part of the first author's PhD coursework under the supervision of the second author. 
Address Correspondence to:

Jennifer Longano

e-mail: jm12042@columbia.edu

Or

R. Douglas Greer

e-mail: dgreer3872@aol.com

Box 76

Teachers College

Columbia University

New York, NY 10027

\section{Advertising in the Journal of Early and Intensive Behavior Intervention}

Advertising is available in JEIBI. All advertising must be paid for in advance.

Make your check payable to Joseph Cautilli. The ad copy should be in our hands at least 3 weeks prior to publication. Copy should be in MS Word or Word Perfect, RTF

format and advertiser should include graphics or logos with ad copy.

The prices for advertising in one issue are as follows:

Page: $\$ 200.00$

1/4 Page: \$50.00 1/2 Page: \$100.00 vertical or horizontal Full

If you wish to run the same ad in both issues for the year, you are eligible for the following discount:

1/4 Pg.: \$40 - per issue

1/2 Pg.: \$75 - per issue -vertical or horizontal

Full Page: \$150.00-per issue.

For more information, or place an ad, contact Halina Dziewolska by phone at (215) 462-6737 or e-mail at: halinadz@ hotmail.com 


\title{
Examination of Eco-Behavioral Assessments Designed for Understanding Complex Behaviors and Environments
}

\author{
Kristie L. Pretti-Frontczak, Sarah M. McGough, Laura Vilardo and Melody Tankersley
}

\begin{abstract}
Second-generation intervention research requires methods for overcoming challenges to understanding complex learning ecologies and interactions of students. Eco-behavioral assessments (EBAs) are one solution to past intervention research challenges. EBAs record the effects of ecological variables in students' behavior and daily interactions. The utility of EBAs in second-generation research has increased substantially. Numerous EBAs now exist for use with all ages of learners and provide a valid, reliable, and cost effective method for intervention research. This paper examines 18 EBAs as well as software systems designed to support and enhance the use of EBAs. The examination serves as a comprehensive resource to better understand how EBAs can be used in answering complex questions about students' learning and for advancing second-generation research.

Keywords: Eco-behavioral assessment, Observational systems
\end{abstract}

The behaviors of students and the environments in which they participate are composed of highly complex events and interactions. Early research sought to answer broad questions regarding the efficacy of intervention efforts on global outcomes (e.g., Does early intervention lead to improved developmental outcomes? Does a particular instructional approach increase math productivity and accuracy?). In essence, the focus of first-generation intervention research in special education was on whether behavior or performance of students changed when an intervention was implemented. The input-output orientation of this collective body of knowledge has provided the field with a wealth of information regarding salient features of instruction (e.g., materials, engagement, and reinforcement) and its impact on student behavior and/or performance (Greenwood \& Carta, 1987; Greenwood, Terry, \& Walker, 1994). In fact, because of this research, we can identify empirically based practices that improve the outcomes of students with disabilities (e.g., Cook \& Schirmer, 2003; Forness, Kavale, Blum, \& Lloyd, 1997).

Although first-generation research has identified effective practices, widespread implementation of those practices continues to present challenges to the field (e.g., Carnine, 1997; Cook \& Schirmer, 2003; Espin \& Deno, 2000; Stone, 1998). The resulting research-to-practice gap has been the topic of discussion at federal, state, and local levels (e.g., No Child Left Behind Act) and reasons for it have been examined (e.g., Gersten \& Dimino, 2001; Greenwood 2001). One consistent theme from the literature on implementing research-based practices for students with disabilities is the necessity to adapt interventions to address the individual needs, teaching strengths, and available resources within various learning environments (e.g., Abbott, Walton, Tapia, \& Greenwood, 1999; Boudah, Logan, \& Greenwood, 2001; Gersten \& Dimino, 2001; Gersten, Vaughn, Deshler, \& Schiller, 1997). In other words, practitioners are not implementing particular practices because they do not always fit into their day-to-day routine and researchers are not consistently making it clear how the practices can be implemented.

Second-generation research has expanded its focus and aims to not only understand the outcomes related to intervention, but also to understand the features or elements of complex events and interactions as they occur within the context of the learning environment. By investigating the dynamic aspects and events surrounding interventions, the relationships among environmental variables and student behavior and performance can be assessed (Odom, Favazza, Brown, \& Horn, 2000). Such assessments can help 
determine which elements of particular interventions are most effective and how elements may affect different students under different circumstances (e.g., Guralnick, 1997; NAEYC and NAECS/SDE, 2003).

Learning environments are multifaceted, vibrant settings where various and interrelated features may affect students' opportunities to engage and learn. Understanding the ecology of environments and the implementation of interventions within these environments provides second-generation researchers the opportunity to examine the process as well as the outcomes of intervention (Odom et al., 2000). Therefore, in order to lessen the research-to-practice gap it is necessary to approach research through means that acknowledge how student behavior and performance is an interactive process and ways that the environments in which these interactions occur have the potential to create or hinder development is necessary.

Conducting second-generation intervention research, although critical, can present several challenges. In particular, the complexities of an intervention that must account for multiple effects, or more likely interactional effects of multiple variables on students and instructional agents (e.g., teachers, families, interventionist) (Greenwood, Peterson, \& Sideridis, 1994-95; LeLaurin, 1984) presents methodological, population, and cost challenges (see Pretti-Frontczak \& Bricker, 2004 for a brief review of the challenges of intervention research). Further, because second-generation intervention research places less emphasis on whether a behavior can be changed and more emphasis on examining the learning opportunities designed to enhance important outcomes (e.g., Greenwood, Carta, Kamps, \& ArreagaMayer, 1990; Pretti-Frontczak \& Bricker), methods are needed to examine both the processes and products related to intervention (Carta \& Greenwood, 1987). One potential method for overcoming the challenges presented by intervention research is the use of eco-behavioral assessments.

\section{Eco-behavioral Assessment}

According to Carta and Greenwood (1985) eco-behavioral assessments evolved from several bodies of inquiry including behavioral ecology, applied behavior analysis, and process-product research. Eco-behavioral assessments (EBAs) are designed to inform day-to-day practices, describe relationships between multiple variables, and lead to the creation of environments and learning opportunities that promote positive outcomes for all students (e.g., Carta, \& Greenwood, 1985; Kontos, Burchinal, Howes, Wisseh, \& Galinsky, 2002). EBAs allow for descriptions of classroom/home environments, examinations of key relationships and interactions, and comparisons between ecological and behavioral variables (e.g., Odom et al., 2000).

To date, EBAs have been used with many populations for a variety of purposes. For example, EBAs have been used to describe developmental outcomes for (a) young children who have been exposed prenatally to drugs or alcohol (e.g., Carta, McConnell, McEvoy, Greenwood, Atwater, Baggett, \& Williams, 1997); and (b) preschool children receiving services in inclusive programs (e.g., Brown, Odom, $\mathrm{Li}$, Zercher, 1999). EBAs have been used to examine interactions between teachers and students across different activities (e.g., Le Agar \& Shapiro, 1995), particularly in describing the frequency in which key instructional behaviors occur (e.g., Capt, 1994a; Kamps, Leonard, Greenwood, 1991; Rotholz, Kamps, Greenwood, 1989; Schwartz, Carta, \& Grant, 1996). EBAs have been used to describe problem behaviors within preschool environments (e.g., Bramlett \& Barnett, 1993), as well as to describe free play experiences of young children with disabilities in inclusive classroom (e.g., Kontos, Moore, \& Giorgetti, 1998). EBAs have been used to compare social interactions and environments for students with and without disabilities (e.g., Carta, Atwater, Schwartz, \& Miller, 1990; Carta, Greenwood, \& Robinson, 1987; Odom, Peterson, McConnell, \& Ostrosky, 1990), and to identify parent-child interaction factors related to resilience in young children who are at risk (e.g., Baggett, 2003; McConnell, Rush, McEvoy, Carta, Atwater, \& Williams, 2002). EBAs have been used to describe and compare classroom 
environments (e.g., Hendrickson 1992; Pretti-Frontczak \& Bricker, 2001) and the relationship between environmental variables and student behaviors (e.g., Rotholz et al., 1989). Moreover, EBAs have been used to compare and monitor the effectiveness of instructional strategies (e.g., Delquadri, Greenwood, Whorton, Carta, \& Hall, 1986; Kamps, Carta, Delquadri, Arreaga-Mayer, Terry, \& Greenwood 1989).

As evidenced by these examples, EBAs have been used to address complex questions regarding not only the effects of interventions, but also the relationship between events and behaviors, and to describe complex ecosystems in which students live and receive services-issues that second-generation research seek to address more fully. As eco-behavioral assessments have grown in number and use over the past several decades (e.g., Arreaga-Mayer, Carta, \& Tapia, 1994; Carta, \& Greenwood, 1985; McConnell, 2000; Morris \& Midgley, 1990), so too has the availability of instruments, tools, and systems for collecting data on ecological features of classroom environments.

\section{Purpose}

Given the broad utility of EBAs it is important that researchers and practitioners have a comprehensive and accessible resource of existing EBAs. A select number of sources have provided partial reviews of the EBA literature and existing instruments/systems (e.g., Thompson, Felce, \& Symons, 2000). Such reviews, however, have been narrow in scope. For example, a review by Odom and colleagues (2000) consisted only of EBAs used in early childhood programs serving young children with disabilities, and a review by Greenwood, Carta, and Dawson (2000), included only EBAs contained within a single software system. Thus, to date, a comprehensive and single source examining the broad range of EBAs has not been compiled. The purpose of this paper is therefore to provide such a resource for researchers and practitioners regarding EBAs in an effort to encourage and promote their use in advancing second-generation intervention research.

\section{Review of the Literature}

Our examination of EBAs began in 1996 and has evolved slowly, overcoming a number of hurdles. The first hurdle was deciding which observational systems should be considered or defined as eco-behavioral. To this end, we used a slightly modified definition of EBAs provided by Odom and colleagues (2000, p. 195) resulting in the inclusion of systems that are composed of direct observational techniques that provide information about structural (e.g., activities, group organization, group composition) and dynamic (e.g., teacher behavior, peer behavior) features of the classroom/home/childcare ecology as well as the behavior of students, adults, and/or peers in the classroom/home/childcare setting. The modified definition allowed us to include observational systems used in studies of homes and childcare ecologies as well as classrooms serving students from various ages.

A second hurdle was gaining access to work conducted using EBAs. Our search of the literature revealed that a number of projects using EBAs have disseminated findings narrowly, making access and review of the work difficult. For example, some research results and descriptions are disseminated in annual or technical reports (e.g., McConnell, McEvoy, Carta, Greenwood, Kaminski, Good, \& Shinn, 1998) at conferences (e.g., Brown \& Odom, 2000; Carta, Atwater, Greenwood, McEvoy, McConnell, \& Williams, 1996; Odom, McWilliam, Pretti-Frontczak, \& Carta, 2001; Walker \& Linebarger, 2002), and on web sites (e.g., Arreaga-Mayer, Greenwood, \& Utley, 2004). Fortunately, a substantial amount of work has been disseminated more broadly, in easily accessed arenas (i.e., through dissertations, articles, chapters) and it is this work that is at the heart of our examination.

Four steps were taken to conduct a comprehensive examination of the literature pertaining to EBAs. First, ERIC, PsychINFO, and the World Wide Web were searched using the terms ecobehavioral 
analysis, ecobehavioral assessment, and the single term, ecobehavioral. We also searched ERIC, PsychINFO, and the World Wide Web using the names of instruments we knew to meet our definition of an EBA (e.g., ESCAPE, CISSAR, ACCESS). Searches were conducted both by the instruments' acronym and entire title. We also searched by authors who had conducted work using EBAs (e.g., Judith Carta, Charles Greenwood, Samuel Odom). Finally, we contacted researchers/authors directly via e-mail to verify answers to many of our questions.

Despite our efforts to provide a comprehensive review of EBAs, it is beyond our capacity to locate and review all observational systems that may have been used in research or practice and that meet our definition of an EBA. We chose to include only EBAs with findings disseminated in doctoral dissertations, peer reviewed articles, or readily accessible book chapters. Note, however, there are a limited number of times when work presented at conferences or disseminated on the World Wide Web is cited as an example of how a particular EBA has been used.

Our examination resulted in the identification of 18 EBAs used in empirical research (including dissertations) for students with and without disabilities. The following contains a review of those 18 EBAs. The review also contains an overview of software systems associated with one or more of the 18 EBAs and a software system that serves as stand alone EBAs (i.e., the MOOSES).

Review of EBAs. The first part of the review contains EBAs that have been used with students with and without disabilities (ages birth through 18 years of age) and with college teacher candidates. The 18 EBAs include ACCESS, CASPER I, CASPER II, CEBAI, CIRCLE I, CIRCLE II, CISSAR, CISSARSPED, EASE, ESCAPE, ESCRIBE, MOOSES, MS-CISSAR, an unnamed observation system by Kontos and colleagues, an unnamed observation system by McCormick, Noonan, and Heck, PICCOLI, POC, and SCOPE. Table 1 contains a summary of the 18 EBAs and provides the main citation, age group for which the EBA was designed/used, examples of past uses, and examples of ecological and behavioral categories/variables contained in the EBA.

All of the EBAs examined, except for the MOOSES, the one used by Kontos and colleagues, the one used by McCormick and colleagues, the POC, and the SCOPE, use solely a momentary time sampling procedure. The MOOSES by design does not use a time sampling procedure, but is referred to as a continuous observation system. The EBA used in work by Kontos and colleagues uses a partial interval sampling procedure and McCormick et al. use a 10 second observe/10 second record procedure. The POC uses a combination of momentary time sampling for states and frequency recording for events, and the SCOPE uses both a momentary and partial interval sampling procedure. Two of the 18 EBAs were developed and/or used specifically with infants and toddlers (i.e., CASPER I and CIRCLE I), eight were developed and/or used with preschool/Kindergarten age children (i.e., ACCESS, CASPER II, EACE, ESCAPE, system by Kontos and colleagues, system by McCormick and colleagues, POC, and SCOPE), two were developed and/or used with children birth through five (i.e., CIRCLE II and PICCOLI), and five were developed and/or used with school age students (i.e., CEBAI, CISSAR, CISSAR-SPED, ESCRIBE, and MS-CISSAR). The MS-CISSAR has also been used with college level teacher candidates. Lastly, the MOOSES can be used with any age/population because the researcher/practitioner creates the variables of interest.

Table 1

Alphabetized List of 18 Eco-Behavioral Assessments

\begin{tabular}{lccl}
\hline Eco-behavioral assessment $^{\mathrm{a}}$ & Age Group & Purposes/Examples of Past Uses & $\begin{array}{c}\text { Examples of } \\
\text { Categories/Variables }\end{array}$ \\
\hline ACCESS & Preschool & To study ecological variables & activity, group size, \\
Atwater, J. B., Carta, J. J., \& & and & influencing a child's ability to & context, teacher \\
Schwartz, I. S. (1989). & Kindergarten & $\begin{array}{c}\text { transition from preschool to } \\
\text { focus, prompts, }\end{array}$
\end{tabular}




\begin{tabular}{l}
\hline Eco-behavioral assessment $^{\mathrm{a}}$ \\
\hline Assessment code/checklist for \\
the evaluation of survival \\
skills: ACCESS. Kansas City: \\
University of Kansas, Juniper \\
Gardens Children's Project
\end{tabular}

\section{CASPER I*}

Favazza, P. C., \& Odom, S L. (1993). CASPER: Code for active student participation and engagement revised. Training manual for observers. Nashville, TN: Vanderbilt University.

\section{CASPER II*}

Brown, W. H., Favazza, P. C., \& Odom, S. L. (1995). Code

for Active Student

Participation and

Engagement-Revised (CASPER II): A training manual for observers (Unpublished observer training manual). Nashville, TN: Vanderbilt University, Early Childhood Research Institute on Inclusion.

\section{CEBAI}

Scott, T. M., \& Sugai, G. (1994). The classroom ecobehavioral assessment instrument: A user-friendly method of assessing instructional/behavioral relationships in the classroom.

Diagnostique, 19(2-3), 59-77

\section{CIRCLE I*}

Baggett, K., Atwater, J., Peterson, P., Montagna, D., Creighton, M., Williams, R., \& Hou, S. (1993). CIRCLE-I: Code for Interactive
Infants and Toddlers

Preschool

To describe preschool children's experiences in inclusive early childhood programs (Brown \& Odom, 2000; Brown, Odom, Li, Zercher 1999).

To categorize and evaluate different types of inclusive programs (Odom, Brown, Schwartz, Zercher, \& Sandall, 2002).

To examine the peer relationships of young children with disabilities in inclusive settings (Odom, Zercher, Li, Marquart, Sandall, 2003).

School age To describe the development and possible application of an eco-behavioral assessment designed for classroom teachers (Scott \& Sugai, 1994).

Birth to six To examine parent -child months interactions during play (Baggett, 2003). active $\mathrm{v}$. passive teaching, student on task/off task.

Researchers and practitioners can be individualized by creating variables

caregiver ecology (e.g., activity, proximity), caregiver behavior (e.g., positioning, physical stimulation), infant 


\begin{tabular}{|c|c|c|c|}
\hline Eco-behavioral assessment $^{\mathrm{a}}$ & Age Group & Purposes/Examples of Past Uses & $\begin{array}{c}\text { Examples of } \\
\text { Categories/Variables }\end{array}$ \\
\hline $\begin{array}{l}\text { Recording of Caregiving and } \\
\text { Learning Environments - } \\
\text { Early Infancy. Kansas City, } \\
\text { KS: Early Childhood } \\
\text { Research Institute on } \\
\text { Substance Abuse, Juniper } \\
\text { Gardens Children's Project. } \\
\text { CIRCLE II* } \\
\text { Atwater, J., Montagna, D., } \\
\text { Creighton, M., Williams, R., } \\
\text { \& Hou, S. (1993). CIRCLE- } \\
\text { II: Code for Interactive } \\
\text { Recording of Caregiving and } \\
\text { Learning Environments - } \\
\text { Infancy through Early } \\
\text { Childhood. Kansas City, KS: } \\
\text { Early Childhood Research } \\
\text { Institute on Substance Abuse, } \\
\text { Juniper Gardens Children's } \\
\text { Project. }\end{array}$ & $\begin{array}{c}\text { Six to } 60 \\
\text { months }\end{array}$ & $\begin{array}{l}\text { To examine the relationship } \\
\text { between caregiver-child } \\
\text { interactions in the home and } \\
\text { children's expressive and } \\
\text { receptive vocabulary skills } \\
\text { (Rush, 1999). } \\
\text { To examine the variables that } \\
\text { influence expressive } \\
\text { language development for } \\
\text { Latino children from low- } \\
\text { income families (Cruzado- } \\
\text { Guerrero, 2001). } \\
\text { To describe child-caregiver } \\
\text { interactions that promote } \\
\text { development of young } \\
\text { children exposed prenatally to } \\
\text { drugs and alcohol } \\
\text { (McConnell, Rush, McEvoy, } \\
\text { Carta, Atwater, \& Williams, } \\
\text { 2002). }\end{array}$ & $\begin{array}{l}\text { caregiver ecology } \\
\text { (e.g., activity, } \\
\text { proximity), caregiver } \\
\text { behavior (e.g., vocal } \\
\text { response, physical } \\
\text { contact), child } \\
\text { behaviors (e.g., } \\
\text { social, partner, } \\
\text { engagement) }\end{array}$ \\
\hline $\begin{array}{l}\text { CISSAR* } \\
\text { Stanley, S. O., \& Greenwood, } \\
\text { C. R. (1981). CISSAR: Code } \\
\text { for instructional structure and } \\
\text { student academic response: } \\
\text { Observer's manual. Kansas } \\
\text { City, KS: University of } \\
\text { Kansas, Juniper Gardens } \\
\text { Children's Project. } \\
\text { Downsized version of } \\
\text { CISSAR } \\
\text { Greenwood, C. R., \& Carta, J. } \\
\text { J. (1987). An ecobehavioral } \\
\text { interaction analysis of } \\
\text { instruction within special } \\
\text { education. Focus on } \\
\text { Exceptional Children, 19(9), } \\
\text { 1-10 }\end{array}$ & School age & $\begin{array}{l}\text { To measure the quality of } \\
\text { various instructional } \\
\text { configurations by examining } \\
\text { student's academic behaviors } \\
\text { (e.g., Greenwood, Delquadri, } \\
\text { \& Hall, 1989; Walker, } \\
\text { Greenwood, Hart, \& Carta, } \\
\text { 1994). } \\
\text { To describe educational settings } \\
\text { and opportunities for } \\
\text { responding for students who } \\
\text { are at risk and/or in urban } \\
\text { settings (e.g., Cooper \& } \\
\text { Speece, 1990; Kamps et al., } \\
\text { 1989). } \\
\text { To measure the effects of } \\
\text { Classwide Peer tutoring for } \\
\text { increasing academic } \\
\text { achievement and opportunity } \\
\text { to respond (e.g., Ezell, } \\
\text { Kohler, \& Strain, 1994; }\end{array}$ & $\begin{array}{l}\text { activities, tasks, } \\
\text { structure, teacher } \\
\text { position, teacher } \\
\text { behaviors (no } \\
\text { response, approval), } \\
\text { student behaviors } \\
\text { (academic response, } \\
\text { task management, } \\
\text { competing behaviors) }\end{array}$ \\
\hline
\end{tabular}




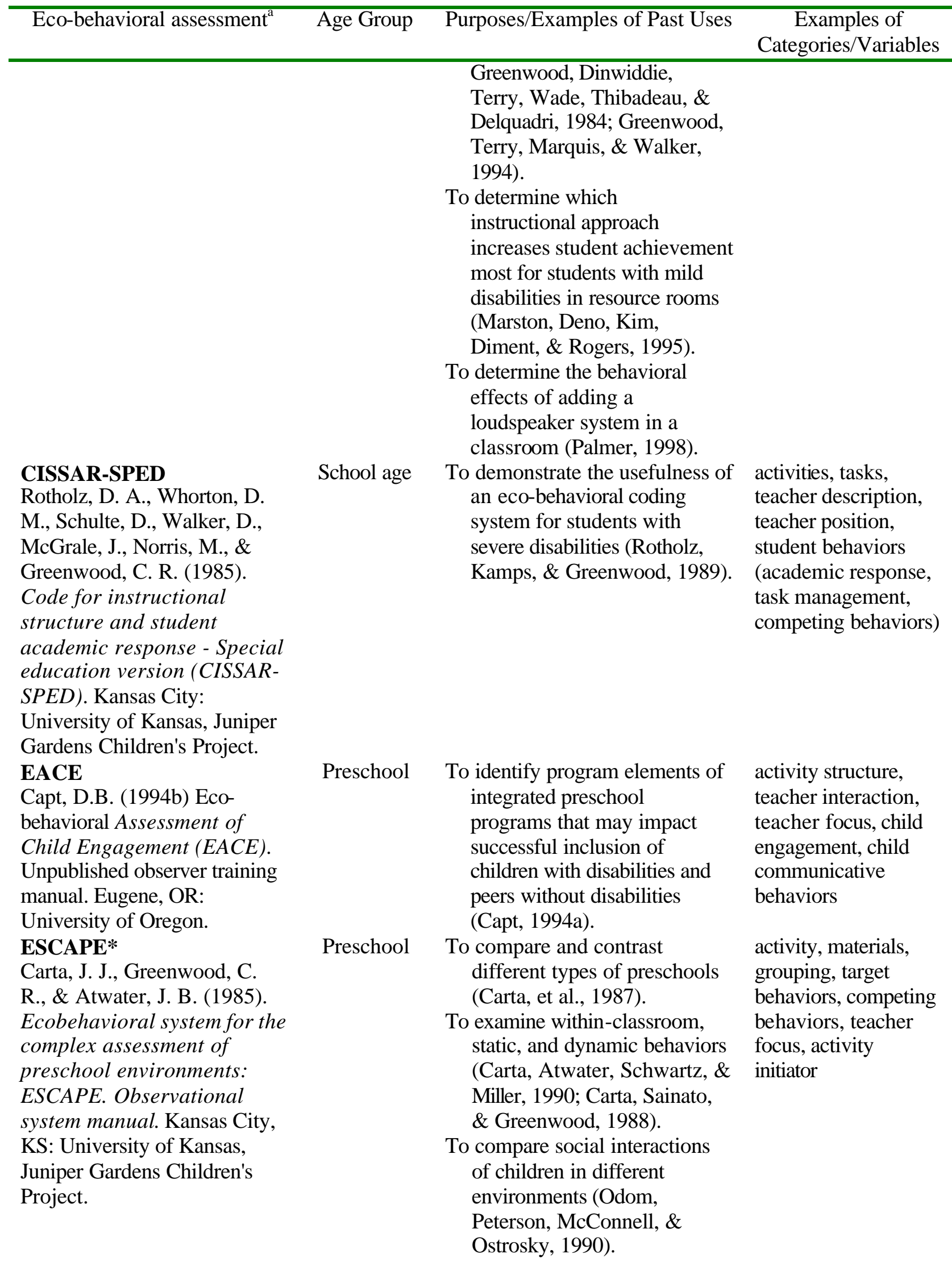




\begin{tabular}{|c|c|c|c|}
\hline 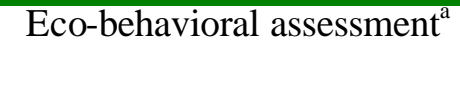 & Age Group & Purposes/Examples of Past Uses & $\begin{array}{c}\text { Examples of } \\
\text { Categories/Variables }\end{array}$ \\
\hline $\begin{array}{l}\text { ESCRIBE* } \\
\text { Arreaga-Mayer, C., \& Tapia, } \\
\text { Y. (1992). Ecobehavioral } \\
\text { system for the contextual } \\
\text { recording of interactional } \\
\text { bilingual environments: } \\
\text { Training manual. Kansas } \\
\text { City: University of Kansas, } \\
\text { Juniper Garden Children's } \\
\text { Project. }\end{array}$ & School age & $\begin{array}{l}\text { To compare teacher activity } \\
\text { schedules and children's } \\
\text { participation in those } \\
\text { activities (Ostrosky, } \\
\text { Skellenger, Odom, } \\
\text { McConnell, \& Peterson, } \\
\text { 1994). } \\
\text { To examine preschool and } \\
\text { kindergarten environments to } \\
\text { assist in successful } \\
\text { transitioning for children with } \\
\text { disabilities (Le Ager \& } \\
\text { Shapiro, 1995). } \\
\text { To determine the use of } \\
\text { recommended practices for } \\
\text { promoting language } \\
\text { development with preschool } \\
\text { age children (Schwartz, } \\
\text { Carta, \& Grant, 1996). } \\
\text { To examine variables affecting } \\
\text { peer interactions of children } \\
\text { with disabilities in inclusive } \\
\text { classrooms (Sontag, 1997). } \\
\text { To examine children's active } \\
\text { engagement in different } \\
\text { settings and to identify effects } \\
\text { of environmental and teacher } \\
\text { variables and global program } \\
\text { quality on active engagement } \\
\text { (Martin, 2004). } \\
\text { To examine the use of an EBA } \\
\text { with students who are } \\
\text { bilingual and to determine } \\
\text { which program aspects are } \\
\text { related to academic and } \\
\text { linguistic gains (Arreaga- } \\
\text { Mayer, Carta, \& Tapia, } \\
\text { 1994). } \\
\text { To examine teacher and student } \\
\text { behaviors and environmental } \\
\text { variables that impact students } \\
\text { with limited English } \\
\text { proficiency (e.g., Arreaga- } \\
\text { Mayer, Carta, \& Tapia, 1995; } \\
\text { Arreaga-Mayer, Utley, } \\
\text { Perdomo-Rivera, \& } \\
\text { Greenwood, 2003). } \\
\text { To evaluate two different }\end{array}$ & $\begin{array}{l}\text { setting, number of } \\
\text { adults, activity, } \\
\text { materials, teacher } \\
\text { definition, teacher } \\
\text { focus, language } \\
\text { initiating/responding }\end{array}$ \\
\hline
\end{tabular}




\begin{tabular}{cccc}
\hline Eco-behavioral assessment $^{\mathrm{a}}$ & Age Group & Purposes/Examples of Past Uses & $\begin{array}{c}\text { Examples of } \\
\text { Categories/Variables }\end{array}$ \\
\hline
\end{tabular}

MOOSES*

Tapp, J. T., Wehby, J. H., \& Ellis, D. N. (1995).

MOOSES: A multi-option observation system for experimental studies. Behavioral Research Methods, Instruments, \& Computers, 27, 25-31.

\section{MS-CISSAR*}

Carta, J. J., Greenwood, C. R., Schulte, D., ArreagaMayer, C., \& Terry, B. (1988). Code for instructional structure and student academic response: mainstream version (MSCISSAR). Kansas City, KS: Juniper Gardens Children's Project, Bureau of Child Research, University of Kansas. instructional settings for language-minority students (Arreaga-Mayer \& PerdomoRivera, 1996).

Any

To assess the effects of a schoolbased prevention program on the frequency and duration of specific antisocial behaviors and social interactions of Head Start children at risk for developing conduct disorders (Tankersley et al., 1996).

To examine how peer training used within social skills and cooperative learning groups impacted the participation of students with autism (Kamps et al., 2002).

To examine the effectiveness of a comprehensive reading intervention with children with emotional and behavioral disorders (Wehby et al., 2003).

To examine the effects of a combined teacher, parent and child training on young children with oppositional defiant disorder (WebsterStratton et al., 2004).

School age To examine classroom and College teacher candidates instruction for students with autism and developmental disabilities in two settings (Kamps, Leonard, \& Greenwood, 1991).

To analyze the effects of instructional variables on the engagement of students' with moderate/severe disabilities in the general education classroom (Logan, Bakeman, $\&$ Keefe, 1997).

To identify which instructional procedures were effective in teaching language arts skills to students with learning disabilities (Greenwood, generated by researcher or practitioner classroom task, physical arrangement, instructional grouping, teacher behaviors (focus, approval) student behaviors (academic, task management, competing responses) 


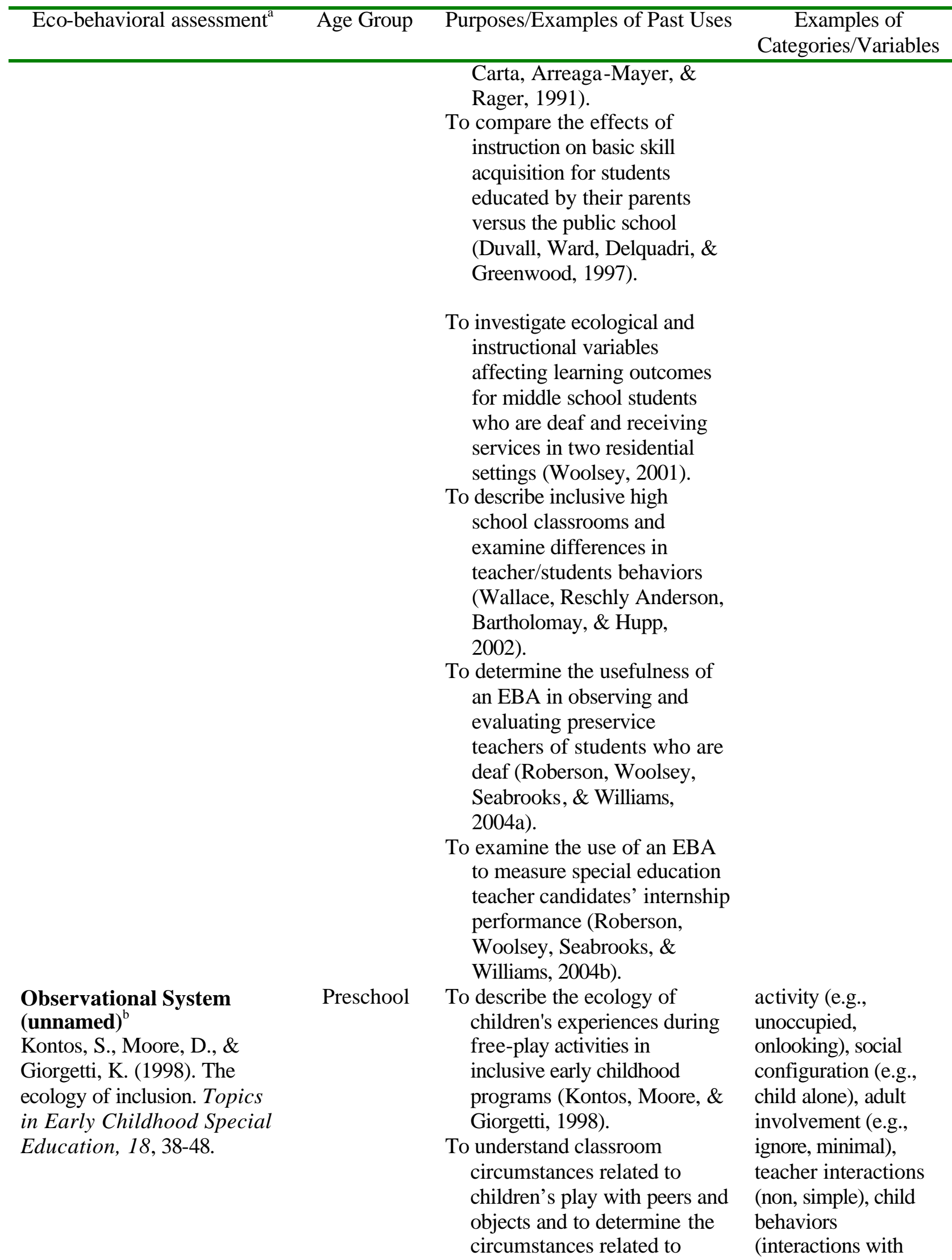




\begin{tabular}{|c|c|c|c|}
\hline 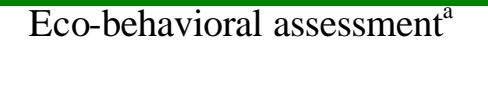 & Age Group & Purposes/Examples of Past Uses & $\begin{array}{c}\text { Examples of } \\
\text { Categories/Variables }\end{array}$ \\
\hline & & $\begin{array}{l}\text { complex interactions by } \\
\text { teachers with children } \\
\text { (Kontos \& Keyes, 1999). } \\
\text { To examine the variables that } \\
\text { co-exist with children's } \\
\text { complex interactions with } \\
\text { peers and objects (Kontos, } \\
\text { Burchinal, Howes, Wisseh, \& } \\
\text { Galinsky, 2002). }\end{array}$ & $\begin{array}{l}\text { peers, interactions } \\
\text { with objects) }\end{array}$ \\
\hline $\begin{array}{l}\text { Observational System } \\
\quad \text { (unnamed) } \\
\text { McCormick, L., Noonan, M. } \\
\text { J., \& Heck, R. (1998). } \\
\text { Variables affecting } \\
\text { engagement in inclusive } \\
\text { preschool classrooms. } \\
\text { Journal of Early Intervention, } \\
\text { 21, 160-176 }\end{array}$ & Preschool & $\begin{array}{l}\text { To explore the extent to which } \\
\text { disability status, type, and } \\
\text { nature of activities and } \\
\text { characteristics of co-teacher } \\
\text { teams are predictors of } \\
\text { engagement. (McCormick, } \\
\text { Noonan, \& Heck, 1998). }\end{array}$ & $\begin{array}{l}\text { engagement, type of } \\
\text { activity, structure of } \\
\text { activity, size of } \\
\text { group, teacher } \\
\text { behavior }\end{array}$ \\
\hline $\begin{array}{l}\text { PICCOLI* } \\
\text { Walker, D., Hart, B. \& } \\
\text { Reynolds L. H. (2003). } \\
\text { Parent Infant Caregiver Code } \\
\text { for the Observation of } \\
\text { Language Interactions } \\
\text { (PICCOLI) (Version 2.0). } \\
\text { Kansas City, KS: Juniper } \\
\text { Gardens Children's Project, } \\
\text { University of Kansas. }\end{array}$ & $\begin{array}{l}\text { Birth to } 40 \\
\text { months }\end{array}$ & $\begin{array}{l}\text { To document longitudinal } \\
\text { findings regarding language } \\
\text { development in homes and } \\
\text { child care settings (Atwater } \\
\text { \& Walker, 2004). } \\
\text { To describe early literacy } \\
\text { experiences of young } \\
\text { children in childcare settings } \\
\text { (Walker \& Linebarger, 2004). } \\
\text { To examine the quality of } \\
\text { childcare in promoting } \\
\text { language (Walker, } \\
\text { Linebarger, Bigelow, Small, } \\
\text { \& Harjusola-Webb, 2004). }\end{array}$ & $\begin{array}{l}\text { activity, materials, } \\
\text { proximity, vocal and } \\
\text { nonvocal social } \\
\text { behaviors, } \\
\text { engagement, } \\
\text { attention, competing } \\
\text { behaviors }\end{array}$ \\
\hline $\begin{array}{l}\text { POC } \\
\text { Bramlett, R. K., \& Barnett, D. } \\
\text { W. (1993). The development } \\
\text { of a direct observation code } \\
\text { for use in preschool settings. } \\
\text { School Psychology Review, } \\
\text { 22(1), 49-62. }\end{array}$ & Preschool & $\begin{array}{l}\text { To assist practitioners in } \\
\text { analyzing problem behaviors } \\
\text { within preschool } \\
\text { environments and to examine } \\
\text { usual behaviors through } \\
\text { observation and then link the } \\
\text { observations to designing } \\
\text { appropriate intervention } \\
\text { (Bramlett, \& Barnett, 1993). }\end{array}$ & $\begin{array}{l}\text { states, events, } \\
\text { disruptive behaviors }\end{array}$ \\
\hline $\begin{array}{l}\text { SCOPE } \\
\text { Pretti-Frontczak, K., \& Capt, } \\
\text { D.B. (1997). System for } \\
\text { Classroom Observations and } \\
\text { Program Evaluation } \\
\text { (SCOPE). Observational } \\
\text { system manual. Kent, Ohio: }\end{array}$ & Preschool & $\begin{array}{l}\text { To describe how often, when, } \\
\text { and how preschool teachers } \\
\text { provided embedded learning } \\
\text { opportunities (Pretti- } \\
\text { Frontczak \& Bricker, 2001). }\end{array}$ & $\begin{array}{l}\text { scheduled activity, } \\
\text { materials, grouping, } \\
\text { teacher embedding, } \\
\text { child behavior } \\
\text { related to targeted } \\
\text { skills }\end{array}$ \\
\hline
\end{tabular}




\begin{tabular}{|c|c|c|}
\hline Eco-behavioral assessment $^{\mathrm{a}}$ & Purposes/Examples of Past Uses & $\begin{array}{c}\text { Examples of } \\
\text { Categories/Variables }\end{array}$ \\
\hline Kent State University. & & \\
\hline
\end{tabular}

All 18 EBAs examined contain ecological and behavioral variables. Many of the ecological variables allow for descriptions of daily activities (e.g., free play, circle, snack, academic content area tasks, gross motor). Many of the EBAs also contain variables describing the number of students involved in a particular activity (e.g., target child was engaged in solitary play, small group, large group) and the composition of students (e.g., number of students with identified disabilities). Each of the EBAs examined include variables that described the proximity/position of key adults in the environments (teachers, caregivers, other service providers) and allow for descriptions of their behaviors (e.g., level of engagement, type of verbal responses, approval, ignoring). Not only were adult behaviors variables of interest, but the EBAs examined also contain a wide variety of student behaviors including level of engagement, interaction with objects, affective states, academic responses, competing behaviors, and communicative behaviors. Because each of the EBAs examined provide for assessment of student behavior as well as environmental and instructional variables, they allow for measuring the process of intervention as well as the outcome. As illustrated in Table 1, the range of purposes, age groups, and variables of interest span an array of research interests.

Table 1 is designed to facilitate a match between future research endeavors and the use of EBAs. In other words, to provide a summary of the primary purposes for which a particular EBA can be used, appropriate populations, and a sampling of existing variables. When selecting an EBA, however, cost, training needs, and flexibility of codes should also be considered. Other than the MOOSES, the EBAs reviewed in Table 1 come with preset variables and operational definitions, potentially limiting their use to a wide variety of types of inquiry. Many of the EBAs also do not have documented psychometric properties, or only report very basic information such as interobserver agreement with the exception of the CISSAR that has documented interobserver agreement, test-re-test reliability, stability, concurrent validity, and treatment validity reports.

EBAs and technological advances. A clear trend related to EBAs is the use or reliance on technology for collecting, storing, and analyzing data. This trend is enhancing the utility and availability of EBAs to researchers and practitioners (Thompson et al., 2000). Specifically, software systems for collecting data regarding ecological and behavioral variables, training observers, calculating interobserver agreement, managing data, and analyzing data are being developed and used (see Kahng \& Iwata, 2000 for an additional review of computer systems designed for collecting realtime observational data). For example, EBASS is a software system that supports three EBAs, the CISSAR, MS-CISSAR and ESCAPE. A number of other software systems have been developed in tandem with the paper-pencil versions of the EBAs to aide in data collection, management, and analysis (e.g., ESCRIBE, PICCOLI). Table 1 provides a notation (indicated by an asterisk beside its name) of which EBAs are supported by a software system. The following is a brief description of four primary EBA software systems.

First, the Ecobehavioral Assessment Systems Software (EBASS) allows for data collection, observer training, inter-observer agreement, data management, and data analysis for the CISSAR, MSCISSAR and ESCAPE (Greenwood, Carta, \& Dawson, 2000; Greenwood, Carta, Kamps, \& Delquadri, 1997). EBASS runs using Microsoft Windows, DOS, or Macintosh operating systems if PC emulation software is used. More information regarding EBASS can be found online at Juniper Gardens Children's Project (http://www.jgcp.ku.edu/EBASS/ebass_descrp.htm). Second, the Ecobehavioral System for the 
Contextual Recording of Interactional Bilingual Environments (ESCRIBE) uses a similar system to EBASS that runs using DOS-based software and Microsoft Windows, or Macintosh operating systems if PC emulation software is used (Arrega-Mayer \& Hou, 1992) and is also available through The Juniper Gardens Children's Project (http://www.jgcp.ku.edu). Third, the Interval Manager (INTMAN) is a software system designed for behavioral research using time sampled observational data (Tapp, Ticha, Eryzer, Gustafson, Gunnar, \& Symons, 2004). Data are collected on Pocket PC or hand held computers running on Windows CE of Windows Mobile 2003. Data analysis is conducted on a computer with Microsoft Windows 98 or higher. Odom and colleagues (2002) used INTMAN with both the CASPER I and CASPER II. For more information contact Jon Tapp at Vanderbilt Kennedy Center (http://www.getintman.com). Lastly, the Parent Infant Caregiver Code of Language Interaction (PICCOLI) allows for simultaneous recording of environmental and interactional variables related to the language opportunities provided to infants and young children (Reynolds \& Walker, 2003). Data analysis software allows for graphic displays of frequencies, percent occurrences, conditional probabilities, and inter-observer reliability. PICCOLI runs on Microsoft Widows based notebook computers and wireless microphones for documenting child and caregiver language samples.

One software system has been created to serve as stand alone EBAs (e.g., MOOSES). In other words, rather than supporting an EBA that originated as a paper-pencil observational tool, MOOSES was created to allow researchers and practitioners to derive their own codes/variables and then collect and analyze the data directly using hand held devises and laptop computers (Tapp, Wehby, \& Ellis, 1995). The MOOSES software system allows for data collection, inter-observer agreement, multi-group analysis, and sequential analysis. Data are collected directly into MOOSES using a Windows based computer or laptop, Windows CE handheld, or Pocket PC using minimoose data collector (Tapp, 2004), or data codes using ProcoderDV - a data collection shell (Tapp, 2003). For more information on ProcoderDV visit http://www.procoderdv.com at Vanderbilt Kennedy Center. For more information or a free demo of MOOSES visit http://getmooses.com at Vanderbilt Kennedy Center. The MOOSES has been used in a wide variety of research studies (e.g., Kamps et al., 2002; Tankersley, Kamps, Mancina, \& Wiedinger, 1996; Webster-Stratton, Reid, \& Hammond, 2004; Wehby, Falk, Barton-Arwood, Lane, \& Cooley, 2003).

\section{Summary}

As evidenced by our examination, numerous EBAs exist and can be used to address a host of second-generation intervention research questions. In particular, EBAs have been used to examine the effects and success of inclusive programs, determine the effects of various instructional strategies/programs, and measure the effects of student disability on classroom interactions. Further, EBAs have been used effectively across age ranges (infants through preservice college students) and with students with a wide range of abilities. Despite the various uses, it is clear that EBAs share common features such as an appreciation of the influence or impact of the learning and social ecology, the utility in examining complex interactions, and the reliance on time sampling procedures.

A clear trend toward the use of technology to assist in the collection, management, and analysis of observational data was also evidenced by our examination of EBAs. The software systems described provide examples of how technology is allowing researchers and practitioners to address complex questions with greater ease. Indeed, computer technology provides the means for collecting data on many important process and outcome variables concurrently and supports the analysis of the resulting data sets making descriptive as well as experimental research more obtainable.

This examination serves as a comprehensive resource for researchers and practitioners interested in EBAs. Specifically, the examination (a) identifies the utility of various EBAs, (b) allows for comparisons regarding which EBA is more applicable for a given set of questions or circumstances, and (c) demonstrates how software systems may aid in analyzing and interpreting complex datasets 
concerning environmental and behavioral interactions. Lastly, and perhaps more importantly in the current age of accountability, this examination illustrates how EBAs have been used to provide programs and schools with "scientifically based research" that provides more contextual information than outcomes data alone. In other words, EBAs provide a valid, reliable, and cost effective method for overcoming many of the challenges presented by intervention research and meting requirements such as those identified in the No Child Left Behind Act. As second-generation research aims to understand features or elements of interventions and contexts in which they are implemented, EBAs provide a valuable option for researchers and practitioners.

\section{References}

Abbott, M., Walton, C., Tapia, Y., \& Greenwood, C. R. (1999). Research to practice: A "blueprint" for closing the gap in local schools. Exceptional Children, 65, 339-352.

Arreaga-Mayer, C., \& Tapia, Y. (1992). Ecobehavioral system for the contextual recording of interactional bilingual environments: Training manual. Kansas City: University of Kansas, Juniper Garden Children's.

Arreaga-Mayer, C., Carta, J. J., \& Tapia, Y. (1994). Ecobehavioral assessment of bilingual special education settings: The opportunity to respond. In R. Gardner III, D. M. Sainato, J. O. Cooper, T. E. Heron, W. L. Howard, J. E. Eshelman, \& T. A. Grossi (Eds.), Behavior analysis in education: Focus on measurably superior instruction (pp. 225-239). Pacific Grove, CA: Brooks/Cole.

Arreaga-Mayer, C., Carta, J. J., \& Tapia, Y. (1995). Ecobehavioral assessment: A new methodology for evaluating instruction for exceptional culturally and linguistically diverse students. In S. B. Garcia (Ed.), Addressing cultural and linguistic diversity in special education: Issues and trends (pp. 10-29). Reston, VA: Division for Culturally and Linguistically Diverse Exceptional Learner Council for Exceptional Children.

Arreaga-Mayer, C., Greenwood, C. R., \& Utley, C. (2004). Promoting literacy through ecobehavioral assessment and classwide peer tutoring for racial/ethnic limited-English proficient minority students with disabilities. Juniper Gardens Children's Project. Retrieved July 13, 2004 from http://www.jgcp.ku.edu/Grants/relepmsd.htm

Arrega-Mayer, C., \& Hou, L. S. (1992). Data analysis programs for the ecobehavioral system for the contextual recording of interactional bilingual environments (ESCRIBE): Training manual. Kansas City: University of Kansas, Juniper Gardens Children's Project.

Arreaga-Mayer, C. \& Perdomo-Rivera, C. (1996). Ecobehavioral analysis of instruction for at-risk language minority students. Elementary School Journal. 96, 245-258.

Arreaga-Mayer, C., Utley, C.A., Perdomo-Rivera, C., \& Greenwood, C.R. (2003). Ecobehavioral assessment of instructional contexts in bilingual special education programs for English language learners at risk for developmental disabilities. Focus on Autism and Other Developmental Studies, $18(1), 28-40$.

Atwater, J. B., Carta, J. J., \& Schwartz, I. S. (1989). Assessment code/checklist for the evaluation of survival skills: ACCESS. Kansas City: University of Kansas, Juniper Gardens Children's Project.

Atwater, J., Montagna, D., Creighton, M., Williams, R., \& Hou, S. (1993). CIRCLE-II: Code for interactive recording of caregiving and learning environments - Infancy through early childhood. 
Kansas City, KS: Early Childhood Research Institute on Substance Abuse, Juniper Gardens Children's Project.

Atwater, J., \& Walker, D. (2004). Natural environments for learning to talk: Findings from a decade of longitudinal research in children's homes and child care settings. Manuscript in preparation. Kansas City, KS: University of Kansas, Juniper Gardens Children's Project.

Baggett, K. M. (2003). Parent responsiveness and infant engagement during play: An ecobehavioral approach to assessment of parent-infant interaction. Dissertation Abstracts International, 63(10), 4939.

Baggett, K., Atwater, J., Peterson, P., Montagna, D., Creighton, M., Williams, R., \& Hou, S. (1993). CIRCLE-I: Code for interactive recording of caregiving and learning environments - Early infancy. Kansas City, KS: Early Childhood Research Institute on Substance Abuse, Juniper Gardens Children's Project.

Bramlett, R. K., \& Barnett, D. W. (1993). The development of a direct observation code for use in preschool settings. School Psychology Review, 22(1), 49-62.

Brown, W. H., Favazza, P. C., \& Odom, S. L. (1995). Code for active student participation and engagement-revised (CASPER II): A training manual for observers (Unpublished observer training manual). Nashville, TN: Vanderbilt University, Early Childhood Research Institute on Inclusion.

Brown, W. H., \& Odom, S. L. (2000, June-July). Reflections on community-based inclusive preschools. Paper presented at the Head Start National Research Conference, Washington, D.C.

Brown, W. H., Odom, S. L., Li, S., \& Zercher, C. (1999). Ecobehavioral assessment in early childhood programs: A portrait of preschool inclusion. Journal of Special Education, 3(33), 138-153.

Capt, D. B. (1994a). Integrated preschool classrooms: An eco-behavioral description. Dissertation Abstracts International, 56(02), 511. (UMI No. 9519661).

Capt, D. B. (1994b) Eco-behavioral assessment of child engagement (EACE). Unpublished observer training manual. Eugene, OR: University of Oregon.

Carnine, D. (1997). Bridging the research-to-practice gap. Exceptional Children, 63, 513-521.

Carta, J. J., Atwater, J., Greenwood, C. R., McEvoy, M. A., McConnell, S. R., \& Williams, R. (1996, February). Preliminary outcomes of the Early Childhood Research Institute on Substance Abuse. In C. Greenwood. Examining early caregiving environmental risks in predicting early school outcomes. Symposium presented at the Pacific Coast Research Conference, LaJolla, CA.

Carta, J. J., Atwater, J. B., Schwartz, I. S., \& Miller, P. A. (1990). Applications of ecobehavioral analysis to the study of transitions across early education. Education and Treatment of Children, 13(4), 298-315.

Carta, J. J., \& Greenwood, C.R. (1985). Eco-behavioral assessment: A methodology for expanding the evaluation of early intervention programs. Topics in Early Childhood Special Education, 5, 88104. 
Carta, J. J., \& Greenwood, C. (1987). Process-product analysis: An approach for studying critical variables in early intervention. Journal of Early Intervention, 12(1), 85-91.

Carta, J. J., Greenwood, C. R., \& Atwater, J. B. (1985). Ecobehavioral system for the complex assessment of preschool environments: ESCAPE. Observational system manual. Kansas City, KS: University of Kansas, Juniper Gardens Children's Project.

Carta, J. J., Greenwood, C. R., \& Robinson, S. L. (1987). Application of an eco-behavioral approach to the evaluation of early intervention programs. In R. Prinz (Ed.), Advances in the behavioral assessment of children and families. (Vol. 3, pp. 123-155). Greenwich, CT: JAI Press.

Carta, J. J., Greenwood, C. R., Schulte, D., Arreaga-Mayer, C., \& Terry, B. (1988). Code for instructional structure and student academic response: mainstream version (MS-CISSAR). Kansas City, KS: University of Kansas, Juniper Gardens Children's Project, Bureau of Child Research.

Carta, J. J., McConnell, S. R., McEvoy, M. A., Greenwood, C. R., Atwater, J. B., Baggett, K., \& Williams, R. (1997). Developmental outcomes associated with "in utero" exposure to alcohol and other drugs. In M. R. Haack (Ed.), Drug dependent mothers and their children: Issues in public policy and public health (pp. 64-90). New York: Springer Publishing Co.

Carta, J. J., Sainato, D. M., \& Greenwood, C. R. (1988). Advances in the ecological assessment of classroom instruction for young children with handicaps. In S. L. Odom \& M. B. Karnes (Eds.), Early intervention for infants and young children with handicaps: An empirical base (pp. 217239). Baltimore: Brookes Publishing Company.

Cook, B. G., \& Schirmer, B. R. (2003). What is special about special education? Overview and analysis of the topical issue [special issue]. Journal of Special Education, 37, 200-205.

Cooper, D. H., \& Speece, D. L. (1990). Instructional correlates of students' academic responses: Comparisons between at-risk and control students. Early Education and Development, 1 (4), 279299.

Cruzado-Guerrero, J. R. (2001). Factors affecting bilingual language development in young children from low-income Latino families. Abstracts International, 62(06), 2009. (UMI No. 3018499).

Delquadri, J., Greenwood, C. R., Whorton, D., Carta, J. J., \& Hall, R. V. (1986). Classwide peer tutoring. Exceptional Children, 52(6), 535-542.

Duvall, S. F., Ward, D. L., Delquadri, J. C., \& Greenwood, C. R. (1997). An exploratory study of home school instructional environments and their effects on the basic skills of students with learning disabilities. Education and Treatment of Children, 20(2), 150-172.

Espin, C. A., \& Deno, S. L. (2000). Introduction to the special issue of Learning Disabilities Research \& Practice: Research to Practice: Views from researchers and practitioners. Learning Disabilities: Research \& Practice, 15, 67-68.

Ezell, H. K., Kohler, F. W., \& Strain, P. S. (1994). A program description and evaluation of academic peer tutoring for reading skills of children with special needs. Education and Treatment of Children, 17, 52-67. 
Favazza, P. C., \& Odom, S. L. (1993). CASPER: Code for active student participation and engagement revised. Training manual for observers. Nashville, TN: Vanderbilt University, John F. Kennedy Center for Research on Human Development.

Forness, S. R., Kavale, K. A., Blum, I. M., \& Lloyd, J. W. (1997). What works in special education and related services: Using meta-analysis to guide practice. Teaching Exceptional Children, 29(6), 49.

Gersten, R., \& Dimino, J. (2001). Realities of translating research into classroom practice. Learning Disabilities: Research \& Practice, 16, 120-130.

Greenwood, C. R. (2001). Introduction to the topical issue: Bridging the gap between research and practice in special education: Issues and implications for teacher preparation. Teacher Education and Special Education, 24, 273-275.

Greenwood, C. R., \& Carta, J. J. (1987). An ecobehavioral interaction analysis of instruction within special education. Focus on Exceptional Children, 19(9), 1-10.

Greenwood, C. R., Carta, J. J., Arreaga-Mayer, C., \& Rager, A. (1991). The Behavior Analyst Consulting Model: Identifying and validating naturally effective instructional procedures. Journal of Behavioral Education, 1(2), 165-191.

Greenwood, C. R., Carta, J. J., \& Dawson, H. (2000). Observational methods for educational settings. In T. Thompson, D. Felce, \& F. J. Symons (Eds.), Behavior observation: Technology and applications in developmental disabilities (pp. 229-252). Baltimore: Brookes Publishing Company.

Greenwood, C. R., Carta, J. J., Kamps, D., \& Arreaga-Mayer, C. (1990). Ecobehavioral Analysis of Classroom Instruction. In S. R. Schroeder (Ed.), Ecobehavioral analysis and developmental disabilities. New York: Springer-Verlag.

Greenwood, C. R., Carta, J. J., Kamps, D., \& Delquadri, J. (1997). Ecobehavioral Assessment Systems Software (EBASS Version 3.0): Practitioners manual. Kansas City, KS: The Juniper Gardens Children's Project, University of Kansas.

Greenwood, C. R., Delquadri, J. C., \& Hall, R. V. (1989). Longitudinal effects of classwide peer tutoring. Journal of Educational Psychology, 81, 371-383.

Greenwood, C. R., Dinwiddie, G., Terry, B., Wade, L., Stanley, S. O., Thibadeau, S., \& Delquadri, J. C. (1984). Teacher- versus peer-mediated instruction: An ecobehavioral analysis of achievement outcomes. Journal of Applied Behavior Analysis, 17, 521-538.

Greenwood, C.R., Peterson, P., \& Sideridis, G. (1994-95). Conceptual, methodological, and technological advances in classroom observational assessment. Diagnostique, 20, 73-99.

Greenwood, C. R., Terry, B., \& Walker, D. (1994). Confirming a performance-based instructional model. School Psychology Review, 23, 652-668.

Greenwood, C. R., Terry, B., Marquis, J., \& Walker, D. (1994). Confirming a performance-based instructional model. School Psychology Review, 23, 652-668. 
Guralnick, M. J. (Ed.) (1997). The effectiveness of early intervention. Baltimore: Paul H. Brookes Publishing Company.

Hendrickson, J. M. (1992). Assessing the student-instructional setting interface using an eco-behavioral observation system. Preventing School Failure, 36, 26-31.

Kahng, S., \& Iwata, B. A. (2000). Computer systems for collecting realtime observational data. In T. Thompson, D. Felce, \& F. J. Symons (Eds.), Behavior observation: Technology and applications in developmental disabilities (pp 35-42). Baltimore: Brookes Publishing Company.

Kamps, D. M., Carta, J. J., Delquadri, J., Arreaga-Mayer, C., Terry, B., \& Greenwood, C. R. (1989). School-based research and intervention. In C. R. Greenwood (Ed.), Special issue devoted to the Juniper Gardens Children's Project. Education and Treatment of Children, 12, 359-390.

Kamps, D. M., Leonard, B. R., \& Greenwood, C. R. (1991). Ecobehavioral assessment of students with autism and developmental disabilities. In R. J., Prinz (Ed.). Advances in Behavioral Assessment of Children and Families. (pp. 201-237). New York: Jessica Kingsley.

Kamps, D., Royer, J., Dugan, E., Kravits, T., Gonzalez-Lopex, A., Garcia, J., Carnazzo, K., Morrison, L., \& Garrison Kane, L. (2002). Peer training to facilitate social interaction for elementary students with Autism and their peers. Exceptional Children, 68(2), 173-187.

Kontos, S., Burchinal, M., Howes, C., Wisseh, S., \& Galinsky, E. (2002). An eco-behavioral approach to examining the contextual effects of early childhood classrooms. Early Childhood Research Quarterly, 17, 239-258.

Kontos, S., \& Keyes, L. (1999). An ecobehavioral analysis of early childhood classrooms. Early Childhood Research Quarterly, 14, 35-50.

Kontos, S., Moore, D., \& Giorgetti, K. (1998). The ecology of inclusion. Topics in Early Childhood Special Education, 18, 38-48.

Le Agar, C. L., \& Shapiro, E. (1995). Template matching as a strategy for assessment of an intervention for preschool children with disabilities. Topics in Early Childhood Special Education, 15, 187218.

LeLaurin K. (1984). Ecobehavioral considerations in developmental research: A review and suggested model of inquiry. Education and Treatment of Children, 7, 305-314.

Logan, K. R., Bakeman, R., \& Keefe, E. B. (1997). Effects of instructional variables on engaged behavior of students with disabilities in general education classrooms. Exceptional Children, 63, 481-498.

Marston D., Deno S. L., Kim D., Diment K., \& Rogers D. (1995). Comparison of reading intervention approaches for students with mild disabilities. Exceptional Children, 62, 20-37.

Martin, B. W. (2004). An ecological study of differences in engagement of preschoolers with disabilities concurrently enrolled in early childhood special education and community-based early childhood programs. Unpublished doctoral dissertation. University of Kansas. 
McConnell, S. R. (2000). Assessment in early intervention and early childhood special education:

Building on the past to project into our future. Topics in Early Childhood Special Education, 20, 43-48.

McConnell, S., McEvoy, M., Carta, J. J., Greenwood, C. R., Kaminski, R., Good, R. H., \& Shinn, M. (1998). Research and development of exploring solutions assessments for children between birth and age eight (Tech. Rep. No. 5). University of Minnesota: Early Childhood Research Institute on Measuring Growth and Development.

McConnell, S. R., Rush, K. L., McEvoy, M. A., Carta, J. J., Atwater, J., \& Williams, R. (2002). Descriptive and experimental analysis of child-caregiver interactions that promote development of young children exposed prenatally to drugs and alcohol. Journal of Behavioral Education, $11(3), 131-161$.

McCormick, L., Noonan, M. J., \& Heck, R. (1998). Variables affecting engagement in inclusive preschool classrooms. Journal of Early Intervention, 21, 160-176.

Morris, E. K., \& Midgley, B. D. (1990). Some Historical and Conceptual Foundations of Ecobehavioral Analysis. In S. R. Schroeder (Ed.), Ecobehavioral analysis and developmental disabilities. New York: Springer-Verlag.

NAEYC and NAECS/SDE (2003). Early Childhood Curriculum, Assessment, and Program Evaluation Building an Effective, Accountable System in Programs for Children Birth through Age 8. Retrieved January 27, 2004 from http://www.naeyc.org/resources/position_statements/CAPEexpand.pdf

Odom, S. L., Brown, W. H., Schwartz, I. S., Zercher, C., \& Sandall, S. R. (2002). Classroom ecology and child participation. In S. L. Odom (Ed.), Widening the circle: Including children with disabilities in preschool programs (pp. 25-45). New York: Teachers College Press.

Odom, S. L., Favazza, P. C., Brown, W. H., \& Horn, E. M. (2000). Approaches to understanding the ecology of early childhood environments for children with disabilities. In T. Thompson, D. Felce, \& F. J. Symons (Eds.), Behavior observation: Technology and applications in developmental disabilities (pp 193-214). Baltimore: Brookes Publishing Company.

Odom, S. L., Peterson, C., McConnell, S., \& Ostrosky, M. (1990). Ecobehavioral analysis of early education/specialized classroom settings and peer social interaction. Education and Treatment of Children, 13, 316-330.

Odom, S., McWilliam, R., Pretti-Frontczak, K., \& Carta, J. (2001, April). Observational assessment of early childhood education settings for children with and without disabilities: Classroom ecology and child behavior. Symposium conducted at the American Educational Research Association, Seattle, Washington.

Odom, S. L., Zercher, C., Li, S., Marquart, J., \& Sandall, S. (2003). Social acceptance and social rejection of young children with disabilities in inclusive classes. Unpublished manuscript. Indiana University.

Ostrosky, M. M., Skellenger, A. C., Odom, S. L., McConnell, S. R., \& Peterson, C. (1994). Teachers' schedules and actual time spent in activities in preschool special education classes. Journal of Early Intervention, 18, 25-33. 
Palmer, C. M. (1998). Quantification of the ecobehavioral impact of a sound field loudspeaker system in elementary classrooms. Journal of Speech, Language, and Hearing Research, 41, 819-833.

Pretti-Frontczak, K. L., \& Bricker, D. D. (2001). Use of the embedding strategy by early childhood education and early childhood special education teachers. Infant and Toddler Intervention: The Transdisciplinary Journal, 11(2), 111-128.

Pretti-Frontczak, K. L., \& Bricker, D. D. (2004). An Activity-based approach to early intervention (3d ed.). Baltimore, Brookes Publishing Company.

Pretti-Frontczak, K. L., \& Capt, D.B. (1997). System for Classroom Observations and Program Evaluation (SCOPE). Observational system manual. Kent, Ohio: Kent State University.

Reynolds, L. H., \& Walker, D. (2003). Parent Infant Caregiver Code for the Observation of Language Interactions (PICCOLI) Software and Technical Manual (Version 2.0). Kansas City, KS: University of Kansas, Juniper Gardens Children's Project.

Roberson, L., Woolsey, M. L., Seabrooks, J. \& Williams, G. (2004a). Data-driven assessment in the evaluation of teacher candidates during their internship experiences in deaf education. American Annals of the Deaf, 148 (5), 403-412.

Roberson, L., Woolsey, M. L., Seabrooks, J., \& Williams, G. (2004b). An ecobehavioral assessment of teacher candidates during their internship experiences. Teacher Education and Special Education, 72(3)

Rotholz, D. A., Kamps, D. M., Greenwood, C. R. (1989). Ecobehavioral assessment and analysis in special education settings for students with autism. Journal of Special Education, 23, 59-81.

Rotholz, D. A., Whorton, D. M., Schulte, D., Walker, D., McGrale, J., Norris, M., \& Greenwood, C. R. (1985). Code for instructional structure and student academic response - Special education version (CISSAR-SPED). Kansas City: University of Kansas, Juniper Gardens Children's Project.

Rush, K. L. (1999). Caregiver-child interactions and early literacy development of preschool children from low-income environments. Topics in Early Childhood Special Education, 19(1), 3-14.

Schwartz, I. S., Carta, J. J., \& Grant, S. (1996). Examining the use of recommended language intervention practices in early childhood special education classrooms. Topics in Early Childhood Special Education, 16, 251-272.

Scott, T. M., \& Sugai, G. (1994). The classroom ecobehavioral assessment instrument: A user-friendly method of assessing instructional/behavioral relationships in the classroom. Diagnostique, 19(23), 59-77.

Sontag, J. C. (1997). Contextual factors influencing the sociability of preschool children with disabilities in integrated and segregated classrooms. Exceptional Children, 63, 389-404.

Stanley, S. O., \& Greenwood, C. R. (1981). CISSAR: Code for instructional structure and student academic response: Observer's manual. Kansas City, KS: University of Kansas, Juniper Gardens Children's Project. 
Stone, C. A. (1998). Moving validated instructional practices into the classroom: Learning from examples about the rough road to success. Learning Disabilities: Research \& Practices, 13, 121-125.

Tankersley, M., Kamps, D., Mancina, K., \& Wiedinger, D. (1996). Social interventions for Head Start children with behavioral risks: Implementation and outcomes. Journal of Emotional and Behavioral Disorders, 4, 171-181.

Tapp, J. T. (2003). ProcoderDV [Computer software and manual]. Vanderbilt Kennedy Center. Retrieved from http://www.procoderdv.com

Tapp, J. T. (2004). Minimoose [Computer software and manual]. Vanderbilt Kennedy Center. Retrieved from http://www.getmooses.com

Tapp, J. T., Ticha, R., Kryzer, E., Gustafson, M., Gunnar, M. R., \& Symons, R. J. (2004). INTMAN: An observational software system for time sampling data. Vanderbilt Kennedy Center, Vanderbilt University. Manuscript in preparation.

Tapp, J. T., Wehby, J. H., \& Ellis, D. N. (1995). MOOSES: A multi-option observation system for experimental studies. Behavioral Research Methods, Instruments, \& Computers, 27, 25-31.

Thompson, T., Felce, D., \& Symons, F. (2000). Behavioral observation: Technology and applications in developmental disabilities. Baltimore: Brookes Publishing Company.

Walker, D., Greenwood, C., Hart, B., \& Carta, J. (1994). Predictions of school outcomes based on early language production and socioeconomic factors. Child Development, 65, 606-621.

Walker, D., Hart, B., \& Reynolds L. H. (2003). Parent Infant Computerized Code for the Observation of Language Interactions (PICCOLI) (Version 2.0). Kansas City, KS: University of Kansas, Juniper Gardens Children's Project.

Walker, D., \& Linebarger, D. M. (2002, March). Beacons of excellence in the promotion of communication: Project of national significance. In D. Walker (Chair), G. Harbin, S. Kontos, \& D. Linebarger, Identifying Elements of Quality Services within Inclusive Early Childhood Settings and the Impact on Child Outcomes. Panel presented at the Conference on Research Innovations in Early Intervention, San Diego, CA.

Walker, D., \& Linebarger, D. M. (2004). Early literacy experiences of infants and toddlers in child care. Kansas City, KS: University of Kansas, Juniper Gardens Children's Project. Manuscript submitted for publication.

Walker, D., Linebarger, D. M., Bigelow, K., Small, C., Harjusola-Webb, S., \& Kirk, S. M. (2004). The quality of child care related to the language-promoting experiences of infants and toddlers. Kansas City, KS: University of Kansas, Juniper Gardens Children's Project. Manuscript in preparation.

Wallace, T., Reschly Anderson, A., Bartholomay, T., \& Hupp, S. (2002). An ecobehavioral examination of high school classrooms that include students with disabilities. Exceptional Children, 68, 345359. 
Webster-Stratton, C., Reid, M. J., \& Hammond, M. (2004). Treating children with early-onset conduct problems: Intervention outcomes for parent, child, and teacher training. Journal of Clinical Child and Adolescent Psychology, 33(1), 105-124.

Wehby, J. H., Falk, K. B., Barton-Arwood, S., Lane, K. L., \& Cooley, C. (2003). The impact of comprehensive reading instruction on the academic and social behavior of students with emotional and behavioral disorders. Journal of Emotional and Behavioral Disorders, 11, 225238.

Woolsey, M. L., (2001). The use of ecobehavioral analysis to identify the critical behavioral variables in two types of residential classrooms for students who are deaf. Dissertation Abstracts International, 62(08), 2729.

Author Contact Information:

Kristie Pretti-Frontczak

405 White Hall

Kent State University

Kent, OH 44242

330-672-0597

330-672-2512

kprettif@kent.edu

\section{Kristie L. Pretti-Frontczak}

405 White Hall

Kent State University

Kent, OH 44242

330-672-0597

$330-672-2512$

\section{Laura Vilardo and Melody Tankersley}

405 White Hall

Kent State University

Kent, OH 44242

330-672-0597

$330-672-2512$

\section{Sarah M. McGough}

University of Illinois 


\title{
The Effects of Daily Intensive Tact Instruction on Preschool Students' Emission of Pure Tacts and Mands in Non-Instructional Setting
}

\author{
Nirvana Pistoljevic and R. Douglas Greer \\ Teachers College, Columbia University
}

\begin{abstract}
We tested the effects of an intensive tact instruction procedure on numbers of tacts emitted in non-instructional settings (NIS) using a multiple probe design across 3participants (3and 4-year old boys with autism). The dependent variable was tacts emitted in NIS before/after the mastery of sets of 5 different stimuli. The non-instructional settings included the toy area of the classroom, lunchtime, and the school hallway during transition. All probe sessions were conducted daily for a cumulative 15 minutes, 5 minutes in each NIS. Intensive instruction involved increasing the tact instructions to 100-tact learn units above the daily learn units students were receiving daily. The intervention increased vocal verbal operants (tacts and mands) emitted by the target students in NIS.
\end{abstract}

One of, if not the, strongest predictors of schools school success is language (Weikart, 1966). Children with native intellectual disabilities and children from impoverished backgrounds frequently lack functional verbal repertoires when they enter schools. Hart and Risley (1995) found that limited exposure to rich language experiences early one in life is a predictor of language deficits in children from low socioeconomic backgrounds. They found that children from low socioeconomic (SES) backgrounds added an average of "168 words in the 6 months from 30-36 months [while] the children in professional families added an average of 350 or twice as many" (Hart \& Risley, 1995, p. 164). From early on, these children develop language and expand their vocabulary at the much slower rate than their peers from the middle class families and over time this gap widens exponentially (Greenwood, Hart, Walker, \& Risely, 1994). Woods (1984) found that children with similar low SES backgrounds also emit fewer verbal interactions than their same-age peers from middle class families. When children with native disabilities lack certain verbal capabilities, they inadvertently have infrequent language experiences. Even when children with deficits in language experiences receive behavioral language interventions, their prior lack of language experiences call for the provision of intensive language learning instruction (Greer, Chavez-Brown, Nirgudkar, Stolfi, \& Rivera-Valdes, 2005; Greer \& Keohane, 2005; Greer, Stolfi, Chavez-Brown, \& Rivera-Valdes, 2005). For both types of children intensive language experiences are needed to compensate for deficits in experiences.

According to Woods, when the verbal antecedents from the parents were absent, children with native disabilities were usually silent, whereas typically developing children were more likely to have nonverbal antecedents. That is these children were less likely to emit "spontaneous" speech. It appears that typically developing children were more likely to respond to nonverbal antecedents or initiate verbal interactions-- that is they responded to the natural establishing operations that control this type of verbal functions. Skinner (1957) characterized these spontaneous verbal initiations as pure mand and pure tact verbal operants. While pure mands are important, building the tact repertoire is most critical to the expansion of verbal repertoires. One reason children with disabilities are often observed not to emit pure tacts apart from instructional setting is that the tact that they are taught is often under the partial antecedent of the verbalizations control of others; that is, impure rather than pure tacts are taught. One may teach the pure tact repertoire by avoiding verbal antecedents may and bringing the tact responses of the student under natural establishing operations. Indeed, Williams and Greer (1993) found that when the establishing operations for pure mands and tacts where incorporated in teaching tacts 
and verbal antecedents were avoided, their participants emitted more of what is typically characterized as spontaneous speech or the initiation of language interactions. These findings were replicated in Ross \& Greer (2003) and Tsiouri \& Greer (2003). Skinner (1957) characterized verbal behavior as behavior that is mediated by a listener, and he identified six primary verbal operants according to their function--echoics, mands, tacts, autoclitics, intraverbals, and textual responses. Tacts are defined as verbal operants emitted as responses to the nonverbal antecedents and are reinforced by generalized reinforcers (Skinner, 1957; Becker 1989; Greer, 2002; Greer \& Ross, in press). Tacts are also affected by deprivation of generalized reinforcers (Gewirtz \& Baer, 1958; Gewirtz, Baer, \& Roth, 1958; Tsiouri \& Greer, 2003). Tacts are under the control of the generalized reinforcers, and "pure tacts" are under the control of nonverbal antecedents (Weinrich, 1964; Greer, 2002; Ross \& Greer, 2003).

Correspondingly, mands are verbal operants emitted under state of deprivation and they specify their own reinforcer (Skinner, 1957; Becker, 1989; Greer, 2002; Greer \& Ross, in press). Pure mands like pure tacts also have nonverbal antecedents.

Some current evidence suggests that the tact repertoire is especially critical to verbal development and, as a result, deserves extensive attention of professionals who are concerned with advancing children's verbal development. Expansion of the tact repertoire appears, at presents, to be the foundation of subsequent verbal development stages associated with complex communication functions including naming (Greer, Stolfi, et al., 2005; Lowe, Horne, Harris, \& Randle, 2002), conversational units (Lodhi \& Greer, 1989) and reading (Greer \& Ross, in press).

The purpose of the present study was to test the effects of an intensive tact instruction on the frequency of pure tacts and mands emitted by students in non-instructional settings. The intensive tact protocol prescribed teachers to increase the numbers of pure tacts taught to students, while at the same time insuring that other instruction continued at the same level.

\section{Participants}

\section{Method}

Three 4-year old male students participated in this study and they were chosen because they emitted low numbers of pure tacts in non-instructional settings, including transition time, lunch, and free play. Table 1 contains a detailed description of each student. They all attended a preschool for children with and without developmental delays that provided a comprehensive behavior analytic approach to all instruction. All standardized tests, Vineland Adaptive Behavior Scales -Interview and Classroom Edition (1984), reported in Table 1 were done by the students' school districts, and therefore, the standardized test information provided varies across students. The students' actual repertoires were assessed maintained in inventory form using The CABAS® International Curriculum and Inventory of Repertoires For Children from Pre-School through Kindergarten (Greer \& McCorkle, 2003). This is a criterion referenced assessment tool that identifies and assess the repertoires needed from preschool through kindergarten and first grade.

Table 1.

Description of Participants

Participants

Age

$$
\begin{aligned}
& \text { Diagnosis/Level of } \\
& \text { Verbal Capability }
\end{aligned}
$$

A

3.6 -Autism

-Listener/Speaker Emergent Reader

\section{Standardized Test $\quad$ CABAS® Repertoires Scores}

-Vineland Adaptive Behavior Scales:

-Mands/Tacts with autoclitic frames Interview Ed.(1984)

-Socialization Domain: 67
-Following vocal verbal directions -Vocal and physical 


\begin{tabular}{|c|c|c|c|c|}
\hline & & & $\begin{array}{l}\text {-Communication } \\
\text { Domain: } 77\end{array}$ & $\begin{array}{l}\text { stereotypy } \\
\text {-Looking at books } \\
\text { appropriately } \\
\text {-Occasional assaultive } \\
\text { behaviors } \\
\text {-Textually responded } \\
\text { to } 200 \text { Dolch Words } \\
\text {-Matching and } \\
\text { Pointing repertoires }\end{array}$ \\
\hline B & 4.1 & $\begin{array}{l}\text {-Pervasive } \\
\text { Developmental } \\
\text { Disorder } \\
\text { - Listener/Speaker }\end{array}$ & $\begin{array}{l}\text {-Vineland Adaptive } \\
\text { Behavior Scales: } \\
\text { Classroom Ed.(1984) } \\
\text {-Socialization } \\
\text { Domain: } 71 \\
\text {-Communication } \\
\text { Domain: } 75 \\
\text {-Composite: } 73\end{array}$ & $\begin{array}{l}\text {-Mands/Tacts with } \\
\text { autoclitic frames } \\
\text {-Following vocal } \\
\text { verbal directions } \\
\text {-Vocal and physical } \\
\text { stereotypy } \\
\text {-Occasional assaultive } \\
\text { behaviors } \\
\text {-Matching and } \\
\text { Pointing repertoires }\end{array}$ \\
\hline $\mathrm{C}$ & 4.0 & $\begin{array}{l}\text {-Autism } \\
\text {-Listener/Speaker } \\
\text { Emergent Reader }\end{array}$ & $\begin{array}{l}\text {-Vineland Adaptive } \\
\text { Behavior Scales: } \\
\text { Classroom Ed.(1984) } \\
\text {-Socialization } \\
\text { Domain: } 68 \\
\text {-Communication } \\
\text { Domain: } 70\end{array}$ & $\begin{array}{l}\text {-Mands/Tacts with } \\
\text { autoclitic frames } \\
\text {-Following vocal } \\
\text { verbal directions } \\
\text {-Vocal and physical } \\
\text { stereotypy } \\
\text {-Looking at books } \\
\text { appropriately } \\
\text {-Matching and } \\
\text { Pointing repertoires }\end{array}$ \\
\hline
\end{tabular}

Setting

The study was conducted in a publicly funded privately-run preschool for children with and without developmental delays. The school employed a comprehensive behavior analytic approach to teaching, curriculum, and behavior management, and was located in a suburban area outside of a large metropolitan city. All three students attended a full day classroom with six students, one teacher and two teaching assistants. All long term and short term objectives for the students in the school were based on the CABAS® International Curriculum and Inventory of Repertoires for Children from Pre-School through Kindergarten (Greer \& McCorkle, 2003) and New York State K-1 Educational Standards.

During the probes for pure tacts and mands, data were collected in three non-instructional settings; the free play area of the classroom, at the lunch table during lunchtime, and in the hallways during the transition to and from the school buses. The free play area of the classroom (a $2 \times 3$ feet area) was located in the corner of the classroom, sectioned off by shelves holding books and toys. Lunch was taken at the large oval table at the center of the classroom. All the students sat at the table for 30 minutes during lunch. The classroom was located at the end of the 30 feet long hallway. The both sides of the hallway walls were decorated with bulletin boards, each being a different theme (i.e. holidays, weather and seasons, animals, each student individual pictures, 
letters, numbers, shapes). During the tact instruction, students set at the small table located in the classroom, facing the experimenter.

\section{Definition of Behavior: The Dependent Variable}

The dependent variable in this study was the numbers of pure tacts and mands emitted during the 5-minute probes across three non-instructional settings; 1) the transition from and to the school bus, 2) during lunch, and 3) in the free play area of the classroom. A tact was defined according to Skinner (1957) as a "verbal operant in which a response of given form is evoked by a particular object or event or property of an object or event, ..., [and] a response of that form is characteristically reinforced in a given verbal community" (p.82). In this study, we targeted "pure tacts" which were defined as vocal verbal operants that are under the control of nonverbal antecedents that were reinforced by generalized reinforcement (Greer, 2002). For example, a student in the study says "violin" in the presence of a toy violin or a picture of a violin, and reinforcement from a listener (i.e. "That's right, it's a violin") would comprise generalized reinforcement of the pure tact emitted. Some of the pure tacts emitted by the participants in this study were: "Hi Ms. P", "It's snowman", "Mike's sandwich", "Bus is here", "It's snow". Also we recorded the numbers of pure mands emitted during the 5-minute probes in the noninstructional settings. A mand was defined as "a verbal operant in which the response is reinforced by characteristic consequence,..., [and ] a mand 'specifies' its reinforcement" (Skinner, 1957, pp.35-36). For example, a student says "juice" and the delivery of the item (i.e. teacher giving the student juice) would comprise reinforcement or the mand emitted. Some of the mands emitted by the participants in this study were: "I want to read Shrek book", "Open please", "I want Bob the Builder please", "Want blocks please", "Banana please".

No impure tacts and mands were recorded. Impure tacts and mands defined as vocal verbal operants under verbal antecedents. For example, an impure tact would be tact of an item "violin" under the verbal antecedent "What is that?" while holding a picture of a violin. An example of the impure mand would be a vocal antecedent "Do you want juice" and an impure mand "Yes, I want juice please".

\section{Independent variable The Intensive Tact Procedure}

The independent variable in this study was the increased daily presentation of tacts; additional 100 tact learn units were delivered throughout the day. Students tact learn units throughout the day were increased without decreasing other types of learn units, and they were interspersed between learn units for other curricular programs. We used learn units (Albers \& Greer, 1991) to teach tact responses. "The learn unit includes an opportunity to respond, a student's response, the teacher's antecedent-consequence, and the student's antecedent-consequence. It is an interlocking three-term contingency between the teacher and the student, and it is an immediate outcome measure" (Greer, 1996, p.141). The teacher or experimenter presents an unambiguous antecedent while the student is attending, the student is provided with an opportunity to respond (in this case an intraverbal response opportunity of 3-secs.), followed by the appropriate consequence. Accurate learn unit consequences to a correct response are the immediate presentation of a generalized reinforcer known to reinforce accurate tact responding. Accurate learn unit consequences to incorrect student responses involves a correction procedure in which the student must repeat the accurate vocal tact provided as a correction for the student's incorrect or missing response and the corrected response is not reinforced.

We used four different sets of 3" x 5" pictures of stimuli to occasion tact responses to 2dimensional stimuli that were pictures of objects. Each set consisted of five categories with four target stimuli in each category. The categories were consistent throughout each set and across all participants. The five categories targeted were musical instruments, transportation, food, animals, 
and community helpers. For each of four target stimuli within the category (i.e. for an instrument category: piano, flute, violin, tuba), similar stimuli with irrelevant characteristics were used (i.e. for a tact of a piano, pictures used were: grand piano, upright piano, black piano, white piano, brown piano). Each set of stimuli is listed in Table 2.

Table 2.

Description of Tact Sets

\begin{tabular}{|c|c|c|c|c|}
\hline Categories & Set 1 & Set 2 & Set 3 & Set 4 \\
\hline Instruments & guitar & tuba & drums & triangle \\
\hline & harp & harmonica & violin & accordion \\
\hline & organ & flute & saxophone & clarinet \\
\hline & xylophone & cello & piano & trombone \\
\hline \multirow[t]{4}{*}{ Transportation } & bulldozer & sled & tractor & bicycle \\
\hline & Sail boat & tricycle & escalator & dump truck \\
\hline & motorcycle & crane & airplane & helicopter \\
\hline & forklift & ferry & train & speed boat \\
\hline Community & photographer & rower & painter & baseball player \\
\hline \multirow[t]{3}{*}{ Helpers } & taxi driver & stewardess & ballerina & fisherman \\
\hline & surgeon & basketball player & garbage man & lifeguard \\
\hline & crossing guard & referee & florist & scientist \\
\hline \multirow[t]{4}{*}{ Food } & cashews & sushi & pasta & bagel \\
\hline & asparagus & donut & beans & potatoes \\
\hline & watermelon & coffee & bacon & pie \\
\hline & cotton candy & salad & waffle & grapes \\
\hline \multirow[t]{4}{*}{ Animals } & crab & dragonfly & penguin & octopus \\
\hline & starfish & squirrel & ants & guinea pig \\
\hline & bumble bee & shark & lizard & turtle \\
\hline & mouse & alligator & fox & goat \\
\hline
\end{tabular}

During the tact intervention, which was mastery training of each set (4-stimuli for each of 5 categories), a correct response was defined as the student tacting the item in the picture presented. For example, when presented with a picture of a watermelon, a response was considered as correct if a student vocally emitted "watermelon" within 3 seconds of the presentation of the stimulus. Any other responses or no response within 3 seconds were recorded as incorrect responses and teacher represented the stimuli and provided a correction for the student. All of the sets were taught by presenting learn units. At the outset of instructions the experimenter showed the child a picture of the four stimuli, and for each of the stimuli, said the name of the stimulus and had the child echo the spoken word for the stimuli and then immediately transitioned to independent tact instruction. For example, prior to teaching Set 1 , tacts of animals, experimenter provided a single echoic presentation for each of the target stimuli (i.e. experimenter "crab", and students echoes "crab"). Subsequently the child received reinforcement or corrections for independent pure tact responses. Students' vocal point-to-point correspondence with the teacher's vocal model was achieved for the echoic trial before proceeding with tact response learn units.

Each day at least 20-learn units were run for each of the 5 categories in a particular set. The sets were rotated until the experimenter had presented 100 tact learn units for the stimuli. For example after teaching sessions for musical instruments, transportation, community helpers, and animals the child received 100 learn units. Once the student mastered a category, learn units were 
devoted only to the remaining categories not yet mastered; this one or more sets were repeated daily until mastered or until the child received the target 100 learn units.

Student A mastered 4sets of 20 stimuli across the 5 categories, Student B mastered 2-sets of 20 stimuli across the 5 categories, and Student $C$ mastered 1-set of 20 stimuli across the 5 categories.

\section{Data Collection}

During the initial probe, and following the mastery of each set, data were collected during 5-minute observation probes conducted across 3 different non-instructional settings; the school bus transition, the lunch table, and the play area of the classroom. We used event recording to record the numbers of tacts and mands emitted by the students during the probes. We counted each tact and mand emitted in the three non-instructional settings, by writing all the utterances students emitted during the designated time period. During the transitioning 5-minute probes, we started a timer as the student left the bus or the classroom, and made sure that the target students always walked in pairs with other students or in line. During the lunch 5-minute probes, we started the timer after the students finished eating their main course and were eating their deserts at the table while sitting with other students. All the free play area probes were conducted while at least one other student was in the area with the target student. We blocked the data for each 5minute non-instructional probe into one 15-minute session for the day.

During the training of each set, data were recorded as responses to learn units. A learn unit consists of at least one interlocking three term contingency (antecedent, response, consequence) for a student and two or more three term contingencies for a teacher and is has been shown to predict learning (Albers \& Greer, 1991; Greer, 1996; Greer, 2002; Greer \& Hogin-McDonough, 1999; Ingham \& Greer, 1992). The learn unit includes opportunity to respond, student's response, the teacher antecedent-consequence, and the student antecedent-consequence. The $\mathrm{Sd}$ for the teacher to present the Sd to a student is the student attending, so presentation of the Sd by the teacher (i.e. "sit still" or "holding up a picture of target stimuli") is teacher's response and an Sd for the student's response (i.e. sitting still or tacting an item in the picture "a car"). The behavior of the student is the consequence for the teacher's behavior and an $\mathrm{Sd}$ for the teacher to reinforce correct response ("good job, nic e sitting" or deliver a generalized reinforcer). In the case of incorrect response, the correction procedure involves the teacher or experimenter repeating the antecedent and modeling the correct response (i.e. "sit still" and model sitting still, or presenting a picture and tacting item in the picture "a car" for the student to echo), which is a consequence for the student. The learn unit is complete only when the student repeats/echoes the teachers correction as part of the correction procedure. The intraresponse time, time between the presentation of the stimulus and students response, was set at three seconds. Therefore, if the student did not emit the response within three seconds, experimenter provided a correction. We recorded a plus (+) on a data collection sheet when the student emitted a correct response to a learn unit, and a minus (-) was recorded if a student emitted an incorrect response or no response. Each intensive tact instructional session consisted of 20-learn units delivered per category; therefore five learn units were delivered per target stimuli in a single category. Criterion was defined as responding correctly with at least $90 \%$ accuracy across 2 consecutive sessions. After achieving criterion on one of the training sets, a new set of tacts was implemented. Students mastered a single set, all five categories, before they were taught the next set.

\section{Interobserver Agreement}

\section{Independent Variable and Fidelity of Treatment}


The experimenter obtained an interobserver agreement for 24 of the 136 sessions of tact training (18\%), with an independent observer in the school. The interobserver agreement was collected using the Teacher Performance Rate Accuracy Protocol (Ingham \& Greer, 1992) which assesses both the accuracy of the measurement of the students' responses and fidelity of the implementation of learn units. The data collectors were trained through observations by the supervisor and cooperative teacher. Across all three students, the mean interobserver agreement for learn unit accuracy for the tact training was $100 \%$ for all sets.

\section{Dependent Variable: Emission of Tacts in Non-Instructional Settings}

During the event recording in non-instructional settings, interobserver agreement was collected by an independent observer recording all of the "spontaneous" verbal operants emitted by the target student. Both the experimenter and an independent observer wrote down all the utterances emitted by the target students during the probes and initiated each with a capital " $T$ " if it was a pure tact, or with a capital " $\mathrm{M}$ " if it was a pure mand. Interobserver agreement was each observer recording the student's verbal operants and recording them as tacts or mands. The agreements between two observers were then divided by their word-by-word agreements plus disagreements and multiplied by $100 \%$ for a percentage for each session. The interobserver agreement for the student's pure tacts for all observations across all three students was $100 \%$.

\section{Design}

A delayed multiple probe design across participants (Horner \& Baer, 1978) was used to compare the number of verbal operants emitted before and after the mastery of each set of tacts in non-instructional settings. The sequence of the design was as follows: a) Three sessions of 15 minute probes of tacts and mands in non-instructional were conducted for each student in a between participant delayed fashion (the sum of 5-minite probes in three different noninstructional settings). After the baseline probe session, b) the students were taught sets of tacts to mastery (Student A mastered four sets, Student B mastered two sets, while Student C mastered only 1 set, due to time constraints). c) After each student mastered a single set (all five categories, four different stimuli each), another cumulative 15-minutes session was conducted. The probe sessions were pre and post-treatment tests of the effect of the intensive tact instruction on the children's emission of pure tacts and mands.

\section{Results}

Student A emitted a total of 20 tacts, and no mands (Figure 1) across 3-probe sessions (i.e., 8 in the first, 7 in the second, and 5 in the third). Following mastery of Set 1, Student A emitted a total of 23 tacts and 2 mands (Figure 1) in a single session. Following the mastery of Set 2 Student A emitted a total of 24 tacts and 4 mands in a single session (Figure 1). After the mastery of Set 3, Student A emitted 33 tacts and 1 mand in a single session (Figure 1). Following the mastery of Set 4, Student A emitted a total of 32 tacts and 1 mand (Figure 1) across all three probes. During the three baseline 15-minute probes, Student A emitted $.53, .47$, and .33 tacts per minute, while following the mastery of Sets 1,2 , 3, and 4, he emitted 1.53, 1.6, 2.2, and 2.13 tacts per minute (Table 4).

As shown in the Figure 1, Student B emitted a total of 4 tacts and 2 mands across three 15-minute probes conducted during the baseline. Following the mastery of Set 1, Student B emitted a total of 21 independent tacts and 5 mands in a single session (Figure 1). Following the mastery of Set 2, Student B emitted 17 tacts and 1 mand (Figure 1). As shown in the Table 4, the number of tacts 
Student B emitted per minute during the baseline probes was .13, 0, and .13, while following the mastery of Sets 1 and 2, he emitted 1.4 and 1.13 tacts per minute respectively.

Across all baseline probes, Student $\mathrm{C}$ emitted a total of 4 tacts and 4 mands (Figure 1). Following the mastery of Set 1 , Student $\mathrm{C}$ emitted a total of 19 tacts, and no mands, across in a single session (Figure 1). As shown in the Table 4, Student C emitted .2, 0, and .07 tacts per minute during the baseline probes and 1.27 tacts per minute following the mastery of Set 1 .

During the tact instruction, Student A's learn units to criteria for Sets 1, 2, 3, and 4, were 56, 80, 48, and 64 (Table 3). For Student B, the learn units to criteria for Sets 1, and 2 were 116 and 80, while for Student C, learn units to criterion on Set 1 were 80.4 (Table 3). All the data collected during instructional sessions for all three students are represented in the Figures 1, 2, and 3.

Table 3.

Learn Units to Criteria for Each Set Mastered

Students

Student A

Set 1

56

Set 2

116

80

Set 3

48

Set 4

Student B

80.4

64

Table 4.

Number of Tacts Emitted per Minute during 15-Minute Sessions

Probes

Baseline Probe 1

Baseline Probe 2

Baseline Probe 3

Post Set 1

Post Set 2

Post Set 3

Post Set 4
Student A

.53

.47

.33

1.53

1.6

2.2

2.13
Student B

.13

0

.13

1.4

1.13

Table 5.

Number of Tacts Emitted in Non-Instructional Settings

Students

Student A

Student B

Student C

Transition
3
2
1
4
11
18
6
1
0
0
12
6
3
0
0

Lunch
2
5
1
6
3
2
9
1
0
0
2
5
0
0
1

Student C

.2

0

.07

1.27

\begin{tabular}{rllll}
\multirow{5}{*}{ Student B } & Post Set 4 & 6 & 9 & 17 \\
& Baseline & 1 & 1 & 0 \\
& Baseline & 0 & 0 & 0 \\
& Baseline & 0 & 0 & 3 \\
& Post Set 1 & 12 & 2 & 7 \\
Student C & Post Set 2 & 6 & 5 & 6 \\
& Baseline & 3 & 0 & 0 \\
& Baseline & 0 & 0 & 0 \\
& Baseline & 0 & 1 &
\end{tabular}



Post Set 1
8
7
4

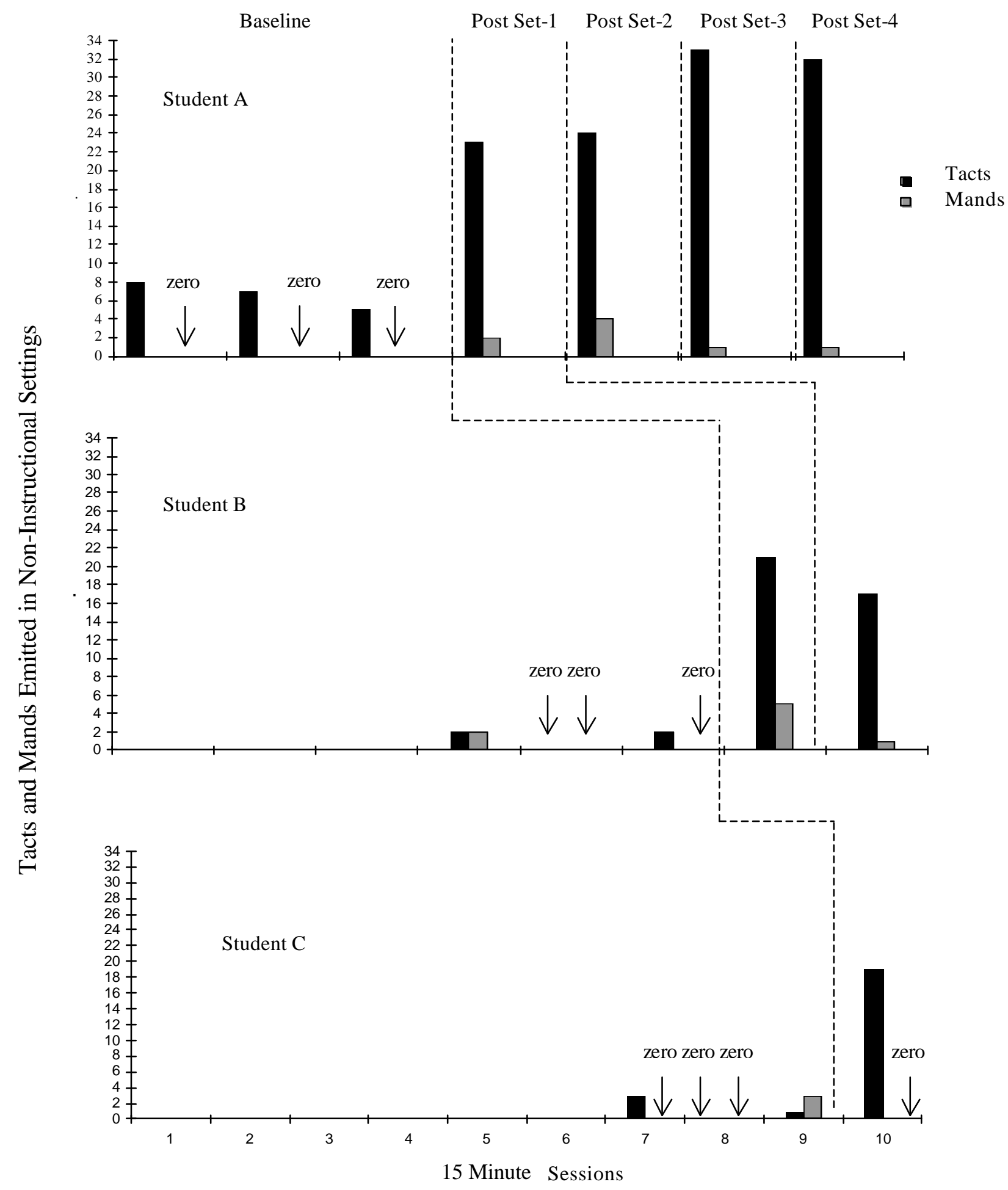


Figure 1. This figure shows Student A, B, and C's numbers of tacts and mands emitted across all non-instructional settings, blocked into 15 -minute session. 


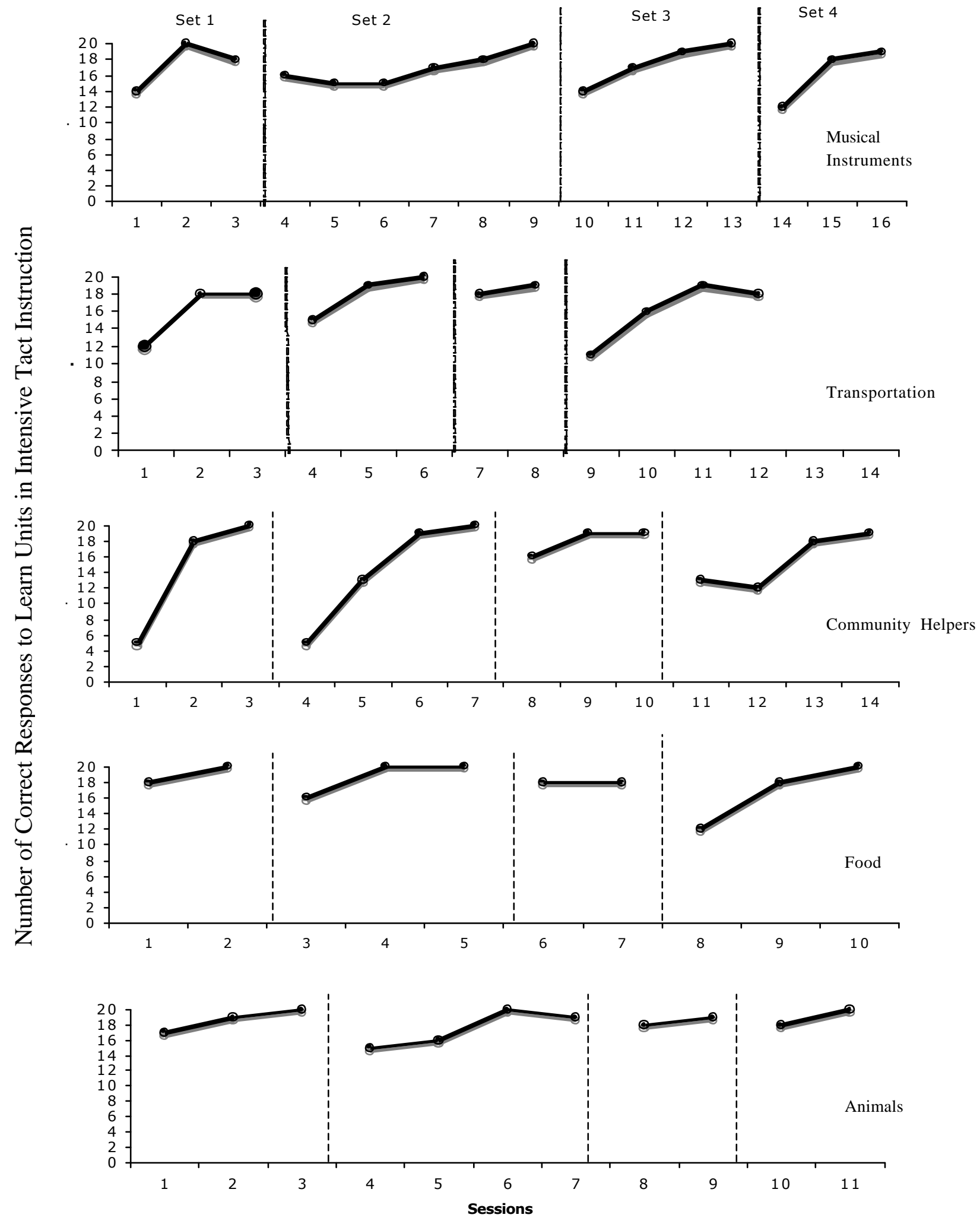

Figure 2. This figure (above) represents Student A's instructional sessions for each category of each set of tacts mastered. 


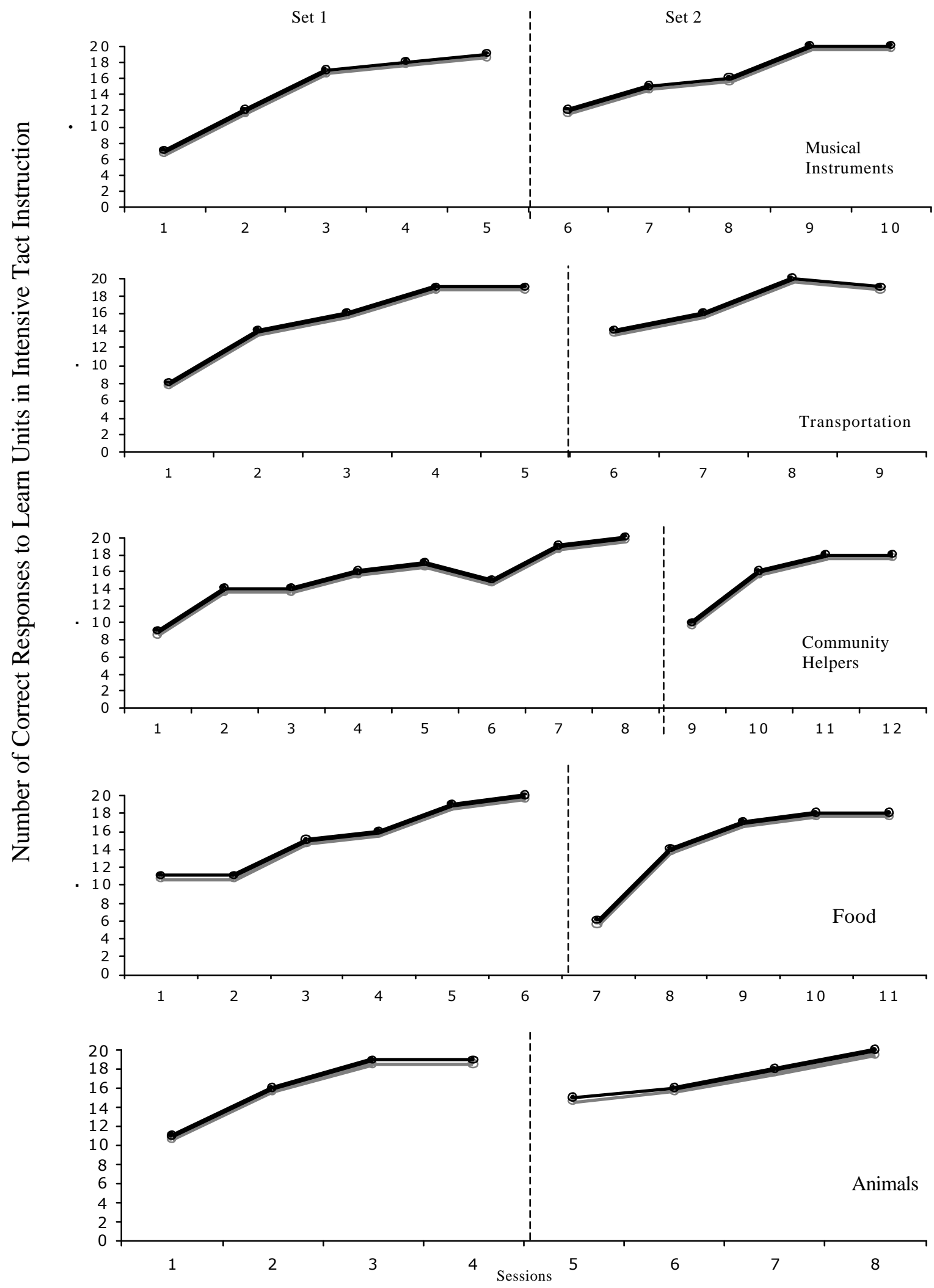

Figure 3. This figure (above) represents Student B's instructional sessions for each category of two sets of tacts mastered. 


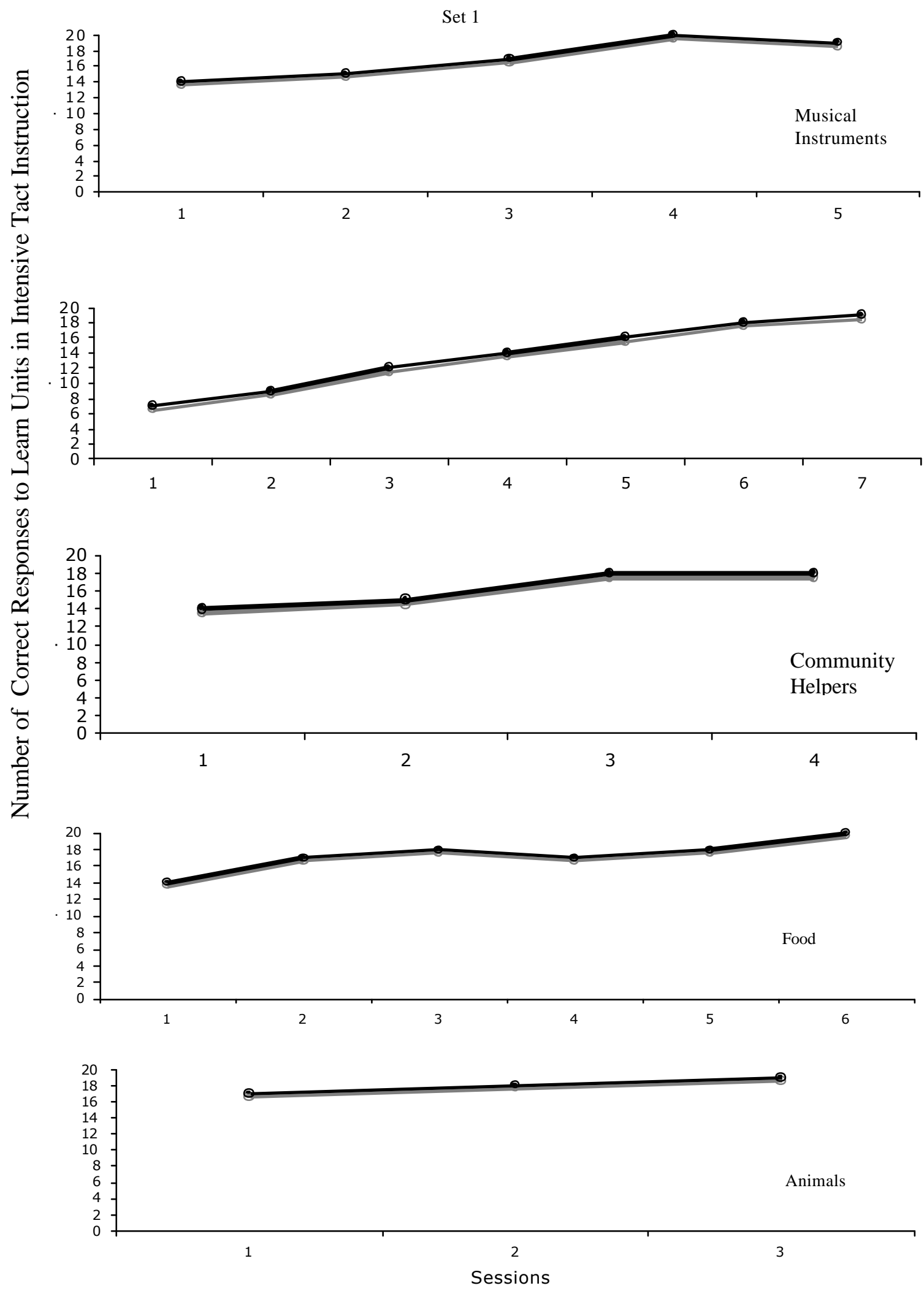

Figure 4. This figure (above) represents Student C's instructional sessions for each category of two sets of tacts mastered. 
Figures 2, 3, and 4 show the acquisition of the criterion for mastering the different set for each of the children. Table 3 shows the numbers of learn units required to match each of the sets for each student. These data show no clear trend in decreases in learn units to criterion across the sets. The breakdown of the non-instructional responses by the different settings do not show consistent trends across children, although there appear to be effects of the different settings for different children. Student A had fewer responses at lunchtime, as did Student B but the differences were less convincing for Student B. Student C had fewer responses in the free play area.

The results of this experiment did demonstrate a functional relationship between the intensive daily tact instruction and the numbers of pure tacts and mands emitted by the students in the noninstructional settings. The numbers of independent tacts emitted for Student A progressively increased as he mastered the first three sets, but there was a slight downturn after mastery of the $4^{\text {th }}$ set of the intensive tact treatment. Student B actually had slightly fewer tacts and mands following mastery of the $2^{\text {nd }}$ set, but the post intervention numbers where significantly higher than baseline; in fact, pure tacts and mands were practically nonexistent in the baseline probe sessions for Student B. Student $\mathrm{C}$ emitted significantly increased numbers of pure tacts following only a single intervention, with no mands. Student C's tacts and mands were also practically nonexistent in the baseline probe sessions. There was no educationally significant change in numbers or rates of mands. The rate of tact responses following the intervention provided a time dimension for the responses, again showing that the children were initiating interactions with the experimenter such that the pure tacts occurred at faster rates.

\section{Discussion}

Student A showed a progressive increase in pure tacts with the mastery of each of the first three sets of 20 different tacts taught, but there was a slight downturn following mastery of the $4^{\text {th }}$ set. Data for Student $C$ also showed an increase in number of tacts following the mastery of a single set, although more data are needed to make clear conclusions. Clearly, more data are needed to determine the degree to which the mastery of more sets will affect the numbers and rates of pure tacts in non-instructional settings. We also need data on the rates of pure tacts that occur with typically developing children under the conditions provided in this experiment. However, it would appear that, until, or unless children have naming, observational learning, and a fairly fluent reading repertoire, the only means that children like those we studied have of obtaining new tacts is through intensive tact instruction. Future research needs to examine the effect of increasing children's pure tacts on the occurrence of conversational units. It does seem that without tacts children would seem to have little to talk about, but this too remains an empirical question.

The procedure that was implemented taught the students to tact stimuli presented in an intensive fashion as an attempt to compensate for prior missing language opportunities. The categories of tacts were selected according curricular objectives specified in The CABAS® International Curriculum and Inventory of Repertoires for Children from Preschool to Kindergarten (Greer \& McCorkle, 2003). The procedure was also developed in order to ensure that the teachers teach significant numbers of tacts throughout the daily instruction by providing a daily instructional goal for teachers to meet (Greer and Ross, in press).

This procedure may also prove to be an effective means to compensate for the missing language opportunities associated with children like those described in the Hart and Risely study. Hart \& Risley (1995) studied 42 families with young children and found that the number of verbal 
interactions that occurred in the presence of those young children played a crucial role on the children's later verbal skills, including vocabulary growth rate, vocabulary use, and IQ scores. Children from impoverished families also initiate fewer verbal interactions with others than typically developing children (Woods, 1984). Perhaps, providing such children with intensive pure tact instruction in preschools may serve to reduce the vocabulary gap. The lack of pure tacts place children at a greater disadvantage in terms of their future language development. Our data suggest that increasing the numbers of pure tacts and mands children are taught could lead to a greater number of verbal interactions with others. By learning to emit more pure tacts and mands, young children can recruit more attention from the adults and peers in their environment, thereby creating still more opportunities for verbal exchanges.

Moreover, acquisition of tacts appears critical to the progressive development of verbal capabilities. The tact repertoire is a prerequisite for the development of higher order operants like naming, which is a verbal capability that provides children with an ability to acquire novel vocabulary without direct instruction (Greer, Chavez-Brown et al., 2005; Greer \& Keohane, 2005; Greer, Stolfi, et al., 2005; Lowe et al. 2002). According to Horne and Lowe (1996), naming is a relation between the object, speaker behavior, and corresponding listener behavior. Lowe, Horne, Harris, \& Randle, (2002) also state that training tact relations to normally developing children, "entails the concomitant training of corresponding listener behavior; that is in training tacting, one is effectively training naming " (p. 529). "Learning to emit tact or speaker responses after learning the listener responses is a key component of naming and naming makes the rapid and incidental expansion of tact responses to novel stimuli possible" (Greer, Stolfi, et al., 2005, p.124). Naming is one of the repertoires crucial for independent learning and acquisition of higher order operants like observational learning. Providing children with the naming capability appears to be a key to providing these children with tools for future success and independence.

Interestingly, most of the tacts that the students emitted in non-instructional settings were not the tacts that they were taught in the intensive tact protocol. Thus the students appear to have learned to emit the tact as a means to recruit generalized reinforcers in the form of attention from the teachers. Using both the tacts that they had in repertoire and those that were taught. Teaching the pure tact resulted in an exponential expansion of emission of pure tacts in non-instructional settings, suggesting that the children were coming progressively more under the control of generalized reinforcement of adult attention. The frequent emission of tacts and recruitment of tacts by typically developing children appears to play a significant role in rapid expansion of vocabulary that characterizes the language development of children subjected to a rich language environment.

There are several limitations to the study. First, it would have been advantageous to teach mastery of more sets of stimuli for Students B and C. Future studies should do so. In addition, collection of data on the numbers of conversational units is needed. Moreover, we need to know more about the mean and ranges of rates of pure tacts and mands by typically developing children. Finally, it is possible that simply increasing the number of learn units received by children, regardless of whether the instruction was devoted to tacts or other types of instruction represents another reason for why the numbers of pure tacts increased significantly. Future research needs to isolate the increase tact instruction from increased instruction of any kind. Clearly these and other questions need to be addressed in verbal behavior analysis.

Despite the limitations of this preliminary research, the results are promising and suggest that additional research is warranted. Without an exponential increase in tacts, children are at a disadvantage. This procedure and related procedures may provide means to overcome language experience gaps between children who have not had the advantage of prior la nguage rich 
environments, whether or not the source was based on poverty or native disabilities.

\section{References}

Albers. A, \& Greer, R. D. (1991). Is the three term contingency trial a predictor of effective instruction? Journal of Behavioral Education, 1, 337-354.

Becker, B. J. (1989). The effects of mands and tacts on conversational units and other verbal operants. Doctoral Dissertation, Columbia University. UMI 8913097.

Gewirtz, J. L. \& Baer, D. M. (1958). The effect of brief social deprivation on behaviors for a social reinforcer. Journal of Abnormal and Social Psychology, 56, 49-56.

Gewirtz, J. L., Baer, D. M., \& Roth, C. L. (1958). A note on the similar effects of low social availability of an adult and brief social deprivation on young children's behavior. Child Development, 29, 149-152.

Greenwood, C. R., Hart, B., Walker, D. I., \& Risely, T. (1994). The opportunity to respond and academic performance revisited: A behavioral theory of developmental retardation. In R. Gardener $3^{\text {rd }}$, et al. (Eds.) Behavior analysis in education: Focus on measurably superior instruction. Pacific Groves, CA: Brooks Cole.

Greer, R.D. (1996). The educational crisis. Finding solutions to social problems (pp. 113-146). Washington, DC: American Psychological Association.

Greer, R.D. (2002). Designing teaching strategies: An applied behavior analysis system approach. San Diego, CA: Academic Press.

Greer, R. D., Chavez-Brown, M. Nirgudkar, A. S., Stolfi, L., \& Rivera-Valdes, C. (In Press). Acquisition of fluent listener responses and the educational advancement of

young children with autism and severe language delays. European Journal of Behavior Analysis, 6 (2).

Greer, R. D., \& Hogin-McDonough, S. (1999). Is the learn unit the fundamental unit of pedagogy? The Behavior Analyst, 20, 5-16.

Greer, R. D., \& Keohane, D. (2005). The evolution of verbal behavior in children. Behavior Development. 1, 31-47

Greer, R. D., \& McCorkle, N. P. (2003). The CABAS® International curriculum and inventory of repertoires for children from preschool to kindergarten. Yonkers, NY: CABAS ${ }$ and the Fred S. Keller School.

Greer, R. D. \& Ross, D. E. (in press). Verbal Behavior Analysis: Inducing and Expanding New Verbal Capabilities in Children with Language Delays. New York, NY: Allyn and Bacon.

Greer, R. D., Stolfi, L., Chavez-Brown, M., Rivera-Valdes, C. (2005). The emergence of the listener to speaker component of naming in children as a function of multiple exemplar instruction. The Analysis of Verbal Behavior, 21, 123-134. 
Hart, B. \& Risley, T.R. (1995). Meaningful Differences in the Everyday Experiences of Young American Children. Baltimore, MD: Paul H. Brookes Publishing Co.

Horne, P. J. \& Lowe, C. F. (1996). On the origins of naming and other symbolic behavior. Journal of Experimental Analysis of Behavior, 65, 185-241.

Horner, R. D., \& Baer, D. M. (1978). Multiple probe technique: A variation on the multiple baseline. Journal of Applied Behavior Analysis, 11, 189-196.

Ingham, P., \& Greer, R.D. (1992). Changes in student and teacher responses in observedand generalized settings as a function of supervisor observations. Journal of Applied Behavior Analysis, 25, 153-164.

Lowe, C. F., Horne, P. J., Harris, D. S., \& Randle, V. R.L. (2002). Naming and categorization in young children: Vocal tact training. Journal of the Experimental Analysis of Behavior, $78,527-549$

Ross, D. E. \& Greer, R. D. (2003). Generalized imitation and the mand: Inducing first instances of speech in young children with autism. Research in Developmental Disabilities, 24, 5874.

Skinner, B.F. (1957). Verbal Behavior. Acton, MA; Copley Publishing Group.

Tsiouri, I. \& Greer, R. D. (2003). Inducing vocal verbal behavior through rapid motor imitation training in young children with language delays. Journal of Behavioral Education, 12, 185-206.

Vineland Adaptive Behavior Scale (Interview Edition). (1984). Circle Pines, MN: Amreican Guidance Service.

Vineland Adaptive Behavior Scale (Classroom Edition). (1984). Circle Pines, MN: Amreican Guidance Service.

Weikart. D.P. (1966). Results of preschool intervention programs. Paper presented at the symposium on the Education of Culturally Disadvantaged Children, University of Kansas.

Weinrich, W. W. (1964). The tact relation: An experiment in verbal behavior. Journal of General Psychology, 71, 71-78.

Williams, G. \& Greer, R. D. (1993). A comparison of verbatbehavior and linguisticcommunication curricula for training developmentally delayed adolescents to acquire and maintain vocal speech. Behaviorology, 1, 31-46.

Woods, T.S. (1984). Generality in the verbal tacting of autistic children as a function of "naturalness" in antecedent control. Journal of Behavioral Therapy \& Experimental Psychiatry, 15(1), 27-32. 


\section{Authors Notes}

This research was done as part of the first author's doctoral coursework under the supervision of the second author. The authors may be contacted at the following addresses:

Nirvana Pistoljevic

npistol@hotmail.com

or

$\mathrm{C} / \mathrm{O}$

R. Douglas Greer

Box 76 Teachers College

Columbia University

New York, NY 10027

dgreer3872@aol.com

\section{Advertising in the Journal of Early and Intensive Behavior Intervention}

Advertising is available in JEIBI. All advertising must be paid for in advance.

Make your check payable to Joseph Cautilli. The ad copy should be in our hands at least 3 weeks prior to publication. Copy should be in MS Word or Word Perfect, RTF

format and advertiser should include graphics or logos with ad copy.

The prices for advertising in one issue are as follows:

Page: $\$ 200.00$

1/4 Page: \$50.00 1/2 Page: $\$ 100.00$ vertical or horizontal Full

If you wish to run the same ad in both issues for the year, you are eligible for the following discount:

1/4 Pg.: \$40 - per issue

1/2 Pg.: \$75 - per issue -vertical or horizontal

Full Page: \$150.00-per issue.

For more information, or place an ad, contact Halina Dziewolska by phone at (215) 462-6737 or e-mail at: halinadz@hotmail.com 


\title{
The Effects of Intensive Tact Instruction on Audience-Accurate Tacts and Conversational Units
}

\author{
Geneva Schauffler and R. Douglas Greer \\ Columbia University Teachers College and Graduate School of Arts and Sciences
}

\begin{abstract}
We examined the effects of intensive tact instruction on emission of audience-accurate verbalizations of 2 middle school students using a delayed multiple baseline design across participants. Dependent variables were accurate and inaccurate audience controlled tacts and conversational units during non-instructional times. Following baselines, students were taught tact sets of 5-novel stimuli. The instruction consisted of teaching 100 tact learn units daily until students met criterion on 10 sets of 5 tact stimuli. Students significantly increased audience-accurate tacts, conversational units, and inaccurate tacts/conversational units decreased for one student. We discuss the role of tact repertories on audience relevant verbalizations by students with histories of low preschool language interactions with parents.

Key words: Tact instruction for young adolescents, audience control and tact repertoires.
\end{abstract}

A growing number research studies have examined the effects of instruction derived from Skinner's (1957) theory of verbal behavior on the development of students' social interactions and their acquisition and maintenance of functional vocal speech (Chu, 1998; Greer \& Keohane, 2005; Greer \& Ross, 2004; Williams \& Greer, 1993). Chu (1998) compared the effects of verbal echoic to mand instruction consistent with Skinner's theory in addition to a social skills package they emitted significantly more conversation and verbal operants than they did when they were taught the social skills package alone. Several reports have tested the validity of conversational units as measures of social behavior, audience control, self-talk and verbal competence (Becker, 1989; Donley \& Greer, 1993; Greer $\&$ Keohane, 2005). Conversational units, extrapolated from Skinner's verbal episode, are comprised of speaker/listener exchanges in which both the participants function as a speaker and a listener in a single episode. Conversational units are a functional measure of social speaker/listener behavior (Greer \& Keohane, 2005; Greer \& Ross, 2004).

Becker (1989) found that conversational units are a function of other verbal operants emitted by the $2^{\text {nd }}$ member of the conversation. In a conversational unit, the speaker is reinforced by the listener, and the listener is reinforced by the initial speaker, who has then become the listener (Greer, 2002). Greer and Keohane (2005) argued that the presence of conversational units in a student's repertoire is a critical developmental milestone in the evolution of children's verbal behavior. They stated that coming under the contingencies of reinforcement related the exchange of roles between listener and speaker is the basic component of being social. This repertoire appears critical to the development of socially competent verbal interactions. Alternative approaches to teaching conversational units directly by script format involve prompting and the natural control does not necessarily accrue. Becker's findings suggested that conversational units are a function of other verbal operants, so that teaching these components may be necessary if not sufficient to the emergence of conversational units. A key verbal operant in conversational units is the tact operant. In order to converse, individuals need something to talk aboutthey need tacts. These tacts also need to be under the control of the relevant audiences. That is tacts that function for peer social exchanges in non school settings should be under a different audience control than tacts emitted in school settings. One's tacts of events under the control of a peer are not accurate or 
socially appropriate for a school audience. It would be appropriate to say, "I'm having a difficult day," to a teacher but inaccurate or inappropriate to say, "I'm having a bloody bad day."

The students in the present study emitted very few accurate tacts that were effective (i.e., appropriate) for a school audience. Many of their inaccurate tacts are typically described as "language usage that is socially inappropriate in school settings." However, as children of low-income families, their deficits in language are not surprising. Research has shown that language deficits of economically disenfranchised children can likely be attributed to their relatively lower levels of exposure to "rich" language interactions as small children (Hart \& Risley, 1996). This body of evidence has demonstrated that children growing up in low-income families are not exposed to the diverse and frequent use of verbal behavior to which the children of higher income families are regularly exposed; moreover the cumulative deficit is multiplicative leading to the eventual designation "developmentally disabled" as reported in Greenwood et al., 1994. These children do not develop the same repertoires of verbal behavior and audience control as students from families with higher education and stable financial circumstances because of a lack of incidental learning opportunities. It is possible that increasing the sophistication of a student's repertoire of verbal behavior may be one of the most socially significant effects a teacher can have on a child's life (Greer, 2002). While the literature has emphasized the importance of verbal interventions in early childhood, little research has attempted to test the effects of verbal interventions in early adolescence.

This study tested the effects of teaching environmentally accurate tacts on young adolescents' emission of accurate tacts and conversational units during the school day. Will significantly increasing the numbers of accurate tact operants taught during the school day affect student's accurate tacts in their non-instructional time, and the number of accurate and inaccurate conversational units emitted by the student?

\section{Method}

\section{Participants}

The participants in this study were two eight graders--one 13-year-old boy and one 13-year-old girl, both diagnosed with emotional and behavioral disorders. Student A was a male and a beginning reader/writer, functioning at a kindergarten level for reading and a first grade level for writing. He had very poor problem-solving skills and a limited community of reinforcers. He had been at this school site for one year. Student B was a female student who emitted reader/writer levels of verbal behavior at approximately three grade levels below her same age peers. Prior to admission to her current school setting she had an instructional history of emitting escape responses when presented with classroom assignments and/or instruction. She functioned at a $6^{\text {th }}$ grade level for reading and writing, and at a $5^{\text {th }}$ grade level for mathematics. This was her first year at this school site.

These students were chosen for this study due to their low levels of accurate vocal verbal behavior for the school environment with respect to their same age peers. Both students emitted low numbers of accurate tacts and even fewer conversational units with peers or adults. Many of the tacts emitted by the students were inaccurate for the school setting, either because they were inaccurate in terms of standard language usage, or they were not functional for school audiences. These students were identified as those who would significantly benefit from an increase in the number of accurate tacts and conversational units emitted in the school setting during transitional periods and free periods of the day. During these times, the teaching staff had reinforced the students for engaging in appropriate conversations with peers, and while this had been effective for most of the students, the target students still had significant deficits in these areas. 


\section{Setting}

The study was conducted in an eighth grade classroom at a middle school that had used the Comprehensive Application of Behavior Analysis to Schooling, or CABAS®, model (Greer, 1991) for the past three years. The school was located in a suburban area outside of a large metropolitan city, and it serviced children with both emotional and behavioral disorders from low socio-economic communities. The student to staff ratio for this classroom was 6-1-2. The students' academic functioning ranged from functioning at grade level to seven years below grade level, but all the curriculum and goals for the students in this classroom were aligned with the New York State Educational Standards for $7^{\text {th }}$ and $8^{\text {th }}$ graders recast as behaviorally functional repertoires according to the CABAS Curricula.

The treatment phase of the study was implemented in both the students' classroom and in the school library. The learn units for tacting the 5 sets of stimuli were dispersed throughout the day. The students often completed the learn units for 2 to 3 sets of stimuli early in the day and received learn units on the final 2 to 3 sets later that day.

\section{Dependent Variables}

The dependent variables measured in this study were the numbers of accurate tacts and accurate conversational units for the school setting that the student emitted during two transitional times and a free periods. Two transition and the free time sessions were blocked to represent a single or cumulative 15minute session representing transitional and leisure time for the day.

Tacts. A tact is a category of verbal operants and is controlled by an object, picture, person, or other item in the speaker's environment that is reinforced by a generalized reinforcer such as attention, affirmation, and praise (Skinner, 1957). A "pure" tact is under the control of nonverbal antecedents, and, in this case, an event or condition evokes a form of verbal behavior that has been correlated with the event and a generalized reinforcer in the past. An example of a pure tact is the student stating, "That's President Bush" upon seeing a picture of President Bush. On the other hand, impure tacts have a verbal antecedent in addition to the presence of the stimulus tacted. An example of an impure tact consists of a situation in which the teacher asks the student, "Who is that?" to which the student replies, "That is President Bush," and the teacher reinforces the student's response (e.g., "You're right, yes").

An accurate tact for the school setting was defined as a tact for the stimuli in the environment using language that was appropriate for a school audience. An appropriate tact is one that would typically receive generalized reinforcement specific to a particular audience. In other words, the tact was recorded as incorrect if the tact emitted by the student was not accurate (i.e. the student called the food "lisha" instead of "delicious") or if the tact emitted by the student included inappropriate language (i.e. "this food tastes like crap"). While the latter tact might be accurate, it was not functionally audience accurate. While the latter tact might function to obtain peer reinforcement in the form of laughter or attention, it is a response that will eventually lead to punitive outcomes in school settings.

Conversational Units. A conversational unit is defined as a category of verbal behavior including one full exchange in which the student emits both a speaker response, reinforced by the verbal behavior of another person responding as a listener, and, in turn, a listener response by the initial speaker (Greer, 2002). A "true conversational unit" occurs when both parties are a part of an interlocking three-term contingency that is verbal, in which the initial speaker's behavior is evoked by the environment and is reinforced by the listener/speaker response of the other person. Similarly, the second speaker's behavior is evoked by the verbal behavior of the initial speaker and reinforced by the listener response of that person. Each of the individuals must complete a three term verbal contingency from the perspective of 
both speaker and listener (Donley \& Greer, 1993; Lodhi \& Greer, 1989). Figure 1 illustrates a conversational unit.

Setting evokes verbal behavior:

Student 1 is speaker (emits mand or tact).

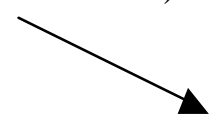

Student 2 is listener. Student 2's

listener behavior functions as $\mathrm{R}+$ for Student 1 .

Student 2 responds as speaker.

Student 1 is listener. Student 1's listener

behavior functions as $\mathrm{R}+$ for Student 2.

Student 1 responds (vocal or non-vocal behavior),

demonstrating speaker $\mathrm{S}$ control over listening.

Figure 1. Diagram of a conversational unit

An accurate conversational unit for the school setting was defined as a "true conversational unit" between two students, during which both students emitted correct/accurate mands, tacts, and autoclitics. During the conversational unit each student also used appropriate language for the school environment throughout the entire verbal exchange, both as a speaker and a listener. The reasons for strict identification of accurate conversational units for the school setting, and the importance of recording their number of occurrences, were consistent with the rationale for conducting the study. If a conversational unit did not fit the definition of being accurate for the school setting (i.e., inappropriate for the audience), it was recorded as an inaccurate conversational unit for both students.

\section{Independent Variable}

The independent variable consisted of a procedure that taught the students to emit accurate tacts to novel sets of stimuli and these were measured, too, as an index of treatment fidelity. The stimuli consisted of colored pictures, mounted on 5"x 7" index cards, of 4 different exemplars for each of the 5 novel stimuli in the set, creating a total of 20 cards per set. A correct response to the presentation of each card was the student emitting the correct vocal verbal tact for a picture within 5 seconds of the presentation of that stimulus. An incorrect response was recorded if the student did not respond within 5 seconds, if the student emitted the incorrect tact for the picture, or if the student emitted any inappropriate language. If the student emitted an incorrect response, the teachers used a correction procedure, in which the student was given the correct tact for that stimulus and was then required to repeat the correct tact in the presence of the stimulus, but the student was not reinforced for the correction. The students were reinforced for using any accurate autoclitics as part of their tacts (i.e. "That is the huge redwood tree.") and students were given appropriate autoclitics to use for each stimulus as part of the correction procedure. There were 5 sets, of 5 stimuli per set ( 4 exemplars of each set), presented in 20-learn units daily totaling 100 total tact learn units per day. The tact learn units were done in addition to the mean number of learn units taught across all curricula during baseline. 


\section{Data Collection}

Data were collected by counting the numbers of accurate and inaccurate tacts and conversational units emitted by each participant across several different times of the school day. One teacher served as the data recorder and two other teachers served as an independent observer. The teachers recorded the numbers of accurate and inaccurate tacts and conversational units emitted by each student during bus arrivals and departures and during 2 transitional times of the day (i.e. when the students transitioned from lunch to gym), for 5 minutes at lunch, and for 5 minutes during the recreational period at the end of the day.

The teachers used data forms that were divided into sections. Sections of the form were assigned to each of the targeted times in the school day during which event recording was conducted. Each of these sections was also divided in half so that Student A's data was recorded on one side and Student B's data was recorded on the other side. On each side, 2 columns were drawn and labeled "T" and "CU" in which the teacher would indicate whether that student had emitted tact or a conversational unit, respectively. The teacher recorded a "plus" in the designated column when the student emitted an accurate tact or conversational unit and a minus in the appropriate column when the student emitted an inaccurate tact or conversational unit. Because the transitional times of the day and the times that the students spent getting on and off the bus were inconsistent in length, the teachers blocked these times into sessions of five minutes total and graphed the data accordingly on a daily basis.

Data were also collected, using event recording, on the students' correct and incorrect responses to the tacting programs that were performed on a daily basis throughout the treatment phases of the study. Each set of stimuli was presented to the student in blocks of 20 learn units throughout the day, providing the student with 100 additional tact learn units per day in addition to the learn units they received for all other instruction. The student was considered to have met criterion on a set of stimuli when he/she emitted at least 18/20 correct responses within one 20 learn unit session. These data consisted of measures of the implementation of the independent variable - intensive tact instruction.

\section{Interobserver Agreement}

Interobserver agreement was calculated throughout the baseline and treatment phases for both participants. Teachers from the participants' classroom, as well as teachers from other classrooms at the middle school took data, using event recording, with one of the authors of this study in order calculate interobserver agreement for measuring the baseline and treatment levels of the dependent variables. All of the teachers had been trained to collect tact and conversational units data as part of the instructional requirements required for this school setting. Point-to-point interobserver agreement was calculated during a 5-minute session as the student's number of tacts and conversational units on which both observers agreed divided by the total number of tacts and conversational units on which the two observers agreed and disagreed. In the baseline phase for Student A, interobserver agreement was taken during $30 \%$ of the sessions and was calculated at $94 \%$, with a range of $88-100 \%$ agreement. In the baseline phase for Student B, interobserver agreement was taken during 35\% of the sessions and was calculated at $92 \%$, with a range of $85-100 \%$ agreement. In the treatment phase for Student A, the interobserver agreement was taken during $40 \%$ of the sessions and was calculated at $92 \%$, with a range of $84-100 \%$. In the treatment phase for Student B, the interobserver agreement was taken during $30 \%$ of the sessions and was calculated at $91 \%$ agreement, with a range of $88-98 \%$. All interobserver agreement was conducted on a point-by-point basis. 
During the intervention phases, when the authors implemented the independent variable for the study, in which they taught the students to tact multiple sets of stimuli, interobserver agreement was calculated using the teacher performance/ rate accuracy (TPRA) measure of instruction (Ingham \& Greer, 1992). The interobserver agreement for the tact procedures used in implementing the independent variable across both participants was calculated at $100 \%$ agreement.

\section{Design}

A delayed multiple baseline design across participants was used to determine the effects of the independent variable on the students' numbers of accurate tacts and conversational units emitted during the school day (Johnston \& Pennypacker, 1993). Student A completed the baseline phase and began the treatment phase one week prior to Student B. Baseline data were continuously recorded for Student B while Student A was in the treatment phase.

\section{Baseline Procedure}

In the baseline phase of the study, the researchers observed the students during transitional and free times, in which the teachers permitted the students to talk to one another and no formal instruction was being delivered. During the free times of the day, the students were permitted to engage in activitie s such as basketball, artwork, board games, card games, computers, etc. Throughout the baseline phase, the teachers corrected students who used inappropriate language by giving them a more appropriate way to express themselves and by stating that "students must use appropriate language at school" as an audience correction."

\section{Treatment Procedure}

In the intensive tact phase, after baseline data were collected, the student was provided with 100 additional learn units per school day, in which the teacher presented learn units for 5 sets of novel stimuli (Greer \& McDonough, 1999). Immediately after the student met criterion on one set of stimuli, the researchers began recording data for the student's treatment phase on the number of accurate and inaccurate tacts and conversational units emitted by the student throughout the same targeted times of the school day as in the baseline phase. Data were then taken multiple times throughout each of the following school days, just as in baseline, and these data were graphed in the treatment phase of the student's graph.

As the student met criterion on each set of stimuli, another set of stimuli was introduced, such that the student received 100 learn units every day on 5 different sets of 5 stimuli each. The sets were made up of 20 pictures which depicted 4 exemplars of each of the 5 stimuli within the same general category, and each session consisted of 20 learn units, one for each of the pictures in the set. The students were taught to tact multiple exemplars of various stimuli such as 5 different kinds of trees, 5 monuments in Washington, D.C., the artwork of 5 different artists, 5 kinds of brass instruments, the landscapes of 5 different national parks, 5 former presidents, 5 foreign landmarks, etc. Sometimes the students were given a choice of which sets they wanted to learn next, and other times the teachers assigned the sets to them.

All learn unit sessions were conducted such that the student emitted pure tacts. In other words, the antecedent was simply the presentation of the stimulus in the student's environment; no vocal verbal antecedents, such as, "what is this?" were delivered. The students were also taught to emit tacts that included autoclitics. Skinner describes verbal as behavior that functions to quantify, qualify, affirm, negate, specify, or in some way modify the effect of a speaker's behavior on a listener or audience (Skinner, 1957). The students in the study were taught to emit autoclitics such as, "that is a birch tree" or 
"he is President Jefferson". In addition, the students often emitted untaught autoclitics when tacting the sets of stimuli, such as "that is the cat with no hair, the sphinx" and "that picture is the one by Ansel Adams".

$$
\text { Results }
$$

\section{Baseline Data}

The baseline data for Student A show a stable trend and low numbers of accurate and inaccurate tacts emitted across all 16 of the five-minute sessions (Figure 1). Under baseline conditions, Student A emitted a mean of 1.8 accurate tacts per five-minute session (range, 0 to 6 ) and a mean of 2.0 inaccurate tacts per five-minute session (range, 0 to 7 ). Student B also emitted a consistently low numbers of accurate and inaccurate tacts across all 24 five-minute sessions in the baseline phase. Student B emitted a mean of 1.8 accurate tacts (range, 0 to 5) and a mean of 2.3 inaccurate tacts (range, 0 to 7 ) per five-minute session under the baseline conditions.

\section{Treatment Data}

Tacts. In the treatment phases, which began immediately after the student had met criterion on one set of novel tacts, both students showed an increase in the number of accurate tacts emitted per fiveminute session. Student A emitted a mean of 5.6 accurate tacts per five-minute session in the treatment phase, with a range of 1 to 15 . Student B emitted a mean of 10.6 accurate tacts per five-minute session in the treatment phase, with a range of 8 to 17. The data for the treatment phase also show that as both students' numbers of accurate tacts increased, their numbers of inaccurate tacts remained low. Student A emitted a mean of 1.95 inaccurate tacts in the treatment phase (range, 0 to 7). Student B emitted a mean of 2.8 inaccurate tacts in the treatment phase (range 0 to 6 ).

The data on Student A's accurate tacts per five minute session show overlap across the baseline and treatment conditions, but the data also show that there were 6 sessions within the treatment phase in which Student A emitted more accurate tacts than he had ever emitted under baseline conditions. The data for Student B's number of accurate tacts per session show that there is no overlap between the number of accurate tacts she emitted in the baseline phase and the number of accurate tacts she emitted per session in the treatment phase. The increase in Student B's number of accurate tacts per session during the treatment phase was immediate and stable over time. These data are shown in Figure 1 

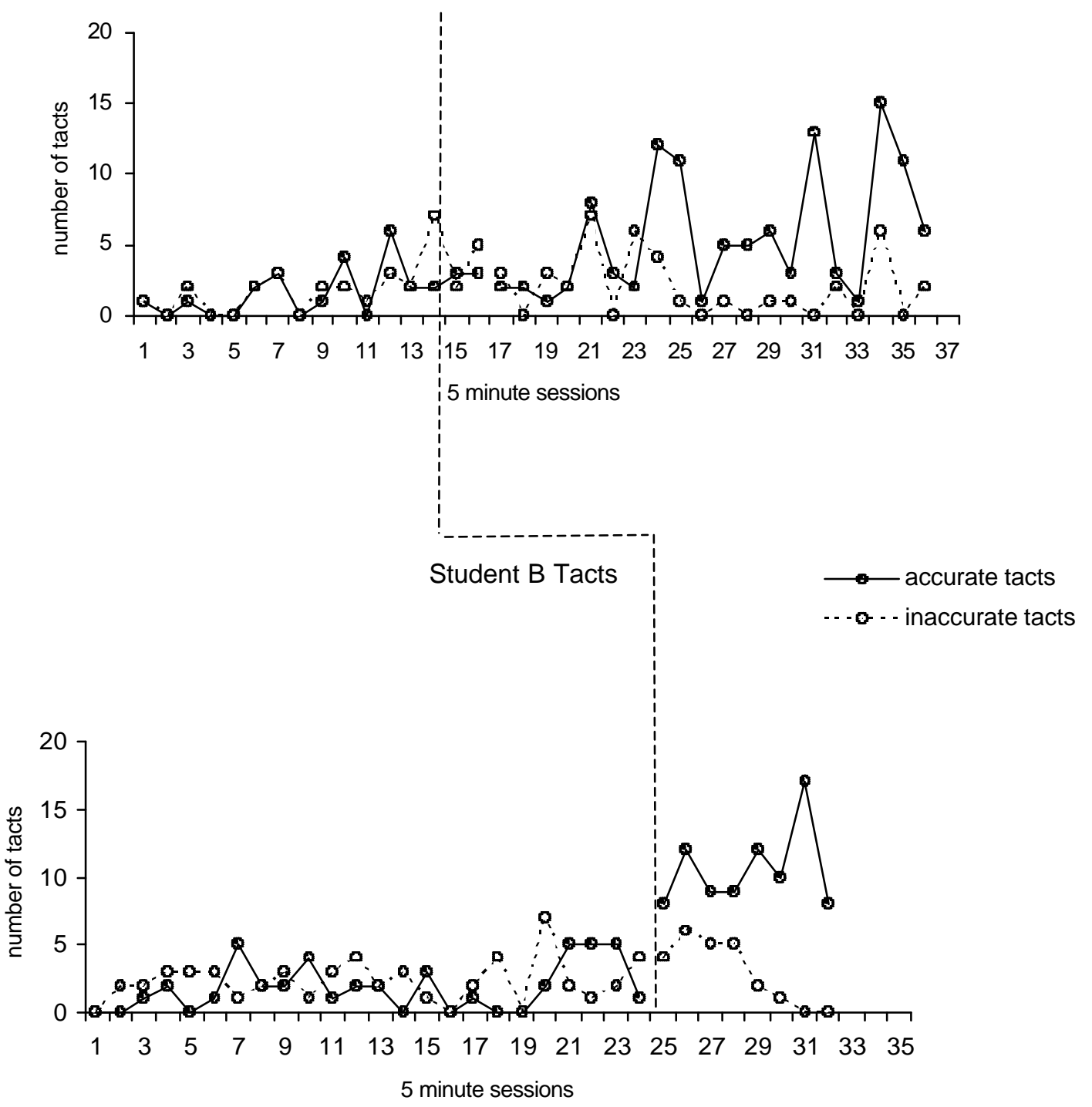

Figure 2. The figure shows both Student A and Student B's number of accurate and inaccurate tacts emitted during non-instructional times of the school day, throughout the baseline and treatment phases of the study. 
Conversational units. The data on the students' number of conversational units emitted per session show a similar effect across the baseline and treatment conditions and are displayed in Figure 2. In the baseline phase, both students emitted a low number of accurate conversational units. Student A emitted a mean of 0.6 accurate conversational units per five-minute session (range, 0 to 1 ). Student B emitted a mean of 1.3 accurate conversational units per five-minute session (range, 0 to 4 ) under baseline conditions. Both students also emitted a low number of inaccurate conversational units under baseline conditions. Student A emitted a mean of 0.14 inaccurate conversational units per five minute session (range, 0 to 1), and Student B emitted a mean of 0.7 inaccurate conversational units per five minute session (range, 0 to 3 ) in the baseline phase.

Just as was demonstrated in the data for the numbers of accurate tacts emitted by both students across the two phases, the data for Student A and Student B show an increase in the number of accurate conversational units emitted within the treatment phase. Student A emitted a mean of 2.0 accurate conversational units (range, 0 to 5) per session, and Student B emitted a mean of 3.6 accurate conversational units per minute (range, 1 to 7 ) in the treatment phase. Both students also maintained low numbers of inaccurate conversational units per session in the treatment phase. Student A emitted a mean of 0.7 inaccurate conversational units per session (range, 0 to 5), and Student B emitted a mean of 0.5 inaccurate conversational units per session (range, 0 to 2 ) in the treatment phase.

Student A conversational units

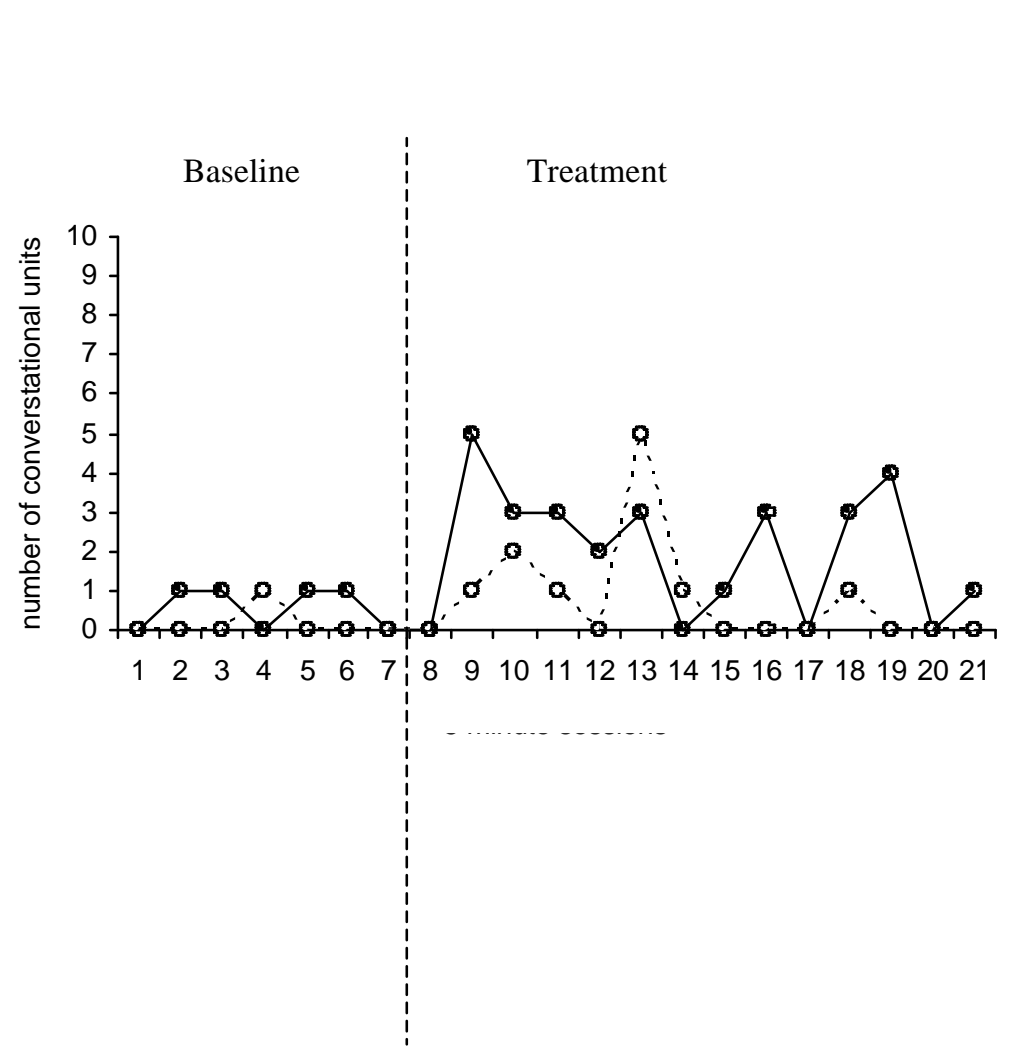

accurate CU 


\section{Student B conversational units}

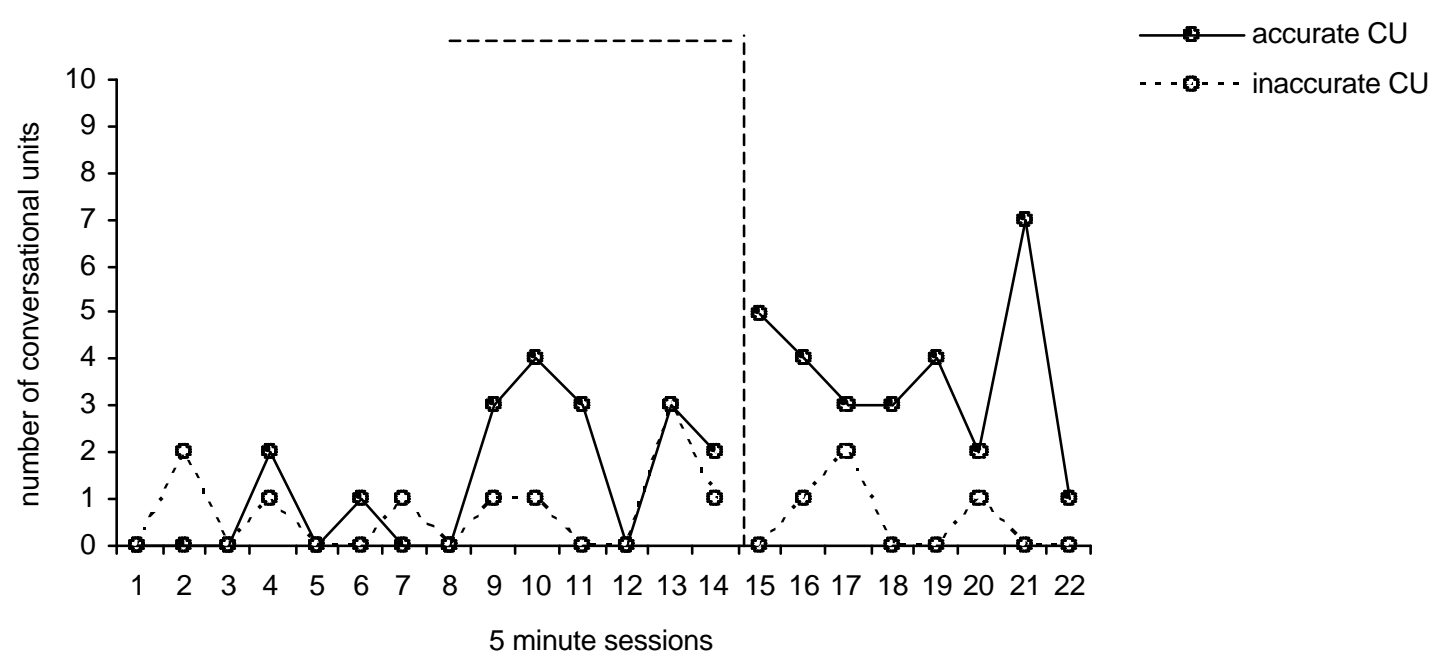

Figure 3. The figure shows both Student A and Student B's number of accurate and inaccurate conversational units emitted during non-instructional times of the school day, during the baseline and treatment phases of the study.

\section{Discussion}

The results of the study showed an increase in the number of accurate tacts and conversational units emitted by both students, following the implementation of the intensive tacting procedure. The results also showed that as both students' number of accurate tacts and conversational units increased, their number of inaccurate tacts and conversational units did not change from the baseline to the treatment phases. In other words, as the students' numbers of total tacts and conversational units increased, their numbers of inaccurate tacts and conversational units stayed relatively stable, thereby increasing their overall percentage of accurate tacts and conversational units. In examining the reasons why the tacting procedure may have had such an effect on the accurate tacts and conversational units emitted by both students, there are numerous factors to consider. In fact, the implementation of the tacting procedure may have affected several variables related to the students' levels of verbal behavior, which both independently and collectively influenced their numbers of accurate tacts and conversational units within the school environment.

\section{Implications for Teaching}

First, it is important to note that the tacting procedure implemented by the researchers functioned to teach the students to emit pure tacts in the presence of multiple exemplars of novel stimuli, for which the students had not previously acquired accurate tacts. In other words, the tacting procedure taught the students to emit novel operants, not simply previously learned responses. We observed that, although the students were often familiar with the category under which the stimuli would be classified (i.e. they knew that the picture showed a tree of some kind), the students did not emit accurate tacts for the specific stimuli themselves.

The researchers also noted that, during the initial probes for the students' responses to the target stimuli, the students often responded by saying the name of the category under which the stimuli could be classified, in addition to an inappropriate autoclitic for the school environment. For example, when first 
presented with a picture of the Washington Monument, Student A said, "That is some stupid pointy building." In addition, when presented with a picture of a pelican, Student B said, "That bird is retarded." In other words, the students' responses in the initial probe further highlighted the significant deficits in these students' tact repertoires, as well as the necessity of teaching the students to emit accurate tacts for their environment.

The tacts that the students emitted under baseline conditions also underscored the social significance of teaching these students to emit accurate tacts for the school environment. Not only did the students emit incorrect tacts for stimuli that were related to the state standards for their grade level, the students emitted tacts that would not be accepted as appropriate responses for the classroom in a regular educational setting. However, such responses are ones that have likely functioned to solicit attention from peers and/or teachers in the past. One of the most important effects of the tacting procedure on the participants' behavior was that it taught the students to emit tacts that functioned for them within the company of a school audience.

\section{Emergence of Untaught Accurate Tacts}

When collecting data for the five minute sessions in the treatment phase, the researchers noted that, although the tacts emitted by the students were almost never the specific tacts that had been taught to the students during the implemented tacting procedure, the stimuli that the students tacted during these times were often closely related to the stimuli that were taught during the tacting procedure. For example, during the treatment phase, Student A (who had been taught to tact states in the U.S. and flags of foreign countries) emitted accurate tacts in the classroom during transitional and free times of the day that related to the map on the classroom wall and the flags of the different countries that were at the bottom of that map. In addition, Student B (who had been taught to tact national parks, as well as national and foreign monuments) tacted, during transitional times of the day, that certain pictures in the art room were "from the desert or the valley," reminded her of "a building like a memorial," or looked "like a national park." The students were accurately tacting stimuli in the classroom and in the school environment that they had not previously tacted under baseline conditions.

In terms of the number of conversational units that were emitted by the students in the treatment phase of the study, the researchers noted that many of the conversational units in the treatment phase began with one of the target students emitting an accurate tact in the environment and continued when another student responded to that tact, followed by the target student emitting a response back to the other student. For example, Student A used the name of a foreign country, which was printed under one of the many flags on the classroom map, as the mystery word in the students' game of "Hangman." After doing so, the other students asked Student A where he had obtained that word, and Student A responded by tacting the picture of the flag for that particular country. Unfortunately, a limitation of the study is that the researchers did not collect data on how many of the conversational units emitted between the students were initiated by the target student and how many of the conversational units were initiated by the other students in the environment. Future studies should record data on this information, during both the baseline and treatment conditions of the study.

\section{Suggestions for Future Research}

In recording the number of conversational units that were emitted under both baseline and treatment conditions, the researchers only recorded the accurate and inaccurate conversational units emitted by the target student and other students in the environment. The researchers did not record the number of conversational units that were emitted by the target student and the teachers during these times. Anecdotally, the researchers noted that, in the treatment phases of the study, the target students asked the teachers and the researchers an increased number of questions, both during the tacting procedure itself, 
and during the 5 minute sessions within the treatment phase; however, not having the data for the number of questions asked by the students and the number of conversational units that were emitted by the students and the teachers during these times is another limitation of this study. Future studies should take data on the students' number of questions, particularly the number of "wh" questions that the students asked, both during the tacting procedure and within the 5-minute sessions of the treatment phase, as well as the number of conversational units emitted by the students and teachers during these times. "Wh" questions are means of recruiting tacts that subsequently obtain generalized reinforcement (Greer \& Ross, 2004; Greer, 2005).

\section{Social Significance}

Finally, it is important to discuss the findings of the study in terms of the levels of verbal behavior measured in the dependent variable and their relationship to the tact procedure that was implemented in the treatment phase. Tact operants are part of the speaker level of verbal behavior (Skinner, 1957). Students who emit pure tacts are reinforced by generalized reinforcers in the environment, such as praise or the attention of others. Students in the speaker stage also emit autoclitics, intraverbal responses, and impure tacts (Greer, 2002). For example, a teacher asks the student "What is it?" and the student responds, "It's the White House." Acquiring this level of verbal behavior allows the student to govern consequences in his environment by affecting the listener. The tact procedure implemented in this study taught the students to emit new tact operants, but it also functioned to increase the tacts that they emitted during non-instructional times, other than the ones that were directly taught. The students began to tact more stimuli in their environment and emit more speaker behavior overall.

These speaker repertoires expand the student's capacity to be part of the social community, but an important prerequisite for being part of the social community is that the student is reinforced as a listener with a speaker response (Greer, 2002). When a student is reinforced as a listener with a speaker response, the student has entered the speaker/listener exchange stage of verbal behavior, in which sequelics and conversational units are emitted. The data for this study show that the tact procedure also functioned to increase the number of conversational units emitted by the target students during non-instructional times. The question is; what did the students learn from the tact procedure that affected their capacity to emit a higher level of verbal behavior? It is likely that continued research on the development of higher order operants might provide answers to these kinds of questions.

\section{Limitations of the Study}

There are several limitations to the study. The procedures need to be replicated with more participants like those we studied. Future research should also identify how many sets of stimuli need to be taught before significant effects accrue. It is likely that continued implementation for the intensive tact instruction may lead to more dramatic effects. The fact that it was possible to increase the tact and conversational repertoires of children at this late stage suggests that a procedure like this could have even more significant effects on much younger children. Also, further research is needed that control for the numbers of learn units received daily. That is, it is possible that simply increasing the numbers of learn units the students received resulted in the effects we found, regardless of whether the learn units were devoted to tacts or other instructional goals. This is probably the biggest limitation; however much of the daily instruction of students is closely tied to the development of new tacts, although it is possible that increase textual learn units might have similar outcomes. However, the results of our pilot efforts are promising and suggestive. 


\section{Conclusions}

Given the severity of the lack of verbal repertoires and corresponding inappropriate audience control of children like the ones we studied, the effects of verbal behavior analysis interventions are particularly relevant. In many such cases, the sources of inappropriate verbal behavior and poor social conversational skills may, in fact, be the result of a deficit of verbal behavior. Thus, the problem is likely not simply one of decreasing inappropriate language, the problem is a deficit in tact repertories and verbal capabilities. The importance of teaching children with severe language delays to use mands and tacts instead of assaultive behavior or tantrums is well documented. However, corresponding treatment of children with no native disabilities, but who have environmental deficits, has received little if any attention. Our efforts suggest that expanding verbal repertoires may be a key to the real solution of socially inappropriate behavior in children who have been economically and culturally disenfranchised. Moreover, even at the late stage of middle school, the educationally damaging effects for severe deficits in preschool language interactions may be remediated to some degree.

\section{References}

Becker, B.J. (1989). The effect of mands and tacts on conversational units and other verbal operants. (Doctoral dissertation, 1989, Columbia University). Abstract from: UMI Proquest Digital Dissertations [on-line]. Dissertations Abstracts Item: AAT 8913097.

Chu, H.C. (1998). A comparison of verbal behavior and social skills approaches for development of social interaction skills and concurrent reduction of aberrant behaviors of children with developmental disabilities in the context of matching theory. (Doctoral dissertation, 1998, Columbia University). Abstract from: UMI Proquest Digital Dissertations [on-line]. Dissertations Abstracts Item: AAT 9838900.

Donley, C.R., \& Greer, R.D. (1993). Setting events controlling social verbal exchanges between students with developmental delays. Journal of Behavioral Education, 3, 387-401.

Greenwood, C. R., Hart, B., Walker, D. I. \& Risely, T. (1994). The opportunity to respond and academic performance revisited: A behavioral theory of developmental retardation. In R. Gardener 3rd, et al. (eds.) Behavior analysis in education: Focus on measurably superior instruction. Pacific Groves, CA: Brooks Cole.

Greer, R.D. (1991). The teacher as strategic scientist: A solution to our educational crisis. Behavior and Social Issues, 1, 25-41.

Greer, R.D. (2002). Designing Teaching Strategies. San Diego, CA: Academic Press

Greer, R.D. (2005). Recruitment of New Tacts by Using “Wh” Questions. Unpublished chapter. Columbia University Teachers College.

Greer, R.D. \& Keohane, D.D. (2005). The evolution of verbal behavior. Behavior Development Bulletin, 1, 31-47.

Greer, R.D. \& McDonough, S.H. (1999). Is the learn unit a fundamental measure of pedagogy? The Behavior Analyst, 22, 5-16. 
Greer, R. D., \& Ross, D. E. (2004). Verbal Behavior Analysis: A Program of Research in the Induction and Expansion of Complex Verbal Behavior. Journal of Early and Intensive Behavioral Intervention, 2, 141-165.

Hart, B. \& Risley, T. (1996). Meaningful Differences in the Everyday Life of America's Children. NY: Paul Brookes.

Ingham, P., \& Greer, R.D. (1992). Changes in student and teacher responses in observed and generalized settings as a function of supervisor observations. Journal of Applied Behavior Analysis, 25, 153164.

Johnston, J.M., \& Pennypacker, H.S. (1993). Strategies and tactics of behavioral research (2 ${ }^{\text {nd }}$ ed.). Hillsdale, NJ: Erlbaum.

Lodhi, S. \& Greer, R.D. (1989). The speaker as listener. Journal of the Experimental Analysis of Behavior, 51, 353-360.

Skinner, B.F. (1957). Verbal behavior. New York: Apple ton-Century-Crofts.

Williams, G. \& Greer, R.D. (1993). A comparison of verbatbehavior and linguistic communication curricula for training developmentally delayed adolescents to acquire and maintain vocal speech. Behaviorology, 1, 31-46.

\section{Authors Note}

This experiment was conducted as part of the first author's master's degree coursework under the supervision of the second author. We are appreciative of the contributions of the children and the cooperation of their families during the conduct of this research.

Author contact Information:

Geneva Schauffler

Box 76 Teachers College

Columbia University

New York, NY 10027

Or

R. Douglas Greer

Box 76 Teachers College

Columbia University

New York, NY 10027

e-mail: dgreer3872@aol.com 


\title{
Effects of Speaker Immersion on Independent Speaker Behavior of Preschool Children with Verbal Delays
}

\author{
Denise E. Ross, Robin Nuzzolo, Lauren Stolfi, and Sarah Natarelli \\ Teachers College Columbia University and The Fred S. Keller School
}

\begin{abstract}
Speaker immersion is a tactic that uses multiple establishing operations to increase speaker behavior for individuals with limited mand and tact repertoires. The purpose of this paper was to evaluate the effects of speaker immersion on the number of independent mands, tacts, and autoclitics emitted by young children with verbal delays. In the first experiment, two children who emitted autoclitic mands in instructional settings, but not in noninstructional settings, participated in 60-minute speaker immersion sessions for three days. Results showed that speaker immersion was effective in increasing the number of independently emitted autoclitic mands in a noninstructional setting for both participants. In the second experiment, two children with independent mands, tacts, and autoclitics in instructional settings, but not in non-instructional settings, received daily, 10-minute speaker immersion sessions. Results showed that speaker immersion also resulted in increased mands, tacts, and autoclitics for these participants. Outcomes are discussed in terms of establishing operations and the utility of speaker immersion as an instructional tactic.

Keywords: Establishing Operation, Mand, Tact, Speaker Immersion
\end{abstract}

In verbal behavior, speaker behavior consists of six basic verbal operants or functions defined by their effect on a listener, including echoics, mands, tacts, intraverbals, textual responses, and autoclitics. Mands are verbal operants controlled by conditions of deprivation or aversive stimulus control and reinforced by the item specified in the mand (i.e., saying "Cookie" is reinforced by receiving a cookie). Tacts are verbal operants controlled by the presence of environmental stimuli and maintained by generalized reinforcement (i.e., saying "Bird" is reinforced by affirmation from a listener). Autoclitics are verbal operants that further modify the mand or tact operant (i.e., "I want the chocolate cookie" or "That's a blue bird)"

Independent or "spontaneous" speaker behavior consists of verbal operants such as mands or tacts that are emitted under non-verbal antecedent control, and possibly used in ways not previously reinforced. This unprompted speaker behavior further implies the presence of a generalized reinforcer, such as a response from a listener. Acquisition of independent speaker behavior is significant because some research indicates that it is one component of language development that distinguishes children with delayed verbal repertoires from children with typically-developing verbal repertoires. For instance, Hart and Risley (1995) found that after minimal verbal instruction, typically-developing children not only used more independent speech than their peers with verbal delays, but also applied acquired vocabulary to untrained or novel stimuli and spoke about more topics. In contrast, children with verbal delays tend to use less independent speaker behavior than their typically-developing peers (Hart \& Risley, 1995), and may not use trained speaker behavior for untaught stimuli or verbal functions unless direct teaching is provided (Greer, 2002; Nuzzolo-Gomez \& Greer, 2004; Twyman, 1996). Thus, a frequent goal of language training programs is to teach children to emit speaker behavior beyond the training setting, or to emit it "independently."

To facilitate independent speaker behavior, verbal behavior training programs incorporate establishing operations (EO), which are contrived or naturally-occurring motivational conditions created by manipulating events or stimuli in a child's environment such that they change the reinforcing effectiveness of other variables and the frequency of responses associated with those variables (Michael, 1988). For example, deprivation involves reducing a child's access to a desired item, which consequently may increase the reinforcing effectiveness of the item and the frequency of responses associated with 
obtaining it. Other examples of establishing operations include satiation and the removal of aversive stimuli. Establishing operations are commonly used to teach mands, although some research suggests that they can be used to teach tacts (Nuzzolo-Gomez \& Greer, 2004; Tsiouri \& Greer, 2003).

A common tactic that uses establishing operations to increase speaker behavior is incidental teaching. Incidental teaching begins when a speaker gestures, comments, or otherwise indicates a desire for an item or activity with which they need assistance to manipulate or obtain. The listener provides a prompt (i.e., a verbal question or model, an expectant look) and waits for the speaker to emit a targeted verbal response. The desired item or activity is subsequently delivered contingent upon the speaker's response. McGee, Morrier, and Daly (1999) found that acquisition of mands increased significantly following an incidental teaching procedure for preschool children with autism. They attributed their findings to the motivational conditions or establishing operations. Dunst et al. (2001), who trained parents to implement incidental teaching, found similar results for young children with delays.

A second common tactic that uses establishing operations to increase speaker behavior is the behavior chain interruption strategy (BCIS). The BCIS incorporates planned interruptions of familiar routines as establishing operations for mands or tacts (Stafford, Sundberg, \& Braam, 1988). Sigafoos and Littlewood (1999) found that the BCIS increased mands for play by a child with autism when chains of play were interrupted. They attributed their findings to BCIS and time-delay procedures. Grunsell and Carter (2002) found that BCIS increased selection requests for four elementary-school children with language delays, and that responses were emitted in out-of-routine contexts.

A third common procedure that utilizes establishing operations to increase speaker behavior is a brief motivational procedure, during which time delay is incorporated as part of mand training (Schwartz, 1994). During the brief motivational procedure, teachers present an item from which a student has been deprived (i.e., candy), wait a few seconds for a response (time delay), and differentially reinforce correct mands by providing contingent access to the desired item. Williams and Greer (1993) found that adolescents with developmental disabilities emitted more functional vocal speech with a brief motivational procedure than when it was not used. Drash, High, and Tudor (1999) also found that children with autism readily acquired vocal speech when brief motivational procedures were used as part of mand training.

Since BCIS, incidental teaching, and brief motivational procedures all incorporate establishing operations, they are used to teach mands under conditions that resemble the natural setting, thus increasing the likelihood that targeted speaker behavior will be emitted independently. However, research suggests that these tactics may not always facilitate independent speaker behavior. For example, Sundberg and Michael (2002) suggested that incidental teaching produces an insufficient variety and number of establishing operations to successfully teach communication because it relies on naturallyoccurring establishing operations. Carter and Grunsell (2001) reported that BCIS had only reliably been shown to create establishing operations in the context of a routine, with most studies using routines that were not naturally-occurring, and consequently training mands only in the context of the interruption. Research on brief motivational procedures suggests that while mands may be the most useful verbal operant to teach initially (Michael, 1988), they do not transfer to tact functions without specific training (Nuzzolo-Gomez \& Greer, 2004; Twyman, 1996). Further, since independent speaker behavior is comprised of much more than mand operants, these motivational procedures may not be sufficient for establishing it across mand, tact, and autoclitic functions. Thus, a need exists for strategies that will result in increased independent speaker behavior outside of a teaching session.

Speaker immersion (Greer, 2002; Greer \& Ross, 2004; Ross, 1995) is a tactic that could facilitate independent speaker behavior, particularly for students who have limited mand and tact repertoires (i.e., they emit very few mands, tacts, or autoclitics). The speaker immersion tactic uses intensive numbers of 
establishing operations, mainly during transitions within a classroom or school, to structure the environment such that rates of mands increase. During speaker immersion, a student is required to mand a number of routine events or desired items in order to engage in or use them; this includes events such as standing, sitting, exiting the classroom, wearing their coat, or receiving a tangible or edible reinforcer. The opportunity to mand such routine events and desired items is presented until the physical response to the speaker immersion procedure requires more effort than the emission of high rates of vocal mands for the same events. In other words, vocal communicative behavior begins to obtain maximum reinforcement with less effort.

To date, there are few experiments testing speaker immersion (i.e., Greer, 2002; Greer \& Ross, 2004). Thus, the purpose of this paper was to report the effects of speaker immersion on the frequency of independent speaker behavior by children with verbal delays. Two studies are presented that examined the effects of speaker immersion for four preschoolers with verbal delays who emitted low rates of independent speaker behavior.

\section{Experiment 1}

Method

\section{Participants}

Two preschool-age children with communication delays were the participants in this study. According to an independent evaluation performed by a special educator using the Hawaii Early Learning Profile (HELP; Parks, 1991), both children had expressive language delays of at least one year. Participant 1 was a 33-month old girl who spoke approximately 300 words; independently - though infrequently - used single word mands; and manded about five items in complete sentences (i.e., "I want cookie, please") when prompted to do so during instruction. Participant 2 was a 36-month old boy who spoke approximately 100 words, and independently - though infrequently - used single word mands (i.e., train). Both participants were selected because they primarily used single words to mand and tact common items, and emitted autoclitic mands and tacts (i.e., used more than single words) only when they were receiving direct training for autoclitic responses during instructional sessions. No autoclitic mands and tacts were emitted by these participants during non-instructional periods, even after several weeks of opportunities-to-respond during which establishing operations were incorporated as part of mand instruction.

\section{Setting}

This study took place in a classroom located in a small early intervention center for children with communication impairments. The classroom had five children, one teacher, and two teacher's assistants. All sessions took place in both the instructional and non-instructional settings. The non-instructional settings included the playground, play area located in the classroom, the hallways, bathroom, and the school bus loading area. The instructional setting was the classroom area in which one-to-one instruction occurred. In each setting, an additional instructor and at least one other student were always present.

\section{Dependent Variables}

The dependent variables for this study were autoclitic mands. Autoclitic mands were defined as instances of vocal verbal behavior that contained three or more words, occurred within the context of known motivational conditions (i.e., deprivation or other antecedent conditions that preceded a targeted mand form) and under non-verbal antecedent control, and were reinforced by the participants' receipt of 
the specified item. Autoclitics were required to affect the mand function. An example of an autoclitic mand emitted by the participants might be, "Can I go into the classroom, please?" or "I want the cookie." Incorrect responses occurred if the participants emitted sentences containing only one or two words (i.e., "Classroom, please" or "Cookie"), or if they did not respond at all.

Generalized mands and captured mands were recorded. Generalized mands occurred in the instructional setting when participants independently requested a reinforcer after a correct response during non-speaker or listener instruction (i.e., asking for a cookie after correctly responding to a direction to touch their nose). Captured mands occurred in non-instructional settings when participants independently requested an event or item while in the non-instructional setting (i.e., asking to play on the slide while on the playground). All mands were collapsed into one data point.

\section{Data Collection and Interobserver Agreement}

The number of correct responses in both instructional and non-instructional settings was recorded by using a mechanical counter or paper and pencil method. Four observers trained to collect data on each participant recorded correct and incorrect responses emitted by the students when they arrived at school until a 60-minute time period was completed. Only correct, independently emitted mands (those without echoic antecedents) were recorded with a plus; all echoic mands and incorrectly emitted mands were recorded with a minus. Because of the 60 -minute duration of sessions, a second observer collected interobserver agreement data with the primary instructor for only $10 \%$ of all sessions (at least one session in each condition for each participant). Interobserver agreement was calculated by dividing the number of correct responses reported by each observer by the number of incorrect responses plus the incorrect responses and multiplying this total by 100 . Mean interobserver agreement was $99 \%$ (range, $98 \%$ to $100 \%$ ) for all sessions in which interobserver agreement data were collected.

\section{Design}

A multiple baseline across subjects design (Baer, Wolf, \& Risley, 1968) was used to evaluate the effects of speaker immersion on autoclitic mands for both participants. The procedure began by selecting a 60-minute time period during which establishing operations could be implemented for common activities for each participant. The time period that was selected began when the participants exited the school bus to enter the school and ended after 60-minutes were completed. Approximately 15 to 25 minutes of the targeted period were spent in the non-instructional setting and approximately 35 to 45 minutes were spent in the instructional setting. Approximately 60 establishing operations were created per session (number varied depending on the setting), and one session was conducted at the same time daily.

\section{Procedures}

Baseline. Baseline data were collected in both non-instructional and instructional settings. During baseline in the instructional setting, an instructor sat facing one participant at a table. The instructor presented an instructional antecedent from the participant's individualized curriculum (i.e., "Touch your nose"), prompted the participant if needed (i.e., modeled the correct response), and waited five seconds for the participant's response. After a correct response to an instructional antecedent, the instructor praised the participant and then gave them an opportunity to emit a generalized mand. During generalized mand opportunities, the instructor first gestured to a tray or set of reinforcers displayed on the table. Then the instructor waited five seconds for the participant to emit an autoclitic mand. If a correct autoclitic mand was emitted, the specified item was immediately given to the participant and a new instructional antecedent was presented. If an incorrect autoclitic mand was emitted or if no mand was 
emitted, the response was ignored and the next instructional antecedent was presented. The instructional sequence, including the generalized mand opportunities, was typical of instruction in the school where the study occurred. The instructional sequence took place for 15 to 25 minutes. Experimenters also used participants' responses to target stimuli during baseline as an assessment of events and items that could be potential reinforcers for the participants during the speaker immersion procedure.

During baseline in non-instructional settings (i.e., bus, playground, play area, hallway, and bathroom), data collection began during the targeted 60-minute time period (i.e., exiting the bus to enter the school in the morning or going to the play area after instruction). When a scheduled routine began, an instructor first ensured that setting events associated with the activity were made obvious for the participant. For example, when exiting the school bus before entering the school in the morning, the participant stayed on the bus and could not exit along with other students. While the opportunity to engage in this routine activity was withheld, the instructor waited $10 \mathrm{~s}$ for the participant to mand the activity (i.e., "I want to get off of the bus, please"). If the participant emitted a correct autoclitic mand, they were allowed to engage in the routine activity, and the response was recorded as a plus. If the participant did not emit a correct autoclitic mand within the $10 \mathrm{~s}$ interreponse time, the instructor enhanced the motivational condition by waving to other students who exited the bus and interjecting phrases to prompt the participant to respond such as "Bye-bye, everyone. They can all leave the bus and go to school." If the participant did not respond, they were allowed to engage in the activity after another $10 \mathrm{~s}$ period, but all further vocalizations were ignored, and a minus was recorded.

Speaker Immersion Training. In the immersion procedure, all movement, environmental change, or activity change required the participant to emit a verbal response. During a speaker immersion training session, participants were rotated in instructional and non-instructional settings. As in baseline, the experimenter withheld a targeted event or item and presented the participant with a $10 \mathrm{~s}$ opportunity to mand it ( $5 \mathrm{~s}$ for generalized mands). If the student manded the item, it was delivered with no vocal approval, and a plus was recorded on the data collection sheet. If the student did not mand the item, an echoic model of the autoclitic mand was presented (i.e., "I want cracker, please") and the participant was given another opportunity-to-respond. The item was delivered if the participant manded the item; the instructor then presented the next response opportunity for a different item or event. For example, after other students exited the bus in the non-instructional setting, the instructor waited $10 \mathrm{~s}$ for the participant to independently say "I want to get off of the bus, please." If the participant did not emit a correct autoclitic mand within the $10 \mathrm{~s}$ intraresponse time, the motivational condition was presented again (i.e., other students were more animatedly praised for engaging in the activity), the instructor said, "I want to get off of the bus, please," and the participant was given another $10 \mathrm{~s}$ opportunity-to-respond. If the correct response was emitted, they were allowed to engage in the activity. If an incorrect response was emitted, the activity (i.e., exiting the bus) was briefly withheld and then the participant was allowed to engage in it. In the non-instructional setting, each setting event (i.e., entering the school door) set the occasion for the next opportunity to emit an autoclitic mand. Approximately 60 establishing operations were presented across both non-instructional and instructional settings.

In addition to the teacher withholding the item, other motivational conditions were created to increase the student's likelihood to mand non-reinforcing items. For example, coming to the instructional area was not a known reinforcer for Participant 1 because she disliked leaving the play area. Therefore, other students were vocally praised and reinforced with the participant's reinforcers for coming to the instructional area until the participant manded the event within the $10 \mathrm{~s}$ intraresponse times. Periodically, the experimenter began the opportunity to mand the event by giving an expectant look to the participant (i.e., raising the eyebrows).

Generalization. After three days of speaker immersion training, the echoic model was removed and speaker immersion procedures occurred as during baseline. Establishing operations for preferred and 
non-preferred items and events were maintained. Data were collected on the number of independent (nonechoic) generalized and captured mands emitted by participants in instructional and non-instructional settings. Echoic models were presented as corrections only (i.e., if a participant did not emit a mand response, the teacher would model the mand form, but ignore any participant responses), and the next establishing operation was then presented.

\section{Results}

Figure 1 displays the total number of independent autoclitic mands emitted by Participants 1 and 2. Participant 1 emitted a mean of 3.5 mands per session (range, 1to 6) during baseline, a mean of 8 mands per session (range, 4 to 10) during speaker immersion training, and a mean of 48 mands per session (range, 19 to 68) during generalization. During baseline and speaker immersion training, Participant 1 emitted only generalized mands and no captured mands. During generalization, 50\% of mands emitted by Participant 1 per session were generalized (mean, 24) and 50\% were captured (mean, 24).

Participant 2 emitted a mean of 13.6 mands per session (range, 1 to 22) during baseline, a mean of 12.3 mands per session (range, 6 to 18) during speaker immersion training, and a mean of 43.6 mands per session (range, 18 to 97) during generalization. Participant 2 primarily emitted generalized mands during baseline (mean, 12.4) and speaker immersion training (mean, 12.3). During generalization, Participant 2 emitted more captured mands (mean, 26) than generalized mands (mean, 17.6).

FIGURE 1, NEXT PAGE 
Figure 1. Total number of correct autoclitic mands emitted by Participants 1 and 2 for captured and generalized mands. 


\section{Discussion}

The purpose of Experiment 1 was to evaluate the effects of speaker immersion, a tactic that uses multiple establishing operations for routine events and known reinforcers, on the number of independent autoclitic mands emitted by preschool children who previously emitted autoclitics only during instruction. Baseline measures showed that multiple establishing operations created in non-instructional and instructional settings resulted in the two participants emitting approximately eight autoclitic mands per session, comprised solely of mands for items presented after correct responses to non-vocal verbal behavior instruction (i.e., listener instruction). Speaker immersion was then implemented by first presenting an establishing operation, waiting $10 \mathrm{~s}$ for a response, presenting an echoic model for the targeted event or stimulus, and waiting $10 \mathrm{~s}$ again for a response. During speaker immersion, participants emitted approximately 10 autoclitic mands per session, also comprised primarily of mands for items presented contingent upon correct responses during instruction. During the generalization phase, establishing operations were presented again but without an echoic model, and participants emitted high numbers of mands per session, with approximately one-half emitted in the non-instructional setting and one-half in the instructional setting.

Results showed that the intervention of pairing an echoic model with an establishing operation increased the number of generalized and captured mands (those emitted in non-instructional contexts) for two preschool children with speech delays. However, there were several limitations to this study. First, the number of sessions during which interobserver agreement data were collected was low, primarily because the duration of sessions was long (60 minutes) within the context of a classroom setting and data collection was intensive. Second, the number of minutes in each setting (instructional and noninstructional) was not standardized (i.e., 30 minutes in each setting), making comparisons difficult across settings.

Third, there may have been sequence effects because of the $\mathrm{ABC}$ design that was used across participants. Specifically, the establishing operation without the echoic model during baseline did not result in the children emitting a high number of independent mands. Later, when the echoic was added, mands increased only slightly from baseline. This may suggest that the increase in mands during the final generalization phase was a function of several sessions of receiving establishing operations during the baseline and treatment phases. It is likely that the two prior phases functioned as a treatment package to evoke the high rate of independent autoclitic mands during the final phase. Additionally, the occurrence of mands during the final phase may suggest that participants did not have target responses in their repertoire or did not know when to emit them. Anecdotally, both participants independently emitted mands for untrained items during the generalization phase. It is possible that throughout the day, classroom teachers were presenting additional establishing operations for untrained items.

The purpose of Experiment 2 was to examine the effects of 10-minute speaker immersion sessions on production of tacts as well as mands and autoclitics. In Experiment 2, similar procedures were used with replicated pre-post designs during sessions of much shorter durations. Further, mands, tacts, and autoclitics were measured instead of measuring only autoclitic mands as in Experiment 1.

\section{Experiment 2}

\section{Participants}

Two preschool-age boys were the participants in this study. Before the study, Participant 3 (5years old) and Participant 4 (4-years old) were diagnosed with developmental disabilities by an independent evaluator based on state criteria. According to the Preschool Inventory of Repertoires for Kindergarten (PIRK; Greer, 2002), a criterion-referenced test administered by a special educator, both 
participants followed directions fluently, and used multiple-word autoclitics to mand and tact common items, but only during instruction. During instruction, Participant 3 used a variety of autoclitics to mand and tact items during instruction; Participant 4, who had beginning reader/writer skills, used the same autoclitics (i.e., "I want cookie, please") to mand items without varying his responses. Both participants were selected for the study because neither child emitted mands for desired stimuli or tacted common items in non-instructional settings.

\section{Setting}

This study took place in the instructional and non-instructional settings of an early childhood school program for 3 to 7-year old children with autism and related developmental delays. Seven students, one teacher, and six teacher's assistants were in the instructional setting which was the participants' classroom. Training took place in the play area of each participant's classroom, and postsessions occurred in the play area of a neighboring classroom. In both settings, the participant was surrounded by toys, puzzles, books, blocks, articles of clothing, and edibles.

\section{Dependent Variables}

The dependent variables in this study included mands, tacts, and autoclitics. A mand was defined as an instance of vocal verbal behavior that occurred under nonverbal antecedent control and a known establishing operation, and was reinforced by receiving the specified stimulus (i.e., saying "Cookie" to receive a cookie was a mand). A tact was defined as an instance of vocal verbal behavior that occurred under nonverbal antecedent control, and was reinforced by a social or generalized reinforcer such as a teacher's approval (i.e., seeing an airplane, saying "Airplane" to a teacher, and being reinforced by "That's right!"). Autoclitics were defined as instances of vocal verbal behavior that modified or specified a mand or tact. For example, in the tact "the blue car," the words the and blue were recorded as separate autoclitics. When participants correctly emitted autoclitic mands or tacts (i.e., mands or tacts with more than one word), the mand or tact function was recorded first, and then each of the modifiers was recorded as an autoclitic. For example, in the response, "I want the green car, please," a plus was recorded for a mand, and then the words $I$, want, the, green, and please were each recorded as separate autoclitics, for a total of five autoclitics. Incorrect responses included emitting inappropriate mands such as screaming or, in the case of a tact, emitting an incorrect tact or omitting a response. Only independent, unprompted mands, tacts, and autoclitics were recorded as correct during pre-sessions, treatment, and post-sessions.

\section{Data Collection and Interobserver Agreement}

The number of correct mands, tacts, and autoclitics were recorded using paper and pencil. Data were recorded by an experimenter or a teacher during 10-minute pre and post sessions before and after daily treatment sessions. A second observer collected interobserver agreement data for approximately $23 \%$ of all sessions. Agreement was collected by the school's behavior analyst supervisor for the entire duration of the session. Interobserver agreement was calculated by dividing the number of correct responses reported by each observer and multiplying by 100 . Interobserver agreement was $100 \%$ for all observed sessions.

\section{Design}

The effects of speaker immersion on speaker behavior were evaluated by using a replicated prepost design consisting of daily pre-sessions, treatment sessions, and post-sessions. For Participant 3 , all sessions were 10 minutes each and occurred between latent time periods in the following manner: 1) 10minute pre-session followed by a 10-minute latent time period, 2) 10-minute speaker immersion session followed by a 10-minute latent time period, 3) 10-minute post-session 1 followed by a 30-minute latent time period, and 4) 10-minute post-session 2. For Participant 4, all pre- and post-sessions were 5 minutes each and also occurred between latent time periods in the following manner: 1) 5-minute pre-session 
followed by a 10-minute latent time period, 2) 10-minute speaker immersion session followed by a 10minute latent time period, 3) 5-minute post-session 1 followed by a 30-minute latent time period, and 4) post-session 2 which also lasted 5-minutes.

\section{Procedures}

Pre-Sessions. Pre-sessions were conducted for Participant 3 by placing him in the play area for 10 minutes and observing him without any interactions from the instructor. Pre-sessions were conducted for Participant 4 by placing him in the play area for 5 minutes, and the instructor continuously creating establishing operations (approximately one every 10 seconds) by interrupting his chain of events (i.e., removing a toy, blocking him from walking to another part of the play area, or tickling and stopping). For both participants, if they emitted appropriate mands, the instructor reinforced the behavior by giving them the item or event that was specified in the mand (i.e., a toy). Several times during this session, the instructor would also point to an object in the environment with no vocal antecedent in order to give an opportunity for the student to emit a tact response. If the student did emit a tact, the instructor reinforced the response with a vocal response such as, "Yes, you're right. That is a (item)." No echoic models for target responses were presented.

Speaker Immersion Training Sessions. Speaker immersion training sessions were conducted 10 minutes after the presession ended. During speaker immersion training sessions, participants were placed in the play area as described above. The instructor created establishing operations by blocking the participants' access to an event or item (as described in the pre-session section above), and then provided echoic models for the participant to gain access to the activity or item. If the participant echoed the instructor, they received the target item as a reinforcer. If the participant did not emit an echoic response, the instructor continued to present echoics. If an echoic was not emitted following multiple opportunities to echo, a different event or item was selected and the speaker immersion procedure began again. Echoic responses were recorded as minuses.

Immediately after the participant echoed the instructor, the same establishing operation was presented again, but without an echoic model. If the participant emitted a correct mand, they received the targeted item as a reinforcer, and another establishing operation (typically for a different item or event) was presented. Approximately 50 establishing operations were presented during each session, and one session was conducted each day. This speaker immersion instructional sequence was repeated until the10-minute period was complete.

\section{Post sessions}

Two post-sessions were conducted after each speaker immersion procedure: Post-session 1 was conducted 10 minutes after the speaker immersion session and Post-session 2 was conducted 30 minutes after the speaker immersion training session. The procedure and duration for each of the post-sessions was the same as pre-session procedures.

\section{Results}

Figure 2 displays the total number of verbal operants (mands, tacts, and autoclitics) emitted by both participants during pre-sessions, treatment, and post-sessions. Participant 3 emitted a mean of 15 verbal operants during pre-sessions (mean range, 0 to 65), a mean of 291 verbal operants during speaker immersion (mean range, 234 to 361), a mean of 337 verbal operants during the 10-minute post-session (mean range, 207 to 495), and a mean of 324 verbal operants during the 30-minute post-sessions (mean range, 153 to 442). Participant 4 emitted a mean of 37.8 verbal operants during pre-sessions (mean range, 5 to 81 ), a mean of 165 verbal operants during speaker immersion (mean range, 137 to 204), a mean of 73 
verbal operants during 10-minute post-sessions (mean range, 44 to 92), and a mean of 39 verbal operants during 30-minute post sessions (mean range, 17 to 53).

The number of verbal operants by type emitted was also measured across all conditions for Participant 3 and during speaker immersion sessions for Participant 4. During the pre-sessions, Participant 3 emitted a mean of 2 mands per session (mean range, 0 to 6), a mean of 10 tacts per session (mean range, 0 to 40), and a mean of 4 autoclitics per session (mean range, 0 to 19). During speaker immersion training, Participant 3 emitted a mean of 46 mands per session (mean range, 27 to 55), 126 tacts per session (mean range, 58 to 217), and a mean of 119 autoclitics per session (mean range, 106 to 131). During Post-session 1, Participant 3 emitted a mean of 64 mands per session (mean range, 50 to 85), a mean of 135 tacts per session (mean range, 46 to 257), and a mean of 139 autoclitics per session (mean range, 76 to 188). During Post-Session 2, Participant 3 emitted a mean of 55 mands per session (mean range, 31 to 83), a mean of 149 tacts per session (mean range, 33 to 246), and a mean of 122 autoclitics per session (mean range, 47 to 165). During speaker immersion training, Participant 4 emitted a mean of 11 mands per session (mean range, 6 to 16), a mean of 24 tacts per session (mean range, 32 to 49), and a mean of 113 autoclitics per session (mean range, 91 to 146).

FIGURE 2, NEXT PAGE 


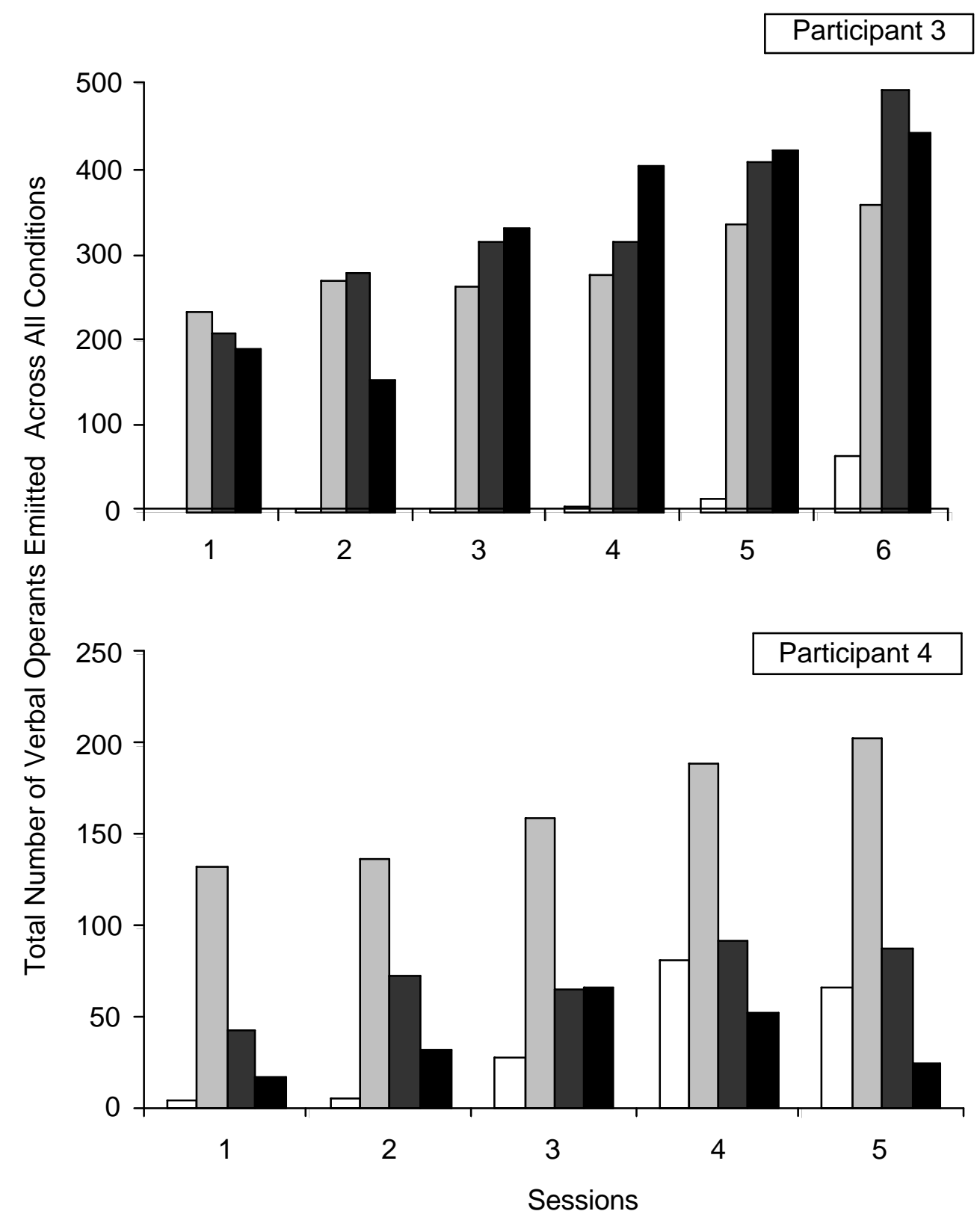

$\square$ Presession $\square$ Training $\square$ Postsession 1 Postsession 2

Figure 2. Total number of verbal operants (mands, tacts, and autoclitics) emitted by both participants during pre-sessions, treatment, and post-sessions. 


\section{Discussion}

The purpose of Experiment 2 was to evaluate the effects of shorter durations of speaker immersion on the number of mands, tacts, and autoclitics emitted by two preschool children with developmental disabilities and communication delays. Pre-session measures were followed by speaker immersion training sessions and two post-sessions presented at 10 minutes and 30 minutes after training. Results showed that the number of mands, tacts, and autoclitics emitted by participants during speaker immersion when compared to pre-session measures for both participants increased. These increased verbal operants were maintained for Participant 3 and maintained only minimally for Participant 4 during post-sessions.

The differences between responses to the treatment for participants may be attributed to several variables. First, Participant 3 entered the study with a variety of autoclitics that he emitted during instruction but not in non-instructional contexts. Thus, it is possible that participants had instructional histories or repertoires that affected their responses. Second, Participant 3 received sessions of 10minutes and Participant 4 received sessions of 5-minutes. The difference in time between the sessions may have resulted in more opportunities to respond and contact with the establishing operations for Participant 3. Further, collecting data for $50 \%$ of the time that data were collected for Participant 3 may make comparisons difficult because with longer sessions, it is possible that Participant 4 may have emitted more verbal operants.

Interestingly, more tacts than mands were emitted by Participant 3 during all conditions and by Participant 4 during speaker immersion. Establishing operations are typically associated with mands in research, but in this study a collateral effect of increasing mands was a greater increase in tacts. It is probable that instructor approval, or generalized reinforcement (which is a reinforcer for tacts) may have been the cause for tacts to increase significantly.

One limitation of this study was that each word associated with a primary verbal function was measured as an autoclitic, making analyses of the autoclitic data difficult. While the data show an increase in the number of autoclitics for each participant, it is unknown from this study how many of those were different from those the participants had prior to the study or how many autoclitics were emitted with each operant. To address this issue, another experiment with Participant 4 was conducted later to establish different forms of autoclitics. A future study would record separate data on the types of autoclitics emitted by participants during and after treatment.

\section{General Discussion}

Two experiments were conducted to examine the effects of a tactic called speaker immersion on the number of verbal operants emitted by four preschoolers with low rates of independent speaker behavior, or mands, tacts, and autoclitics emitted outside of instruction. Following baseline sessions (Experiment 1) or daily pre-sessions (Experiment 2), participants were exposed to multiple establishing operations and an echoic model of a targeted form to mand objects or events. Results from post-treatment data suggest that the speaker immersion procedure resulted in increases in autoclitic mands for two participants in Experiment 1, greater increases in tacts than mands for one participant in Experiment 2, but little increase in mean number of verbal operants for a fourth participant. It should be noted that Participant 4 received echoic mands and tacts during pre-treatment probes, whereas Participant 3 did not, possibly resulting in differences in responding.

The design of Experiment 1 precludes attributing increases in autoclitic mands to the establishing 
operation alone; increases in mands were more likely attributed to the pairing of echoic models with establishing operations or to a treatment package consisting of exposure to establishing operations during both baseline and speaker immersion measures. The design of Experiment 2 allowed for comparisons between pre-treatment, treatment, and post-treatment sessions, with results showing that speaker immersion did result in increased verbal operants. However, limitations included recording each modifier as a separate autoclitic, and using different amounts of time for each participant (Participant 3 was exposed to speaker immersion for only 50\% of Participant 4's time).

When speaker immersion was removed, ascending trends were clear for all participants except for Participant 4. This may be because not all participants received establishing operations during their baseline sessions, suggesting that speaker immersion may be more effective if children are not exposed to establishing operations before the treatment procedure. To test this possibility, future studies would use establishing operations only during treatment procedures and not during baseline. Additionally, although data were not collected on non-target verbal responses, experimenters observed that Participant 3 emitted less palilalia during speaker immersion than during baseline. It was also noted that the number of different forms independently emitted by Participant 4 did not vary significantly when speaker immersion was removed, although several different forms were presented during speaker immersion sessions.

The results of this study may be potentially attributed to the use of the establishing operation. Michael (1988) noted that the presence of an establishing operation is not enough to evoke a response, but it must be mediated by the presence of an appropriate audience or other circumstances in which the behavior has been likely to be reinforced. The training period may have established this relationship with the participants. The type of establishing operation that was used in this study may be a blocked-response conditioned establishing operation, defined by Michael (1988) as "a stimulus event that functions as an Sd for a type of behavior which is in some sense blocked - cannot occur - until some other object or event becomes available. The stimulus event then also functions as a CEO with respect to the behavior that has been reinforced by obtaining this other object or event (p. 5)." In the current study, behaviors were blocked in natural routines and consequent events that did not previously function as reinforcers.

It is also possible that the effects of multiple exemplars resulted in the outcomes. In some ways, presenting establishing operations and echoic models across different settings and with varying stimuli may have produced the instructional history needed to obtain the desired response. Thus, it is possible that presenting participants with mand training across various settings before using speaker immersion would have produced similar outcomes.

Further, it is possible that before the study, participants simply did not have the target responses in their repertoire or did not emit them under relevant conditions. For instance, only a small number of verbal operants were produced when establishing operations were used without echoics for most participants. However, when echoic models were presented, verbal operants increased. This suggests that participants did not respond to relevant establishing operations during baseline because they did not have the responses in their repertoires; however, upon learning to emit the response in the presence of establishing operations, the outcomes were produced. In other words, speaker immersion may present multiple exemplars to the degree that the relevant antecedent conditions become salient to the participant and, once the targeted response is modeled, they gain the repertoire of "spontaneous" or independent speaker behavior.

One methodological concern in this study was related to the low numbers of sessions with interobserver agreement reported for Study 1. Future studies using the same design would obtain not only more interobserver agreement, but procedural reliability as well. Further, in both studies, using establishing operations during treatment instead of during baseline or pre/post sessions may have 
provided a better comparison for the treatment condition. Finally, probes conducted several days after the experiments could have shown if speaker immersion resulted in long-term gains.

In summary, the two studies described here examined the effects of the speaker immersion tactic, which involves presenting multiple establishing operations to immerse speakers with low rates of independent mands and tacts Results of post-treatment sessions showed that speaker immersion resulted in increased independent verbal operants for three participants, but not for a fourth participant.

\section{References}

Billeaud, F. P. (1998). Communication impairment in infants and toddlers: A frame of reference. In F. P. Billeaud (Ed.), Communication disorders in infants and toddlers (pp. 1-30). Massachusetts: Butterworth-Heinemann.

Billeaud, F. P. (1998). Causes of developmental delays and disorders: Implications for communication competence. In F. P. Billeaud (Ed.), Communication disorders in infants and toddlers (pp. 3148). Massachusetts: Butterworth-Heinemann.

Billeaud, F. P. (1998). Assessment: Examination, interpretation, and reporting. In F. P. Billeaud (Ed.), Communication disorders in infants and toddlers (pp. 123-152). Massachusetts: ButterworthHeinemann.

Brady, N. C., Saunders, K. J., \& Spradlin, J. E. (1994). A conceptual analysis of request teaching procedures for individuals with severely limited verbal repertoires. The Analysis of Verbal Behavior, 12, 43-52.

Carroll, R. J., \& Hesse, B. E. (1987). The effects of alternating mand and tact training on the acquisition of tacts. The Analysis of Verbal Behavior, 5, 55-65.

Carter, M. \& Grunsell, J. (2001). The behavior chain interruption strategy: A review of research and discussion of future directions. The Journal of the Association for Persons with Severe Handicaps, 26(1), 37-49.

Drash, P. W., High. R. L., \& Tudor, R. M. (1999). Using mand training to establish an echoic repertoire in young children with autism. The Analysis of Verbal Behavior, 16, 29-44.

Grunsell, J., \& Carter, M. (2002). The behavior chain interruption strategy: Generalization to out-ofroutine contexts. Education and Training in Mental Retardation and Developmental Disabilities, 37(4), 378-390.

Hall, G., \& Sundberg, M. L. (1987). Teaching mands by manipulating conditioned establishing operations. The Analysis of Verbal Behavior, 5, 41-53.

Howard, V. F., Williams, B. F., Port, P. D., \& Lepper, C. (Eds.). (2001). Very young children with special needs. Upper Saddle River, NJ: Prentice-Hall, Inc.

McGee, C., Morrier, M. J., \& Daly, T. (1999). An incidental teaching approach to early intervention for toddlers with autism. The Journal of the Association for Persons with Severe Handicaps, 24(3), 133-146. 
Michael, J. (1988). Establishing operations and the mand. The Analysis of Verbal Behavior, 6, 3-9.

Oah, S., \& Dickinson, A. M. (1989). A review of empirical studies of verbal behavior. The Analysis of Verbal Behavior, 7, 53-68.

Rapin, I., Allen, D.A., Aram, D. M., Dunn, M. A., Fein, D., Morris, R., et al (1996). Classification Issues. In I. Rapin (Ed.), Preschool children with inadequate communication (pp. 190-213). London: Mac Keith Press.

Shafer, E. (1999). A review of Sundberg and Partington's Teaching language to children with autism or other developmental disabilities. The Analysis of Verbal Behavior, 16, 45-48.

Shafer, E. (1994). A revie w of interventions to teach mand repertoire. The Analysis of Verbal Behavior, $12,53-66$.

Sigafoos, J. \& Littlewood, R. (1999). Communication intervention on the playground: A case study on teaching requesting to a young child with autism. International Journal of Disability, Development and Education, 46(3), 421-429.

Sundberg, M., \& Michael, J. (2001). The benefits of Skinner's analysis of verbal behavior for children with autism. Behavior Modification, 25(5), 698-724.

Author contact information:

Denise E. Ross, $\mathrm{PhD}$

Teachers College

$525125^{\text {th }}$ Street Box 223

New York, NY 10027

dross@exchange.tc.columbia.edu

Robin Nuzzolo, Ph.D.

76 Alexander Court

Nanuet, NY 10954

robinonpoint@cs.com

Lauren Stolfi, Ph.D.

155 West $76^{\text {th }}$ Street Apt. 4B

New York, NY 10023

laurenstolfi@msn.com

Sarah Natarelli, MA

155 West $76^{\text {th }}$ Street Apt. 4B

New York, NY 10023

littlenats@hotmail.com 


\title{
Teaching the Function of Writing to Middle School Students With Academic Delays
}

\author{
Tracy Reilly Lawson and R. Douglas Greer \\ Columbia University Teachers College and Graduate School of Arts and Sciences
}

\begin{abstract}
Using multiple baseline designs, we studied the effects of having seven $9^{\text {th }}$ graders edit their papers until a naïve reader accomplished a drawing assignment during writer immersion (communication in writing only). During Experiment I, students received no feedback in the first phase, teacher editing feedback in phase 2 , and writer immersion plus viewing the effects of their writing on a naïve reader in phase 3. In Experiment II, students received the baseline followed by writer immersion and viewing effects on a reader. The dependent variables in both experiments were the structural components of the writing and accurately drawn components by a naïve reader. The writer immersion and self-editing package increased accuracy in structure and function in both experiments. Keywords: Writer Immersion, Establishing Operations, Function, Teacher Editing, Self-Editing
\end{abstract}

While most state and national educational standards emphasize the importance of writing, the standards refer often only to the structural components of writing and ignore the functional effects. While structure is a necessary component of effective writing, it is not sufficient alone for functionally effective writing.

From a verbal behavior analysis perspective, writing is a social behavior. According to Skinner (1953), social behavior is behavior between two or more people that makes contact with a common environment. "Verbal behavior always involves social reinforcement and derives its characteristic properties from this fact" (Skinner, 1953, p. 299). Verbal behavior is characterized by the effect one person has on another person including effects on the listener and speaker, as well as the effects of the writer on the reader (Greer \& Ross, 2004).

Establishing operations, key components of all verbal behavior, are "changes in the environment with alter the effectiveness of any object or event as reinforcement and simultaneously alters the frequency of the behavior followed by the reinforcement" (Michael, 1982, 1984, 1993). Several experiments have identified establishing operation tactics that have been effective in producing the motivational contexts necessary to teach listener and speaker verbal capabilities (Greer \& Keohane, 2005, Greer \& Ross, 2004).

Listener immersion is an establishing operation that immerses the student in listener instruction to induce the immersion of basic listener literacy (Greer, Chavez-Brown, Nirgudkar, Stolfi, \& Rivera-Valdes, 2005; Greer \& Ross, in press). During listener immersion, students are taught to respond to vowel-consonant combinations to teach auditory control of responding (Greer \& Ross, 2004). Greer, Chavez-Brown et al. implemented listener immersion with eight three to four year olds diagnosed with developmental disabilities who did not meet instructional objectives. In the procedure, all instruction throughout the day was devoted to teaching children to respond solely to vowel consonant combinations until they had mastered a sequence of successively more difficult responses. That is, only responding to vowel consonant combinations was reinforced, thus the immersion created an establishing operation. The procedure resulted in 
the immersion of listener literacy that, in turn, led to decrease in numbers of learn units to criterion from four to ten times faster learning for all students across all curricular areas.

Other studies have identified a speaker immersion procedure that arranges conditions that require students to use different forms of speaker behaviors to make transitions in their environment (Greer, 1994, Ross, 1995). Ross, Nuzzolo, Stolfi, Naterelli and Greer (2006; See this issue) tested the effects of speaker immersion on four students diagnosed with developmental disabilities and found significant increases in the numbers of independent mands emitted by all of the students during the implementation of speaker immersion and during generalization probes.

A third establishing operation tactic is writer immersion. Writer immersion is a procedure that includes setting aside a period of time in which all communication is done through written responses (Greer, 2002; Greer \& Ross, 2001; Madho, 1997). This includes responding in written form to writing assignments, as well as questions and mands for access to reinforcers. This procedure is designed to teach the relevant establishing operations for writing that is essential to the acquisition of a functional verbal response. In order for writing to be socially effective, it must have particular effects on the reader-effects sought by the writer.

Madho (1997) tested the effects of the responses of a reader upon the effectiveness of a written composition. In a delayed multiple baseline across subjects design, the students were given writing assignments requiring them to write a description without identifying the item or to write directions. The students were required to rewrite the composition until the reader identified the object or perform the desired goal. Before they received the writer immersion procedure they could not provide accurate descriptions. After the writer immersion intervention the data show that there was a significant improvement in the writer's descriptions (Madho, 1997).

The editing of verbal behavior, according to Skinner (1957) is controlled by the potential for punishment by a reader when the writing is ineffective. Therefore, writers need to "affect the speaker before it reaches a listener [or reader]" (Skinner, 1957, p. 369). Students can self-edit their own writing after the acquisition of the self-editing repertoire. The writer must react as a reader to his own behavior (Skinner, 1957). In order to do so, experiences that result in the writer learning to affect the behavior of a reader need to occur as the controlling consequence for the writer before the editing repertoire can be developed.

During the implementation of writer immersion, the student is required to rewrite the written response until it produces the desired effect (Greer, 2002, Madho, 1997). Rewriting, or doing drafts until the writing affects the behavior of a reader, teaches a student to edit their own writing, and thus teaches the student self-editing (Greer \& Ross, in press). The student writes such that they can affect the behavior of a reader - the function of writing.

Jadlowski (2000) tested the effects of self-editing and revising on writing functions. In that study, with three $7^{\text {th }}$ graders diagnosed with a learning disability and a $3^{\text {rd }}$ grader diagnosed with a speech and language impairment, Jadlowski (2000) found that having a peer editor read a student's written responses resulted in fewer necessary corrections and students completed compositions in fewer learn units (recycles) when a peer served as the reader than when the teacher served as the reader. In a second experiment study with students, ages 7 and 11 who were diagnosed with mental retardation and speech and language disorder respectfully, she found that it was serving as an editor for the other writers was the source of improvements in writer functions rather than who did the editing for the writers. 
Building on the prior work, the present studies sought to test the effects of writer immersion and viewing the effects of the students writing on responses emitted by readers who were naïve to the conditions and objective of the experiments. Thus, we tested the effects of our procedures on both the function and structural components of the students' writing.

\section{Experiment 1}

\section{Method}

Participants. Three students, attending a $9^{\text {th }}$ grade class in which all instruction applied behavior analysis to all curriculum and pedagogical procedures, participated in this study. Participant A was a 15-year old male diagnosed with a behavioral disorder. He functioned academically at approximately a $3^{\text {rd }}$ grade level. Participant B was a 16-year old male diagnosed with a behavioral disorder. He functioned academically at approximately a $2^{\text {nd }}$ grade level. Participant $\mathrm{C}$ was a 15-year old female diagnosed with a behavioral disorder. She functioned academically at approximately a $6^{\text {th }}$ grade level. All of the participants followed directions in class, but had difficulty working independently. The students were from economically disenfranchised communities and were similar, but older, to the children in the low socioeconomic group who participated in the Hart and Risley (1995) longitudinal study. The participants were chosen because of many structural errors in their writing, as well as their inability to write functionally (Table 1).

Table 1: Participants in Experiment 1

\begin{tabular}{|c|c|c|c|}
\hline Student & $\begin{array}{l}\text { Student A: } \\
9^{\text {th }} \text { grade student }\end{array}$ & $\begin{array}{l}\text { Student B: } \\
9^{\text {th }} \text { grade student }\end{array}$ & $\begin{array}{l}\text { Student C: } \\
9^{\text {th }} \text { grade student }\end{array}$ \\
\hline $\begin{array}{l}\text { Level of } \\
\text { Verbal } \\
\text { Behavior }\end{array}$ & Reader/writer & Reader/writer & $\begin{array}{l}\text { Reader/writer/ } \\
\text { emergent self-editor }\end{array}$ \\
\hline Diagnosis & $\begin{array}{l}\text { Behavior Disorder } \\
\text { Learning Disability }\end{array}$ & $\begin{array}{l}\text { Behavior } \\
\text { Disorder }\end{array}$ & Behavior Disorder \\
\hline $\begin{array}{l}\text { Functioning } \\
\text { Grade Level }\end{array}$ & $3^{\text {rd }}$ Grade & $2^{\text {nd }}$ Grade & $6^{\text {th }}$ Grade \\
\hline Repertoires & $\begin{array}{l}\text { High percentage of } \\
\text { structural errors in } \\
\text { writing } \\
\text { Functional writing was } \\
\text { not in student's repertoire }\end{array}$ & $\begin{array}{l}\text { High percentage of } \\
\text { structural errors in } \\
\text { writing } \\
\text { Functional writing was } \\
\text { not in student's } \\
\text { repertoire }\end{array}$ & $\begin{array}{l}\text { High percentage of } \\
\text { structural errors in } \\
\text { writing } \\
\text { Functional writing was } \\
\text { not in student's } \\
\text { repertoire }\end{array}$ \\
\hline
\end{tabular}

Setting. All writing occurred in the $9^{\text {th }}$ grade classroom or in the library in the public school. Each student was seated at a desk and given a timer, a pen, a blank sheet of paper, and the written instructions on a separate piece of paper. The teacher/experimenter was in the room at all times during each session. The classroom had 8 students: 1 teacher: 2 teaching assistants. All of the students in the class were diagnosed with behavioral disorders. Instruction in the school 
was delivered through learn units by the teacher and teaching assistants in groups and 1:1 tutored instructional settings with a teacher and by peer tutoring (Albers \& Greer, 1991, Greer \& McDonough, 1999).

Definition of Behaviors: Dependent Variables. The dependent variables in this study were the structural components and functional effects of the students 'writing. The function of the students' writing was measured by the effects the writing had on a reader who was naive to the objectives of the study. Each student was given pictures to describe in writing. All of the pictures were counterbalanced across participants and included the same numbers of components. Ten components were determined for each picture prior to the onset of the study. Each student was given pictures that included colored shapes, lines, and a word. Each of these components of pictures was located in different areas of the page. Figure 1 shows an example of a picture and Figure 2 is the instructional page given to the students. Students were to include detailed descriptions of (1) the shape, (2) the color of the shape, (3) the position of the shape on the page (4) the word, (5) the color of the word, (6) whether the word was written in uppercase letters or lowercase letters, (7) the position of the word, (8) the line, (9) the color of the line, and (10) the position of the line on the page. Table 2 details the components of the drawings. At the end of each session throughout each phase of the study, the student's writing was given to at least one independent reader who was naïve to the purpose of the study. The naive readers, who were blind as to the conditions and objectives of the study, were a teaching assistant in the classroom and another teacher in the school. The naive reader did not know who the student was or the purpose of the study. The naive reader drew the pictures according to the students' written description. The numbers of components the independent reader drew correctly was measured as one of the dependent variables. A description was determined functional if a naïve reader drew the components of the picture correctly based on the student's description.

Figure 1

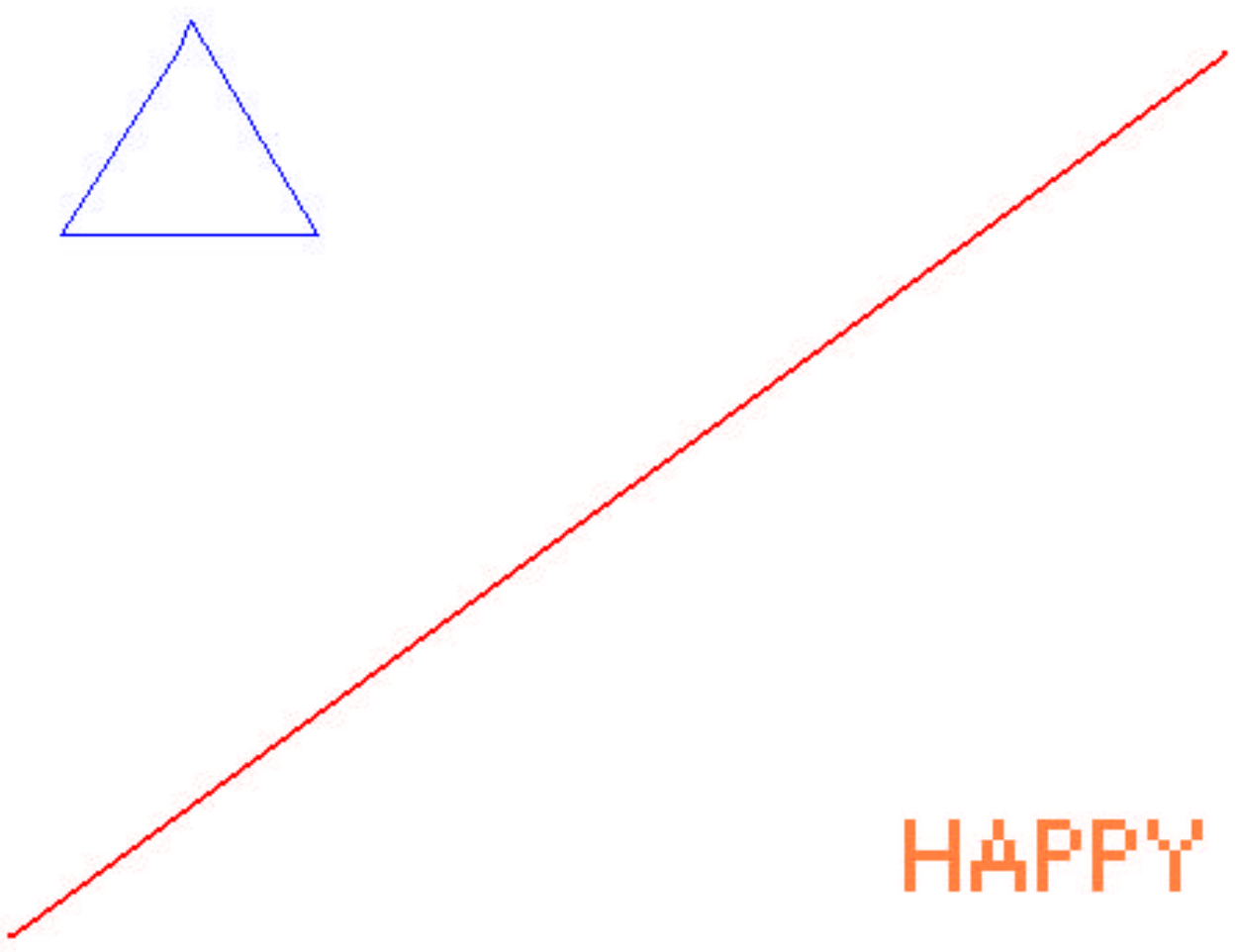


Figure 1. An example of a picture that the students used to provide written instructions to the naïve reader.

Figure 2

Name:

Date:

Directions: Describe the picture so that someone who has never seen it before will be able to draw it.

Figure 2. The written instructions given to the students for the data collection of the dependent variable.

Table 2: Functional Components of the Drawing Shown in Figure 1

\begin{tabular}{|c|c|c|}
\hline Number & Component & Description in Figure 1 \\
\hline 1 & Shape & Triangle \\
\hline 2 & Color of the shape & Blue \\
\hline 3 & $\begin{array}{l}\text { Position of the shape on } \\
\text { the page }\end{array}$ & Top left hand corner of the page \\
\hline 4 & Word & Happy \\
\hline 5 & Color of the word & Orange \\
\hline 6 & Lettering of the word & All uppercase letters \\
\hline 7 & $\begin{array}{l}\text { Position of the word on } \\
\text { the page }\end{array}$ & Lower right hand corner of the page \\
\hline 8 & Line & Diagonal line \\
\hline 9 & Color of the line & Red \\
\hline 10 & $\begin{array}{l}\text { Position of the line on the } \\
\text { page }\end{array}$ & $\begin{array}{l}\text { Diagonal from the top right hand corner to the bottom left } \\
\text { hand corner of the page }\end{array}$ \\
\hline
\end{tabular}

In addition to function, data were also collected on the structural components of the students writing. Structural measures included the numbers of accurate structural components throughout the essay (i.e. percentage of correct responses to grammar and punctuation of the total grammatical and structural components possible in the paper), the numbers of novel sentence frames, the numbers of adjectives and adverbs used, and the numbers of words and sentences written. These were converted to the percentage of accurate structural components out of the total possibilities and were calculated by dividing the numbers of correct responses to spelling, punctuation, capitalization, word choice, and sentence structure divided by the total numbers of opportunities to respond within each essay for each of these categories and multiplied by $100 \%$.

Independent Variable: Teacher Editing. The independent variables in this study were (a) reader/writer learn units and (b) writer immersion. The teacher instructed the students, in writing, to describe a picture so that a reader could draw it. The written directions and picture served as the antecedent for the student and the structural and functional outcomes of the students' written responses were the dependent variables. 
After the baseline phase, the teacher provided learn units for the student's written responses. The learn units consisted of providing the student with written praise for correct responses to the structure and function of writing, and corrections for incorrect responses. For the corrections the students observed the written corrections from the teacher and the students then rewrote the section as corrected. The students' corrected response were not reinforced consistent with learn unit protocol. Criterion was set at $100 \%$ correct responses for structure, including capitalization, punctuation, spelling, and sentence form after editing. That is, papers were redone until the $100 \%$ criterion was achieved.

Independent Variable: Writer Immersion and Self-Editing. Writer immersion was implemented in the third phase of this study. Writer immersion is an establishing operation tactic in which all communication is done in written form (Greer, 2002). During writer immersion, a period of time in each school day was arranged in which all communication required written responses. The time period for each student was determined by identifying the mean number of minutes each student took to complete writing assignments during the baseline phase. Questions, comments, requests for back-up reinforcers and breaks were done in writing. The students received written instructions instructing them that they were to describe pictures such that a reader could draw the pictures. After the student described the picture, the teacher gave the writing to a naïve reader (in another setting, and at a different time) who drew the components of the picture as described by the student, and provided written learn units for structural components. The teacher returned the students' written essay, the original picture with the structural corrections and the drawing done by the reader. The students then edited their paper for the functional and structural components of writing based on the reader's responses. In order to meet the criterion, the student had to affect the reader such that the reader drew all of the components correctly (100\%) and there were no structural errors.

Design and Procedure. We used a multiple baseline across subjects design (Baer, Wolf, \& Risley, 1968). All sessions were conducted individually with three phases. The three phases were: a non-instructional baseline phase in which the students did not receive feedback on structure or function, the first experimental phase that implemented teacher editing, and the second experimental phase that implemented writer immersion and self-editing. Table 3 outlines the steps followed during the procedure for Experiment 1.

Table 3: Sequence of Steps in Experiment 1

Pre-

instructional

Baseline

Teacher

Editing

Reader/Writer

Learn Units
Step 1 The experimenter gave students a picture with all of the components and a written antecedent to write a paragraph describing the picture during a typical instructional session.

Step 2 An adult reader, who was naïve to the purposes of the experiment and the students involved, read the students' written instructions. The reader drew a picture based only on the student's written responses and data were collected and measured. In this phase, the students' did not see the effects of their writing on the reader's drawings. No feedback in structure or function was given to the reader.

Step 3 The experimenter gave the students a picture and written antecedent as in the Baseline phase during typical instruction.

Step 4 The reader read the students' written responses and the reader drew a picture based on the students' written essay. The results were scored separately by the experimenter and independent scorers (i.e., a 
Writer Immersion And SelfEditing photocopy of the students' writing was done prior to the teacher and reader feedback).

Step 5 The experimenter provided learn units for the structural components of the writing (grammar, punctuation, spelling, word choice, sentence format) in written form.

Step 6 The experimenter/teacher reviewed the writing with the student and provided verbal praise for correct responses to each structural and functional component of the writing. The teacher and the student discussed the function and the teacher provided learn units in vocal form. The paper was returned to the student with the written structural component corrections and the directions to recycle, or rewrite, the essay with the necessary corrections for each structural and functional component.

Step 7 The experimenter repeated Steps 3-6 until the student met criterion specified at $100 \%$ accurate structural components for each essay after editing.

Step 8 Writer immersion was implemented for a specified period of time each day. The experimenter gave the students paper and pen to write down any questions they had for the experimenter, including mands for access to backup reinforcers, a break, or the bathroom, or questions about what to do. The students also communicated with each other in written form during writer immersion sessions.

Step 9 During the writer immersion period, the experimenter also gave the students a picture and written directions to describe the picture as in the earlier phases.

Step The students wrote an essay with the establishing operation in place. 10

Step The naïve reader read the students' written instructions. The reader

11 drew a picture based only on the description provided in the student's essay. Accurate and inaccurate components of the drawing were counted.

Step The experimenter provided learn units in written form for the 12 structural components of the essay only (grammar, punctuation, sentence form, and spelling).

Step With the establishing operation still in place (writer immersion), the 13 teacher returned the students written essay, the original picture, and the picture drawn by the naive reader. The teacher and the students communicated in writing to discuss whether the pic ture drawn by the reader matched the original drawing. If the pictures matched, the teacher reinforced the student with written praise. If the pictures did not match, the student self-edited his/her writing to provide the reader with the necessary information to draw the components accurately.

Step The students rewrote the instructions until they believed that the 14 reader could draw the picture accurately.

Step The experimenter repeated Steps 8 to 14 until the student met 15 criterion, specified as $100 \%$ accurate structural components and $100 \%$ of the components drawn accurately by the naïve reader after editing. 
Each of the above steps is described in detail in the following sections.

Pre-instructional Baseline. The teacher read aloud the directions to the students at the start of each session. These included: "Write a paragraph to describe the picture so that someone who has never seen the picture will be able to draw it." The teacher gave the students a picture, a black pen, and a lined piece of paper with the directions on the top. Each picture included one word, one shape, and one line drawn with different colored markers on a plain white $81 / 2$ inch by 11 inch piece of paper. Figure 1 shows and example of a drawing and Figure 2 shows the written directions sheet used to collect data. The pictures were counterbalanced across students and phases throughout the study.

Teacher Editing. During the first intervention phase, the teacher provided learn units. After each session of writing, the students submitted their writing to the teacher. The teacher delivered the picture to a reader who was naïve to the purpose of the assignment and the identity of the student. The naive reader drew the picture described. The teacher edited the student's written responses for spelling, punctuation, and capitalization. The teacher reinforced a correct response with a check mark and circled each incorrect response. The teacher vocally discussed the effects the writing had on the reader with the student. The student did not have access to the reader's picture. The teacher vocally reinforced the student for each component described and corrected the student for the components of the picture that were not described. The teacher returned the students' written assignment, the picture, and directions to rewrite, or recycle, their assignment. The student was required to make all corrections to the structural components of their writing and include the necessary functional components missing. The student rewrote the entire essay and resubmitted it to the teacher again to re-edit until the students met criterion specified as $100 \%$ accurate structural components. The student was reinforced with points that they could exchange for back-up reinforcers including candy and preferred activities at the end of the writing session. Following the first experimental phase involving teacher presented learn units without the student viewing the effects of their writing on the drawing of the naïve reader, we implemented writer immersion plus the opportunity to view the effects of their writing on the drawing of the naïve reader.

Writer Immersion and Viewing the Effects of Writing on the Reader's Drawn Responses. During the writer immersion phase, the teacher gave vocal directions at the beginning of each session. The directions stated that for the set period of time, all communication, including questions about the assignment and mands to go to the bathroom, access backup reinforcers, or for a break, was to be done in written form. The teacher gave the student a pen, the picture to describe and written directions to describe the picture. The teacher responded to the student's written essay in written form only. The teacher gave the essay to a naive reader who drew the picture described by the student. The teacher edited the writing and made corrections on the structure (defined as sentence form, punctuation. capitalization, and spelling). The student and teacher interaction was measured in learn units in the same manner that was done in the reader/writer learn unit phase. The teacher returned the edited essay to the student, as well as the picture drawn by the naive reader. The student rewrote, or recycled, the essay. The student was required to make the necessary corrections in structure, and edit their own writing for the effects 
on the reader by including or describing each of the components of the original picture that were missing or incorrect in the reader's picture. The student self-edited the functional effects of their writing. The student returned it to the teacher again to re-edit if there were any corrections until the structure and function were accurate. The student was reinforced with points for following directions and completing their writing assignment that they could exchange for back-up reinforcers anytime throughout the school day.

Data Collection. At the end of each writing session, the student's product was given to a naive reader who did not have access to the picture described. The reader drew the picture based only on the student's description. The numbers of the ten components drawn correctly by the reader served as the measure of the effects of the writer on the reader. In addition, we assessed the structural accuracy by the counting the numbers of sentences written, the numbers of adjectives and adverbs used, structurally correct components, and the numbers of novel autoclitic frames used for each assignment. During baseline phases, no feedback was given to the students on their writing structure or function. During the teacher editing learn unit phase, the students edited and rewrote their essays until they met a criterion of $100 \%$ for accurate structural components after editing. During the final phase, the writer immersion plus the students viewing the effects their writing, the criterion was $100 \%$ for accurate structural components and $100 \%$ of accurate functional components after editing.

Interscorer agreement. Interscorer agreements were done by comparing the teacher and an independent reader measure of all aspects of the students' writing for $30 \%$ of all writing assignments. Each assignment constituted a session. Each had an unmarked copy of the functional components needed and produced the permanent product data individually. The teacher and reader recorded the numbers of components drawn by the reader, the numbers of words written, the numbers of adjectives and adverbs used, the numbers of novel frames, and the percent accurate structural components. Point-by-point inter-scorer agreement was calculated by dividing the numbers of agreements by the number of agreements and disagreements and multiplying by 100 . Interscorer agreement was $98 \%$ for the functional effects, $100 \%$ for number of sentences written, $88 \%$ for numbers of adjectives and adverbs used, $100 \%$ for numbers of novel frames and $84 \%$ for the percentage of accurate structural components.

Results

Figure 3 shows the numbers of components of the drawing (colors, shapes, words, lines) the student described accurately measured by the components drawn by the naive reader. The naive reader for Student A's writing drew 2 of the 10 components of the drawing correctly during all of the baseline sessions. After teacher editing, the numbers of components drawn prior to editing ranged from 1 to 4 , with a mean of 2.50. After the implementation of writer immersion, the numbers of components drawn prior to editing ranged from 5 to 10 , with a mean of 7.33 .

The numbers of components of the drawing drawn by the reader during baseline sessions ranged from 0 to1, with a mean of .80, for Student B. After teacher editing, the numbers of components drawn prior to editing ranged from 1 to 3 , with a mean of 2.00. This increased to a range of 5 to 8 , with a mean of 6.80 after the implementation of writer immersion package that included the students' viewing the effects of their writing.

After reading Student C's writing, the reader drew between 2 and 3 components of the drawing, with a mean of 2.83, during baseline sessions. After the teacher editing, the mean numbers of components drawn prior to editing ranged from 2 to 5 , with a mean of 4.17. This 
increased to a range of 9 to 10 , with a mean of 9.5 components drawn by the reader after the implementation of writer immersion and self-editing.

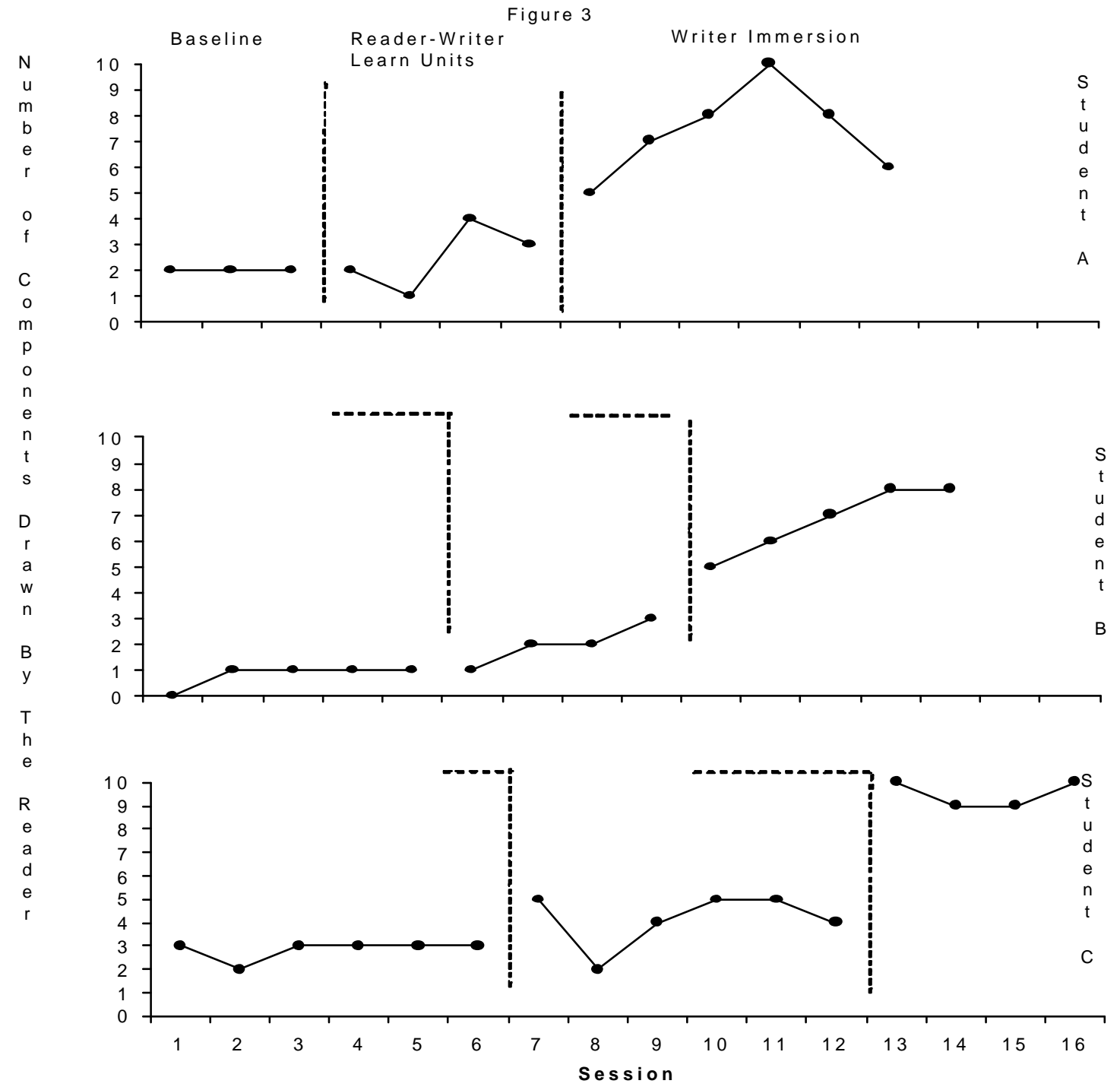

Figure 3. The numbers of components of the drawing drawn by an independent reader after reading essays prior to editing written by Students A, B, and C in Experiment 1.

Figure 4 shows the percentage of accurate structural components written on essays prior to editing. Student A emitted a mean of 30\% accurate structural components during the baseline phase. This increased to a mean of $73.25 \%$ during teacher editing prior to rewriting and a mean of $88.33 \%$ during writer immersion. Student B emitted a mean of $26.60 \%$ accurate structural components during the baseline phases. This increased to a mean of $76.75 \%$ accurate structural components during reader/writer learn units prior to editing and a mean of $85.60 \%$ after the implementation of writer immersion. Student $C$ emitted $46.67 \%$ accurate structural components 
during the baseline phase, a mean of $70.17 \%$ accurate structural components during teacher editing on essays prior to editing, and a mean of $95 \%$ accurate structural components after the implementation of writer immersion and self-editing.

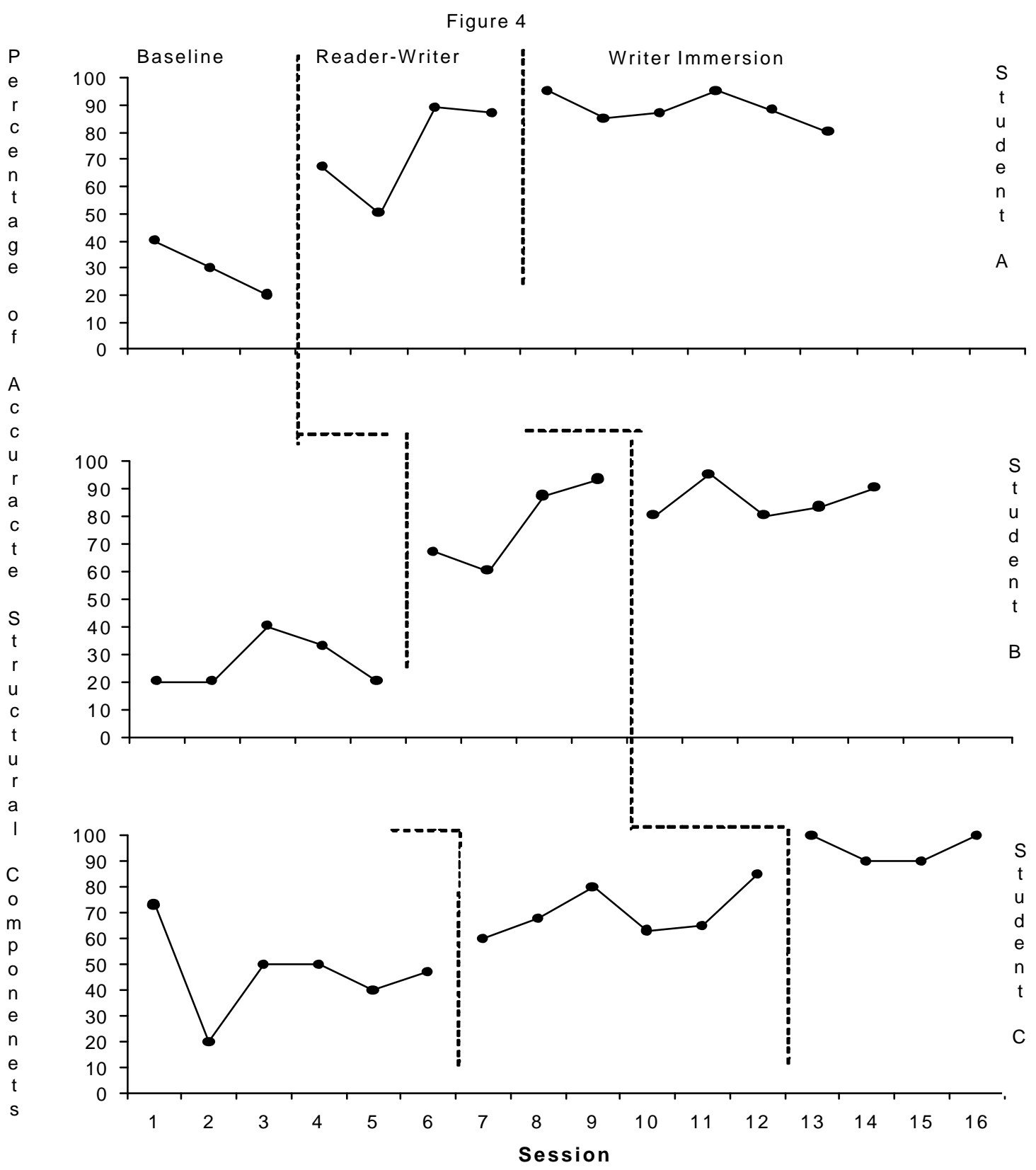

Figure 4. The percent accurate structural components in essays for each of the three phases prior to teacher editing are shown for Student A, B, and C in Experiment 1.

Data were also collected on the numbers of sentences written, the numbers of novel responses to sentence frames, and the numbers of adverbs and adjectives used. These data are 
represented in Table 4. Although the data show only slight increases in each of these variables, the function and the accuracy of structure of the writing increased.

Table 4: Structural Components of Writing of Participants in Experiment 1

Mean Numbers of Sentences Written

\begin{tabular}{|c|c|c|}
\hline Student & $\underline{\text { Baseline }}$ & Writer Immersion \\
\hline Student A & 1.00 sentence & 8.83 sentences (range: $4-14)$ \\
\hline Student B & 1.80 sentences (range:0-3) & 5.60 sentences (range: $7-14$ ) \\
\hline Student C & 2.15 sentences (range: $1-3$ ) & 5.00 sentences (range: $4-6)$ \\
\hline
\end{tabular}

Mean Numbers of Adjectives and Adverbs Used

\begin{tabular}{|c|c|c|}
\hline Student & Baseline & Writer Immersion \\
\hline Student A & 4.33 (range: 45 ) & 33.50 (range: 16-73) \\
\hline Student B & 4.80 (range: $3-7$ ) & 9.60 (range: 7-14) \\
\hline Student C & 9.33 (range: 8-18) & 13.33 (range: $13-21$ ) \\
\hline
\end{tabular}

Mean Numbers of Novel Autoclitic Sentence Frames

\begin{tabular}{|c|c|c|}
\hline Student & Baseline & Writer Immersion \\
\hline Student A & 1.00 (range: $1-1)$ & 3.16 (range: $1-5)$ \\
\hline Student B & 1.80 (range: 1-2) & 2.00 (range: $1-5$ ) \\
\hline Student C & 1.33 (range: 1-2) & 2.75 (range: $2-4$ ) \\
\hline
\end{tabular}

\section{Discussion}

The data showed increases in the numbers of sentences written and the percent accurate structural components after the implementation of reader/writer learn units. However, the numbers of adjectives and adverbs used, the numbers of novel sentence frames, and the numbers of components drawn by the reader did not increase until after the implementation of writer immersion.

The use of the teacher/experimenter's learn units alone was not effective to teach middle school students the function of writing. The data showed a signific ant difference in the numbers of components drawn by the reader for all of the participants in this study after the implementation of writer immersion with the student's viewing the effects of their writing on the reader's drawings. This showed that writer immersion was an effective tactic for teaching middle school students diagnosed with behavioral and learning disabilities to write to affect the behavior of the reader. This tactic was also effective in increasing the numbers of sentences written, and the numbers of novel sentence frames and adjectives and adverbs used. As students wrote to affect the behavior of the reader, the numbers of novel responses increased.

Experiment 2 was a systematic replication of the first experiment with four new participants diagnosed with behavior disorders to further test the effects of writer immersion. 
Since the results of Experiment 1 showed that teacher editing alone was not effective in teaching students to write functionally, only the package of writer immersion plus viewing the effects of the writing was implemented as a tactic in the replication. This avoided the possible cumulative effect of receiving learn units prior to the writer immersion package. That is, in the first experiment the effects of the second intervention could not be separated from any additive effects. The baseline phase was the same as Experiment 1 followed immediately by the implementation of the immersion with self-editing by the students after the students viewed the effects of their writing on reader's drawings. Another change in Experiment 2 was a change in the criterion for the structure and function of the student writing. In Experiment 1, the students were required to recycle, or rewrite the essays until they emitted $100 \%$ accurate structural components and $100 \%$ of the components were drawn by the readers as a result of teacher learn units alone. In Experiment 2, the performance criterion was the same; however, they had to meet the criterion prior to recycling. The students were required to write until accurate functional effects accrued and the structure was correct after viewing a picture for the first time.

\section{Experiment 2}

All of the components of the second experiment were the same as Experiment 1 except for the following: the participants differed, only writer immersion plus the students' viewing the effects of their writing constituted the independent variable package, and the criterion for mastery differed.

\section{Method}

Participants. Four students participated in Experiment 2. Student D was a 16-year-old female diagnosed with a behavioral disorder. The student functioned at approximately a $6^{\text {th }}$ grade academic level. Student E was a 16-year old female diagnosed with a behavior disorder and functioned academically at approximately at $6^{\text {th }}$ grade level. Student F was a 14-year old female diagnosed with a behavior disorder. The student functioned at approximately a $6^{\text {th }}$ grade academic level. Student $\mathrm{G}$ was a 15 year old male diagnosed with a behavior disorder and functioned approximately at a $5^{\text {th }}$ grade academic level. All of the students attended a $9^{\text {th }}$ grade class at the same publicly funded school just outside a major metropolitan area utilizing a comprehensively behavior analytic educational model as those students who participated in the first experiment. Table 5 describes additional information about the participants.

Table 5: Participants in Experiment 2

\begin{tabular}{|c|c|c|c|c|}
\hline Student & $\begin{array}{l}\text { Student D: } \\
9^{\text {th }} \text { grade student }\end{array}$ & $\begin{array}{l}\text { Student E: } \\
9^{\text {th }} \text { grade student }\end{array}$ & $\begin{array}{l}\text { Student F: } \\
9^{\text {th }} \text { grade student }\end{array}$ & $\begin{array}{l}\text { Student G: } \\
9^{\text {th }} \text { grade student }\end{array}$ \\
\hline Level of & Reader/ & Reader/ & Reader/ & Reader/ Emergent \\
\hline $\begin{array}{l}\text { Verbal } \\
\text { Behavior }\end{array}$ & Writer & Writer & $\begin{array}{l}\text { Emergent } \\
\text { Writer }\end{array}$ & writer \\
\hline Diagnosis & $\begin{array}{l}\text { Behavior } \\
\text { Disorder }\end{array}$ & $\begin{array}{l}\text { Behavior } \\
\text { Disorder }\end{array}$ & Behavior Disorder & Behavior Disorder \\
\hline $\begin{array}{l}\text { Functioning } \\
\text { Grade Level }\end{array}$ & $6^{\text {th }}$ Grade & $6^{\text {th }}$ Grade & $6^{\text {th }}$ Grade & $5^{\text {th }}$ Grade \\
\hline Repertoires & $\begin{array}{l}\text {-High percentage } \\
\text { of structural }\end{array}$ & $\begin{array}{l}\text { High percentage } \\
\text { of structural }\end{array}$ & $\begin{array}{l}\text {-High percentage of } \\
\text { structural errors in }\end{array}$ & $\begin{array}{l}\text {-High percentage of } \\
\text { structural errors in }\end{array}$ \\
\hline
\end{tabular}


errors in writing

-Functional writing was not in student's repertoire errors in writing

-Functional

writing was not

in student's

repertoire writing

-Functional writing was not in student's repertoire writing -Functional writing was not in student's repertoire

Design. A multiple baseline design across students was implemented. A baseline phase, in which the participants described a picture and no feedback was given, was followed by the implementation of writer immersion with the provision of the opportunity to view the effects of the students' writing on the reader's drawings.

Dependent Variables. The dependent variables in Experiment 2 were the same as those collected in Experiment 1 with one exception-- data were not collected on the numbers of novel sentence frames.

Independent Variables. The tactic was implemented using the same procedures in Experiment 1 . The students edited their own writing after viewing drawings done by a reader who was naïve to the conditions of the experiment. However, the criterion for effective writing was changed from the first experiment. In the second experiment the students continued in the writer immersion phase until their writing met a criterion of $100 \%$ accurate structural components and $100 \%$ functional components on essays prior to editing by the teacher-experimenter.

Interscorer agreement. Interscorer agreement was scored on the numbers of components drawn by the naïve reader, the numbers of words, numbers of sentences, numbers of adjectives and adverbs and numbers of structural errors recorded on each written paper as described in Experiment 1. Interscorer agreement was $100 \%$ for the numbers of components drawn by the naïve reader, $100 \%$ for the numbers of sentences written, $94 \%$ for the percent of accurate structural components, and $96 \%$ for the numbers of adjectives and adverbs used.

\section{Results}

Figure 5 shows the numbers of accurate components drawn by the reader per written assignment. The numbers of components drawn for Student D during the baseline phase was a mean of 3.33 (range of three to four) out of 10 possible correct components and increased to a mean of 8.00 (range of 2 to 10) during the implementation of writer immersion package prior to teacher editing. The mean numbers of components drawn on essays prior to editing for Student $\mathrm{E}$ increased from a mean of 2.75 (range of 2 to 4 ) during the baseline phase to a mean of 8.00 (range of 4 to 10) during the implementation of writer immersion. The numbers of components drawn increased for Student F as well, from a mean of 3.6 (range of 3 to 4) during the baseline phase to a mean of 6.53 (range of 1 to 10) after the implementation of writer immersion. For Student G, the numbers of components drawn by the reader on essays prior to editing increased from a mean of 4.00 (range of 3 to 6) during the baseline phase to a mean of 7.66 (range of 3 to 10) after the implementation of writer immersion. These data showed a significant increase in the writer's functional effects on the reader as a result of the writer immersion package involving the students' viewing the effects of their writing on the reader's drawings. 


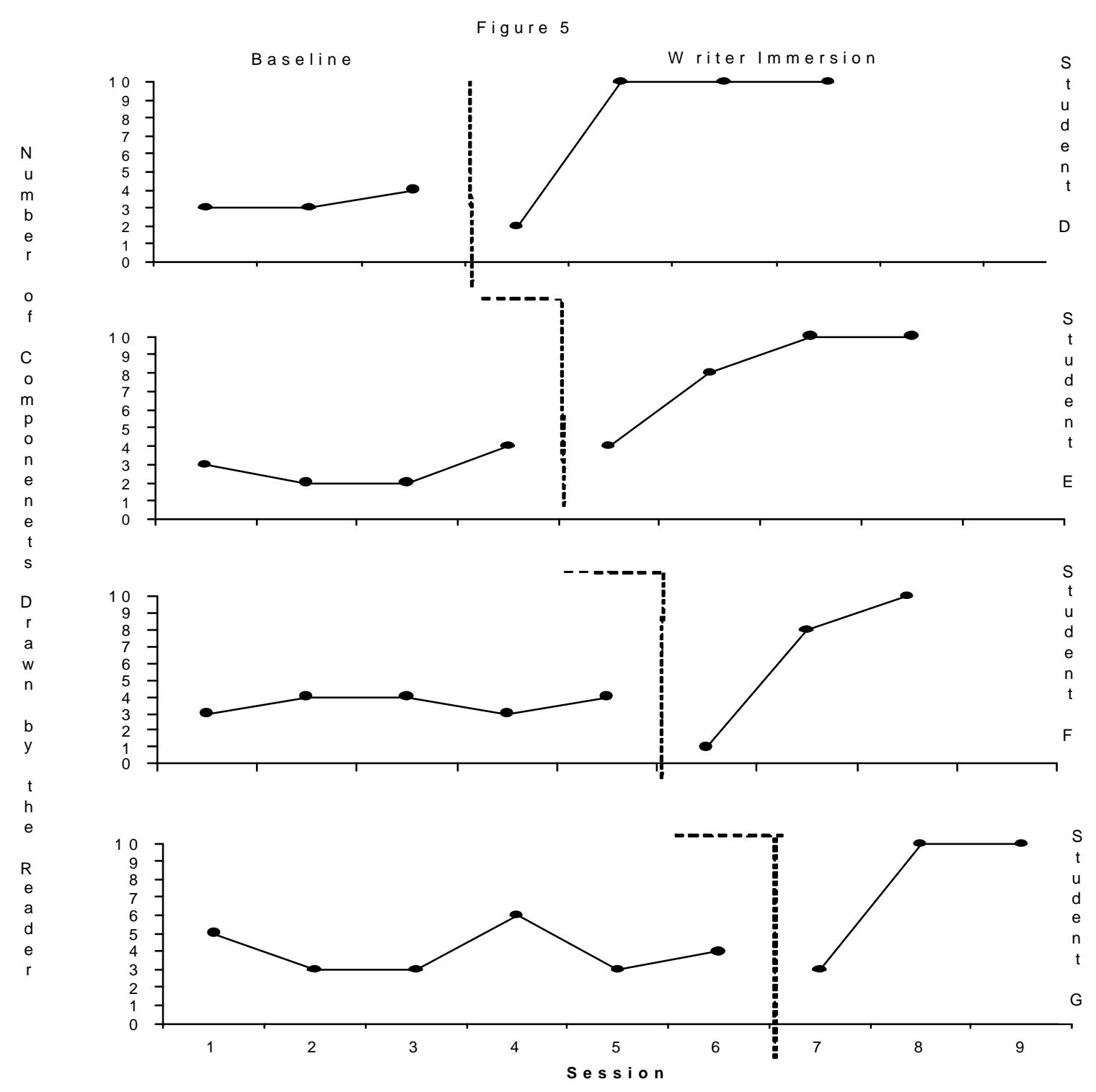

Figure 5. The numbers of components of the drawing drawn by an independent reader after reading essays prior to editing written by Students D, E, F, and G in Experiment 2.

Figure 6 shows the percentage of accurate structural components that was calculated by dividing the numbers of correct responses to spelling, grammar and punctuation and dividing by the total number of opportunities to respond within the written essay. The mean percentage of accurate structural components for Participant D increased from $53.33 \%$ (range of $40 \%$ to $60 \%$ ) during baseline sessions to $77.50 \%$ (range of 60 to $100 \%$ ) during writer immersion. The mean percentage of accurate structural components for Participant E increased from a 55.00\% (range of $40 \%$ to $60 \%$ ) during baseline to a mean of $75 \%$ (range of $40 \%$ to $100 \%$ ) during writer immersion. The mean percentage of accurate structural components for Participant F increased from $20.00 \%$ during baseline sessions to a mean of $63.33 \%$ (range of $20 \%$ to $90 \%$ ) during writer immersion. For Participant G, the mean percentage of accurate structural components increased from a mean of $43.33 \%$ (range of $40 \%$ to $60 \%$ ) during baseline phases to $86.67 \%$ (range of $80 \%$ to $100 \%$ ) during writer immersion. 


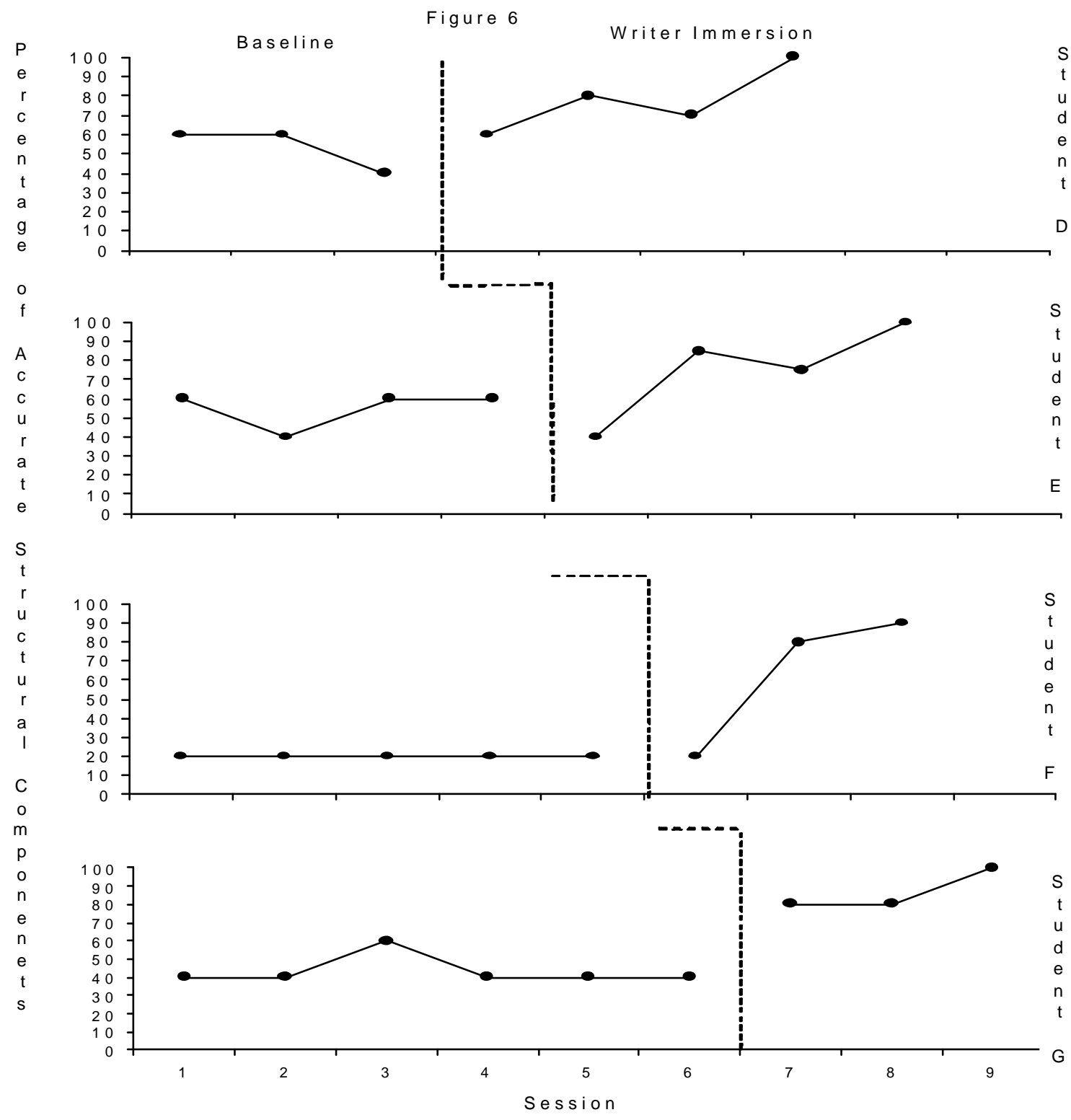

Figure 6. The percent accurate structural components in essays prior to editing are represented for Students D, E, F, and G in Experiment 2.

The numbers of adjectives and adverbs written for Student $F$ and $G$ and the numbers of sentences written for all students are shown in Table 6 . There was a significant increase in the numbers of adjectives and adverbs used after the implementation of writer immersion. 
Table 6: Structural Components of Writing of Participants in Experiment 2

Mean Numbers of Sentences Written

\begin{tabular}{|c|c|c|}
\hline Student & Baseline & Writer Immersion \\
\hline Student D & 2.33 sentences (range: $1-3$ ) & 4.50 sentences (range: $1-6$ ) \\
\hline Student E & 1.50 sentences (range: $1-3$ ) & 4.75 sentences (range: $1-7$ ) \\
\hline Student F & 0.00 sentences & 3.33 sentences (range:0-6) \\
\hline Student G & 1.00 sentence (range: $1-1)$ & 4.00 sentences (range: $1-7$ ) \\
\hline
\end{tabular}

Mean Numbers of Adjectives and Adverbs Used

\begin{tabular}{|c|c|c|}
\hline Student & Baseline & Writer Immersion \\
\hline Student D & 4.00 (range: $2-4)$ & 10.50 (range: $2-14)$ \\
\hline Student E & N/A & N/A \\
\hline Student F & 2.80 (range: $2-4)$ & 9.35 (range:0-16) \\
\hline Student G & N/A & N/A \\
\hline
\end{tabular}

\section{Discussion}

There was a significant difference in the functional and structural components of writing after the implementation of writer immersion. The results of Experiment 2 demonstrate that writer immersion is an effective tactic to teach these students to write more functionally and also improve their accuracy in the use of the structural components of writing. Writer immersion taught the students to write to affect the behavior of the reader.

The results of the second experiment replicated the findings of the first experiment in that writer immersion is an effective tactic to teach students the functional components of writing. However, it also demonstrated that writer immersion was also effective in increasing the structural components of writing. This could not be determined from the first experiment since increases in the numbers of correct responses to grammar and punctuation were measured after the implementation of reader/writer learn units through teacher editing alone.

\section{General Discussion}

In Experiment 1, an effectiveness criterion for structure and function for the writer immersion was not specified. With the specification of criteria for writing in Experiment 2, data were collected until the students met the specified criterion for both structure (100\% accurate structural components) and function (100\% accurate functional components) on an essay prior to teacher editing feedback. The data also showed increases in the numbers of sentences and the numbers of adverbs and adjectives. As the student wrote to affect the behavior of the reader, the numbers of novel adjectives and adverbs increased. Because both functional effects and increases in the use of novel adjective-adverbs occurred, we speculate that the adjective-adverb usage functioned as autoclitics to affect the reader's behavior. Future research should directly test this 
possibility. It would be beneficial to replicate the study with criterion specified for these autoclitic functions.

Jadlowski (1997) found that having a student writer edit another student's written responses while the teacher served as a reader for their written responses resulted in criterion in fewer recycles of their written responses. Thus the effect was due to the writer serving as an editor of other student's writing. Future studies should explore the effects of having students edit other students' papers as part of writer immersion package on the functional and structural components of writing.

Skinner (1957) suggested that different audiences should affect a writer such that the writer comes under the control of different target audiences. Future studies should address teaching students to write and self-edit to affect the behaviors of different audiences, and test the effects of different procedures on aesthetic writing.

The results of the present study together with the finding of other studies that were designed to teach writer function provide empirically based procedures for teaching the function of writing. The evidence from all of these studies suggests that teaching functional writing results in collateral improvements in the use of the structural components of writing. The establishing operation is key to teaching function whether the response is written or spoken. In summary, research in verbal behavior identifies how to teach the function of writing and this perspective advances the pedagogical procedures for teaching students to write well.

\section{References}

Albers, A. \& Greer, R.D. (1991). Is the three term contingency trial a predictor of effective instruction? Journal of Behavioral Education, 1, 331-354

Baer, Wolf, M.M. \& Risley, T.R. (1968). Some current dimensions of applied behavior analysis. Journal of Applied Behavior Analysis, 1(1), 91 - 97

Greer, R.D. (1994). A systems analysis of the behaviors of schooling. Journal of Behavioral Education, 4, 255-264.

Greer, R.D. (2002). Designing Teaching Strategies: An Applied Behavior Analysis Systems Approach. San Diego, California: Academic Press.

Greer, R. D., Chavez-Brown, M. Nirgudkar, A. S., Stolfi, L., \& Rivera-Valdes, C. (In Press). Acquisition of fluent listener responses and the educational advancement of young children with autism and severe language delays. European Journal of Behavior Analysis.

Greer, R.D., \& Keohane, D.D. (2005). The evolution of verbal behavior in young children. Behavioral Development Bulletin, 1, 31 - 48.

Greer. R.D. \& McDonough, S. H. (1999). Is the learn unit a fundamental measure of pedagogy? Behavior Analyst, 22, 5-16.

Greer, R.D., \& Ross, D.E. (2001). Treatments for language disorders from research on 
Skinner's theory of verbal behavior. Unpublished manuscript, Teachers College, Columbia University.

Greer, R.D. \& Ross, D.E. (2004). Research in the induction and expansion of complex verbal behavior. Journal of Early Intensive Behavioral Intervention, 1 (2), 141-165

Greer, R.D. \& Ross, D.E. (in press). Verbal Behavior Analysis: Inducing and Expanding New Verbal Capabilities in Children with Language Delays. Unpublished document, Teachers College, Columbia University.

Hart, B. \& Risley, T.R. (1995). Meaningful Differences in the Everyday Experience of Young American Children. Baltimore, Maryland: Paul H. Brookes Publishing Co.

Jadlowski, S.M. (2000). The effects of a teacher editor, peer editing, and serving as a peer editor on elementary students' self-editing behavior. (Doctoral Dissertation, Columbia University, 2000). Dissertation Abstracts International, 9970212.

Madho, V. (1997). The effects of the responses of a reader on the writing effectiveness of children with developmental disorders. (Doctoral Dissertation, Columbia University, 1997). Dissertation Abstracts International, 9809740.

Michael, J. (1982). Distinguishing between discriminative and motivational functions of stimuli. Journal of the Experimental Analysis of Behavior, 37, 149 - 155.

Michael, J. (1984). Verbal behavior. Journal of the Experimental Analysis of Behavior, 42, 363-376.

Michael, J. (1993). Establishing operations. The Behavior Analyst, 16, 191-206.

Ross, D.E. (1995). Verbal immersion to increase speaker behavior. Poster presentation at the $21^{\text {st }}$ Annual International Conference for the Association for Behavior Analysis, May, Washington D.C.

Ross, D.E., Nuzzolo, R., Stolfi, L, Natarelli S., \& Greer R. D. (2006). Effects of speaker immersion on the spontaneous speaker behavior of preschool children with communication delays, Journal of Early and Intensive Behavioral Intervention, 3(1), 135-150.

Skinner, B.F. (1953). Science and Human Behavior. New York, NY: The Macmillan Company.

Skinner, B.F. (1957). Verbal Behavior. Acton, MA: Copley Publishing Group.

\section{Authors Note}

The authors would like to thank Jiwon Kang for all of her help with the collection of the data presented in this paper. We would also like to thank all of our colleagues who served as readers throughout the data collection.

Address Correspondence to: 
Tracy Reilly Lawson

Email: trlr2009@columbia.edu

Or

R. Douglas Greer

E-mail: dgreer3872@aol.com

Box 76 Teachers College

Columbia University

New York, NY 10027

\section{Advertising in the Journal of Early and Intensive Behavior Intervention}

Advertising is available in JEIBI. All advertising must be paid for in advance.

Make your check payable to Joseph Cautilli. The ad copy should be in our hands at least 3 weeks prior to publication. Copy should be in MS Word or Word Perfect, RTF

format and advertiser should include graphics or logos with ad copy.

The prices for advertising in one issue are as follows:

Page: $\$ 200.00$

1/4 Page: $\$ 50.00 \quad 1 / 2$ Page: $\$ 100.00$ vertical or horizontal Full

If you wish to run the same ad in both issues for the year, you are eligible for the following discount:

1/4 Pg.: $\$ 40$ - per issue

1/2 Pg.: \$75 - per issue -vertical or horizontal

Full Page: \$150.00-per issue.

For more information, or place an ad, contact Halina Dziewolska by phone at (215) 462-6737 or e-mail at: halinadz@hotmail.com 


\title{
Promoting Positive Learning Outcomes for Young Children in Inclusive Classrooms: A Preliminary Study of Children's Progress Toward Pre-Writing Standards
}

\author{
Jennifer Grisham-Brown, Ed.D. \\ University of Kentucky \\ Robyn Ridgley, Ed.D. \\ Middle Tennessee State University \\ Kristie Pretti-Frontczak, Ph.D. \\ Kent State University \\ Cissie Litt and Andrea Nielson \\ Jessamine County Early Learning Village
}

\begin{abstract}
We used a multiple baseline across students in preliminary study to investigate the effects of embedding learning opportunities on the acquisition of pre-writing skills in 3 preschool-aged children of varying abilities enrolled in inclusive preschool programs. Acquiring pre-writing skills is part of most states' pre-kindergarten standards and is considered an important early literacy skill. Instruction was distributed across the school day within developmentally appropriate activities. Results showed that 2 of the 3 children acquired their target skill, while the third made progress over baseline performance. As preschool teachers struggle to teach children with differing abilities and to promote progress toward statewide standards, creating embedded learning opportunities may offer an effective tactic. Implications for practice and future research are discussed.

Key Words: embedding, pre-kindergarten standards, inclusive preschool
\end{abstract}

\section{Introduction}

Since the passage of No Child Left Behind and specifically the Good Start Grow Smart Provisions of that Act, 43 states have developed pre-kindergarten standards for children who are 3-5 years of age (Neuman \& Roskos, 2005). Predictably, programs serving this age group are now being held responsible for children's attainment of these standards. For example, beginning in 2000, the Administration for Children and Families began requiring Head Start programs to report children's progress on identified outcomes in the areas of language, literacy and numeracy. The Office of Special Education Programs, too, now requires that states report the progress of children being served through Part 619 (preschool act) of the Individuals with Disabilities Education Act in the area of knowledge and skills, including early literacy (Office of Special Education Programs, 2005).

This trend toward accountability in early care and education programs has three (3) implications for programs serving young children. First, because many young children are being served in inclusive early childhood settings (Grisham-Brown, Hemmeter, \& Pretti-Frontczak, 2005), it is possible that they may be benefiting from the services of a number of agencies. Programs may have to determine who will receive "credit" for children's progress (Harbin, Rous, $\&$ McLean. 2005). For example, a child may be in a public preschool program that combines funding from IDEA (Part 619), Head Start, and perhaps Title 1. Programs may have to determine if progress made by children is a result of the special education services they receive or from their 
experiences in Head Start. Second, as a result of movement toward more inclusive education, teachers are challenged to demonstrate the progress of a highly diverse group of children toward a single set of program standards. For example, teachers may have to demonstrate all children are acquiring skills toward a pre-kindergarten standard that reads "demonstrates competence in the beginning skills and strategies of the writing process" (Kentucky Department of Education, 2003). Within any inclusive preschool classroom, children may demonstrate their acquisition of this competency in a variety of ways (e.g., making a mark on a piece of paper, copying shapes, writing letters). Teachers presented with the challenge of teaching heterogeneous groups of children have the added pressure of ensuring that all children are making progress within this accountability climate; the third implication of the current "standards-based" environment.

The educational climate described above requires the implementation of interventions that will result in positive outcomes for children. One strategy that has produced positive results for young children with disabilities has been activity-based intervention or more specifically the embedding of learning opportunities into classroom activities (Pretti-Frontczak \& Bricker, 2005). A number of studies have shown that interspersing instructional opportunities into existing classroom activities positively influences the acquisition of skills in preschoolers with disabilities (e.g., Daugherty, Grisham-Brown, \& Hemmeter, 2001; Grisham-Brown, Schuster, Hemmeter, \& Collins, 2000; Horn, Lieber, Li, Sandall, \& Schwartz, 2000). For example, Daugherty, et al. (2001) used a constant time delay technique to teach three (3) preschool-aged children with speech/language delays to count objects in their environment when instruction was embedded into ongoing classroom activities (e.g., playing with blocks, snack, small group activities). All three children acquired and maintained their target number set.

As previously mentioned, research related to the effects of creating embedded learning opportunities during daily activities has primarily been conducted with children who have disabilities (see Grisham-Brown, et al, 2000 and Garfinkle \& Schwartz, 2002 for examples). The present study differs from previous research related to embedding in that the population of children with whom the research was conducted includes children with and without disabilities. This is a more realistic situation in that many preschool teachers are now teaching within inclusive programs (Grisham-Brown, et al., 2005). Furthermore, while there is research on the effects of embedding learning opportunities on the acquisition of literacy skills with primary-aged children (e.g., Wolery, Anthony, Caldwell, Snyder, \& Morgante, 2002), there is little, if any research, on the attainment of literacy skills, with preschool children when learning opportunities are embedded into daily activities.

Instructional strategies that promote literacy development in a developmentally appropriate manner are crucial given the present emphasis on this area of development (Gambrell \& Mazzoni, 1999; Neuman, Copple \& Bredekamp, 2000; Owocki, 2001; Schickedanz, 1999; Schickedanz \& Casbergue, 2004) and the diverse nature of preschool classrooms (GrishamBrown, et al., 2005). The purpose of this study was to add to the current research on the effects of embedding learning opportunities during daily activities. The specific research questions were: Will preschool children with varying abilities acquire pre-writing skills when learning opportunities are embedded into existing classroom activities? Will preschool children with varying abilities maintain pre-writing skills when learning opportunities are embedded into existing classroom activities?

\section{Methods}

\section{Participants and Setting}


Three preschool children, one boy and two girls, participated in the study. The children attended a rural early childhood center, administered by the local school district, which provided preschool services to children with disabilities, those who were at-risk due to family income, and those whose families opted to pay tuition to enroll their child in the program. All children enrolled in the program attended four days per week for approximately 3.5 hours each day. The participating children were four-years-old and were scheduled to enter kindergarten the following school year. Arthur was developing typically as evidenced by beginning-of-the-year screenings. Hanna had a speech/language delay and received services from a speech/language pathologist and Kaleigh had developmental delays and received services from a speech/language pathologist and special education teacher. All services were provided within the preschool classroom that was comprised of approximately 16 children, one certified teacher, and two teaching assistants.

The classroom teacher or the teaching assistants working within the classroom implemented baseline and intervention sessions. All classroom teachers and teaching assistants had participated in a federally funded model demonstration grant in which they were trained to conduct activity-based assessments, plan interventions, and embed learning opportunities into classroom activities. All sessions occurred in the classroom during center and small group activities using common classroom materials (e.g., paper, art work, pencils, markers).

\section{Procedures}

Prior to intervention, each child's cognitive skills, including pre-literacy, gross and fine motor development, adaptive skills, socialcommunication, and social skills were assessed using the Assessment, Evaluation, and Programming System (AEPS®; Bricker, 2002). Each child's pre-writing skills were further assessed using a writing rubric (see Table 1). The rubric was developed by the researchers and was based upon several resources that describe the development of writing skills in young children (e.g., Bricker, 2002; Bodrova, Leong, Paynter, \& Semenov, 2000; Bodrova \& Leong, 1998; Temple, Nathan, Temple, \& Burris, 1993). The rubric outlines the developmental spectrum of writing skills from novice to mastery and was used to aid the teachers in targeting developmentally appropriate pre-writing skills for each child. Arthur and Hanna's target skill was to write his or her entire name from memory with all le tters in the correct order. Kaleigh's target skill was to write the first three letters of her name from memory with the letters in the correct order.

The classroom teachers and researchers also met to develop an intervention plan for each child. The intervention plans outlined how learning opportunities related to pre-writing (and specifically the child's target skill) could be embedded into small group and center-time activities. The intervention plan included identifying (a) naturally occurring antecedents that set the occasion for the learning opportunity (e.g., child arrives at school and the teacher asks him sign in as he enters the classroom; child's finishes her painting and is reminded to put her name on her work), (b) possible child responses to the antecedent (e.g., writes her name; writes something else; child does nothing or says, "I don't know how; ignores the antecedent), and (c) naturally occurring consequences for the child's response that ensured the child had an opportunity to practice the target skill if he/she responded incorrectly (or not at all), or receive reinforcement (i.e., verbal praise) for correctly demonstrating the skill. Teachers and teaching assistants gave increasing amounts of assistance (e.g., verbal, model, physical prompting) as needed by the child if the child did not correctly perform any part of writing his/her name using procedures described in the literature as system of least prompts and constant time delay (Wolery, Ault, \& Doyle, 1992). 
Table 1: Writing rubric

\begin{tabular}{|c|c|c|c|c|}
\hline Novice & Apprentice & Intermediate & Proficient & Mastery \\
\hline $\begin{array}{l}\text { - Simultaneously } \\
\text { brings hands to } \\
\text { midline } \\
\text { Brings two } \\
\text { objects together } \\
\text { at or near } \\
\text { midline } \\
\text { - Grasps hand- } \\
\text { size object with } \\
\text { either hand } \\
\text { using ends of } \\
\text { thumb, index, } \\
\text { and second } \\
\text { fingers } \\
\text { Grasps fat } \\
\text { crayon/marker/ } \\
\text { other tool and } \\
\text { scribbles on } \\
\text { paper }\end{array}$ & $\begin{array}{l}\text { Holds } \\
\text { object with } \\
\text { one hand } \\
\text { while the } \\
\text { other hand } \\
\text { manipulates } \\
\text { Child holds } \\
\text { crayon, } \\
\text { marker, } \\
\text { pencil, or } \\
\text { other } \\
\text { writing } \\
\text { implement } \\
\text { using the } \\
\text { thumb and } \\
\text { first two } \\
\text { fingers. } \\
\text { Child may } \\
\text { move whole } \\
\text { arm across } \\
\text { writing } \\
\text { surface to } \\
\text { write or } \\
\text { draw. } \\
\text { Uses } \\
\text { scribble } \\
\text { writing or } \\
\text { letter-like } \\
\text { forms to } \\
\text { represent } \\
\text { words or } \\
\text { ideas - } \\
\text { assigns } \\
\text { meaning to } \\
\text { scribbles } \\
\text { Copies } \\
\text { simple } \\
\text { written } \\
\text { shapes after } \\
\text { demonstrati } \\
\text { on (e.g., } \\
\text { circle, } \\
\text { cross, T); } \\
\text { shape } \\
\text { should } \\
\text { resemble } \\
\text { the }\end{array}$ & $\begin{array}{l}\text { Uses three- } \\
\text { finger grasp } \\
\text { to hold } \\
\text { writing } \\
\text { implement } \\
\text { (experiment } \\
\text { s with grasp } \\
\text { when using } \\
\text { a variety of } \\
\text { writing } \\
\text { tools) } \\
\text { Produces } \\
\text { simple texts } \\
\text { using letter- } \\
\text { like forms } \\
\text { (writing } \\
\text { includes } \\
\text { lines and } \\
\text { circles) } \\
\text { Draws using } \\
\text { representatio } \\
\text { nal figures } \\
\text { (i.e., } \\
\text { drawings to } \\
\text { represent } \\
\text { people, } \\
\text { places, } \\
\text { events, and } \\
\text { objects. } \\
\text { Recognizabl } \\
\text { e to others } \\
\text { or child is } \\
\text { able to } \\
\text { describe or } \\
\text { label } \\
\text { features of } \\
\text { the } \\
\text { drawings) } \\
\text { Prints } \\
\text { pseudo- } \\
\text { letters (i.e., } \\
\text { produce } \\
\text { characters } \\
\text { that } \\
\text { resemble } \\
\text { letters and } \\
\text { words, } \\
\text { - }\end{array}$ & $\begin{array}{l}\text { Adjust } \\
\text { body } \\
\text { position } \\
\text { when } \\
\text { writing } \\
\text { Adjust } \\
\text { paper } \\
\text { position } \\
\text { when } \\
\text { writing } \\
\text { Child } \\
\text { draws or } \\
\text { writes with } \\
\text { crayon, } \\
\text { marker, } \\
\text { pencil, or } \\
\text { other } \\
\text { writing } \\
\text { implement } \\
\text { using three- } \\
\text { finger } \\
\text { grasp- } \\
\text { fingers near } \\
\text { point of } \\
\text { implement, } \\
\text { moving the } \\
\text { implement } \\
\text { primarily } \\
\text { with finger } \\
\text { movements } \\
\text { rather than } \\
\text { whole arm } \\
\text { movements } \\
\text {. Child is } \\
\text { able to } \\
\text { position } \\
\text { writing } \\
\text { implement } \\
\text { with one } \\
\text { hand by } \\
\text { moving } \\
\text { fingers of } \\
\text { the writing } \\
\text { hand rather } \\
\text { than using } \\
\text { two hands. } \\
\text { Copies }\end{array}$ & $\begin{array}{l}\text { - Uses two } \\
\text { hands to } \\
\text { manipulate } \\
\text { objects, each } \\
\text { hand } \\
\text { performing } \\
\text { different } \\
\text { movements } \\
\text { Writes } \\
\text { common } \\
\text { words using } \\
\text { three-finger } \\
\text { grasp (i.e., } \\
\text { moving } \\
\text { implement } \\
\text { with fingers } \\
\text { while wrist } \\
\text { and forearm } \\
\text { remain stable } \\
\text { on writing } \\
\text { surface) } \\
\text { Consistently } \\
\text { shows } \\
\text { evidence of } \\
\text { directionality } \\
\text { (top to } \\
\text { bottom, left } \\
\text { to write) } \\
\text { Prints first } \\
\text { name or } \\
\text { familiar } \\
\text { words } \\
\text { without a } \\
\text { model. } \\
\text { Letters must } \\
\text { be in correct } \\
\text { order; errors } \\
\text { are } \\
\text { permissible } \\
\text { but words are } \\
\text { recognizable } \\
\text { invented } \\
\text { spellings (i.e., } \\
\text { uses } \\
\text { phonemic } \\
\text { based }\end{array}$ \\
\hline
\end{tabular}




\begin{tabular}{|c|c|c|c|}
\hline $\begin{array}{l}\text { demonstrate } \\
\text { d model; } \\
\text { any writing } \\
\text { implement } \\
\text { is } \\
\text { acceptable } \\
\text { (e.g., chalk, } \\
\text { crayon, } \\
\text { marker, } \\
\text { paintbrush) }\end{array}$ & $\begin{array}{l}\text { starting at } \\
\text { the top of } \\
\text { the page and } \\
\text { moving } \\
\text { downward } \\
\text { from left to } \\
\text { right on } \\
\text { each line. } \\
\text { Do not need } \\
\text { to be actual } \\
\text { letters or } \\
\text { words.) } \\
\text { Produces } \\
\text { simple texts } \\
\text { using } \\
\text { scribble } \\
\text { writing (e.g., } \\
\text { tries to write } \\
\text { name at top } \\
\text { of paper } \\
\text { with lines) }\end{array}$ & $\begin{array}{l}\text { complex } \\
\text { shapes } \\
\text { (e.g., } \\
\text { rectangle, } \\
\text { square, } \\
\text { triangle) } \\
\text { from a } \\
\text { drawn } \\
\text { model (e.g., } \\
\text { drawn on } \\
\text { cards, } \\
\text { paper, the } \\
\text { sidewalk) } \\
\text { Copies } \\
\text { three letters } \\
\text { (i.e., } \\
\text { Upper- or } \\
\text { lowercase } \\
\text { letter from } \\
\text { model; } \\
\text { printing } \\
\text { errors } \\
\text { okay; } \\
\text { letters } \\
\text { recognizabl } \\
\text { e) } \\
\text { Copies first } \\
\text { name (i.e., } \\
\text { from } \\
\text { model; } \\
\text { letters in } \\
\text { correct } \\
\text { order; } \\
\text { printing } \\
\text { errors } \\
\text { okay; name } \\
\text { is } \\
\text { recognizabl } \\
\text { e) } \\
\text { Prints three } \\
\text { letters (i.e., } \\
\text { upper- or } \\
\text { lowercase } \\
\text { without } \\
\text { model; } \\
\text { printing } \\
\text { errors } \\
\text { okay; } \\
\text { recognizabl } \\
\text { e) }\end{array}$ & $\begin{array}{l}\text { spelling } \\
\text { where letters } \\
\text { match how } \\
\text { the word } \\
\text { sounds v. } \\
\text { conventional } \\
\text { spelling } \\
\text { rules) }\end{array}$ \\
\hline
\end{tabular}




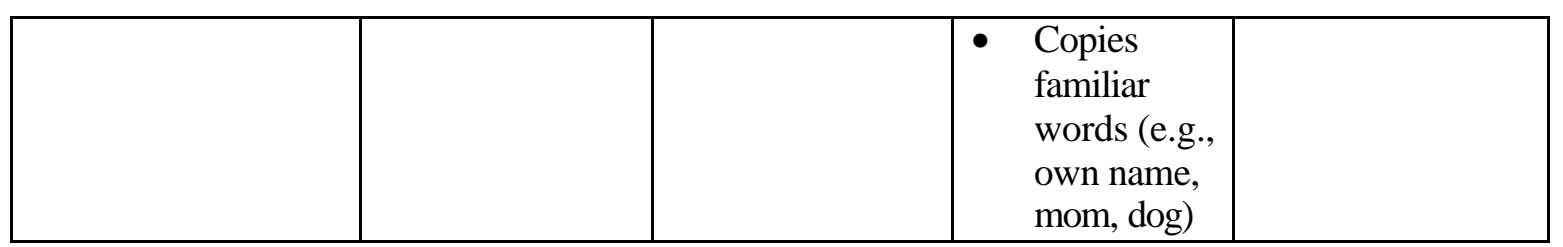

\section{Baseline}

The classroom teachers and teaching assistants conducted baseline sessions prior to intervention. One session was conducted weekly until three days prior to intervention beginning with a child. At that time, three consecutive days of baseline sessions were conducted for Arthur and Hanna. Due to an implementation error, Kaleigh had only two consecutive days of baseline sessions just prior to intervention beginning. Each session, for all children, consisted of three (3) learning opportunities embedded within each targeted activity (i.e., small group and centers), resulting in a total of six (6) embedded learning opportunities per session.

During baseline sessions, after the teacher or teaching assistant recognized the child was engaged in an activity that could provide a writing opportunity, she entered the activity, waited until an appropriate time for the child to write, provided the task direction (e.g., "Write your name on your paper."), and waited 5 seconds for the child to initiate a response. A correct response for Arthur and Hanna was defined as writing his/her name with letters in the correct order with all letters facing the correct direction. A correct response for Kaleigh included writing the first three letters of her name with letters in the correct order and facing the correct direction. Correct responses received verbal praise, while no response or incorrect responses were ignored. The teacher or teaching assistant recorded the type of activity in which the embedded learning opportunity occurred (e.g., small group, art, dramatic play) and the letters the child correctly wrote during each trial. The number and percentage of letters written was summarized at the end of each session.

\section{Intervention Procedures}

When developing intervention plans for each child, the classroom teachers identified the art and dramatic play centers as potential places for providing embedded learning opportunities related to pre-writing skills. Therefore, intervention procedures were implemented in those two areas during center time (dramatic play) and during small group activities (art), which involved the children completing an activity at a table with their peers. During dramatic play, children were sometimes asked to sign in when they entered the center, encouraged to create a list of food to prepare for their friends in the kitchen, or take messages when pretending to talk on the telephone. During small group time, children were asked to write their names on their papers, sign their name on an attendance sheet, and write their name on their written daily work plan.

For Arthur and Hanna, intervention sessions included three days of learning opportunities with zero-second response intervals and 5-second response intervals for the remainder of the intervention. Due to an implementation error, Kaleigh had four days of zero-second response intervals, rather than three, and 5-second response intervals thereafter. Three learning opportunities were embedded into each type of activity (i.e., center time and small group activity) resulting in a total of six (6) embedded learning opportunities per session. During the zero-second response interval sessions, after the teacher or teaching assistant recognized the child was engaged in an activity that could provide a writing opportunity, she entered the activity, waited until an appropriate time for the child to write, gave the task direction (e.g., "Write your name on 
your paper. The first letter is A.”), then immediately provided a controlling prompt (i.e., a written model of each letter the child needs to write, one letter at a time). The teacher or teaching assistant provided verbal praise after each letter the child wrote independently. If the child wrote a letter incorrectly or did not respond, the teacher provided hand-over-hand assistance to the child.

The procedures during the 5-second response interval sessions were similar to the zerosecond response interval sessions. The teacher or teaching assistant recognized the child was engaged in an activity that could provide a writing opportunity, she entered the activity, waited until an appropriate time for the child to write, and then gave the task direction (e.g., "Write your name on your paper."). If the child wrote his/her name or first three letters of her name, respectively, the child received verbal praise. If the child wrote something other than the correct letters or did not respond, the teacher or teaching assistant provided the following prompts in the order provided until the child had correctly written all letters needed: a verbal prompt (e.g., "Write your H," or "The next letter is A."), a written model of the le tter, hand-over-hand assistance. A 5-second response interval was provided after each prompt to allow the child to respond. Consequences after each prompt included verbal praise for a correct response or the next most intrusive prompt.

The teacher or teaching assistant recorded the type of activity in which each embedded learning opportunity occurred (e.g., small group, dramatic play) and the letters the child wrote independently during each trial. In addition, the types of prompts provided after an incorrect response or no response (i.e., verbal prompt, model, or hand-over-hand assistance) were recorded. After each session the number and percentage of independent responses and correct responses after a verbal prompt, model, or hand-over-hand assistance were summarized.

\section{Maintenance}

One maintenance session was conducted with Arthur approximately 7 days after he reached criterion. No maintenance data were collected for Kaleigh and Hanna due to the end of the school year. The procedures used during the maintenance session were identical to those used during baseline sessions.

\section{Interobserver Agreement}

The researchers (i.e., first and second authors) collected both independent and dependent variable reliability data. Reliability data were collected one time during baseline sessions for all children (i.e., 25\% of sessions for Arthur, 33\% of sessions for Kaleigh, and 20\% of session for Hanna), three times during intervention sessions for Hanna (i.e., $43 \%$ of sessions) and Kaleigh (i.e., 33\% of sessions), and four times during intervention sessions for Arthur (i.e., $40 \%$ of sessions). Dependent variable reliability data were calculated using the point-by-point method (i.e., number of agreements divided by the number of agreements plus disagreements and multiplied by 100). Dependent variable reliability averaged $96 \%$ (range $=89 \%-100 \%$ ) during baseline sessions and 99\% (range $=94 \%-100 \%$ ) during intervention sessions.

Independent or procedural reliability indices were calculated by dividing the number of observed behaviors by the number of planned behaviors and multiplying by 100 (Billingsley, White, \& Munson, 1980). Procedural behaviors for all sessions included presenting the antecedent (e.g., joining the activity and providing the task direction), waiting the correct response interval (i.e., zero or 5-seconds), and providing the correct consequences based on the 
child response (i.e., correct, no response, incorrect) and type of session (i.e., baseline, zero-second response interval, 5-second response interval). Procedural reliability during baseline sessions was $100 \%$. During intervention sessions, procedural reliability averaged $96 \%$ (range $=81 \%-100 \%$ ).

\section{Experimental Design}

A multiple probe design (Blackhurst, Schuster, Ault, \& Doyle, 1996) across three children was used to assess the effectiveness of embedded learning opportunities to assist children in acquiring pre-writing skills that are inherent within early childhood standards. When a child receiving intervention performed the target skill at $20 \%$ above the average baseline performance for three consecutive days during 5-second response interval sessions, intervention began with the next child. The criterion for ending intervention was $100 \%$ accuracy across all embedded learning opportunities for three of four school days. Experimental control was demonstrated when the children's performance improved only after the intervention was implemented.

\section{Results}

Figure 1 shows the data for each child during baseline, intervention, and maintenance sessions. The percentage of unprompted correct responses is shown on the ordinate, while the number of sessions is shown on the abscissa. Arthur and Kaleigh reached criterion for their target skills after 10 and 8 intervention sessions $($ mean $=9)$ respectively. The mean number of embedded learning opportunities to criterion for Arthur and Kaleigh was 54 (range $=48-60$ ). Although the intervention resulted in a therapeutic trend for Hanna, she did not reach criterion before the school year ended. The zero-second response interval sessions were effective in improving the children's ability to perform the target skills. However, in order for the children to learn their respective target skills, prompting (e.g., verbal, model, hand-over-hand assistance) was needed during the 5-second response interval sessions. During the maintenance session, Arthur wrote his name with $100 \%$ accuracy during all embedded learning opportunities.

FIGURE 1, NEXT PAGE 


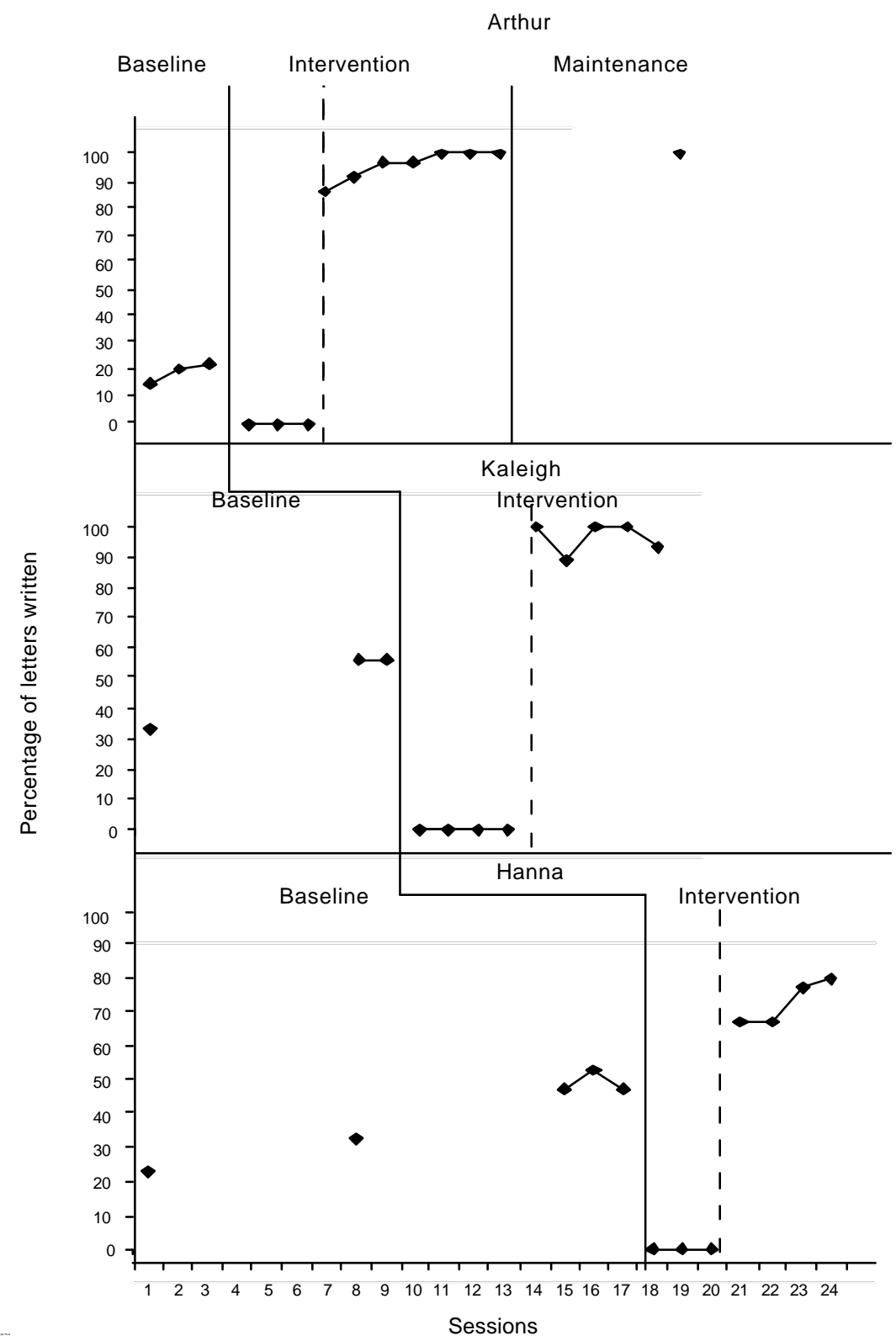

Figure 1: Results for Author, Kaleigh, and Hanna

\section{Discussion}

The purpose of this study was to determine if embedding learning opportunities into classroom activities would result in the acquisition and maintenance of pre-writing skills for preschoolers with varying abilities who attend an inclusive preschool program. Three conclusions can be drawn from the results of this study. First, embedding learning opportunities during daily activities may be an effective strategy for teaching preschoolers with varying abilities in inclusive preschool settings. Given the diversity of preschool programs (Grisham-Brown et al., 2005), preschool teachers are in need of teaching strategies that address the learning needs of diverse populations of children. More research is needed to determine the effectiveness of this tactic on outcomes for children with more significant disabilities and those from culturally and linguistically different backgrounds. 
Second, the results of this preliminary study suggest that embedding learning opportunities during daily activities may be a feasible way to address important pre-kindergarten standards within inclusive classrooms. Early childhood experts suggest that preschool teachers should not compromise developmentally appropriate practice because of the present emphasis on young children to attain pre-kindergarten standards (Branscombe, Castle, Dorsey, \& Taylor, 2003). In the present study, two of the three children reached criterion on their targeted prewriting skill and one child made substantial progress following baseline performance. One child maintained his pre-writing skill following intervention. These preliminary findings demonstrate that instruction can occur within developmentally appropriate activities and that children can achieve important standards. As well, the study extends previous research on embedding (e.g., Horn, et al., 2000) by addressing literacy skills that are needed by the children and included in most states' pre-kindergarten standards. Additional research is needed to extend these findings to determine the effectiveness of embedding learning opportunities to address other outcomes targeted in state standards, such as math and science skills.

Third, the procedure was implemented with a high level of inter-rater and procedural reliability. Some previous studies on embedding learning opportunities have been conducted by researchers (e.g., Wolery, et al., 2002). This present study was conducted by classroom teachers and teaching assistants. It is important to acknowledge, however, that these staff had received training and on-site technical assistance by the first and second authors. Given that most classroom staff in inclusive programs may not have access to that level of support, research is needed to determine what support is necessary so that teachers can produce positive outcomes with their children when utilizing these procedures.

\section{Limitations}

Despite these findings, the study has a number of limitations. First, there were implementation errors with one of the subjects (i.e., Kaleigh). With this particular child, only two days of baseline data were collected just prior to intervention. Although the data for both days were similar, enough data may not have been collected to determine if a stable baseline data trend was established. In addition, Kaleigh received one additional day of zero-second response interval instruction than the other 2 children. Both of these errors potentially threatened the validity of the study.

A second limitation of the study is that one child did not reach criterion. Hannah's performance, however, was well above baseline when the study had to conclude because of the end of the school year. The inability to complete the intervention with Hannah is problematic given the small number of children in the study.

All children in the study were taught their respective skills using the same procedures (i.e., during specific activities with specific numbers of prompts given). One could argue that this is an additional limitation in terms of how embedding learning opportunities are to be designed. The spirit of embedding learning opportunities includes the notion that instruction related to a targeted skill can be provided in a variety of ways (e.g., prompting approaches, questioning strategies, peer modeling), across types of activities, and is a match for the child (Pretti-Frontczak $\&$ Bricker, 2004). Learning opportunities are considered a match when a teacher considers the child's current developmental abilities, interests, and the prompt to practice/use a target skill is provided within the context of authentic activities or transactions. In this study, the teachers were required to provide a specific number of learning opportunities using specific/consistent prompts, and at specific times of the day. So while the teachers did consider children's developmental 
abilities in the targeting of skills, they were not necessarily required to provide learning opportunities at times that were a match with the child's interests and/or using a variety of prompts across activities.

\section{Implications and Future Research}

This study shows how embedding learning opportunities that combine wait time and prompting levels results in positive learning outcomes when teaching pre-writing skills within classroom activities. But as stated by Pretti-Frontczak and Bricker (2004), successful creation and embedding of meaningful learning opportunities requires teachers to "1) conduct comprehensive and ongoing assessments; 2) target functional and generative goals; 3) select appropriate antecedents and consequences to deliver during child-directed, routine, and planned activities; and 4) systematically monitor the effects of intervention." Teachers and teaching assistants in the present study were highly trained in the areas of assessment, goal writing, embedding learning opportunities, and monitoring children's progress. To ensure teachers are able to create embedded learning opportunities, additional preservice and in-service training may be required. Training teachers and teaching assistants how to systematically plan for providing antecedents and consequences and for collecting data related to the effects of using those antecedents and consequences may be needed. In addition, teachers may need support or resources, such as rubrics, that will enable them to target appropriate skills that are connected to state standards.

Embedding learning opportunities during daily activities continues to have appeal to those working with young children and continues to show promise in terms of a research-based practice that can lead to improved outcomes, particularly outcomes outlined in state standards. Future research should examine teachers' ability to embed learning opportunitie s that are more dynamic versus the prescribed approach taken in the present study. Future research should also continue to build evidence that a wide range of children can learn functional and meaningful skills when learning opportunities are embedded during daily activities.

\section{References}

Billingsley, F. F., White, O. R., \& Munson, R. (1980). Procedural reliability: A rationale and an example. Behavioral Assessment, 2, 229-241. 
Blackhurst, A. E., Schuster, J. W., Ault, M. J., \& Doyle, P. M. (1996). Single subject research advisor \{Computer software\}. Lexington, KY: University of Kentucky.

Bodrova, E., \& Leong, D. L. (1998). Scaffolding emergent writing in the zone of proximal development [Electronic version]. Literacy Teaching and Learning, 3(2), 1-18.

Bodrova, E., Leong, D. J., Paynter, D. E., \& Semenov, D. (2000). A framework for early literacy instruction: Aligning standards to developmental accomplishments and student behaviors: Pre-k through kindergarten (Rev. ed.). Retrieved June 1, 2004, from http://www.mcrel.org/PDF/Literacy/4006CM_EL_Framework.pdf

Branscombe, N. A., Castle, K., Dorsey, A. G., Surbeck, E., \& Taylor, J. B. (2003). Early childhood curriculum: A constructivist perspective. Boston, MA: Houghton Mifflin.

Bricker, D. (Series Ed.). (1993). Assessment, evaluation, and programming system for infants and children. (Vols. 1-4). Baltimore: Paul H. Brookes Publishing Co.

Daugherty, S., Grisham-Brown, J., Hemmeter, M. L. (2001). The effects of embedded instruction on the acquisition of target and nontarget skills in preschoolers with developmental delays. Topics in Early Childhood Special Education, 21(4), 213-221.

Gambrell, L. B., \& Mazzoni, S. A. (1999). Emergent literacy: What research reveals about learning to read. In C. Seefeldt (Ed.), The early childhood curriculum: Current findings in theory and practice (pp. 80-105). New York, NY: Teachers College Press.

Garfinkle, A. N. \& Schwartz, I. S. (2002). Peer imitation: Increasing social interactions in children with Autism and other developmental disabilities in inclusive preschool classrooms. Topics in Early Childhood Special Education, 22,(1), 26 - 38.

Grisham-Brown, J., Schuster, J. W., Hemmeter, M. L., \& Collins, B. C. (2000). Using an embedding strategy to teach preschoolers with significant disabilities. Journal of Behavioral Education, 10, 139-162.

Grisham Brown, J. L., Hemmeter, M. L., \& Pretti-Frontczak, K. L. (2005). Blended Practices for Teaching Preschoolers in Inclusive Settings. Paul Brookes Publishing Company.

Harbin, G., Rous, B., \& McLean, M. (2005). Issues in designing state accountability systems. Journal of Early Intervention, 27(3), 137-164.

Horn, E., Lieber, J., Li, S. M., Sandall, S., \& Schwartz, I. (2000). Supporting young children's IEP goals in inclusive settings through embedded learning opportunities. Topics in Early Childhood Special Education, 20, 208-223.

Kentucky Department of Education (2003). Building a strong foundation for school success: Kentucky's Early Childhood Standards. Frankfort, KY: Author.

Neuman, S. B., Copple, C., \& Bredekamp, S. (2000). Learning to read and write: Developmentally appropriate practices for young children. Washington, D.C.: NAEYC.

Neuman, S., \& Roskos, K. (2005,). The state of state pre-kindergarten standards. Early Childhood Research Quarterly, 20, 2, P. 125-145. 
Office of Special Education Programs. (2005). Part B State Performance Plan and Annual Performance Report. Retrieved September 16, 2005 from http: http://www.ed.gov/policy/speced/guid/idea/bapr/ptbtable2.pdf

Owocki, G. (2001). Making way for literacy! Teaching the way young children learn. Washington, D.C.: NAEYC.

Pretti-Frontczak, K. \& Bricker, D. (2004). An activity-based intervention approach to early intervention ( $3^{\text {rd }}$ ed.) Baltimore, MD: Paul H. Brookes.

Schickedanz, J. A. (1999). Much more than the ABCs: The early stages of reading and writing. Washington, D.C.: NAEYC.

Schickedanz, J. A., \& Casbergue, R. M. (2004). Writing in preschool: Learning to orchestrate meaning and marks. Newark, DE: International Reading Association.

Temple, C., Nathan, R., Temple, F., \& Burris, N. A. (1993). The beginnings of writing. Needham, MA: Allyn \& Bacon.

Wolery, M., Anthony, L., Caldwell, N. K., Snyder, E. D., \& Morgante, J. D. (2002). Embedding and distributing constant time delay in circle time and transitions. Topics in Early Childhood Special Education, 22(1), 14-25.

Wolery, M., Ault, M. J., \& Doyle, P. M. (1992). Teaching students with moderate to severe disabilities: Use of response prompting strategies. White Plains, NY: Longman.

\section{Authors Note}

Preparation of this article was supported in part by a grant from the U.S. Department of Education (H324M0100304).

Author contact information:

Jennifer Grisham-Brown

Jgleat00@uky.edu

229 Taylor Education Building

University of Kentucky

Lexington, KY 40506-0001 